\title{
Food security in rural sub-Saharan Africa
}

A houshold level assessment of mixed crop-livestock systems

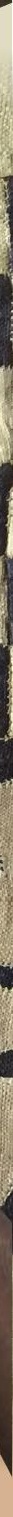





\section{Propositions}

1. Increasing on-farm productivity does not necessarily combat chronic and hidden hunger.

(this thesis)

2. Livestock is a critical source of micronutrients for rural households in sub-Saharan Africa.

(this thesis)

3. Gut microbiome health needs to be incorporated in nutrient adequacy ratio calculations.

4. The longevity of human knowledge does not depend on technology, but on the resilience of our global community.

5. Environmental stewardship infringes upon the human liberties to eat and procreate at will.

6. The success stories of economic prosperity give too much credit to market forces and ignore the role of grass-roots interventions.

Propositions belonging to the thesis, entitled

Food security in rural sub-Saharan Africa:

a household level assessment of crop-livestock systems

Simon Fraval

Wageningen, 10 April 2019 



\section{Food security in rural sub-Saharan Africa}

A household level assessment of crop-livestock systems 


\section{Thesis committee}

\section{Promotor:}

Prof. Dr I.J.M. de Boer

Professor of Animal Production Systems

Wageningen University \& Research

\section{Co-promotors:}

Dr S.J. Oosting

Associate professor, Animal Production Systems group

Wageningen University \& Research

Dr M.T. van Wijk

Senior scientist

International Livestock Research Institute

\section{Other members:}

Prof. Dr C. Leeuwis, Wageningen University \& Research

Dr I. Brouwer, Wageningen University \& Research

Dr M.A. Slingerland, Wageningen University \& Research

Prof. Dr G. Djurfeldt, Lund University, Sweden

This research was conducted under the auspices of the Graduate School Wageningen Institute of Animal Sciences (WIAS) 


\title{
Food security in rural sub-Saharan Africa
}

A household level assessment of crop-livestock systems

\author{
Simon Fraval
}

\section{Thesis}

submitted in fulfilment of the requirements for the degree of doctor at Wageningen University

by the authority of the Rector Magnificus,

Prof. Dr A.P.J. Mol,

in the presence of the

Thesis Committee appointed by the Academic Board to be defended in public

on Wednesday 10 April 2019

at 11 a.m. in the Aula. 


\section{Simon Fraval}

Food security in rural sub-Saharan Africa: A household level assessment of crop-livestock systems 180 pages.

$\mathrm{PhD}$ thesis, Wageningen University, Wageningen, the Netherlands (2019)

With references, with summaries in English and Swahili

ISBN 978-94-6343-573-4

DOI https:/ / doi.org/10.18174/467544 


\section{Abstract}

Members of rural households in sub-Saharan Africa (SSA) are both vulnerable to the health burdens that stem from food insecurity and central to improving the availability and affordability of wholesome foods. It has been estimated that chronic and hidden hunger can be alleviated by implementing a suite of nutrition-specific interventions at a cost of US $\$ 9.6$ billion per annum. This can be accelerated with complementary food system-based interventions. However, such interventions are hampered by a limited understanding of food security status and its associations with rural livelihoods. Therefore, the primary objective of this thesis was to describe, analyse and understand food security in rural landholding households in predominantly mixed crop-livestock agricultural systems of sub-Saharan Africa (SSA). The secondary objective was to improve the methodological basis of household level food security studies. The rural household multi-indicator survey (RHOMIS) tool was developed to describe and analyse the circumstances of rural households. The RHOMIS tool aims to adhere to the principles of being timeefficient, utilitarian, user-friendly, flexible and reliable. The credibility, consistency and reliability of data collected using three different farm household surveys. The shorter and more targeted survey tool, RHOMIS, performed better in terms of staying within credible bounds. Measurements of maize yields and land area owned were found to be less reliable than other variables. Despite the limitations in data quality, our analysis shows that if the same farm households are followed over time, the sample sizes needed to detect substantial changes are in the order of hundreds of surveys, and not in the thousands. The RHOMIS tool was then used to quantify changes in livelihoods and food security status in an urban linked, high potential region of Tanzania. Households in the study site adaptively responded to local and national circumstances. Changes in land ownership, livestock-holdings and high value crop production were most likely related to market opportunities and personal circumstances, rather than to direct interventions. Several households made strategic changes by expanding land ownership, planting perennial crops and investing in exotic cattle breeds; many households tactically utilised their land for diversified, mixed crop-livestock production. A central finding of this study is that the complex risk management strategies and market responsiveness demonstrated by the 'Rising' clusters are at odds with single focus activities that external organisations tend to promote. Subsequently, instances of chronic and hidden hunger were analysed in two provinces of Burkina Faso. The results of this study show that in both provinces, the ability to purchase food is what differentiates the more food secure households from their less food secure counterparts. This finding does not detract from the utility of subsistence production where consumption of own-farm sourced food catered for between $72 \%$ and $91 \%$ of the annual energy requirements. Further, households were observed to be pursuing market-oriented strategies in combination with production diversification - likely to reduce risk exposure to climatic or economic shocks. In a large sample of households across SSA, we found that as many as $40 \%$ of households were classified as chronically hungry in the lean period. Prevalence of micronutrient dietary gaps were high, ranging from $35 \%$ of households to $68 \%$. Vulnerability to dietary gaps differed by household composition, livelihood characteristics and agro-ecological zone (AEZ). It is the combination of livelihood characteristics and the agro-ecological production potential that drive the availability of food and income. It was found that households fail to purchase food categories that nutritionally complement their own agricultural products. Furthermore, households with a livestock component to their farm were found to have a lower prevalence of chronic and hidden hunger. In extended analyses, the gender of household head and stage of life were found to be associated with the number of household inhabitants and thus influence nutritional requirements and food security status throughout the year. The high prevalence of food insecurity, the complexity of associations and the failure to nutritionally complement own-production with purchases have implications for developing effective interventions. Programs can be designed as 'packages' of agricultural and non-agricultural interventions to maximise adoption and maximise the positive impact on food and nutrition security throughout the year. 



\section{Contents}

Chapter $1 \quad$ General introduction . . . . . . . . . . . . . . . . 1

Chapter 2 The Rural Household Multi-Indicator Survey for rapid characterisation of rural households . . . . . . . . . . . . . . . . . . . . . 13

Chapter 3 Making the most of imperfect farm household data: a critical evaluation of standard information collected in farm household surveys . . . . . . . . . 23

Chapter 4 Livelihoods and food security in an urban linked, high potential region of Tanzania: Changes over a three-year period . . . . . . . . . . . . . . . . . 43

Chapter 5 Pathways to food security in rural Burkina Faso: the importance of consumption of home-produced food versus purchased food . . . . . . . . 63

Chapter 6 Dietary gaps in sub-Saharan Africa: prevalence and implications for agricultural interventions ................... 83

Chapter $7 \quad$ General discussion . . . . . . . . . . . . . . 107

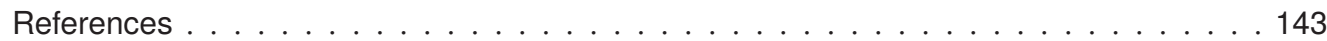

Appendices . . . . . . . . . . . . . . . . . . . . . . 145

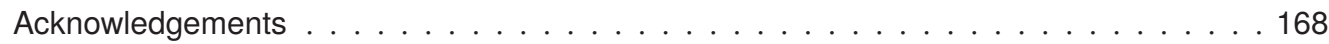

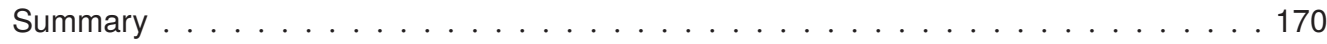

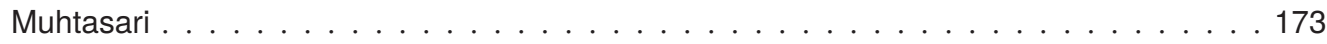

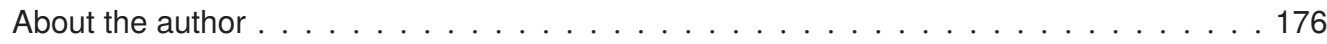

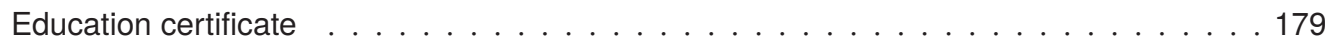

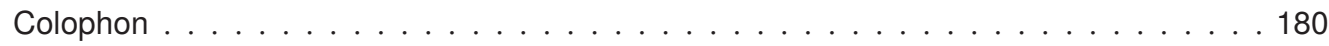




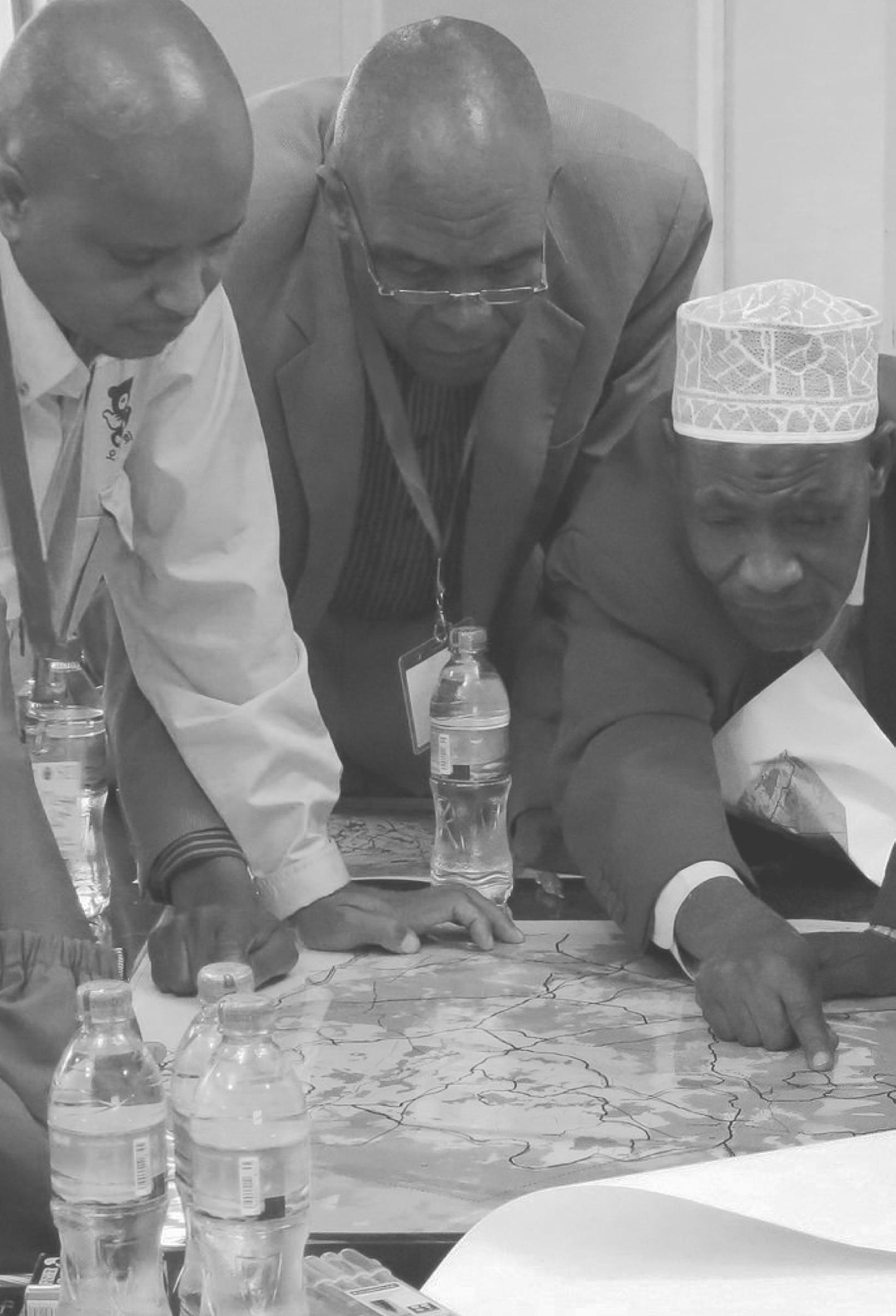


Chapter 1

General introduction 


\subsection{Background}

Malnutrition affects the quality of life for a substantial portion of the human population (GBD 2016 Risk Factors Collaborators, 2017). Chronic undernourishment, micronutrient deficiencies and obesity increasingly co-exist within the same communities - forming a triple burden of malnutrition (May, 2018). The incidence of adverse health effects due to chronic undernourishment and micronutrient deficiencies are substantially higher in sub-Saharan Africa (SSA) compared to the rest of the world (Gödecke et al., 2018; GBD 2016 Risk Factors Collaborators, 2017). In addition, the rural population in SSA bear a disproportionately large share of the individual and societal implications following such nutritional gaps when compared to urban communities (Headey et al., 2018b; Green et al., 2016).

This thesis focuses on the food security status of rural landholding households in SSA. Members of rural landholding households are both vulnerable to the health burdens that stem from food insecurity and central to improving the availability and affordability of a diversity of wholesome foods for both rural and urban markets (Fanzo, 2018).

\subsubsection{Food security}

Food security forms the basis of human well-being. By definition, food security exists "when all people, at all times, have physical and economic access to sufficient safe and nutritious food that meets their dietary needs and food preferences for an active and healthy life" (FAO, 2008, p. 1). This definition of food security encompasses four dimensions, namely: food availability, food access, food utilisation and stability (FAO, 2008). Food access refers to an ability to source or acquire food using available resources (Maxwell \& Smith, 1992). Having the ability to access food does not necessarily result in consumption - this distinction is made in the food utilisation dimension of food security. Food utilisation can be diminished by competing livelihood goals or decisions related to the distribution of food. Furthermore, the sufficiency of food utilisation depends on an individual's nutritional requirements which can vary depending on age, gender, exertion and health. Stability refers to how food access and food utilisation are experienced over time. Food security only exists when each individual is able to consume sufficient, safe and nutritious foods at all times - throughout the weeks, months and years. People, however, cannot access or utilise food when it is not available. This makes the functioning of agricultural systems central to food security.

\subsubsection{Food availability and agricultural systems}

Agricultural systems in SSA are diverse and dynamic - driven by numerous exogenous (e.g. agro-ecological conditions, soil fertility, urban proximity and local policies) and endogenous (i.e. related to the livelihoods of the rural population) factors. Agricultural systems can be classified in terms of their crop and livestock production mix, dependence on precipitation, agronomic practices, animal husbandry practices, market orientation, scale, or capital intensity (Garrity et al., 2012; Seré et al., 1996). 


\section{Overview of agricultural systems in SSA}

The production potential of agricultural systems in SSA are generally determined by the annual and seasonal rainfall quantity (van Oort et al., 2016). This dependence means that agroecological zones (AEZs) play a significant role in determining land use, both for the vast rangeland areas and the two million hectares of cultivated land in SSA. Rangelands are typically located in arid (length of growing period (LGP) < 75 days) and semi-arid (LGP 75 - 180 days) lands (ASALs). Nomadic and transhumance communities utilise these rangelands as a feed resource for small and large ruminants (Seré et al., 1996). Sedentary farmers also occupy ASALs, in instances where soil conditions, water availability and market conditions allow. These sedentary farmers, however, are generally limited in the range of crops cultivated (USAID, 2012; Little et al., 2001). In contrast, a wide array of staple and cash crops can be cultivated under rainfed conditions in sub-humid (LGP 181-270 days) and humid (LGP > 270 days) AEZs. Warm sub-humid zones are suited to cereals, legumes, bananas, oilseeds, sugarcane, forages, sisal and tree-nuts (e.g. western Kenya and large areas of Tanzania; USAID, 2012, 2009). Cool subhumid and humid zones (highland regions) are suited to cereals, legumes, bananas, root crops, coffee, tea, cacao, vegetables, fruits and forages. Mixed crop-livestock systems are common across AEZs and geographical regions (Perry et al., 2002). These systems are defined as those that feed $10 \%$ of crop residue dry matter to livestock or earn at least $10 \%$ of farm income from crop production (Seré et al., 1996).

\section{Food availability: current status and future trends}

Despite this wide-ranging diversity of agricultural production systems in SSA, the availability of energy-dense and nutrient-rich foods is worryingly strained. On balance, one-quarter of the one billion people in SSA are suffering from insufficient food energy supply (FAO et al., 2018). In addition, the availability of micronutrients falls short of requirements - resulting in what is termed 'hidden hunger' (Joy et al., 2014; Kumssa et al., 2015; Harika et al., 2017). It is estimated, for example, that $50 \%$ of the African population is at risk of calcium deficiency, $40 \%$ of zinc deficiency, 28\% of selenium deficiency and 19\% of iodine deficiency (Joy et al., 2014). These supply shortfalls are compounded by barriers to access and utilisation. The insufficient availability of energy dense and diverse foods is forecast to worsen in the medium to long term as demand for animal source foods exceeds supply, yields stagnate or decline, and the homogeneity of crop species increases (Enahoro et al., 2018; van Oort et al., 2016; Pingali, 2015). Medium and small-scale farms serve differing functions in SSA food systems. Regardless of farm scale, however, yield gaps will need to be closed for energy dense and micronutrient rich foods.

In SSA, medium scale farms (2 - 20 ha) produce $50 \%$ of the volume of each food category (e.g. cereals, root crops, vegetables and livestock; Herrero et al., 2017). Smallholder farmers ( $\leq 2 \mathrm{ha})$ also contribute substantially to food availability (Samberg et al., 2016) as they allocate a greater proportion of their land to food crops, including a greater diversity of food crops compared to medium scale farms (Ricciardi et al., 2018). In total, smallholder farmers produce $25 \%$ of the volume of most food commodities (Herrero et al., 2017), while using 40\% of agricultural land 
(based on an assessment of 9 countries in SSA by Lowder et al., 2016).

There are substantial gaps between actual and potential yields in SSA farming communities, both for crops and livestock. Thus, total food availability is far below the potential. It has been estimated that livestock productivity can almost double and crop productivity can more than double (Henderson et al., 2016). Existing yield gaps are common due to climatic shocks (Gebrechorkos et al., 2018), pests and diseases (Biber-freudenberger et al., 2016), long-term depletion of soil resources (Tittonell \& Giller, 2013), and resource constraints of the farmers (both for inputs and capital expenditure). By closing the crop yield gaps alone, $95 \%$ of SSA nations could meet their current human metabolic energy needs (Luan et al., 2018).

Meeting the full dietary needs of SSA populations will require a diversity of foods to be readily available (i.e. more diverse than energy-dense foods alone). The increasing homogeneity of species cultivated is evident globally (Khoury et al., 2014). African nations are no exception, where traditional lower yielding grains such as tef, millets and sorghum are gradually being substituted with maize, traditional vegetables replaced with market vegetables, and livestock genetic resources have narrowed. This increased homogeneity may be positive for overall kilocalorie availability, but this benefit has trade-offs with the need to have access to nutritionally diverse and culturally relevant food for the population (Schipanski et al., 2016; Pingali, 2015; Remans et al., 2014; Popkin et al., 2001). This is evident in the substantial supply deficiency of fruits and vegetables in African nations - ranging from a shortage of 12\% (Ghana and Camaroon) to $90 \%$ (Burkina Faso; Siegel et al., 2014).

\subsubsection{Food access, utilisation and stability in the context of rural livelihoods}

Agriculture generates between $20 \%$ and $50 \%$ of gross domestic product (GDP) across SSA (Proctor, 2014). In rural SSA, $92 \%$ of households are engaged in farming to some extent and $52 \%$ are specialised in farming - with farming in accounting for approximately $69 \%$ of rural incomes (Davis et al., 2017). Rural landholding households, therefore, a) provide livelihood opportunities for rural landless households, b) are vital contributors to domestic food availability, from local to national level, and c) depend on agriculture to meet their own needs for a stable supply of safe and nutritious food. Meeting nutritional needs, however, is only one goal of many. Instead, individuals within households strategically and adaptively make use of various capabilities to increase income, to maximise well-being, to reduce vulnerabilities and to reinvest in productive assets (including the natural resource base; Ashley \& Carney, 1999; Farrington et al., 1999; Scoones, 1998). To define this use of capabilities more formally, 'livelihoods' are "the control an individual, family, or other social group has over an income and/or a package of sources that can be used or changed to maintain a living" (Blaikie et al., 1994, p. 9). Capabilities stem from five 'livelihood assets' termed: financial, human, natural, physical and social capital (Farrington et al., 1999). These capabilities in rural SSA are often pooled at the household level. 


\section{Households in SSA}

A 'household' is an amorphous concept that defines an economic unit above the individual (Randall et al., 2015). A household has been defined as a group of people "who combine to occupy the whole or part of a housing unit and to provide themselves with food or other essentials for living" (UN, 1959, p. 74) - where there may be some variability in co-habitation and frequency of meal sharing. In rural SSA, a household can be composed of family members (including extended), non-family dependents and workers. The composition of a household is influenced by relationship status, marital arrangements, life stage, fertility, family planning, available resources and health circumstances. There are a large number of possible household compositions, for example three generations of family, single parents and families where one parent works away from home (Randall et al., 2015). The composition of a household has a significant influence on livelihood assets and goals.

The use of livelihood assets and the prioritisation of livelihood goals (e.g. food security or education) can be a strategic or an adaptive process - mediated by complex intra-household dynamics (Kazianga \& Wahhaj, 2017; Galiè et al., 2015). The gendered dimensions of decision making, labour allocation and control of resources are highly context specific (Doss, 2013). In rural SSA, patriarchal norms prevail, and women tend to have higher labour burdens, less decision-making power and less control of financial resources (Sofa \& Doss, 2011). Land use decisions and control of financial resources have a substantial bearing on food security (Dzanku, 2019; Price et al., 2018; Andersson Djurfeldt, 2018b). There is a tendency for female-headed households in SSA to cultivate a greater proportion of food crops than their male-headed counterparts who tend to favour cash crops (Tibesigwa et al., 2018). In general, improved 'status' of women in households is positively associated with nutritional outcomes of the household and children more specifically (Bhandari, 2017; Oddo \& Ickes, 2018; Jin \& Iannotti, 2014). Land use decisions, off-farm income opportunities and intra-household dynamics are central to the livelihoods of rural landholders, and their food security.

\section{Land use decisions and land size trends}

Land and livestock ownership are important enabling assets for rural households. Land provides production opportunities and livestock provide a means of diversifying income sources, buffering exposure to climatic and market shocks, draught power, recycling nutrients and storing wealth (Thornton \& Herrero, 2015; Swanepoel et al., 2010; Moll, 2005; McIntire et al., 1992). Exogenous factors (e.g. agro-ecological conditions, soil fertility, urban proximity and local policies) determine production possibilities and potential returns. Agricultural production decisions are then made based on exogenous factors, livelihood goals, intra-household dynamics and livelihood assets. Specifically, decisions may be made on composition (crop and livestock species), area allocated, and practices adopted. In tandem, households decide on whether to 'value-add' (e.g. by milling grain or processing milk), what proportion to retain for home consumption, and which market avenues to pursue. Land use decisions are also significantly influenced by land sizes.

Small land sizes limit a household's capacity to produce enough food and income to meet their 
basic needs. In many cultures of SSA, parents sub-divide land amongst their children. This practice has progressed to the point where smallholder farms are no longer economically viable (Lowder et al., 2016; Jayne et al., 2014). The size of smallholder farms has now stagnated, and medium scale farmers are managing an increasing share of total farm area (Andersson Djurfeldt, 2018a; Jayne et al., 2016). In a study of four African nations, Jayne et al. (2016) found that half of the medium scale farmers purchased land later in life with capital raised from off-farm income. These medium scale farms are characterised as being highly commercialised with substantial influence on government policy. On the other hand, smaller farm sizes have resulted in prioritisation of short-term needs, often at the expense of soil quality - manifested as shortened fallow periods, minimal inputs and limited utilisation of other soil conservation practices (Tittonell \& Giller, 2013). Additionally, instances of crop-livestock integration tend to decrease as farm sizes become too small to cater for the needs of their livestock (Thornton \& Herrero, 2015).

\section{Diversified income sources: off-farm}

Off-farm income can be earned through entrepreneurial activities, seasonal informal employment and formal employment - earned in the household or sent back as remittances. Diversifying income sources in this way buffers exposure to climatic and market shocks (Silvestri et al., 2015), increases net incomes (Andersson Djurfeldt et al., 2018) and may provide a means to access credit for the farm business. There are, however, limited opportunities to earn off-farm income, where the most readily available informal farm labour options offer low returns (Jayne et al., 2014), and wealthier and more educated households have a greater capacity to gain employment or invest in a non-farm business (Davis et al., 2010; Haggblade et al., 2010; Reardon et al., 1992). This constrained labour market is forecasted to continue as population density increases - particularly for poorer, less educated households (FAO \& OECD, 2015; de Brauw et al., 2014).

\section{Temporal dynamics of livelihoods}

Household composition, enabling assets and off-farm income opportunities are by no means static. Livelihoods change over time through strategic efforts and adaptive responses to shocks and opportunities. For example, households can strategically invest in irrigation (Nakawuka et al., 2017), or adaptively respond to drought (Ulrich et al., 2012). The temporal dynamics of livelihoods highlights the point that short-term needs are met in a broader context of long-term resilience. Specifically, the depletion of livelihood assets (such as soil fertility) to meet shortterm needs can increase long-term risk exposure to shocks and reduce capacity to capitalise on opportunities. As such, livelihood strategies have been classified as those that are 'Hangingin' (trying to maintain a livelihood), 'Stepping-up' (improving livelihoods by expanding an activity) or 'Stepping-out' (using asset base to move into new livelihood activities; Dorward, 2009) and 'Dropping-out' (unwillingly leaving agriculture; Valbuena et al., 2015). 


\subsubsection{Monitoring nutrition, diets and food security}

Improving livelihoods does not necessarily improve human nutrition. As such, human nutrition and food security need to be monitored over time to inform policies and interventions. The constituents of human nutrition include macronutrients (carbohydrates, protein, fat and fibre), micronutrients (vitamins and minerals) and water. Nutritional requirements will depend on age, gender, physical activity, health status, physiological status (e.g. pregnant), and genetics. The absorption of nutrients delivered to the gastrointestinal tract will depend on diet composition, health status and physiological status. Dysfunction and disease can arise due to unbalanced and deficient diets. Food insecurity, in this broader context, refers to deficient diets due to food access and utilisation constraints. To emphasise the centrality of human nutrition in food security, this thesis at times uses the term 'food and nutrition security' instead of food security.

Nutritional status can be most directly monitored through biomarkers and anthropometrics (e.g. body mass index or height for age). Monitoring diets, however, is less invasive and less costly. Therefore, monitoring national and sub-population diets has provided a foundation for preventative health strategies in many countries. Individual and household diets have traditionally been monitored using 24-hour dietary recall (24hR), food frequency questionnaires (FFQ) and, to a lesser extent, longitudinal food records (Micha et al., 2018; Vila-real et al., 2018). These methods are highly heterogeneous with various modes of data collection, food classification systems, food volume quantification protocols and professional capacity requirements (Micha et al., 2018; de Keyzer et al., 2015). The 24hR and FFQ methods can be self-administered or conducted by an interview with pen-and-paper, computer-aided or over the telephone. The $24 \mathrm{hR}$ method can be applied multiple times, enumerating all food, beverages and dietary supplements consumed for the previous 24 hours - where a minimum of three observations is recommended (Ma et al., 2009). The FFQ method can elicit information on the frequency of tens or hundreds of items consumed over one week or longer. Quantifying food volumes is one of the most challenging aspects of these methods, where various physical, visual and technical aides are in use. Interviews are generally conducted by nutritionists, dietitians or enumerators familiar with local diets (de Keyzer et al., 2015). Policy makers and researchers have also used $24 \mathrm{hR}$ and FFQ to study SSA populations.

In East and West Africa, 24hR were predominantly applied for epidemiological studies, nutritional monitoring or impact assessments of interventions (Pisa et al., 2017). In contrast, FFQs were used to assess food habits and nutrient intakes. These various applications were highly heterogeneous in duration, number of recalls (24hR), recall period (FFQ), validation (e.g. only 3 out of $924 \mathrm{hR}$ programs in West Africa and no 24hR programs in East Africa were validated against biomarkers) and reliability assessments (see Pisa et al., 2017, p. 56; Vila-real et al., 2018, Tables 2 \& 3). All national programs assessed in Pisa et al. (2017) conducted interviews by pen-and-paper.

In SSA, the relatively high cost of anthropometric, biomarker and diet surveillance has necessitated coarser estimates of food security status - initially using existing data. At a macro-level, 
food balance sheets (FBS) provide an estimate of food availability per capita based on production, transformation, trade and population requirements (Micha et al., 2018). At a micro-level, household consumption and expenditure surveys (HCES) - primarily designed to calculate consumer price indices (CPI) - have been utilised as a means of assessing dietary adequacy of purchased foods (Micha et al., 2018; Burchi \& Muro, 2016; Carletto et al., 2013).

More recently, proxies have been developed to enable frequent and wide-scale measurement (Pisa et al., 2017; de Keyzer et al., 2015). Two prominent indicators are: household food security of access and diet diversity. The household food security of access indicator is based on a series of nine questions of increasing severity, from worry about food availability to missing an entire day of food due to availability. For example, severe food insecurity (of access) is defined as regularly eating smaller meals than desired, regularly eating fewer meals than desired or worse. Diet diversity indicators are based on a count of food categories consumed. There are a range of diet diversity indicators, varying by the aggregation and inclusion of food categories. Food insecurity of access and diet diversity metrics have been assessed against traditional anthropometric status and adequacy ratios and have emerged as valid proxies (evident in McDonald et al., 2015; Rah et al., 2010; Saha et al., 2009; Coates \& Bilinsky, 2007; Savy et al., 2005; Steyn et al., 2006; Arimond \& Ruel, 2004; Torheim et al., 2004).

\subsection{Knowledge gaps and objectives}

The global community has committed itself to reverse trends in food insecurity, here denoting the two concepts of chronic and hidden hunger (FAO et al., 2018). It has been estimated that much of the chronic and hidden hunger that we see today can be alleviated by implementing a suite of interventions at a cost of US\$9.6 billion per annum (Bhutta et al., 2013). Figure 1.1 outlines three strategies that can accelerate the effectiveness of such an investment - including increasing supply, adding nutrition value and increasing demand. However, such strategies are hampered by a limited understanding of: a) the prevalence of food insecurity b) the spatial distribution of food insecurity, and c) the associations between food insecurity and livelihoods - the outcomes and impact section of Figure 1.1. These three knowledge gaps are summarised in this section.

\subsubsection{The prevalence and spatial distribution of food insecurity}

Our best estimates of chronic and hidden hunger globally are based on FBS. These estimates provide vital insights into the deficiencies of global and regional food supplies. FBS for energy are compiled annually - providing insights into trends and macro level associations (such as conflict and climate change; FAO et al., 2018). Assessments of hidden hunger are less common (Kumssa et al., 2015; Joy et al., 2014). Estimates from FBS are limited by low-quality data, simplifying assumptions, under-representation of informal trade and subsistence food, and assumptions of equal access to food supplies (Micha et al., 2018). The accuracy of FBS has been assessed against nationally representative household microdata - generally finding poor agree- 


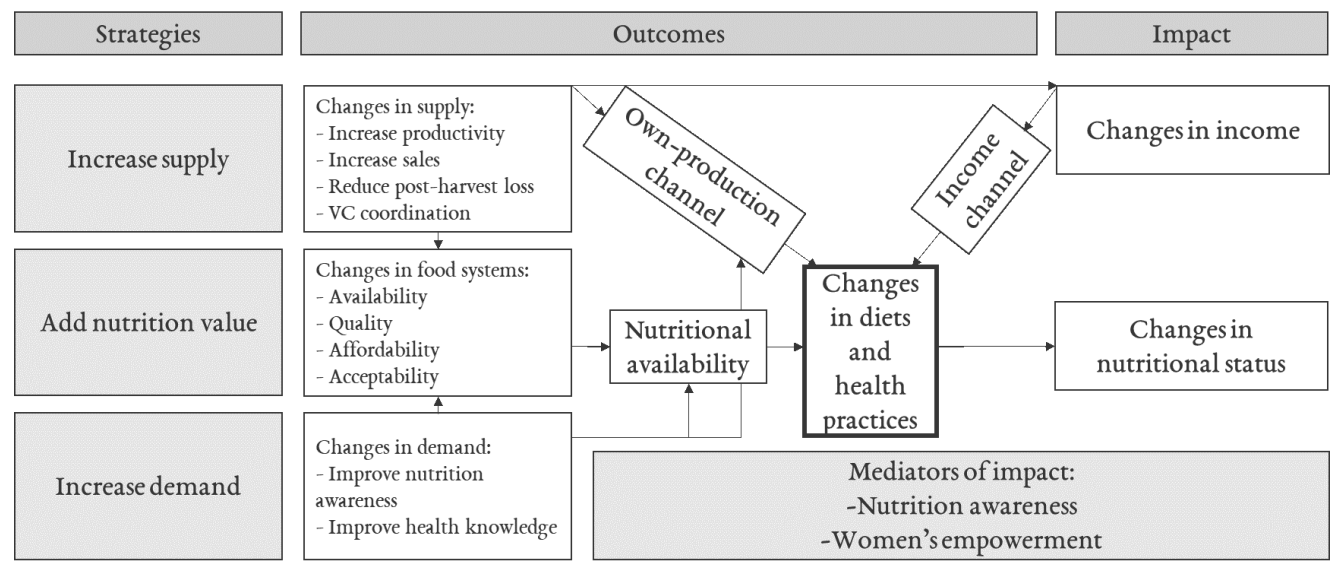

Figure 1.1 Impact pathways of food system-based nutrition-specific and nutrition-sensitive interventions

$\mathrm{VC}=$ value-chain

(Reproduced with permission from IFAD, 2018)

ment, with some level of convergence (Desiere et al., 2018; Gobbo et al., 2015; Dowler \& Seo, 1985). The assumption that each individual in the population has equal access to food and utilises what they need, however, under-represents food insecurity and masks the spatial distribution of food insecurity (Micha et al., 2018).

In contrast to FBS, the household level assessments (24hR, FFQ and food (in)security proxies) can provide more accurate and spatially explicit prevalence estimates of food insecurity. The food insecurity experience scale (FIES), for example, has been implemented in 140 countries with samples of more than 1,000 respondents per country (FAO et al., 2018). However, as the FIES indicator only represents food insecurity of access, other aspects of food security such as diet diversity and nutrient adequacy do not have the same global scale and frequency of application. These knowledge gaps related to the prevalence and spatial distribution of food insecurity also have a bearing on our knowledge of the associations between food security and livelihoods.

\subsubsection{Associations between food security and rural livelihoods}

The research community has been exploring the associations between food insecurity and rural livelihoods on national and sub-national scales. The emerging areas of investigation have centred on the role that agricultural production (subsistence and market-orientated) and offfarm income plays in improving food insecurity of access, diet diversity and nutrient adequacy ratios. Income, and thus purchased foods has been found to be highly associated with dietary diversity in a majority of these studies, whereas food from subsistence production, while also significant, has had a limited association with dietary diversity (Bellon et al., 2016; Koppmair 
et al., 2016; Luckett et al., 2015; Sibhatu et al., 2015; Snapp \& Fisher, 2015; Dillon et al., 2014). In comparison, Jones (2016) and M'Kaibi et al. (2015) emphasised the positive relationship farm production has with nutrition metrics. In the most geographically diverse study to date, the role of farm production on nutrition was found to be of varying importance depending on market opportunities (Sibhatu et al., 2015). These findings, however, are dependent on food security at the time of survey and, as mentioned previously, have a limited geographical scope - limiting cross-site comparisons and more generalisable inference.

The limitations in performing cross-site comparisons are - in part - due to a lack of coordination between organisations. This lack of coordination has resulted in a "multiplicity of survey instruments collecting information on various dimensions of food and nutrition security" (Carletto et al., 2013, p. 30). The impetus to harmonise rural household microdata comes as nationally representative studies have been constrained in uptake and frequency of implementation (Desiere et al., 2018; Carletto et al., 2013). Progress has been made to overcome this research gap over the past decade (e.g. Carletto, 2009; Herrero et al., 2007). A harmonised data collection effort, however, has still not yet been realised. Carletto et al. (2013, p.39) suggest that this harmonisation can be developed over time, with a "combination of short-term fixes and long-term methodological advancements".

\subsubsection{Objectives}

The primary objective of this thesis was to characterise food and nutrition security in rural landholding households in predominantly mixed crop-livestock agricultural systems of subSaharan Africa (SSA). Characterisation in this respect refers to describing the multiple facets of food and nutrition security, and identifying their associations with livelihoods. The related hypothesis is that variation in livelihoods between communities are strongly influenced by agroclimatic conditions, market opportunities and productive assets. It is also hypothesised that nutrition-related outcomes to a certain extent are determined by the livelihood characteristics present in a community. Understanding the context-specific relationships between livelihoods and food security will be essential to inform nutrition-specific (e.g. supplementation \& fortification) and nutrition-sensitive interventions (e.g. agricultural interventions that indirectly improve nutrition).

The secondary objective was to improve the methodological basis of household level food security studies. The related hypotheses to this objective are: 1) existing rural household surveys can be improved upon based on critical evaluation of reliability and credibility, 2) the quantification of food and nutrition security can be integrated with rural household surveys to capture conditions throughout the year, independent of survey timing, 3) research efforts of multiple organisations can be harmonised by providing an effective tool (survey). 


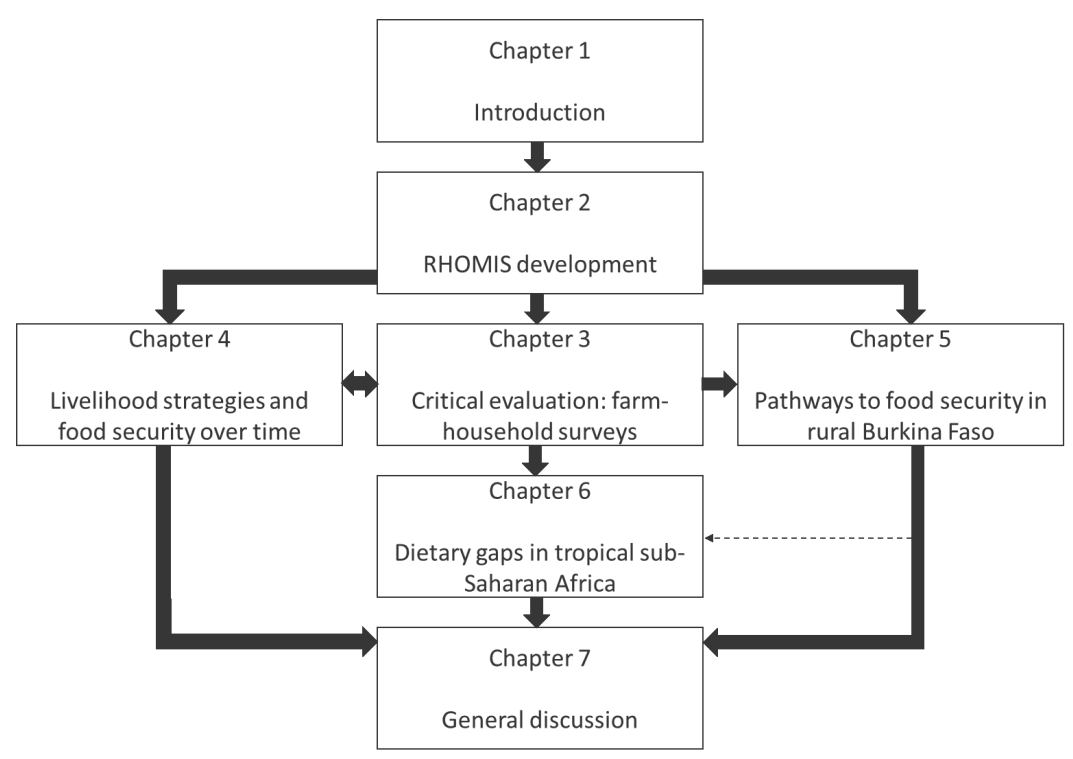

Figure 1.2 Overview of thesis structure

\subsection{Outline of the thesis}

This thesis proceeds by introducing the 'rural household multi-indicator survey' - RHOMIS. Chapter 2 provides a summary of the design principles, indicators and pilot applications of RHOMIS. The data quality associated with rural household surveys is then critically evaluated in Chapter 3. The results of Chapter 3 then have a bearing on the analysis and inference of the three proceeding observational chapters. Chapter 4 provides an assessment of the livelihoods and food security status of households in an urban linked, high potential region of Tanzania over a three-year period. Chapter 5 provides an assessment of the pathways to food security in northern Burkina Faso, with a specific focus on the consumption of home-produced food versus purchased food. Chapter 6 provides an assessment of dietary gaps across multiple locations in sub-Saharan Africa. Chapter 7 then provides a synthesis of findings in this thesis, drawing together common themes and identifying areas for future research. Figure 1.2 provides a diagrammatic overview of this thesis.

\section{Summary of study sites}

The primary objective of this research is addressed by drawing on harmonised rural household datasets across SSA. Research sites were located exclusively in rural communities and limited to landholding households. Sites were sampled from a diverse range of AEZs, with differing livelihoods and a presence of mixed crop-livestock systems. The study sites are presented in Figure 1.3. Appendix Table A1 summarises the characteristics of study sites. A total of 9,126 households were sampled, of which, 4,323 households were located in warm semi-arid zones, 


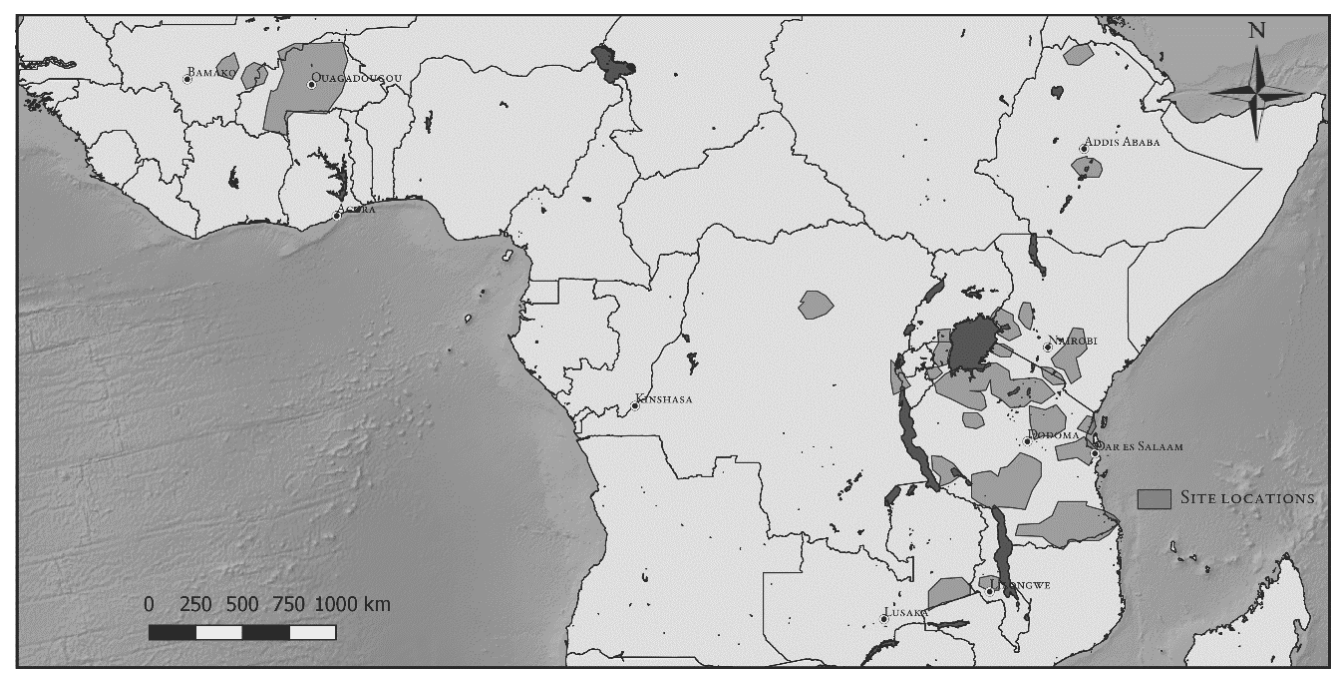

Figure 1.3 Map of study sites

1,402 households were located in warm sub-humid and humid zones, 250 households were located in a cool semi-arid zone, 1,872 households were located in cool (sub)humid AEZs and two studies spanned multiple AEZs with 1,279 observations. Livestock keeping and staple crop cultivation were prominent livelihood activities in all sites (not represented in Appendix Table A1). The presence of dairy, cash-crops and off-farm income opportunities differed by site. Market orientation and market access also differed. These harmonised rural household datasets were utilised in Chapters 2 to 6, with the majority of observations employed to explore dietary gaps in Chapter 6 (Appendix Table A1 summarises which chapter each site relates to). 


\section{Chapter 2}

\section{The Rural Household Multi-Indicator Survey for rapid characterisation of rural households}

This chapter is based on:

Hammond, J., Fraval, S., van Etten, J., Suchini, J. G., Mercado, L., Pagella, T., Frelat, R., Lannerstan, M., Douxchamps, D., Teufel, N., Valbuena, D., van Wijk, M. T. (2017). The Rural Household Multi-Indicator Survey (RHoMIS) for rapid characterisation of households to inform climate smart agriculture interventions: Description and applications in East Africa and Central America. Agricultural Systems, 151, 225-233. doi:10.1016/j.agsy.2016.05.003

A full version of the RHOMIS tool is available in Hammond, 2018, pp. 114-131. Refer to the following weblink link: https ://research. bangor . ac.uk/portal/files/22079255/2018_Hammond_ J_PhD . pdf\#page=132 


\subsection{Abstract}

The rural household multi-indicator survey (RHOMIS) is designed to rapidly characterise a series of standardised indicators of agricultural production and market integration, nutrition, food security, poverty and GHG emissions. The core of the survey takes 40-60 min to administer per household using a digital implementation platform. This is linked to a set of automated analysis procedures that enable immediate cross-site bench-marking and intra-site characterisation. We trialled the survey in two contrasting agro-ecosystems, in Lushoto district of Tanzania $(n=150)$ and in the Trifinio border region of Guatemala, El Salvador and Honduras ( $n=285)$. The tool rapidly characterised variability between farming systems at landscape scales in both locations identifying key differences across the population of farm households. 


\subsection{Introduction}

At present, approximately 75\% of the world's poor live in rural areas (Livingston et al., 2011), and many of those are in areas where climate change is expected to have a significant detrimental impact on top of current and future agricultural demand and development challenges.

Predicted changes in rainfall and temperature patterns will strongly affect agricultural production, with changed crop production and yields; causing increased vulnerability of many rural communities. As much as $22 \%$ of the cultivated area under the world's most important crops is projected to experience negative impacts from climate change by 2050 , with as much as $56 \%$ of the land area in sub-Saharan Africa being impacted (Campbell et al., 2011). The overall aim of Climate smart agriculture (CSA) is to 'support efforts from the local to global levels for sustainably using agricultural systems to achieve food and nutrition security for all people at all times, integrating necessary adaptation and capturing potential mitigation' (Lipper et al., 2014; Neufeldt et al., 2013). Climate smart agriculture therefore has three main pillars, to be considered at different spatial and temporal scales (FAO, 2013): 1) achieve food security, 2) adapt and build resilience to climate change and 3) reduce greenhouse gas emissions to mitigate further climate change.

There is an urgent need to improve the characterisation of agricultural systems at household level to enable a more efficient assessment of the capacity households to adopt of climate smart measures. Capacity to adopt is intrinsically linked with the potential success of those measures, which means assessing trade-offs amongst multiple outcome objectives for adopters. Local drivers and factors need to be identified that might constrain or provide opportunities within a specified agricultural system (Carletto et al., 2015a), while on the other hand generalisable standardised characteristics need to be identified that would allow robust comparisons between different systems (Frelat et al., 2016; van Wijk et al., 2014).

One way to assist the assessment of opportunities at smallholder farm household level for CSA can be through integration of standardised agricultural, poverty, nutrition and environmental indicators in the quantitative characterisation of these households. This will allow us to assess how these performance indicators vary across a farm population, across different sets of farm practices present in the farm population and across different agro-ecological and socioeconomic conditions as well as how they may change over time. At present household level characterisation studies are hampered by a variety of problems. A recent analysis of farm household level survey data collected in different agricultural development oriented projects, showed large differences in content between different survey instruments, with lack of standardisation of indicators and evidence that only a small amount of the information collected during lengthy surveys could actually be used for cross-site comparisons (Frelat et al., 2016). This lack of standardisation in combination with often relatively poor data quality (Tiffen, 2003), generally caused by unsuitable survey design (Randall \& Coast, 2015) or by biases due to perverse incentives (Sandefur \& Glassman, 2015), has led to a lack of quantitative insight beyond the locality of each study regarding the effect of interactions between proposed adaptation 
options and the wider socio-economic and biophysical environment on household level performance indicators. For example, we know little on how household food security has been affected by trends in agricultural production in different regions of the world (Carletto et al., 2013) or what the effects of adopting CSA measures are. The lack of integrated survey approaches hampers our knowledge of trade-offs and/or synergies between indicators at farm household level (e.g. Klapwijk et al., 2014). Furthermore, it is unknown how these relationships and trade-offs are shaped by farm management and by social and bio-physical environments (Carletto et al., 2015a; De Weerdt et al., 2015).

In this paper we describe a new standardised modular survey tool called rural household multiindicator survey (RHOMIS) that tries to overcome the current problems associated with household characterisation surveys. The RHOMIS tool is constructed from a set of standardised performance indicators that run across the three pillars of CSA, and aims to allow us to quantitatively analyse the links between agricultural management strategies and farm household performance.

\subsection{Methods}

\subsubsection{Principles and general design of the RHOMIS tool}

The RHOMIS (Rural Household Multiple Indicator Survey) tool consists of a farm household survey that can be conducted on a digital platform using smart phones or tablets using the open data kit (ODK) suite of software installed on Android based mobile phones or tablets (Hartung et al., 2010). Data can be directly uploaded to a web-server, and an associated set of analysis tools programmed in R extract the data and calculate indicators. The tool has been set up in such a way that additional modules of questions and indicators can be incorporated and analysed depending on the local study needs. The survey tool was designed according to the following five principles:

i. the survey has to be rapid enough to avoid participant fatigue or annoyance, and keeping costs low to allow for larger sample sizes on a limited budget;

ii. the survey has to be utilitarian, in that all questions asked in the survey are being used in pre-defined analyses, in order to minimise superfluous data collection;

iii. the survey has to be user-friendly, so that all participants in the process of collecting and analysing data can perform the tasks with minimum hassle and resistance, and therefore increase speed and data quality;

iv. the survey has to be flexible, so that it can be modified easily to suit the local context of the farming systems and farm households where it will be deployed;

v. the data gathered has to be reliable, in that questions should be easy for respondents to understand and the answers should be based on observable criteria or respondents' direct experience rather than abstract scales or abstract concepts. 


\subsubsection{Household performance indicators}

The indicators that are captured by the RHOMIS tool were chosen to represent important factors of the agricultural production, nutrition and poverty, while also capturing key indicators of interest related to CSA (i.e. greenhouse gas emissions and gender equity). The survey tool was constructed in a modular way, with each module collecting the information needed to be able to calculate the performance indicator of interest. New indicators of interest to the user can therefore be added easily. The indicator set collected in the initial version of the RHOMIS tool consisted of the following elements:

1. Food availability is supply-based estimate of the potential amount of food that can be generated through on and off-farm activities by any one household, and is measured in kilo-calories (kcal) per person (adult equivalent) per day (Frelat et al., 2016; Ritzema et al., 2017; van Wijk, 2014). The indicator is calculated from on-farm consumption of food crops and livestock products, and from the amount of food (local staple crop) that could be purchased using the cash incomes earned through selling farm produce and through offfarm activities. It ignores farm costs and household expenses, and therefore only gives an indication of whether certain activities lead to enough food being potentially available to feed the family, and the relative importance of these activities compared to each other. It does not quantify actual consumption.

2. The household dietary diversity score (HDDS) is calculated according to the number of different food groups consumed over a given reference period, and is a proxy indicator for diet diversity, the improvement of which is associated with a number of key health indicators such as birth weight, child anthropometric status, and improved haemoglobin concentrations. The HDDS score in RHOMIS follows the instructions of Swindale \& Bilinsky (2006) in most aspects but departs from the standard advice in terms of reference time period. A $24 \mathrm{~h}$ recall method is recommended, but we instead asked how often foodstuffs from each food group were eaten during a 4 week period in 'the flush period' and 'the lean period'; where respondents could answer that they consume foods from each group either 'daily', 'weekly', 'monthly', or 'never/less then monthly'. Whilst this approach might result in lower accuracy than a $24 \mathrm{~h}$ recall, the required survey intensity is much less in order to capture seasonal variations. The 12 food groups used were standard, but locally appropriate examples were chosen in each location. The indicator results are on a scale of 0 to 12 , where 12 is the most diverse diet in which all 12 food groups are eaten on at least a weekly basis. The data on consumption frequency within the recall period will allow us more complex interpretations in terms of micro-nutrient use, but will not be analysed in this study.

3. The Household Food Insecurity Access Scale (HFIAS) indicator estimates the prevalence of food insecurity and is based on the idea that the experience of food insecurity (access to food) causes predictable reactions and responses that can be captured and quantified through a survey and summarised in a scale. There are nine questions that represent a generally increasing level of severity of food insecurity, and nine "frequency- 
of-occurrence" questions that are asked as a follow-up to each occurrence question to determine how often the condition occurred (Coates \& Bilinsky, 2007). The approach has been applied successfully in numerous studies in developing countries (Coates et al., 2006). We asked respondents about food insecurity during the worst month ('lean period') of the previous year, and frequency options were again 'daily', weekly', 'monthly',or 'never/less then monthly'. The indicator is scored on a range of 0 to 27 , where a higher number means a household experiences more food insecurity.

4. The Progress out of Poverty Index (PPI) is a widely used standard indicator of poverty (Desiere et al., 2015). The PPI is a rapid ten-question survey which estimates the likelihood that a household has an expenditure below a given poverty line, where the score ranges between 0 and 100, and a higher score means a household is less likely to be below the poverty line (Grameen foundation, 2015). The scorecard uses ten simple indicator questions based on observable household characteristics that are correlated with poverty levels using Living Standards Measurement Surveys or similar, detailed surveys. The PPI approach is now available for 55 countries, amongst which are Guatemala and Tanzania.

5. A gender equity indicator was included to quantify the role of women in decision-making and household resource management. The inclusion of gender in resilience and vulnerability assessments is a burgeoning topic (Smyth \& Sweetman, 2015; Morchain et al., 2015), and achieving gender equity is an aim of many policies in developing countries. The indicator is constructed based on three questions asked for each farm product or income source: who does most of the work, who usually decides when to eat it, and who sells it; where the possible answers are 'household males', 'household females' and/or 'children'. The information was aggregated to an overall score by weighing each activity along the importance it has in the food availability indicator, resulting in a final score between 0 and 1, where 1 implies that female decides completely what happens with the benefits generated by different on and off farm activities. This indicator therefore does not deal with ownership of resources, but with the agency to decide what to do with the benefits that result from these resources. We constructed a novel indicator in this case, because although alternatives do exist, they were too detailed and complex for our purposes (Johnson \& Diego-Rosell, 2015). For example, the Women's Agricultural Empowerment Index requires 60- 80 minutes of interview time per household (Alkire et al., 2013), which is longer than our target time for the full questionnaire.

6. Farm level estimates of greenhouse gas (GHG) emissions were calculated using the IPCC Tier 1 approach (IPCC, 2006). Tier 1 was chosen because it is a recognised method and has low data demands. Although the Tier 2 approach yields a more detailed GHG assessment, the substantially higher data demands can lead to unreliable data when relying on farmer recall. Key determinants of the Tier 1 estimate of emissions for this indicator are number of cattle and other livestock, land use area and type, inputs of mineral fertiliser and the production and use of manure and crop residues. The indicator does not account for carbon sinks, land use change (even if implemented longitudinally), capital infrastructure, 


\begin{tabular}{|c|c|c|c|}
\hline \multicolumn{4}{|c|}{ Survey question modules } \\
\hline \multirow{2}{*}{$\begin{array}{l}\text { Time } \\
\text { efficient }\end{array}$} & Core & \multicolumn{2}{|c|}{ Additional } \\
\hline & Farm & Cattle feed & $\begin{array}{c}\text { Cattle } \\
\text { diseases }\end{array}$ \\
\hline Utilitarian & Household & Debt \& aid & Expenditure \\
\hline \multirow{2}{*}{$\begin{array}{l}\text { User- } \\
\text { friendly }\end{array}$} & Food security & WASH & Tree-use \\
\hline & Wild foods & $\begin{array}{c}\text { Information } \\
\text { sharing }\end{array}$ & $\begin{array}{l}\text { Recent } \\
\text { changes }\end{array}$ \\
\hline Flexible & PPI & Motivations & — Languages \\
\hline Reliable & Gender & Localisation & {$\left[\begin{array}{l}\text { Units } \\
\text { Foods } \\
\text { Species }\end{array}\right.$} \\
\hline
\end{tabular}

Figure 2.1 Core and additional indicators in the RHOMIS tool.Including the progress out of poverty in$\operatorname{dex}(\mathrm{PPI})$ and; water, sanitation and health (WASH) modules from the rural household multi-indicator survey

6. nor farm related electricity or fuel use. Farm greenhouse gas emissions are reported in kilograms CO2-equivalent per farm per year.

These were the six core indicators that can be quantified with this version of the RHOMIS tool. The information used to calculate these indicators was also used to calculate several other performance indicators: The questions used to calculate the Food Availability indicator were used to quantify

7. Farm Productivity, measured in total kilo-calories produced per year per hectare;

8. Farm Produce Value, which is the calculated total value of everything produced on the farm, using local prices and reported in US dollars per year;

9. Off farm income, also expressed in 2010 equivalent US dollars, as reported by the households. Finally, the GHG emission indicator and the agricultural production component of FA (including sales and consumption), expressed in kcal per year, were used to calculate

10. GHG emission intensity, expressed in kg of CO2-eq/kcal.

The core of the RHOMIS tool has been extended to include wild foods. Several modules have also been added to extend the capabilities of the RHOMIS tool (see Figure 2.1). In line with the principle of flexibility, the RHOMIS tool can be localised by languages, units of enumeration, foods and species (Figure 2.1). 


\subsubsection{Site selection and survey implementation}

Surveys were carried out in two contrasting sites: Trifinio border region of El Salvador, Guatemala and Honduras in Central America, and the Lushoto district in Tanzania, East Africa. Agriculture and livelihoods in both sites are vulnerable to climate change. The contrasting nature of the sites aims to demonstrate the wide applicability of the RHOMIS tool. The sites were selected because they are part of a concerted data gathering effort by various ongoing research programs and projects mentioned below. Lushoto is part of the Eastern Arc Mountains of East Africa which is seen as a global hotspot for biodiversity with diverse micro eco-zones within a relatively small area; mixed crop-livestock, quite intensive farming systems in higher elevation and agro-pastoral farming systems in lower elevation. The Usambara Mountains are an important source of water for north-eastern Tanzania and the Pangani River is utilised for urban water supply, irrigation and hydropower generation. Deforestation, poor land management and inadequate funds for watershed management pose a threat to the long-term supply of quality water from the Usambaras to downstream communities. The supply of water might be further affected by climate change with rainfall predicted to become more irregularly distributed. The agricultural system in the Trifinio region in Central America is dominated by dry, steep and with sporadic rainfall and little to no irrigation infrastructure, where the major crops are maize and beans. Trifinio is part of the 'dry corridor' of Central America, and during the past few years rains have become more sporadic, leading to drought conditions since 2014.

In Lushoto, Tanzania, the survey was conducted on a resample of the farm households that were also surveyed in 2012 with the CCAFS research program (https://ccafs.cgiar.org/). In the 2012 survey 200 farm households were randomly selected within the 10 by $10 \mathrm{~km}$ land block containing representative agroecologies in the study region that were chosen through a participatory process involving a wide range of partners and expert opinion (Kristjanson et al., 2012; Förch et al., 2014). Twenty villages within each block, and then 10 households on average within each village were randomly chosen (Kristjanson et al., 2012) for the household survey. In June 2015150 households were randomly chosen from the 200 sampled in 2012, and they were interviewed in the first two weeks of July using the digital version of the RHOMIS survey tool. In Trifinio the survey was carried out in conjunction with the baseline survey for the USAIDfunded Prueba3 project, implemented by Bioversity, CATIE and Zamorano in Trifinio to test Crowdsourcing Crop Improvement (van Etten, 2011). Villages were selected by collaborating organisations as candidate villages for a bean variety introduction experiment, and a subset of 285 households was randomly selected for the RHOMIS survey from the full list of households taking part in the project. Surveys were trialled with scientific experts in each study region; with scientific and technical staff resident in each study site; with the enumerators who would implement the surveys; and finally with rural households within the intended implementation area of the surveys. Specific changes were made on the phrasing and use of language, on local units of measurement used, on examples of locally available foodstuffs and other products (e.g. types of fertiliser), on the crops, livestock and livestock products commonly produced, routes to market, and common sources of off-farm income. The survey was conducted in Spanish in Trifinio, and in Swahili in Lushoto. 


\subsection{Results}

Across both sites, the running time for the survey was 40-60 minutes per household (Table 2.1). Gathering data for the food availability indicator took the longest, between 15 and 35 minutes, as it is based on the whole of agricultural production, sales and off farm income. The dietary diversity indicator took the second longest to complete, at around 10 minutes per household, due to the complexity of explaining the different food types, and introducing the concepts of the 'flush period' and 'lean period'. All other indicators only took up to 5 minutes each (Table 2.1). The indicators were calculated successfully for most households, we were only unable to calculate $<1 \%$ of all potential indicator data points due to lack of adequate responses.

The interviewers were asked to rate the 'easiness' of gathering the data at the end of each module, whilst undertaking the surveys. Ease related to both the ease of asking and phrasing questions, and the ease of extracting the right type of response from the informant. All modules were rated as 'easy' between 50 and $60 \%$ of the time, and rated as medium approximately $30 \%$ of the time, except for off-farm incomes, which was rated 'medium' more often than it was rated 'easy'. The Progress out of Poverty Indicator was rated as difficult only $5 \%$ of the time, and other modules rated as difficult $11-13 \%$ of the time (details shown in Table 2.1). This provides evidence that the survey is indeed user friendly. Adaptation of the survey questions, language and training of interviewers took about two weeks in both Trifinio and Lushoto. In Lushoto, Tanzania, in two weeks of data collection with 3 interviewers the responses from 150 households were collected, at a total cost of around US $\$ 5000$, including the purchase of three tablets. The implementation in Trifinio was a little more complex, as the RHOMIS survey was only one of two surveys implemented as part of a larger project, so it is not possible to determine survey costs working only with RHOMIS. It does however illustrate that the tool is flexible enough to be used in conjunction with other research methods.

Table 2.1 Time taken to gather data for each indicator, and the ease of that data gathering, as rated by the interviewers during the Lushoto survey, $\mathrm{n}=151$

\begin{tabular}{lcccc}
\hline Module & $\begin{array}{l}\text { Duration (minutes } \\
\text { per household) }\end{array}$ & \multicolumn{3}{c}{ Perceived ease of enumerating (\%) } \\
\cline { 3 - 5 } & & Easy & Medium & Difficult \\
\hline FA & $15-35$ & 56 & 31 & 13 \\
HFIAS & 5 & 54 & 34 & 12 \\
Dietary Diversity & 10 & 54 & 34 & 12 \\
PPI & $3-5$ & 61 & 34 & 5 \\
Gender Equity & 5 & 61 & 28 & 11 \\
GHG Emissions & 5 & 57 & 32 & 11 \\
\hline
\end{tabular}




\subsection{Discussion}

In both study sites the RHOMIS tool met our stated goals of providing rapid, user friendly, and flexible output; both in terms of ease of implementation of the survey by enumerators and by providing efficient data management and analysis. Some of the indicators could be improved upon to give more nuanced interpretations, although there is always tension between speed of survey and detail of results (e.g. Mina et al., 2008; Coates, 2013; De Weerdt et al., 2015). When considering food security and nutrition there is a clear trade-off between the level of detail that can be achieved in quantifying intake of different foodstuffs of individual actors, versus the goal of obtaining a sufficiently accurate picture of the village or local eating habits (Kennedy et al., 2013). In nutrition oriented research the gold standard is (at the moment) the 24 hour recall collecting detailed information on what several individual members of a household consumed the previous $24 \mathrm{~h}$ (Coates, 2013). However, these data are more time consuming to collect, plus provides only a current snapshot of the nutritional situation. Several surveys per year are required to capture seasonal variation and repeat surveys to measure trends have to take place during the same season to avoid confounding effects. Our approach of asking about frequency of consumption (daily/weekly/monthly) in the 'flush' and 'lean' periods may be less accurate, but may obtain a general picture much more quickly.

\subsection{Acknowledgements}

We thank all the people involved in collecting the field data that formed the basis for the analyses and especially the farmers for sharing their valuable information and time. We thank the two anonymous referees and the editors of Agricultural Systems for their useful comments that helped improve this manuscript. 


\section{Chapter 3}

\section{Making the most of imperfect farm household data: a critical evaluation of standard information collected in farm household surveys}

This chapter is based on:

Fraval, S., Hammond, J., Wichern, J., Oosting, S. J., de Boer, I. J. M., Teufel, N., Lannerstad, M., Waha, K., Pagella, T., Rosenstock, T. S., Giller, K. E., Herrero, M., Harris, D., van Wijk, M. T. (2018). Making the most of imperfect data: a critical evaluation of standard information collected in farm household surveys. Experimental Agriculture, 1-21. doi:10.1017/S0014479718000388.

Supplementary information is publically available online, accessable via the doi. 


\section{Abstract}

Household surveys are one of the most commonly used tools for generating insight into rural communities. These methods are frequently used in the design and evaluation of agricultural development programmes. Despite their prevalence, few studies have evaluated the quality of such data. We reviewed data from three different farm household surveys deployed in four African countries. We found issues concerning the quality of many reported values and indicators. Surprisingly, even variables which might be considered 'easy to estimate' had instances of non-credible observations. Assessment of food security and food self-sufficiency showed that between 29-57\% of observations in the World Bank's 'living standards measurement survey' were deemed beyond credible bounds, while for shorter and more targeted survey tools like the 'rural household multiple indicator survey' this value decreased to $25 \%$. Measurements of maize yields and land owned were found to be less reliable than other stationary variables. This lack of reliability has implications for monitoring food security status, poverty status and the land productivity of households. Despite this rather bleak picture, our analysis shows that if the same farm households are followed over time, the sample sizes needed to detect substantial changes are in the order of hundreds of surveys, and not in the thousands. Our research highlights the value of targeted and systematised household surveys for detecting such changes. Furthermore, ongoing developments in data collection strategies and tools are likely to improve data quality. Aspects that need sustained or improved attention include: survey design (questions and length), transparency of experimental design, effective training, improved coordination between agencies, incorporating mixed modes of data collection and ongoing systematic validation programs. Improvements in the quality of rural statistics will maximise the impact of evidence-based decision making. 


\subsection{Introduction}

Smallholder agricultural production in sub-Saharan Africa (SSA) remains a vital source of sustenance, revenue and employment. In the context of forecasted population growth and rapid economic development in many African nations, rural communities will have new opportunities and heightened challenges. Effective, inclusive, and poverty-reducing rural transformation is not an inevitable outcome in future scenarios for SSA nor the broader global rural population (IFAD, 2016). Rather, pro-poor and equitable rural transformation requires well designed and executed policies and interventions guided by the rural communities themselves.

Household surveys are one of the most commonly used tools for generating insights into rural communities (Christiaensen, 2017). These tools are used in place of more detailed studies because they are relatively cost-effective. The surveys rely heavily on farmer assessment and recall in place of (more detailed) external monitoring and measurement. The utilisation of lowcost farmer recall enables them to be deployed quickly and at scale which is vital for obtaining representative samples of rural communities and regions. Household surveys can be used for ex-ante and ex-post analyses. Ex-ante applications can be focused on strategic planning purposes, involving prioritisation, characterisation and simulations. Ex-post assessments measure the effect of some 'change'; typical examples include evaluation of new technologies and practices (e.g. those related to cropping, livestock production, land management and natural resource management), or changes to policies and infrastructure (e.g. new roads and market interventions). Ex-post assessments will often assess effects on productivity, decisions (farm management, investments, marketing and off-farm activities) and livelihoods (income, wealth and equity).

Evidence generated to develop and evaluate policies and interventions should be representative of the population of interest, as well as of sufficient quality. Such evidence needs to be founded on a statistically robust sampling protocol that is of sufficient size and designed to minimise sampling error (biases in respondent selection contrary to the population composition) and coverage error (biases from an incomplete sampling frame). The total measurement error of household survey data also consists of random and systematic error, caused by the implementation process of a household survey. Random error can be thought of as instances where repeated measures result in randomly inconsistent values, and systematic errors are errors that are not caused by chance but rather are consistently over or under-reported in a given measurement and observation context. The stages where error can be introduced in a household survey include: designing the data collection tool, training enumerators, soliciting households to participate (which can result in unit non-response error) and collecting information from the farmers - often based on estimation and remembering past events. As detailed by Weisburg (2005), there are also specific aspects of survey design, mode of collection, data management and analysis that can introduce random and systematic error.

There is a continuous drive to improve the quality of rural statistics, with a particular focus on reducing random and systematic errors. The central statistical bureaus of many medium 
and high-income countries have the resources to continuously improve processes and meet domestic data needs and international reporting commitments. For low-income countries, where resources and capacity for agricultural and rural development are constrained, international partners have taken a more active role, for instance by providing guidelines and training (e.g. FAO, 2017b; UNFCCC, 2012; OECD, 2009; UN, 2005, as well as the CGIAR and the World Bank). Efforts to improve statistics have addressed the full breadth of issues from experimental design, survey design, enumerator training, data management, analysis and open data policies. The efforts to standardise survey design and indicators are most relevant for this present study because they represent 'best-practice' and a process of ongoing improvement. Three comparable survey designs that are multi-topic, multi-purpose and have been internationally applied are: the World Bank's 'living standards measurement study' program (LSMS; World Bank, 2017), the lite version of the 'integrated modelling platform for mixed animal crop systems' (IMPACTlite; Herrero et al., 2007) and the 'rural household multiple indicator survey' (RHOMIS; Hammond et al., 2017). Each of these tools aim to improve the consistency and quality of data collection between sites and within sites.

Despite the importance of rural statistics, there are relatively few studies that systematically evaluate the data quality of household level enumeration. Nevertheless, contributions have been made towards identifying sources and implications of poor data quality. For instance, in a special issue on data quality in Africa, Jerven \& Johnston (2015) concluded that limited resources tend to reduce the quality of statistics and that there are risks of bias at many levels. Kilic \& Sohnesen (2015) found that survey length has a statistically significant effect on data quality, regardless of topic and question type - potentially mediated through respondent and enumerator fatigue. Finn \& Ranchhod (2017) explored methods to detect household survey data fabrication and the implications of fabrication on statistical inference. Pica-ciamarra et al. (2012) reported the perceptions that users (researchers, government departments, ect.) have of the quality of livestock statistics. The effects of gender bias, recall length and respondents' fatigue on response accuracy have also been explored (de Nicola \& Giné, 2014; Beegle et al., 2012).

Furthermore, the methodological validation program of the LSMS Integrated Survey on Agriculture (LSMS-ISA) program has systematically assessed the deviation of espoused volumes and areas from higher quality measurements (Gibson et al., 2015; Zezza et al., 2014; Kilic et al., 2013; these are akin to the pioneering validation-based improvements made by the USDANASS since the 1950s as detailed in Fecso, 2011). The LSMS-ISA and other 'donor-funded surveys' have also provided opportunities to test new methods that can then improve the quality of data collected in national statistical programs (Jerven \& Johnston, 2015).

The objective of this study was to further our understanding of the quality of rural statistics by critically evaluating a series of reported values and indicators captured in panel and test-retest farm household surveys. We do this by assessing the credibility and reliability of information commonly collected in farm household surveys. The results of this assessment are essential in view of the use of survey data in the scientific literature and more practical, policy formula- 
tion and agricultural development planning. Based on our results we suggest ways in which data collection approaches could be improved and the impact of low-quality data can be minimised.

\subsection{Methods}

We first describe the household survey data we used in the analyses, and then describe in detail the analyses we have performed focusing on credibility, consistency and reliability.

\subsubsection{Farm household survey data}

Our analysis draws on three comparable multi-topic survey tools: IMPACTlite (Rufino et al., 2013), RHOMIS (Hammond et al., 2017) and LSMS-ISA (World Bank, n.d.). IMPACTlite was developed in the context of a large-scale climate change mitigation and adaptation research program. The IMPACTlite tool was designed to better understand the implications of mitigation and adaptation strategies "on livelihoods, food security and the environment" (Rufino et al., 2013, p. 3).

RHOMIS was developed in response to the general challenges caused by the "inefficient multiplicity of survey instruments" (Carletto et al., 2013, p. 30), and in particular inspired by efforts to conduct cross-dataset analyses of farm household surveys in sub-Saharan Africa (Frelat et al., 2016). The tool was designed to capture information efficiently and systematically, allowing the analyst to link farm management to issues of livelihoods, poverty, food security, and gender. The indicators which can be calculated from the survey are generally widely validated and internationally recognised. The scope of the survey was defined in relation to the Sustainable Development Goals, specifically SDGs 1, 2, 5, and 13 (no poverty, zero hunger, gender equality and climate action); but the scope is also of relevance to the assessment of Climate Smart Agriculture principles, and Sustainable Intensification. Data collation and analysis are also components of RHOMIS. There are two overall purposes of the RHOMIS tool: to provide a rapid characterisation of farm systems, for use in ex-ante or ex-post analyses, and secondly, through the building of a large, harmonised dataset from many sites, to permit identification of general principles which can guide the design of rural development interventions. Data from IMPACTlite (2012) and RHOMIS (2015 and 2016) sample the same households and so form testretest datasets over three sites, namely: Lushoto, Tanzania $(n=149)$, Wote, Kenya $(n=160)$ and Nyando, Kenya ( $\mathrm{n}=161)$.

The LSMS-ISA tool was developed with a specific focus on Africa with the intention of improving the quality of rural statistics and building the capacity of local statistics offices. The core purpose of a LSMS-ISA implementation is to "improve the understanding of the links between agriculture, socioeconomic status, and non-farm income activities" (World Bank, n.d., p. 1). LSMS-ISA has been implemented in several countries and collected as panel datasets. In this study, the analysis is limited primarily to Uganda $(n=2,374)$ for the surveys held in 2009/10, 2010/2011 and 2011/12. Analysis of LSMS-ISA data from Tanzania $(n=3,265)$ and Ethiopia 
( $n=4,000)$ from 2010/11 are also included.

The sampling approach differed between the two datasets. IMPACTlite and RHOMIS sampled villages in a $10 \times 10$ kilometre grid across multiple locations. The household member most aware of farm activities were interviewed in RHOMIS, and in IMPACTlite other household members contributed to specific sections where necessary. The LSMS-ISA for Uganda, in contrast has been designed to be nationally representative (UBOS, 2007; UBOS, n.d; UBOS, 2002). The household head was interviewed and in his/her absence, a 'usual member of the household' capable of responding was interviewed (UBOS, n.d).

The formulation of questions and mode of data collection also differed in each survey (summarised in Table 3.1). Perhaps most notably, LSMS-ISA revisits households on a seasonal basis within a 12-month period, whereas IMPACTlite and RHOMIS were conducted only once with multiple recall periods. Surveys incorporated questions on household demographics, farm characteristics, product marketing, income and household diet diversity (in the case of IMPACTlite and RHOMIS, this was calculated based on Swindale \& Bilinsky, 2006). All variables assessed in this study were answered by all respondents. In addition, zero values (for land holdings, maize yield and livestock) were crosschecked with other sections of the surveys to identify potential item non-responses - all zero values were corroborated.

\subsubsection{Data analyses}

We use the household data described to assess their credibility (in terms of inaccuracies) and reliability (measurement precision; Alwin, 2006; Evans, 1995). We first assess the credibility of observations in one survey round, which also gives us insight into systematic errors. Credibility (identifying inaccurate observations) in this context is concerned with whether values fall outside acceptable bounds. We then assess the consistency of measurements between two rounds with two household survey instruments that are similar in complexity and are focused on single site applications, i.e. RHOMIS and IMPACTlite. For a more robust assessment of consistency, we also model the reliability of the LSMS-ISA dataset using three rounds of survey data. This measure of reliability better accounts for survey round specific systematic errors, but does not distinguish between true population scale temporal volatility, random error and non-survey round based systematic error.

To conclude our analysis, we assess the implications of varying levels of reliability on required sample sizes. Although all of these analyses give insight into the possible existence of systematic errors, none of the methods above will allow us to really quantify these. For that mixed method approaches are needed, e.g. weighed crop yields or GPS based field size estimates, where one can quantify the deviation between farmer recall based information and 'reality'. This lies outside the scope of this study.

\subsubsection{Credibility analysis}

Crop yields and market prices were used to assess the credibility of farmer reported and estimated values. As indicated in Table 3.1, we calculated crop yields as a composite of farmer reported harvest volumes and area planted, and market prices could be enumerated as the unit 
Table 3.1 Characteristics, question formulation and relevant period of survey tools

\begin{tabular}{|c|c|c|c|c|}
\hline & & IMPACTlite & RHOMIS & LSMS-ISA \\
\hline \multicolumn{2}{|l|}{ Locations } & Kenya, Tanzania & Kenya, Tanzania & Uganda \\
\hline \multicolumn{2}{|c|}{ Survey rounds } & 1 & 1 & 3 revisits \\
\hline \multicolumn{2}{|c|}{ Observations } & 470 & 470 & 2,374 \\
\hline \multicolumn{2}{|c|}{ Representativeness } & Development domains & Development domains & Nationally \\
\hline \multicolumn{2}{|c|}{ Duration } & $2.5-3$ hours & $45 \mathrm{~min}$ to 1 hour & Unknown \\
\hline \multirow[t]{2}{*}{$\begin{array}{l}\text { Crop } \\
\text { harvest }\end{array}$} & $\begin{array}{l}\text { Question } \\
\text { formulation }\end{array}$ & $\begin{array}{l}\text { Subplot harvest by } \\
\text { crop and }\end{array}$ & $\begin{array}{l}\text { Crop harvest - local } \\
\text { volume units }\end{array}$ & $\begin{array}{l}\text { Subplot harvest by } \\
\text { crop }\end{array}$ \\
\hline & $\begin{array}{l}\text { Relevant } \\
\text { period }\end{array}$ & Seasonal & Seasonal and annual & Seasonal - revisits \\
\hline \multirow[t]{2}{*}{$\begin{array}{l}\text { Crop area } \\
\text { planted }\end{array}$} & $\begin{array}{l}\text { Question } \\
\text { formulation }\end{array}$ & Area planted by crop & $\begin{array}{l}\text { Area planted by crop } \\
\text { - local area units }\end{array}$ & Area planted by crop \\
\hline & $\begin{array}{l}\text { Relevant } \\
\text { period }\end{array}$ & Seasonal & Seasonal and annual & Seasonal - revisits \\
\hline \multirow[t]{2}{*}{ Price } & $\begin{array}{l}\text { Question } \\
\text { formulation }\end{array}$ & Price per kg & $\begin{array}{l}\text { Price per } \\
\mathrm{kg} / \text { tonne/unit or } \\
\text { total value }\end{array}$ & Value of yield in plot \\
\hline & $\begin{array}{l}\text { Relevant } \\
\text { period }\end{array}$ & Seasonal & Annual & Seasonal - revisits \\
\hline \multirow[t]{2}{*}{$\begin{array}{l}\text { Household } \\
\text { head age }\end{array}$} & $\begin{array}{l}\text { Question } \\
\text { formulation }\end{array}$ & $\begin{array}{l}\text { Date of birth all } \\
\text { members }\end{array}$ & Age of head & $\begin{array}{l}\text { Date of birth all } \\
\text { members }\end{array}$ \\
\hline & $\begin{array}{l}\text { Relevant } \\
\text { period }\end{array}$ & As of interview date & As of interview date & As of interview date \\
\hline \multirow[t]{2}{*}{$\begin{array}{l}\text { Household } \\
\text { size }\end{array}$} & $\begin{array}{l}\text { Question } \\
\text { formulation }\end{array}$ & Full household roster & By age category & Full household roster \\
\hline & $\begin{array}{l}\text { Relevant } \\
\text { period }\end{array}$ & $>1$ season & $>3$ months per year & 12 months \\
\hline \multirow[t]{2}{*}{$\begin{array}{l}\text { Livestock } \\
\text { holdings }\end{array}$} & $\begin{array}{l}\text { Question } \\
\text { formulation }\end{array}$ & $\begin{array}{l}\text { Full list converted to } \\
\text { TLU }\end{array}$ & $\begin{array}{l}\text { Full list converted to } \\
\text { TLU }\end{array}$ & $\begin{array}{l}\text { Full list converted to } \\
\text { TLU }\end{array}$ \\
\hline & $\begin{array}{l}\text { Relevant } \\
\text { period }\end{array}$ & Current holdings & Current holdings & Current holdings \\
\hline \multirow[t]{2}{*}{$\begin{array}{l}\text { Land } \\
\text { owned }\end{array}$} & $\begin{array}{l}\text { Question } \\
\text { formulation }\end{array}$ & Parcel size & Total land owned & Parcel size \\
\hline & $\begin{array}{l}\text { Relevant } \\
\text { period }\end{array}$ & Annual & Annual & Annual \\
\hline \multirow[t]{2}{*}{$\begin{array}{l}\text { Off-farm } \\
\text { income }\end{array}$} & $\begin{array}{l}\text { Question } \\
\text { formulation }\end{array}$ & Full income register & Proportion of total & Full income register \\
\hline & $\begin{array}{l}\text { Relevant } \\
\text { period }\end{array}$ & $\begin{array}{l}\text { An- } \\
\text { nual/Monthly/week }\end{array}$ & Annual & Annual \\
\hline \multirow{2}{*}{$\begin{array}{l}\text { Household } \\
\text { diet } \\
\text { diversity }\end{array}$} & $\begin{array}{l}\text { Question } \\
\text { formulation }\end{array}$ & $\begin{array}{l}\text { Itemised food list } \\
\text { open question }\end{array}$ & $\begin{array}{l}12 \text { or } 10 \text { category list } \\
\text { prompted }\end{array}$ & 61 item food list \\
\hline & $\begin{array}{l}\text { Relevant } \\
\text { period }\end{array}$ & Seasonal & Seasonal & 7 day recall \\
\hline
\end{tabular}


price or a composite of total value and volume sold. Due to the limited availability of secondary data, crop productivity and market prices were only assessed for maize (Zea mays L.), quantifying the yield $\left(\mathrm{kg} \mathrm{ha}^{-1}\right)$ and the farm-gate price per kilogram for each farm household. Yields calculated from farmer reported harvest volumes and area planted were compared with historical yield estimates (from fertilised crop trials and government monitored plots) from the Global Yield Gap Atlas (GYGA, n.d.). Historical yield estimates compiled in the GYGA formed the basis for setting lower credible bounds. The threshold was set at $10 \%$ of the average historical GYGA yield for the same climate-zone and country. Simulated water-limited yield potential formed the basis for setting credible upper bounds. It is unlikely that enumerated yields exceed the simulated potential. Historical, potential and survey reported yields were compared on a country and climate-zone basis (using the GYGA climate zones). The historical yields in Uganda, for example, ranged from 0.7 tonnes per ha to 1.31 tonnes per ha (a summary of used thresholds is provided in SI Table 1).

Farm-gate prices were compared with the average price for each location (i.e. Lushoto, Wote, Nyando, Kampala, western Uganda, ect.) and survey tool as well as the wholesale market prices in major cities (Kampala in Uganda and Nairobi in Kenya and Tanzania; sourced from FAO, 2017a). In this component of our credibility analysis, we assume a high degree of market integration, where there is a close association with farm gate price, regional price and market price. Prices in the surveys were also averaged across seasons to give an annual average. Lower limits were set at $10 \%$ of the average survey prices for a given location; upper limits were set at the maximum wholesale market price. A summary of price thresholds is provided in Supplementary Information Table 2. The statistics on wholesale market prices also have errors associated with them, this analysis only provides information about the uncertainty surrounding farmer estimates rather than an absolute benchmarking of data quality.

To assess the consequences of data credibility for more complex, constructed indicators, we examine the commonly used indicators of food self-sufficiency and potential food availability (as detailed in Frelat et al., 2016). The food availability indicator (FA) is a quantification of the potential kilocalories available for each male adult equivalent per day consumed from farm production, and from cash obtained through the sale of farm produce and off-farm income, where all income is converted to a calorific value based on the cost of a local staple crop. For our calculations of FA, we used the median farm gate price for each location and time period. Results of these calculations can be used to perform a combined data quality assessment of information obtained on crop and livestock production, sales, consumption and off-farm income. Two problems with this composite indicator are commonly encountered. First, an underestimation of the calorie availability at the lower end of the scale, suggesting an extreme level of starvation. Although this may be a true representation of some households, it can also be an indication of missing information on income or food consumption. Second, there can be a substantial over-estimation of consumption of crop and livestock products for a large number of households (i.e. food self-sufficiency), indicating problems with yield, consumption or household size data. The lower bound threshold for credible food availability was set at 1250 kilocalories (kcal) per male adult equivalent per day, which is below the basal metabolic rate 


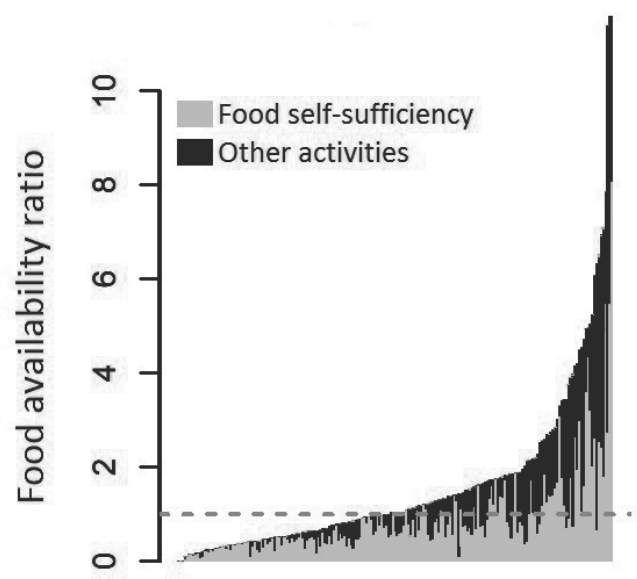

Figure 3.1 Food availability, food self-sufficiency and household energy needs: an example of unreliable values

Dashed line represents a case where 2,500 kilocalories are provided for each male adult equivalent (Source: Rosenstock et al., 2017; based on 200 households in northern Ghana)

for adult males (approximately $1590 \mathrm{kcal}$ for a $60 \mathrm{~kg}$ male; FAO, 2001). Two upper bounds for credible food self-sufficiency were set: a) $3500 \mathrm{kcal}$ per adult equivalent per day, representing the average intake of developed nations $(\operatorname{OECD}(2017)$ \& FAO, 2017), and; b) 5000 kcal, which is double the approximate requirement for an adult male.

The results from Rosenstock et al. (2017) provide an example of extremes in food availability and food self-sufficiency for households in northern Ghana. This case is represented here in Figure 3.1 as the ratio of food availability, where the value 1 represents a case where 2,500 kilocalories are provided for each male adult equivalent (indicated with a horizontal dotted line). Also represented is the ratio of food availability sourced directly from farm production (the grey bars). Instances of apparent starvation are increasingly severe as the ratio decreases below 1, which eventually declines below the basal metabolic rate for adult males. Over-estimated consumption is apparent in households that have more energy sourced directly from the farm than is required (grey bars larger than 1 ).

\subsubsection{Consistency and reliability analyses}

In the consistency and reliability analyses we included variables that we would expect to be: a) highly consistent (age of the household head), b) relatively stationary in East Africa over the whole population over short time periods, including household size, productive assets (land owned and livestock holdings) and crop yields, and c) those that may be more variable (offfarm income, food availability and food self-sufficiency). Age of household head is expected to be highly consistent after accounting for the time elapsed between survey rounds and whether 
there was a change in household head. Household size was expected to be relatively stationary in East Africa given that death rates have been estimated to be less than 1\% per annum (CIA, 2016a) and the rate of urbanisation estimated to be less than $5.5 \%$ per annum (CIA, 2016b). Productive assets are also expected to be relatively stationary due to their livelihood and cultural value - for both land (Jayne et al., 2016) and livestock (Thornton \& Herrero, 2015). Livestock holdings, however, are expected to be more temporally variable than land holdings due to their role in financing large expenditures, cultural utility (i.e. bride-wealth) and exposure to climatic and disease risks (ibid.). Similarly, crop yields are expected to be temporally stable (at a population level) in the absence of extreme weather events (Gollin, 2006). During the periods of observation, there were instances of extreme weather events, with a severe drought impacting northern Kenya and north-eastern Uganda (potentially impacting < $0.5 \%$ of households in LSMS-ISA Uganda) and some evidence of increased extreme precipitation events in western Kenya, but to our knowledge this did not affect the sampled households (Gebrechorkos et al., 2018). Climatic conditions were consistent over the two survey rounds in Tanzania (Fraval et al., 2018).

We explored the consistency of data collected in farm household surveys between two points in time, comparing respectively, IMPACTlite (2012) with RHOMIS (2015/16), and LSMS-ISA (2009/10 and 2011/12). Summary statistics of these changes between initial survey and revisit are provided in supplementary Information Table 3. In the absence of survey round specific biases, the correlations in these consistency results would provide a measure of reliability (Alwin, 2006). As this is not the case, we can only interpret the strength of correlation as a measure of consistency, rather than reliability. Spearman's correlation was used to assess association, as it is less sensitive to extreme non-credible values.

Reliability was more formally modelled using the core variables and derived indicators quantified from LSMS-ISA Uganda (2009/10, 2010/11, 2011/12), excluding some non-credible values. We used an approach described by Shrout \& Fleiss (1979) that calculates intraclass correlation (ICC). In this specification, we assume the following linear model:

$$
x_{i j}=\mu+b_{j}+w_{i j}
$$

Where $x_{i j}$ is the value in the ith survey round $(i=1,2,3)$ of $j$ household $(j=1, \ldots, n) ; \mu$ is the population mean; $b_{j}$ is the difference from $\mu$ to the $j$ th household's mean across the survey rounds; $\mathrm{w}_{\mathrm{ij}}$ is the residual, equal to the sum of the effects of survey round, survey round-household interaction, and error. The intraclass correlation is then estimated as follows:

$$
I C C=\frac{M S B-M S W}{M S B}
$$

Where MSB is the mean square between (sum of square total/obs) and MSW is mean square 
within, calculated as:

$$
\mathrm{MSW}=\frac{S S_{\text {round }}+S S_{\text {resid }}}{d f_{\text {round }}+d f_{\text {resid }}}
$$

For this analysis, some non-credible observations were excluded as they had a disproportionate influence on the linear models. Observations with off-farm income above US\$60,000 in one survey round were excluded $(n=1)$, as were maize yields above 15 tonnes per ha $(n=33)$, livestock holdings (TLU > 100, $\mathrm{n}=3$ ), land owned (ha > 100; $\mathrm{n}=2$ ) and food availability (FA $>1,500,000 \mathrm{kcal}, \mathrm{n}=2$ ). The reliability analysis was implemented using the psych package in $\mathrm{R}$ (Revelle, 2017). This analysis resulted in a reliability estimate ranging between 0 ('low reliability') and 1 ('high reliability') together with a 95\% confidence interval of this estimate. The three methodological steps and associated datasets, locations and years are summarised in Table 3.2.

Table 3.2 Summary of analysis, datasets and variables

\begin{tabular}{lllccc}
\hline Survey tool & Country & Year & $\begin{array}{l}\text { Credibility } \\
\text { (one round) }\end{array}$ & $\begin{array}{c}\text { Consistency } \\
\text { (two rounds) }\end{array}$ & $\begin{array}{l}\text { Reliability } \\
\text { (three rounds) }\end{array}$ \\
\hline IMPACTlite & Kenya \& Tanzania & 2012 & $\mathrm{x}$ & $\mathrm{a}$ & \\
RHOMIS & Kenya \& Tanzania & $2015 / 16$ & $\mathrm{x}$ & $\mathrm{a}$ & $\mathrm{c}$ \\
LSMS-ISA & Uganda & $2009 / 10$ & & $\mathrm{~b}$ & $\mathrm{c}$ \\
LSMS-ISA & Uganda & $2010 / 11$ & $\mathrm{x}$ & $\mathrm{b}$ & $\mathrm{c}$ \\
LSMS-ISA & Uganda & $2011 / 12$ & & & \\
LSMS-ISA & Tanzania & $2010 / 11$ & $\mathrm{x}$ & & \\
LSMS-ISA & Ethiopia & $2010 / 11$ & $\mathrm{x}$ & &
\end{tabular}

$\mathrm{x}=$ used in credibility assessment

$\mathrm{a}, \mathrm{b}, \mathrm{c}=$ dataset, where two or three survey rounds are used in an analysis

The relationship between sample reliability, effect size and sample size was simulated using the 'pwr' package in $\mathrm{R}$ (Champely, 2018), where reliability is mediated through the effect size $(E S=$ population $E S \times \sqrt{r}$, assuming equal variace and sample sizes; Phillips \& Jiang, 2016). Using the pwr package, we simulated both a paired (panel type of data) and two-sample (Randomised Control Trial type of data) t-tests to quantify detectable differences for the core variables and derived indicators of which we have quantified reliability and uncertainty estimates. The simulated t-tests assumed a Type II error rate of 20\% (Power of 0.8 ) and a Type I error rate of $5 \%$ ( $\alpha$ of 0.05$)$.

\subsection{Results}

\subsubsection{Credible bounds of core variables and derived indicators}

Yields and prices were highly variable in each of the three farm household survey tools. This variability across a wide range of crops could reflect agro-climatic or management differences, 
Table 3.3 Credibility of maize yield data: comparing enumerated yields with historical yields and water-limited potential yields, by survey tool* (proportion of households)

\begin{tabular}{lcccc}
\hline & $\begin{array}{c}\text { Less than 10\% of } \\
\text { historical yields }\end{array}$ & $\begin{array}{c}\text { Greater than } \\
\text { potential yield \& } \\
\text { less than double }\end{array}$ & $\begin{array}{c}\text { Double potential } \\
\text { yield }\end{array}$ & Within bounds \\
\hline IMPACTlite 2012 & 0.43 & 0.00 & 0.01 & 0.56 \\
RHOMIS 2015/16 & 0.12 & 0.00 & 0.00 & 0.88 \\
LSMS-ISA 2010/11 & 0.03 & 0.04 & 0.03 & 0.90 \\
\hline
\end{tabular}

*Impact lite and RHOMIS include sites from Kenya and Tanzania, LSMS-ISA is limited to Uganda

market volatility, as well as biases and errors introduced by the survey tool, enumerator or the respondent (UN, 2005; Mathiowetz et al., 2001). This section provides a summary of noncredible values for yields (Table 3.3), prices (Table 3.4), food availability and food self-sufficiency (Table 3.5).

Comparing our calculated maize yields with historical yield statistics compiled in the Global Yield Gap Atlas gives a reference point to assess yield estimates for each of the three survey tools. IMPACTlite had the highest proportion of households with crop yields less than $10 \%$ of GYGA historical maize yields, followed by RHOMIS and then LSMS-ISA (Table 3.3). On the other extreme, LSMS-ISA had the most substantial proportion of yields exceeding the simulated water-limited potential yield for the region - occurring in $7 \%$ of households. Four percent of households in LSMS-ISA 2010/11 Uganda exceeded potential maize yields and an additional $3 \%$ were double this potential yield (Table 3.3).

Exceeding the simulated potential yield is possible, but unlikely - even historical yields in optimal growing conditions were never more than $50 \%$ of simulated potential yields (results not shown). It is more difficult, however, to assess the credibility of calculated yields at the lower end of the scale, which are far more prevalent. Comparing maize yields from the same sites from both IMPACTlite (2012) and RHOMIS (2015/16) data, 62\% of households that had yields less than one tonne per hectare had those low yields in both surveys. An additional tonne per hectare was reported by $27 \%$ of households in the RHOMIS (2015/16) survey.

The farm-gate price per kilogram of maize was compared with the median price for each data collection instance as well as the market wholesale price (sourced from FAO, 2017a). The average market wholesale price of maize in Kampala, Uganda during the year of data collection was 20 US cents per kilogram, with a minimum of 11 cents. Approximately 15\% of LSMSISA (2011/12) Uganda crop prices exceeded the maximum wholesale price, and $1 \%$ was below the lower threshold. There were also such potential credibility issues in the IMPACTlite and RHOMIS datasets, with maize prices exceeding maximum wholesale prices in $53 \%$ and $14 \%$ of cases respectively (Table 3.4). Similar to yield, the lower range on price is more difficult to assess. There are product quality aspects, market timing and geographical differences also influencing price (particularly for LSMS-ISA in Uganda which aims to be nationally representative). These aspects could result in farm gate prices well below the regional average. 
Table 3.4 Credibility of maize price data: comparing enumerated prices with average survey prices and wholesale market prices by survey tool* (proportion of households)

\begin{tabular}{lcccc}
\hline & $\begin{array}{c}\text { less than 10\% of } \\
\text { average prices of } \\
\text { survey }\end{array}$ & $\begin{array}{c}\text { Greater than } \\
\text { maximum } \\
\text { wholesale price \& } \\
\text { less than double }\end{array}$ & $\begin{array}{c}\text { Double maximum } \\
\text { wholesale price }\end{array}$ & Within bounds \\
\hline IMPACTlite 2012 & 0.03 & 0.50 & 0.03 & 0.43 \\
RHOMIS 2015/16 & 0.02 & 0.09 & 0.05 & 0.84 \\
LSMS-ISA 2010/11 & 0.01 & 0.11 & 0.04 & 0.84 \\
\hline
\end{tabular}

*Impact lite and RHOMIS include sites from Kenya and Tanzania, LSMS-ISA is limited to Uganda

Table 3.5 Credibility of food availability (FA) and food self-sufficiency (FSS) by survey tool (proportion of households)

\begin{tabular}{lcccc}
\hline & $\begin{array}{c}\text { Food } \\
\text { availability less } \\
\text { than 1250 kcal } \\
\text { adult } \\
\text { equivalent }\end{array}$ & $\begin{array}{c}\text { FSS above } \\
\text { OECD average } \\
\text { \& Less than } \\
\text { double }\end{array}$ & $\begin{array}{c}\text { FSS double } \\
\text { 2500 kcal adult } \\
\text { equivalent }^{-1}\end{array}$ & Within bounds \\
\hline IMPACTlite 2012 & 0.39 & 0.05 & 0.04 & 0.52 \\
RHOMIS 2015/16 & 0.15 & 0.06 & 0.04 & 0.75 \\
LSMS-ISA Uganda 2010/11 & 0.12 & 0.07 & 0.14 & 0.66 \\
LSMS-ISA Tanzania 2010/11 & 0.20 & 0.06 & 0.07 & 0.67 \\
LSMS-ISA Ethiopia 2010/11 & 0.40 & 0.02 & 0.07 & 0.51 \\
\hline
\end{tabular}

*Impact lite and RHOMIS include sites from Kenya and Tanzania

Non-credible values in core variables will propagate through to composite indicators, such as food self-sufficiency and potential Food Availability (FA). Specifically, non-credible values in farm production, area planted, product marketing, off-farm income and household size can be compounded in these indicators. Table 3.5 shows the proportion of households that have noncredible food availability and self-sufficiency values (defined by being below half or more than double the energy demands of the household). Instances of non-credible FA values exist in all survey implementations, but more so in IMPACTlite. LSMS-ISA Uganda and LSMS-ISA Tanzania had the most non-credible food self-sufficiency values. LSMS-ISA Tanzania and Ethiopia are included in this table as an example of the variability in data quality generated with the same survey tool. LSMS-ISA Tanzania and Ethiopia appear to provide much lower quality food availability and food self-sufficiency estimates as compared to LSMS-ISA Uganda. 


\subsubsection{Consistency of core variable measurements and derived indicators over time}

After accounting for the time elapsed between the two surveys and excluding households where the household head had changed (LSMS-ISA, $n=168$ ) or household head gender was different between rounds (IMPACTlite 2012-RHOMIS 2015/16, $\mathrm{n}=67$ ), 84\% of households in LSMS-ISA Uganda were within one year of the expected age. In contrast, only $47 \%$ were within the expected range of one year in IMPACTlite-RHOMIS. The relationship between the successive surveys, as shown by Spearman's correlation coefficient in Figure 3.2a, is strong in both LSMS-ISA $(\mathrm{r}=0.99)$ and IMPACTlite-RHOMIS $(\mathrm{r}=0.93)$. However, there were instances of substantial differences, with $1 \%$ of households in LSMS-ISA, and $8 \%$ of households in IMPACTlite-RHOMIS being 10 years greater or less at revisit than the expected age.

Household size was highly correlated between the 2009/10 and 2011/12 surveys in Uganda ( $\mathrm{r}=$ 0.9 ) and moderately correlated in IMPACTlite-RHOMIS ( $r=0.51$; Figure $3.2 b)$. The majority of households in each dataset, however, remained within one adult equivalent of the initial visit. For instance, $62 \%$ of households remained within one adult equivalent in LSMS-ISA and 55\% in IMPACTlite-RHOMIS (results not shown). There were isolated cases of extreme increases in each dataset, with the maximum increase in LSMS-ISA being 11 adult equivalents and 14 in IMPACTlite-RHOMIS (Figure 3.2b).

Land owned in LSMS-ISA survey rounds had a higher correlation $(r=0.68)$ than IMPACTliteRHOMIS ( $r=0.55$; Figure 3.2c). Isolated cases of extreme changes in land owned were present in LSMS-ISA. Livestock holdings in LSMS-ISA Uganda had a Spearman's correlation coefficient of 0.68 between survey rounds. The level of association between rounds was lower in IMPACTliteRHOMIS ( $\mathrm{r}=0.50$; Figure 3.2d). There was a similar level of correlation for maize yields in IMPACTlite-RHOMIS $(\mathrm{r}=0.23)$ and LSMS-ISA $(\mathrm{r}=0.19$; Figure 3.2e).

Off-farm income was moderately correlated between rounds in LSMS-ISA $(r=0.53)$ and less so in IMPACTlite-RHOMIS ( $r=0.33$; Figure 3.2f). Changes in off-farm income of US\$5,000 or more occurred in $6 \%$ of the households in Uganda and $2 \%$ in IMPACTlite-RHOMIS. Households in LSMS-ISA, span a wide geographical range with varying proximity to urban locations which may explain such outliers.

Food availability at initial visit and revisit had a moderate association in LSMS-ISA $(r=0.54)$ and less so in IMPACTlite-RHOMIS ( $\mathrm{r}=0.14$; Figure 3.2g). There were instances of outliers in both survey comparisons; these few cases, however, could be realistic given large changes in onfarm and off-farm income. Food self-sufficiency followed a similar pattern to food availability, with LSMS-ISA having a having a greater level of correlation between survey rounds $(\mathrm{r}=0.68)$ when compared to IMPACTlite-RHOMIS ( $\mathrm{r}=0.12$; Figure 3.2h).

Household diet diversity in the IMPACTlite-RHOMIS surveys also provides a notable case of inconsistency between survey rounds. For example, median increases in diet diversity range from three food categories in the lean peiod, and up to six food categories in the Tanzanian post-harvest period. As desirable as leaps in diet diversity are, it is unlikely to observe such a change over a short space of time in these communities (IFAD, 2016). Figure 3.3 shows the 

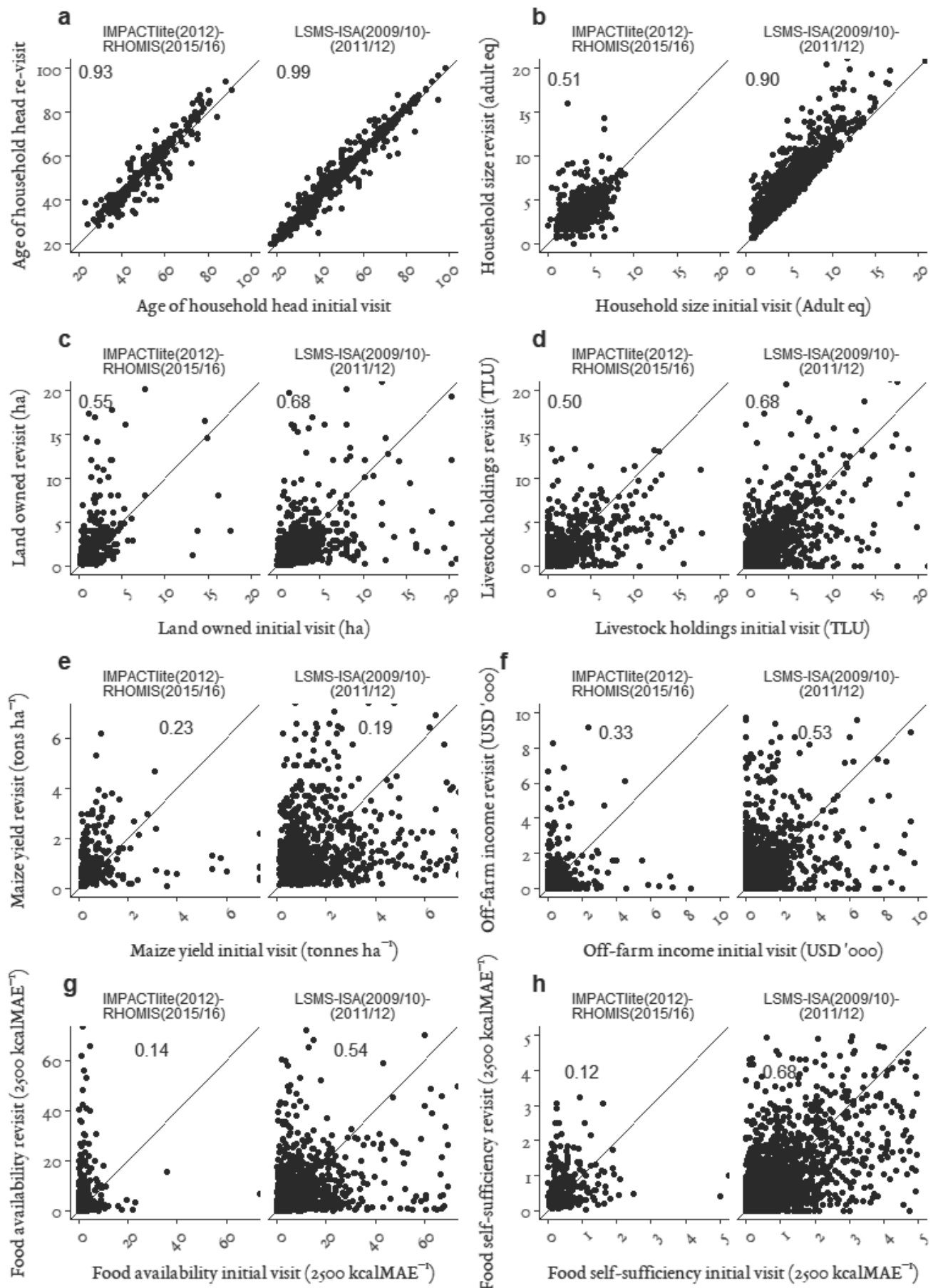

Food self-sufficiency initial visit (2500 kcalMAE ${ }^{-1}$ )

Figure 3.2 Consistency between IMPACTlite (2012)-RHOMIS (2015/16) in Kenya and Tanzania and LSMS-ISA (2009/10-2011/12) in Uganda*

*Spearman's correlation coefficient (initial visit to revisit) indicated on each respective plot 
differences between the survey rounds in both periods for Tanzania as an example, where the same applies for IMPACTlite-RHOMIS in Kenya. The initial visit has instances where common food categories (e.g. fats and oils) are supposedly not consumed at all. The likely causes of these differences relate to survey design and duration. IMPACTlite enumerated a wide range of food items (not food groups) asked as an open question. Furthermore, these questions came at the end of a three-hour interview, potentially resulting in respondent fatigue. RHOMIS, on the other hand, asked about these food groups specifically and was completed within an hour.
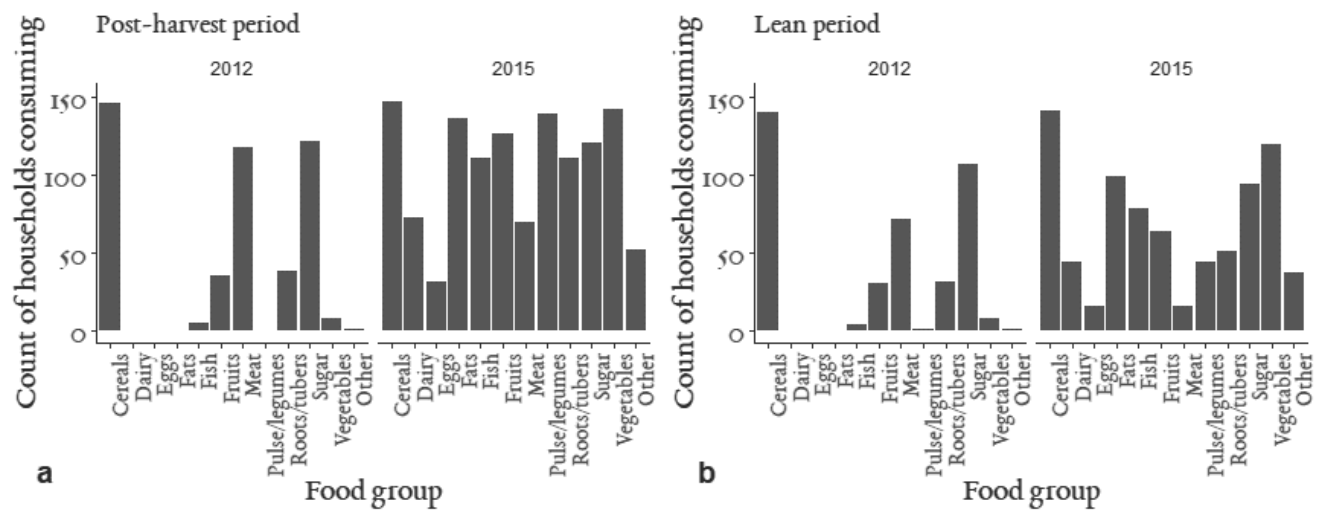

Figure 3.3 Diet diversity by category and period in IMPACTlite-RHOMIS Tanzania

\subsubsection{Reliability of variables in LSMS-ISA Uganda}

Modelling the reliability of variables explored in the consistency analysis provides further insight into the three waves in the LSMS-ISA Uganda case. The model outputs suggest a high degree of reliability for age, household size and livestock holdings (Figure 3.4); land owned was less reliable than these other stationary variables and maize yield was one of the least reliable variables. It is more difficult to evaluate the reliability estimates of off-farm income, food availability and food self-sufficiency. The paucity of information about the temporal stability of these variables (despite efforts to assess the quality of variables such as income - notably by Neri \& Ranalli, 2012; Fisher et al., 2010; Juster et al., 2007; Moore et al., 2000) make it difficult to identify whether the reliability scores of these three variables are influenced by true population level temporal volatility, but it is clear that the reliability of these variables is low. 


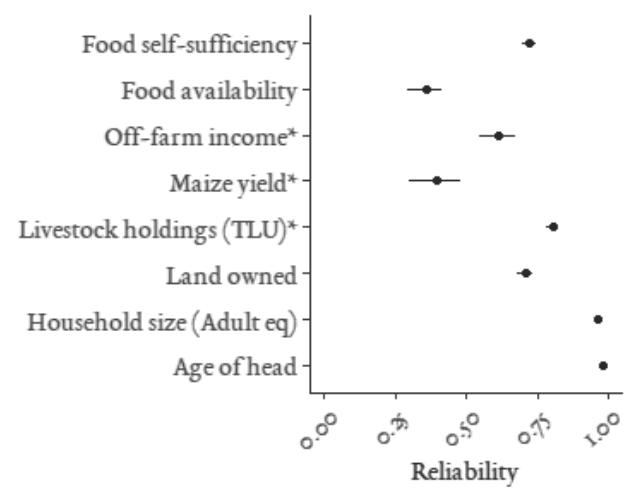

Figure 3.4 Reliability of initial visit variables in the living standards measurement survey, Uganda: output from intraclass correlations with $95 \%$ Confidence Intervals

* Limited to households that were $>0$ in each survey round. $27 \%$ of households had off-farm income in all 3 rounds, $75 \%$ cultivated maize, $60 \%$ kept livestock

The reliability of these variables will ultimately affect inference as it reduces the power of tests (increasing Type II error) and inflates error estimates in multivariate analyses. Additionally, in instances of new studies using existing data for setting required sample sizes, consideration needs to be given to the reliability of available variables and how the proposed study will differ in terms of measurement error; a new study with a coarser measurement tool will require a larger sample than a previous study with more accurate measures. Figure 3.5 shows the relationship between sample reliability, effect size and sample size for paired and two-sample t-tests. For example, the sample size required to detect a relatively small effect size (0.2) in a paired test with a Type II error rate of $20 \%$ and Type I error rate of $5 \%$, will be 220 with a reliability of 0.9 (as we see for household size) and 983 households for a reliability of 0.2 (as we see for off-farm income and crop yield). These sample sizes will be higher when design effects are incorporated and when two-sample tests are needed.

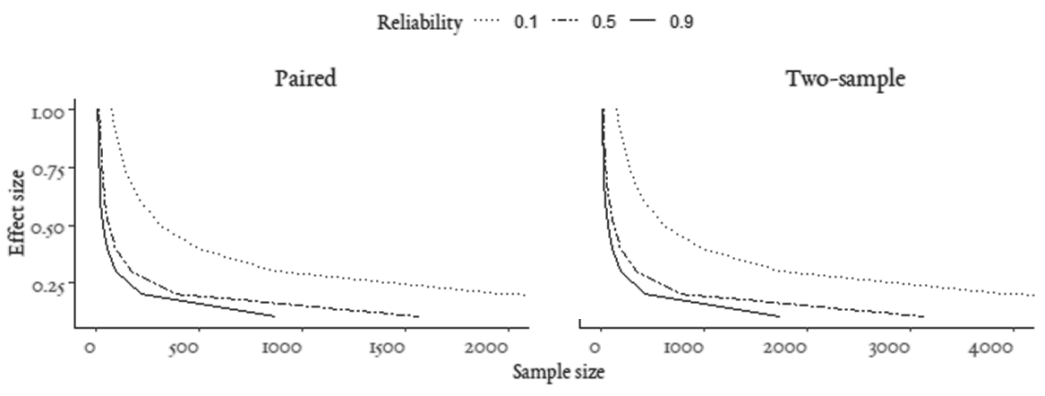

Figure 3.5 Sample size and effect size given different levels of reliability for t-test (power $=0.8 ; \alpha=$ $0.05)$ 


\subsection{Discussion}

\subsubsection{Credibility of crop yield and market price}

Using data from three cross-sectional farm household survey approaches, we assessed the credibility and reliability of core variables and derived indicators. This study has identified quality limitations in each survey tool - with LSMS-ISA and RHOMIS staying within credible bounds more frequently than IMPACTlite (Tables 3.3 and 3.4). The higher performance of these two survey tools may be due to their innovative data collection strategies - particularly in the case of enumerating cropping activity. In the case of LSMS-ISA, enumerators visit households each cropping season - with the intention of minimising recall error. In the case of RHOMIS, households can quantify harvest volumes in a unit of their choice (such as standard sized sacks) rather than force kilogram estimates - minimising error due to respondent estimation. These innovations are positive, however they are not sufficient to eliminate non-credible values.

\subsubsection{Consistency of variables between two survey rounds}

The inconsistencies identified in this study - including age of household head, household size (Figure 3.2) and diet diversity (Figure 3.3) - reinforce the notion that researchers need to consider their data collection strategy for each variable rather than assuming that some are 'easy' to enumerate. In the instance of diet diversity, the differences between survey rounds may be explained by an unfortunate combination of question design and survey length. The data collection strategy of IMPACTlite, in this instance, was to ask an open question - "what food items did you consume?" - and allow the enumeration of a detailed list of food items. These questions on diet diversity, however, came at the end of more than two hours of questions and so the quality of data may have suffered from the farmer (and enumerator) being fatigued (as systematically explored by Kilic et al., 2013).

\subsubsection{Implications of the lower reliability over three survey rounds}

The lack of reliability of land owned and crop yields variables has implications in the monitoring of food security status, poverty status and land productivity of households. These variables are also used to answer essential questions of cause and effect and can have a substantial bearing on policy decisions. For instance, the question of whether smaller farms are more productive than larger farms in developing countries has implications for reducing yield gaps and has been an active area of debate. Recently, the robustness of the data underpinning the analysis of this relationship was tested using LSMS-ISA data. In order to test the robustness of underpinning data, farmer reported values were compared against Global Positioning System (GPS) based land area estimates (Kilic et al., 2013; Carletto et al., 2011). These studies found that despite measurement error in farmer reported values, the inverse productivity relationship was still detected.

The implications of non-credible values and lower reliability are more pronounced in composite indicators such as food self-sufficiency and food availability - where the uncertainty propagates from multiple variables. This leads to i) substantial portions of the survey results to be beyond 
credible bounds (Table 3.5); ii) the need for larger sample sizes so that change and differences between groups can be detected (Figure 3.5), and; iii) limitations in identifying relationships in multivariate analysis, such as food availability and agricultural land use strategies (among households and over time).

\subsubsection{Data quality in perspective - sample sizes, continuous improvement and trans- parency}

Despite this seemingly bleak picture of data quality of variables derived from farm household surveys, there is still cause for optimism. First, the sample sizes needed to detect substantial changes (which are often the changes of interest in agricultural development research) in the variables assessed in this study are in the hundreds, and not in the thousands such as for a Randomised Control Trial (see Figure 3.5). With tight controls on quality and a less variable population to represent, this sample size can be even smaller. The second cause for optimism is that ongoing developments in data collection strategies and tools are likely to improve data quality and reduce measurement error. There have been many areas of progress in the last 10 years that have improved quality including: harmonised survey tools, in-country capacity building, mixed modes of data collection (e.g. GPS data, phone, SMS; Carletto et al., 2016; Deininger et al., 2011; Leeuw, 2005), quality control protocols (e.g. rapid data quality checks and variable triangulation; Fisher et al., 2010) and non-paper based collection (Rosenstock et al., 2017).

An example of a new, more systematised household survey is RHOMIS (Hammond et al., 2017). The evaluations in this study show that such targeted data collection does result in highly credible quantification of indicators like food self-sufficiency and food availability (e.g. Table 3.5). RHOMIS furthermore assesses food security by quantifying clusters of indicators rather than a single indicator (Household Diet Diversity score, the USAID Hunger and Food Insecurity Access scale, Food Availability and the number of hunger months as indicators), thereby allowing for a more integral picture of food security. These benefits do have some limitations when used to follow up on households that have been surveyed with different tools, where Figure 3.3 shows inconsistencies and thus a potential to increase Type II error - not having the power to identify significant differences between communities and over time.

The third cause for being optimistic about the use of household-based rural statistics is that the survey tools analysed in this study were transparent about sampling and data collection procedures. This practice informs data users of what the sample is representative of, and the nature of the questions asked. Such transparency guides the secondary utilisation of these data and can reduce misuse and misinterpretation.

\subsubsection{Improving the quality of farm household survey data}

Several steps can be taken to improve the data quality of farm household surveys further. First, researchers can compare a subset of collected data to the 'truth', where there is a possibility to collect detailed data from a smaller subset of households (referred to as 'two method measurement designs', Little \& Rhemtulla, 2013) which is widely accepted to be of far greater reliability 
and accuracy (as demonstrated by Giller et al., 2011). For instance, plot sizes of a sub-sample might be measured using Global Positioning System (GPS) receivers or through remote sensing, providing a more consistent level of accuracy across households. Secondly, researchers can analyse data for reliability (as done in this study) and potential instances of data fraud (as discussed in Finn \& Ranchhod, 2017) which would highlight issues that could improve overall quality.

Rural sub-Saharan Africa is entering a stage of transformation where the opportunities and challenges for rural communities are becoming more pronounced, and at the same time, the means of gaining insight into these communities is broadening. In this setting, the fundamentals of generating fit-for-purpose and representative observations remain a vital basis for informed decision making. For decision makers to make the most of such inherently coarse data, it is essential to have the foundation of robust sampling, quality-centric survey design (questions and length), transparency of experimental design and effective training. The quality and usability of such data can be further enhanced by improving coordination between agencies, incorporating mixed modes of data collection and continuing systematic validation programs.

\subsection{Acknowledgements}

We are grateful to the research teams who were involved in designing and implementing the three surveys assessed in this study. Without their rigor, openness and thorough documentation this study would not have been possible. We also thank the two anonymous reviewers and special edition editor Jens Andersson, whose comments and suggestions greatly improved the quality of this article. This study was made possible by the CGIAR Research Program on Livestock and its donors and by support of the American People provided to the Feed the Future Innovation Lab for Sustainable Intensification through the United States Agency for International Development (USAID). The views expressed in this paper cannot be taken to reflect the official opinions of these organisations. 


\section{Chapter 4}

\section{Livelihoods and food security in an urban linked, high potential region of Tanzania: Changes over a three-year period}

This chapter is based on:

Fraval, S., Hammond, J., Lannerstad, M., Oosting, S. J., Sayula, G., Teufel, N., Silvestri, S., Poole, E. J., Herrero, M., van Wijk, M. T. (2018). Livelihoods and food security in an urban linked, high potential region of Tanzania: Changes over a three year period. Agricultural Systems, 160 (January 2018), 87-95. doi:10.1016/j.agsy.2017.10.013 


\section{Abstract}

Projected changes to rural communities in sub-Saharan Africa (SSA) are unprecedented in scale and pace. This paper investigates to what extent significant changes in livelihoods, poverty and food security performance are already taking place. The study focuses on households in Lushoto district $(\mathrm{n}=147)$, a remote but urban linked area of Tanzania. Within the short time period between 2012 and 2015, 77\% of households made changes in farm resources or farm characteristics. Households in the study site can be broadly classified as 'Rising high value crop', 'Rising livestock', 'Subsisting mixed' and 'Subsisting crops'. Some of the most substantial changes we observed in the three year period of study were most likely not related to any of the agricultural orientated interventions that are being promoted in the region, but are likely endogenous changes. The land expansion seen in the 'Rising' households $(n=58)$ provides a counterpoint to the trend established in the literature of decreasing farm sizes across lower income countries more broadly, and specifically in Africa. The strategy of land expansion is risky, potentially representing a future of winners and losers, ultimately with some landholders falling further into poverty rather than leveraging their agricultural enterprises to improve their well-being. Our results show that in sites like Lushoto with a good rural to urban connection (increasingly common in SSA), households can be agile and diverse. This means that agency interventions are aiming for a moving target. In order to achieve income and food security outcomes, targeted and rapid monitoring tools will be needed. 


\subsection{Introduction}

The projected changes to rural communities in sub-Saharan Africa (SSA) are unprecedented in scale and pace. Global population projections in 2050 exceed 9.5 billion people, with the greatest growth to be seen in SSA nations - increasing to $22 \%$ of the global population (from $13 \%$ in 2015; UN, 2015). The average rate of rural to urban migration in SSA between 1990 and 2000 was low, at $1.07 \%$ (de Brauw et al., 2014); this rate of migration is forecast to remain low, contributing to a net increase in the rural SSA population from 579 million in 2014 to 938 million in 2050 (UN, 2014). In this context, the dynamics within rural communities will undoubtedly change, influencing livelihoods, human nutrition and the environmental base on which these depend. While the full effect of these changes may be some years away, there is evidence that rural communities are already undergoing rapid transformation.

Tanzania is one example of an African country showing rapid economic progress. Since the reformation of the East African Community in 1999, the Tanzanian economy has performed well (GDP in 2015 was 6 times that of 2000), growing consistently by 7\% from 2013 to 2015 (NBST, 2016). Agriculture has remained a significant contributor to Gross Domestic Product (GDP; $>28 \%$ ) and is the sector employing the majority of the population (70\%; NBST, 2015; IFAD, 2016). Despite this strong economic growth, rural poverty and food insecurity are still high, with between 7.7 and $7.9 \%$ of households experiencing both poverty and food insecurity in 2010/11 and 2012/13 respectively (NBST, 2014).

The future of food security in rural and urban communities in Tanzania will be influenced by population dynamics as well as changing livelihood opportunities and threats. The population in Tanzania is forecast to increase from 55 million in 2014 to 129 million in 2050. Although urban dwellers will be in the majority (53\% of the population), the rural population will have increased 1.7 times in absolute terms (United Nations, 2014). These estimates indicate that there will be drastic transformations for the rural population in terms of a rising urban majority requiring more food and increased local pressure from a growing rural population. These trends will necessitate improvements in agricultural productivity and more employment opportunities in both rural and urban areas (IFAD, 2016; Jayne et al., 2014).

To-date, relatively few studies have assessed the relationship between changing rural livelihoods and food security. Rather, the vast majority of related studies either a) assess the relationship between rural household characteristics and food security (often limited to diet diversity) for one year (e.g. Bellon et al., 2016; Koppmair et al., 2016; Luckett et al., 2015; M'Kaibi et al., 2015; Sibhatu et al., 2015; Snapp \& Fisher, 2015; and, Dillon et al., 2014), or b) assess rural household characteristics over time without incorporating metrics on food security (e.g. Ollenburger et al., 2016; Valbuena et al., 2015; Ulrich et al., 2012; Orr \& Mwale, 2001). Further, studies that have observed rural households over time and incorporated an aspect of food security either have limitations in scope or representativeness. Jones (2016), for example, investigates changes in diet diversity over time (2010 to 2013) for a large number of households in Malawi ( $n=3000$ ); this study, however, focuses on the relationship with crop species richness rather 
than the broader context of changing livelihoods. Falconnier et al. (2015) investigates farm trajectories (over 17 years), with a limited number of farms $(n=32)$ and only incorporates food self-sufficiency as a metric of food security.

This study observes households from 20 villages in Lushoto district, Tanzania, over a short timespan (3 years). The site's rapid economic growth (Regional GDP increasing by $78 \%$ between 2012 and 2015; NBST, 2016), favourable agro-climatic conditions and improving rural-urban infrastructure (i.e. improved roads, electrification and telecommunications) makes it conducive to 1) realising the poverty and hunger oriented Sustainable Development Goals (Frelat et al., 2016; Dorward, 2009; Pender et al., 2001); and 2) observing a variety of livelihood based responses to opportunities (farm and non-farm business opportunities from a growing economy and population and improved technologies) and threats (e.g. climatic or market-based). In doing so we investigate the extent to which significant changes in livelihoods, poverty and food security performance are already taking place. Of particular interest is how these insights can help in designing interventions to raise the standard of living for differing groups within communities.

\subsection{Methods}

\subsubsection{Study area}

This study is focused on households in the western Usambara highlands, Lushoto district, Tanzania (shown in Figure 4.1). Twenty villages were sampled from seven contiguous wards, chosen to represent the wide range of surrounding agro-ecosystems (Rufino et al., 2013). The site ranges in elevation from 780 to $2010 \mathrm{~m}$ above sea level. Rainfall is bi-modal, ranging from 690 to $1230 \mathrm{~mm}$ per annum, with heavier rains occurring from March to May, and from October to December. Soil types vary along the topographic gradient, progressing from limited and shallow soils (Regosols and Lithic Leptosols) on the peaks, to more developed soils (Cutanic Acrisols and Ferralic Cambisols) and then to alluvial and wet soils in the valleys (Mollic Gleyic Fluvisols and Fluvic Gleysols; Massawe 2011). Many cultivated soils are degraded, with low levels of soil organic carbon indicating limited nutrient retention capacity (Winowiecki et al., 2016), and observed deficiencies in phosphorus and nitrogen (Ndakidemi \& Semoka, 2006). This site is an important catchment for the Pangani basin and hosts rich biodiversity sheltered by ancient forests.

The Usambara massif is densely populated by three ethnic communities: The Shambaa, Pare and Mbugu peoples (Lyamchai et al., 2011). Tribal social networks are still important but have become less distinctive in contemporary society, often secondary to family and religious networks (Islam and Christianity). A unique element of the culture and history in the Usambara highlands related to food security and soil conservation is that "Access to unimproved subsistence land ... was still accepted as every resident's right... right up until the end of 1988" (Feierman, 1990, p. 183). Modern livelihoods are largely based on agriculture and micro-enterprises, with some garnering formal employment, and others migrating to urban centres. In the villages 


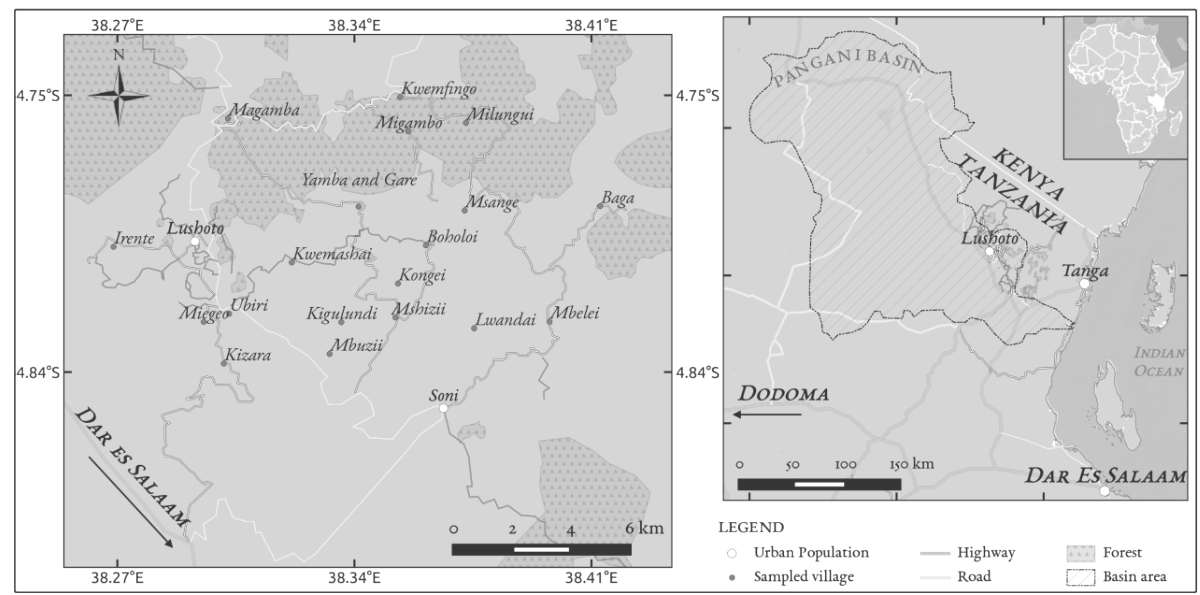

Figure 4.1 Study area, market infrastructure and environmental interactions

(Authors' composition based on GADM database and Open Street Maps)

of interest to this study, households generally have small land-holdings with a high dependency on agriculture (Lyamchai et al., 2011).

Several development activities have focused their efforts on the Usambara highlands, including projects on dairy, potatoes, sweet potatoes, forestry and bee-keeping. Three agricultural interventions were implemented at the time of this study (excluding forestry). One project released new bean varieties suited to the region (Kimeli et al., 2014); the second project trialled new potato varieties and provided farmer training on cultivation and value-chains in one of the study site's villages (namely Boheloi; Harahagazwe et al., 2016; Harahagazwe et al., 2014); the third project on dairy development, established trial plots of cultivated fodder, facilitated village level planning and worked to improve value-chain linkages. This dairy oriented project was implemented in four villages in the study site (namely Mbuzii, Ubiri, Kwemashai, Lwandai; Kilelu et al., 2017). Government initiatives at multiple levels have also been working towards extending and improving the standard of the road network, electrification grid, water supply system, medical facilities and schools.

\subsubsection{Data collection}

Households in the study area were originally interviewed in July 2012. Data collection in 2012 was part of the Africa and South-East Asia wide CCAFS project, IMPACTlite. In Lushoto district, 200 households were sampled for IMPACTlite, being 10 households per village in a multistage clustered sampling design. Households were sampled based on a random geographic distribution of points within village boundaries - as detailed in Rufino et al. (2013). The survey was designed to collect details on farm inputs/outputs, farm activities, labour allocation, asset ownership, income and food security over a one year period. The survey's purpose was 
to be able to represent within site variability of livelihood indicators and provide insights into key performance indicators in terms of farm performance, food security, and the environment (Rufino et al., 2013).

In June-July 2015 a total of 147 households were re-sampled, with random selection at the village level resulting in six to eight households per village. Not all 200 households from 2012 were re-sampled; sampling in 2012 was more conservative as there was more uncertainty about variation between households in the site. The Rural Household Multi-Indicator Survey (RHOMIS) was utilised to represent livelihood strategies and some temporally consistent performance indicators (namely: food availability and household diet diversity). The RHOMIS tool evolved out of the IMPACTlite tool and has been designed to collect reliable information at minimum burden on respondents, providing a rapid characterisation of farm systems and performance indicators (Hammond et al., 2017). This revised tool was used instead of the original IMPACTlite survey, as it collected information relevant only to a clear set of research questions and thus kept the burden to the farmer at a minimum. Interviews were conducted in Swahili and local tribal dialects by three trained enumerators and to a lesser extent by the first author. Enumerators differed from 2012, but the original site coordinator was closely engaged and worked with the enumerators in the study site to improve consistency and reduce biases that could be introduced by the way questions were phrased.

Village leaders and extension officers were interviewed concurrently to the household level interviews; in total 16 village level interviews were conducted. Topics of discussion included: changes in population, changes in land size, the importance of particular crops/livestock, livestock productivity, the condition of infrastructure and development activities (local, government or NGO led).

Additionally, insights were drawn from publicly available remote sensing products, namely: the 'global satellite rain gauge', vegetative index and estimated soil properties.

\subsubsection{Analysis}

Using the paired observations over 2012 and 2015, this study analyses the financial and food security performance of differing adaptive responses for 147 households (thus excluding 53 out of the 200 households sampled in 2012). Changes between 2012 and 2015 were first assessed at the aggregate level. Summaries of the central tendency and distribution of households were provided for variables related to resource endowments (e.g. land, livestock and off-farm income), farm characteristics and performance indicators. As several variables of interest were not normally distributed, the central tendency was represented by the median and the distribution as the inter-quartile range (IQR).

Following on from analysis at the aggregate level, a hierarchical K-means clustering algorithm (Kassambara \& Mundt, 2016) then incorporated variables that would differentiate households in terms of long-term (strategic) and short-term (tactical) configurations of resources and farm characteristics - termed 'adaptive responses'. Variables included were: household population (in adult equivalents), total land cultivated, crop market participation (percentage of crop pro- 
duction sold), crop diversity (number of different crops grown), importance of high value crops (percentage of the area grown), crop-livestock integration (manure and crop residue utilisation), livestock-holdings and livestock market participation (percentage of livestock products sold) and off-farm income. Off-farm income was collected differently in 2012 and 2015. To maintain consistency, only income from business and employment was included, which was then evaluated as a percentage of total income. Market participation was assessed on a kilo-calorie basis (\% sold), providing a common unit of comparison across crops and livestock products. The final inputs into the clustering algorithm included the variables listed above from 2015 as well as the difference between 2015 and 2012 for each variable, all of which were centred and scaled.

Food security and poverty indicators were calculated using standardised methodologies as described in Hammond et al. (2017). The 'household diet diversity score' (HDDS) is based on a count of a total of 12 food groups consumed (Swindale \& Bilinsky, 2006) with recall of 'flush' and 'lean' periods. The 'household food insecurity access scale' (HFIAS) is based on nine questions on the household's experience of food insecurity for the flush and lean periods; touching on sensitive issues for the respondents such as missed meals and consumption of undesirable foods (Coates \& Bilinsky, 2007). The progress out of poverty index (PPI) is based on a countryspecific set of 10 questions, scoring households from 0 to 100 (with higher scores increasingly less likely to be below the poverty line; Grameen, n.d.). Food availability is a supply and purchase potential estimate based on production, off-farm income and cost of a key staple food (maize; Zea mays L.), expressed as Potential Food Equivalent (PFE) energy (kilocalories) per adult equivalent per day; a common calorie content was taken over the time period, with varying staple food price. It should be noted that the purchase potential from farm income has limitations as it is based on revenue rather than profit. Thus, food availability is calculated as follows (Eq. 4.1) and further detailed in Frelat et al. (2016).

$$
P F E=\frac{E_{\text {cons }}+E_{\text {income }}}{365 \times n_{h h}}
$$

Remotely sensed products were used as explanatory variables for differences between years and clusters. Estimated monthly rainfall for the study site was used to identify variations from long-term average rainfall across the site as a whole (Janowiak, 1999). Additionally, the enhanced vegetative index (EVI; NASA, n.d.), soil organic carbon (SOC) and $\mathrm{pH}$ estimates were extracted for the households where reliable GPS coordinates were collected ( $n=78$ due to GPS errors; estimation of soil properties detailed in Hengl et al., 2016). These products were at a 250 $\mathrm{m}$ resolution, as such these data represent approximate metrics for rainfall, temperature and soil for the farm and surrounds.

To account for the multi-stage clustered sampling design, changes over time and differences between clusters were modelled with mixed-effects regression, with random effects on the intercept from the village. Changes and differences in land, livestock holdings, income, fertiliser, food availability and food security of access were analysed using linear regressions; differences 
in HDDS between clusters were analysed using negative binomial regressions. All linear and negative binomial regressions were performed using the lme4 package in $R$ (Bates, 2017). Linear regressions with non-parametric residuals were re-run with cuberoot transformed dependent variables. The statistical significance of fixed effects in linear regressions were assessed using the F-test with Kenward-Roger approximation (Kenward \& Roger, 1997), comparing models additively from the intercept only model. The statistical significance of fixed effects in negative binomial regressions were assessed using the wald test using the aod package in R (Lesnoff \& Lancelot, 2012).

\subsection{Results}

\subsubsection{Summary of resources, farm characteristics and performance indicators}

Resources and farm characteristics were highly variable between households, both in 2012 and 2015 (Table 4.1). While highly variable, these results support previous characterisations of the study site. Households generally have small land-holdings ( $85 \%$ of households $<1.5$ ha in 2015 ) with agricultural based livelihoods $(87 \%$ of households $>$ half of their income coming from the farm in 2015) and a low level of input (88\% of households applying less than $15 \mathrm{~kg}$ of fertiliser $\mathrm{ha}^{-1}$ year $^{-1}$ ). Results from the village level interviews indicated that agricultural development programs were implemented in five of the villages. Additional to these development programs, $12 \%$ of households (from a total of 12 villages) received aid in the form of seed, fertiliser, food or money.

Over the observed period there were statistically significant changes in the distribution of land ownership, crop diversity $(\operatorname{pr}(>|F|)<0.01)$ and crop income $(\operatorname{pr}(>|F|)<0.05$, Appendix Table A2). Between 2012 and 2015 some households aggregated land and others reduced landholdings, flattening the overall distribution of land ownership in 2015 (Figure $4.2 \mathrm{a}$; pr < 0.01, F-test of variance). There were no statistically significant differences in livestock or off-farm income between 2012 and 2015.
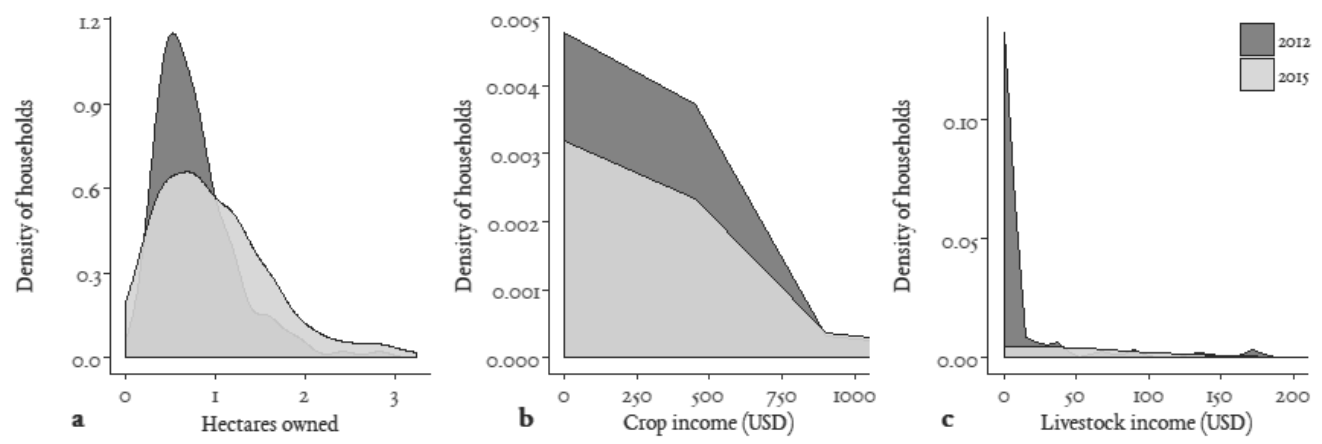

Figure 4.2 Distributions in 2012 and 2015 (a) Land owned (ha); b) Crop income (USD year ${ }^{-1}$ ); c) Livestock income (USD year ${ }^{-1}$ ) 


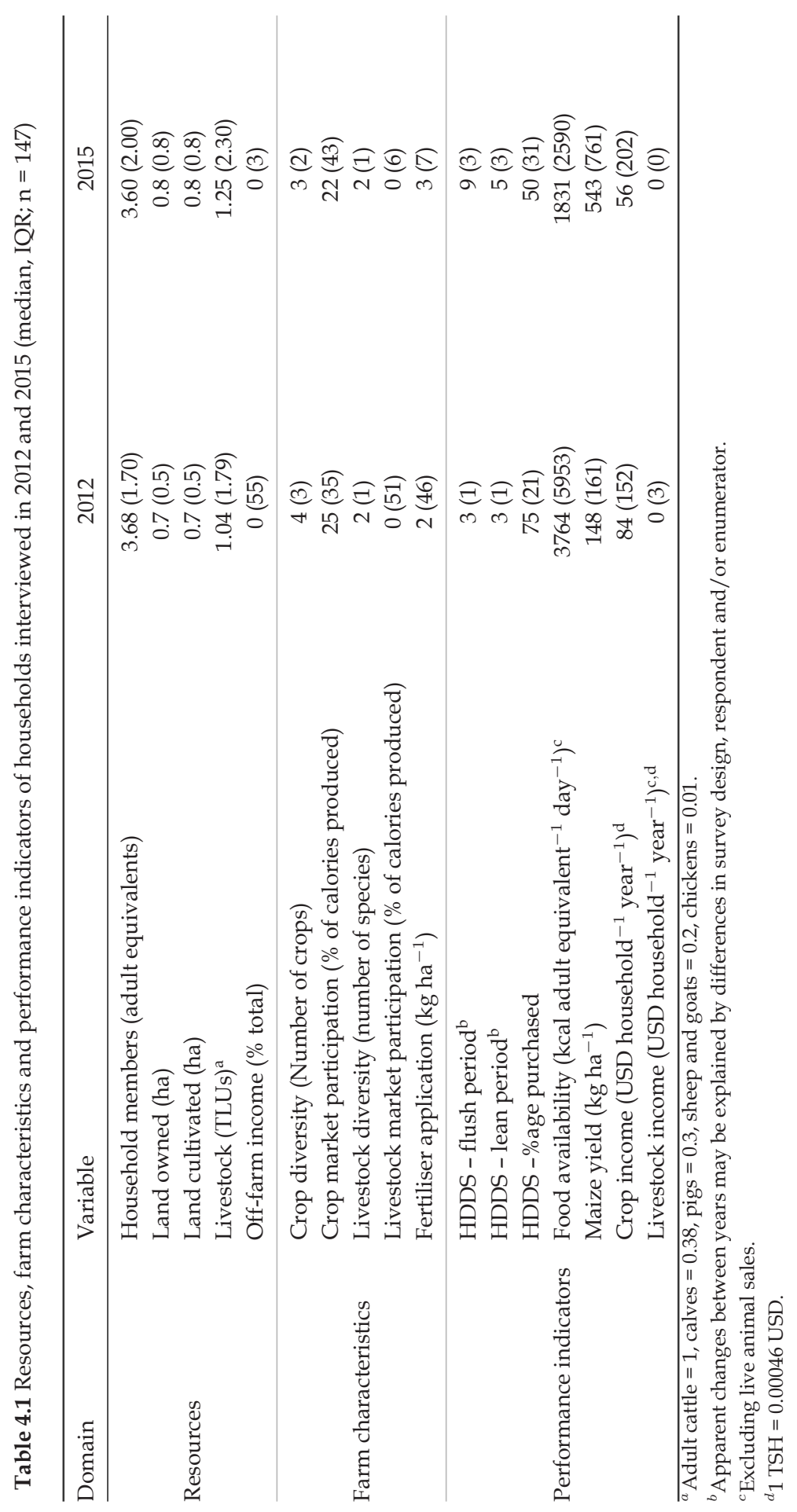


Annual crop income was significantly lower in 2015; this was weakly related to changes in crop market orientation $(\hat{\alpha}=64$ (47), $\hat{\beta}=394$ (112) $\operatorname{pr}(>|\mathrm{F}|)<0.001$, mixed-effects linear regression; Figure 4.3), where some households decreased market participation and also decreased crop income, and others either remained stable or increased market participation and increased crop income.

There was no significant difference in vegetative index (EVI) between 2012, 2015 and the longterm annual average. Estimated rainfall, however, was more erratic in 2011 - 2012, with approximately $90 \mathrm{~mm}$ more than average falling in November 2011 and approximately $90 \mathrm{~mm}$ less than average falling in May 2012. The most influential drought events (in terms of recorded crop yields), were recorded in both April 2011 (-100 mm) and April 2014 (-90mm), potentially influencing the main harvest recorded for each year (August 2011 and 2014; Janowiak, 1999). The effects of these rainfall differences are uncertain; harvests in 2012 may have been greater from the short rain planting period in 2011 (September - November) and reduced for the long rain planting period in 2012 (February - April).

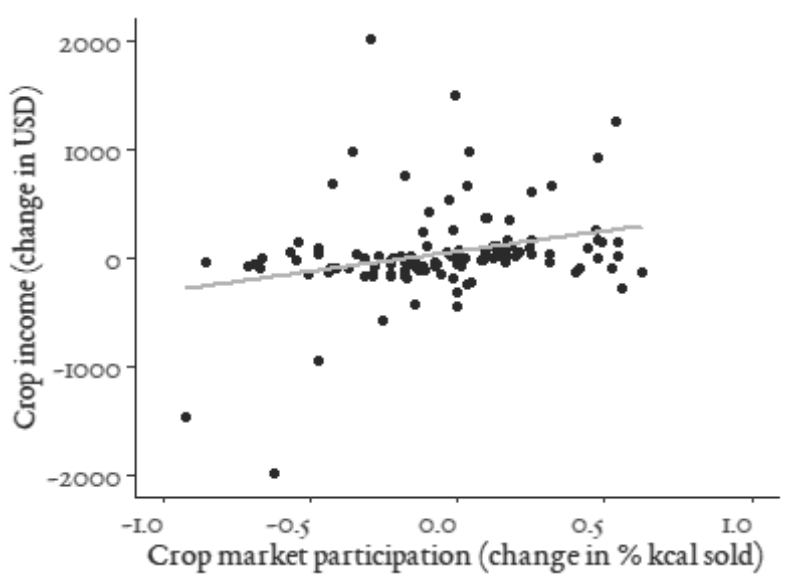

Figure 4.3 Change in crop income (USD) and market participation (\% kcal sold), with regression line

The majority $(>70 \%)$ of households either did not have off-farm income opportunities or only earned a small proportion of their income from off-farm activities. In 2015, 3\% of households earned over $50 \%$ of their income from off-farm activities, which is in contrast to $29 \%$ of households in 2012. This change in off-farm income has no obvious explanation, but may indicate a lack of job security and a high risk of failure for off-farm businesses.

Observing these resources and farm characteristics over time, a diversity of concurrent changes are evident for a majority of households. Seventeen percent of households had a change in land area owned $( \pm 1 \mathrm{ha})$. Seventy-seven percent of farmers show a change in land area owned, number of TLUs $( \pm 2)$, market orientation of crops $( \pm 50 \%)$, market orientation of livestock ( \pm $50 \%)$, or changed crop diversity $( \pm 2)$. 


\subsubsection{Types of adaptive responses}

Four distinct groups were identified from the clustering process. Adaptive response clusters were named: 'Rising high value crop' ( $n=25)$, 'Rising livestock' ( $n=33)$, 'Subsisting mixed' ( $n=42)$, and 'Subsisting crops' ( $\mathrm{n}=47$; Table 4.2).

Households in the 'Rising high value crop' cluster were named based on their increased land area ( $64 \%$ of households increased by $>0.25$ ha), a larger allocation of land to non-staple crops (92\% of households), and their increased crop market participation. Increases in land area were allocated to tomatoes ( $29 \%$ of households that increased land), potatoes ( $17 \%$ of households) and coffee (16\% of households). Households in this cluster continued to cultivate staple crops, maintaining their high level of crop diversity over the three year period. Several households in this cluster also increased their livestock-holdings (predominantly cattle); the majority $(73 \%)$, however, reduced their market participation of livestock products. Twenty-four percent of households earned off-farm income in 2015, considerably less than the $56 \%$ of households earning in 2012. Increases in land ownership indicate a shift in strategy for households in this cluster. While cultivating staple crops has been a consistent aspect of their farm strategy, cultivating high value crops may be a long-term strategy for some (e.g. $28 \%$ of households had coffee bushes in 2012 and 2015), or a short-term tactic for others (e.g. 68\% of households added high value crops to their production mix in 2015).

Households in the 'Rising livestock' cluster were named based on their increased land area (66\% increasing by $>0.25 \mathrm{ha}$ ), increased livestock-holdings ( $90 \%$ of households) and their recent livestock market participation. These households also increased their cultivation and market participation of staple crops and cultivated a small portion of high value vegetables. Increases in land area were allocated to maize (60\% of households that increased land) and to a lesser extent increases in potatoes or tomatoes (14\%). Households that increased livestock-holdings generally did so by increasing cattle numbers (the majority of which were cross-bred or 'exotic'), with a few exceptions of increased sheep and goat numbers. Livestock products were predominantly used for home consumption in both 2012 and 2015. Market participation of livestock products was not common in 2012; in 2015, however, $45 \%$ of households in this cluster sold milk, eggs or home butchered meat. Live animals were marketed by the majority of households (51\%). Off-farm income was also earned by the majority of households (51\%) in 2015, ranging from 25 to $70 \%$ of total income.

Households in the 'Rising livestock' cluster sold live animals and increased livestock-holdings, indicating a viable long-term strategy, rather than short-term tactical destocking. The ownership of higher value mixed or 'exotic' breeds (56\% of households) may also indicate a long-term strategy. Marketing of livestock products, however, may be a strategy for some (e.g. 15\% of households kept non-local cattle and marketed milk in 2015) and a tactic for others.

Households in the 'Subsisting mixed' cluster, in general, maintained land-holdings, increased the portion of their land dedicated to staples and increased livestock-holdings. Crop and livestock market orientation decreased considerably when compared to 2012. The majority (65\%) of households kept cattle in 2012 and 2015, largely for home consumed milk production in 2015. 
Cattle keeping in the context of these communities is a considerable investment with barriers to procurement and sale; these households appear to be acting strategically on their asset ownership but may act tactically on whether to sell their milk or not.

Households in the 'Subsisting crop' cluster reduced land cultivation, reduced crop market orientation and reduced livestock-holdings. The majority (91\%) kept poultry in both 2012 and 2015 indicating that livestock plays an important tactical role in this cluster; several households $(29 \%)$ ceased to keep cattle in 2015 , indicating a potential strategic change.

\subsubsection{Analysis of adaptive responses}

A range of non-clustering variables were considered as potential covariate attributes of the clusters. These included: gender of the household head, whether the household head changed, household structure (e.g. tri-generational, parent-child, individuals), aid (seed, fertiliser, food and financial), distance of plot (from homestead), fertiliser application, debt, elevation, SOC, soil acidity and average EVI in 2012 and 2015.

The gender of household head was significantly different between clusters $(\hat{\alpha}=-1.63(0.30, \hat{\beta}$ $=1.77(0.44) \operatorname{pr}\left(>\left|\chi^{2}\right|\right)<0.05$, mixed-effects logistic regression, reference categories - male head and non-'Subsisting crops'), with 'Subsisting crops' having the highest instance of femaleheaded households (53\% of households), followed by 'Subsisting mixed' (26\% of households). The gender and marital status of the household head can have land tenure implications, as well as implications on livestock ownership. In this case, there were significant differences in the full data set, with female heads cultivating less land than their male counterparts $(\operatorname{pr}(>|\mathrm{F}|)$ $<0.001$, Appendix Table A3); and, female heads owning less livestock assets in 2015 (TLU; $\operatorname{pr}(>|\mathrm{F}|)<0.001$, Appendix Table A3). Within the 'Subsisting' clusters, however, there were no differences between male and female heads in terms of land-holdings. In the 'Subsisting mixed' cluster, male-headed households had significantly higher livestock-holdings (particularly cattle; $\operatorname{pr}(>|\mathrm{F}|)<0.05$, Appendix A Table A4).

Spatial analysis of a digital elevation model and soil property estimates (Hengl et al., 2016) of the study area showed that elevation was negatively correlated with $\mathrm{pH}$ and positively correlated SOC ( $\mathrm{r}=-0.61, \mathrm{pr}<0.05 ; \mathrm{r}=0.79, \mathrm{pr}<0.01$, Pearson's correlation). Despite this spatial variability, the modelled acidity and SOC levels would not present significant differences in crop or pasture constraints between clusters (e.g. $\mathrm{pH}$ was between 5.3 and 6.2 and optimal pH for maize in a nutrient solution is between 5.2 and 6.5; Islam et al., 1980). It should be noted, however, that non-publicly available, finer scale modelling of the study area suggests that there is greater variability and instances of lower SOC than available at a $250 \mathrm{~m}$ resolution (compared to Winowiecki et al., 2016).

Households in 'Rising' clusters applied significantly more synthetic fertiliser per hectare in 2015 when compared to 'Subsisting' households $(\hat{\alpha}=3.85$ (2.43), $\hat{\beta}=8.98$ (3.59) $\operatorname{pr}(>|\mathrm{F}|)<$ 0.05 , mixed-effects linear regression). Manure was often applied along with synthetic fertilisers, particularly for potatoes in 'Rising' clusters and the 'Subsisting mixed' households, as well as tomatoes and other vegetables in 'Rising high value crops' households. Yields were signifi- 


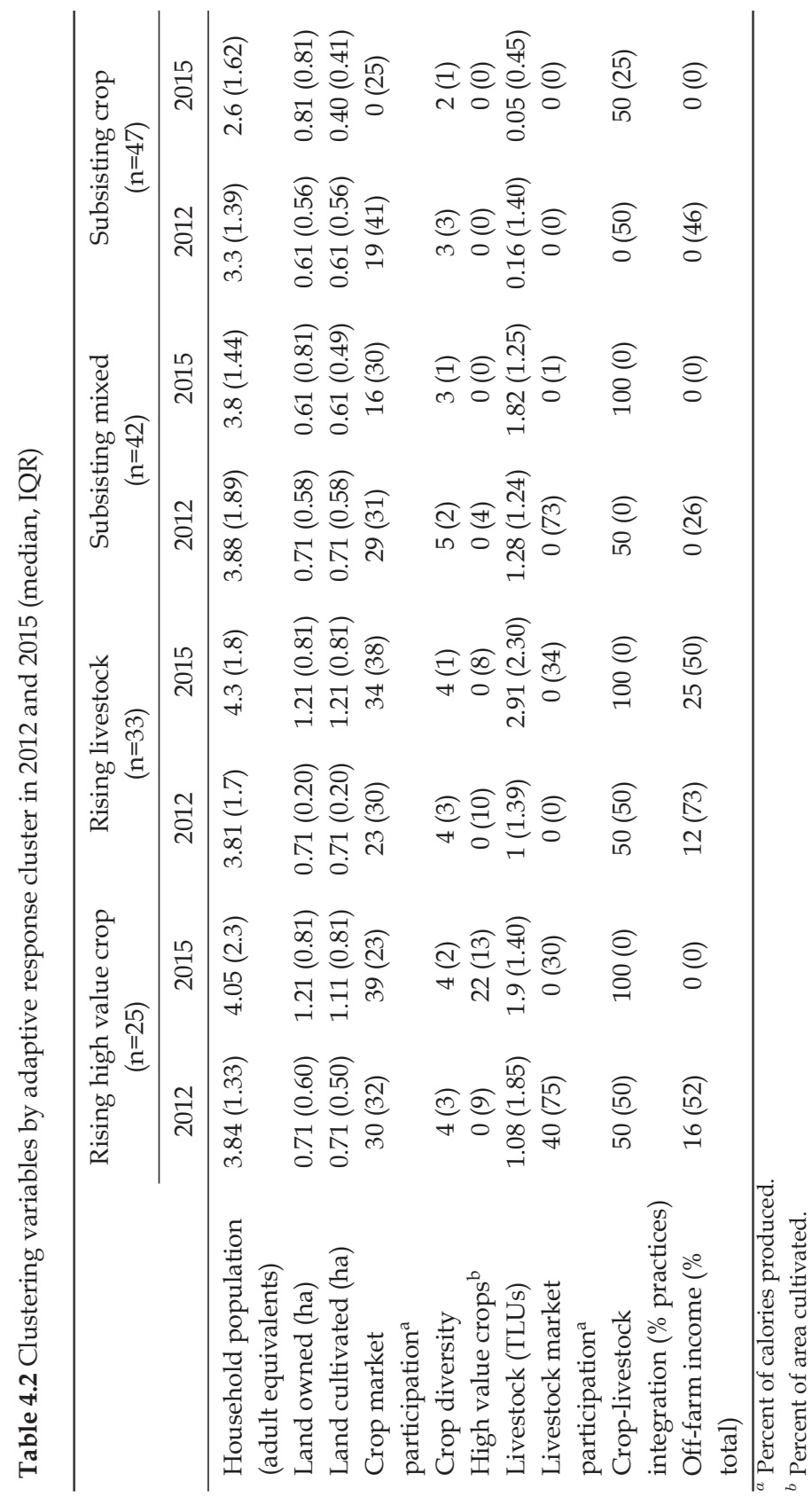


cantly higher for households applying synthetic fertilisers to maize $(\hat{\alpha}=719(212), \hat{\beta}=813(288)$ $\operatorname{pr}(>|\mathrm{F}|)<0.01$, mixed-effects linear regression).

There was no statistically significant difference in receipt of aid, level of debt, distance of plot, household structure or EVI. Further, households in villages with ongoing interventions (potato and dairy) did not increase in scale or market orientation for those livelihood activities more than households in other villages.

\subsubsection{Outcomes of adaptive responses}

The distribution of crop incomes changed over time for all clusters, with median income increasing in 'Rising' clusters and decreasing in 'Subsisting' clusters (Figure 4.4; $\hat{\alpha}=7.57$ (0.77), $\hat{\beta}=-4.30(1.21) \operatorname{pr}(>|F|)<0.01$, mixed-effects linear regression). The increased crop income in the 'Rising high value crop' cluster was attributable to market vegetables such as tomatoes, rather than coffee which halved in price between 2012 and 2015.
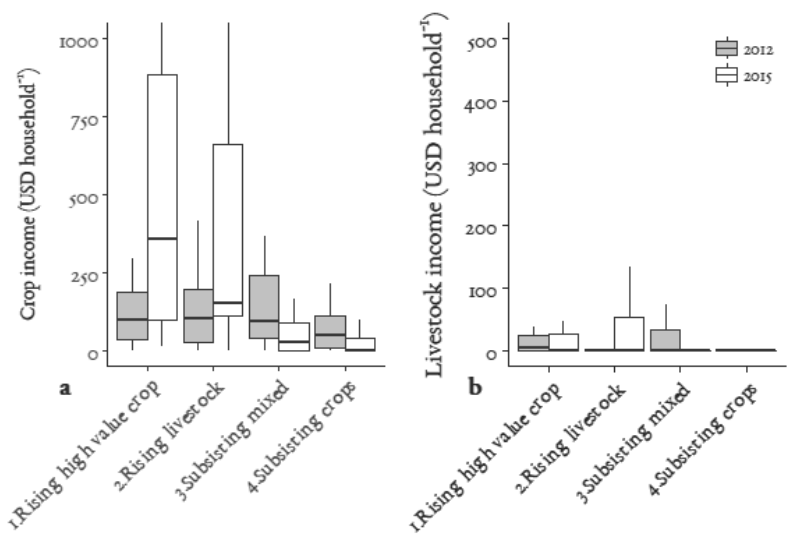

Figure 4.4 a) crop income (USD household ${ }^{-1}$ ) by adaptive response cluster b) Livestock income performance (USD household ${ }^{-1}$ ) by cluster

The distribution of livestock incomes did not differ significantly between 2012 and 2015. However, fresh milk producers in the 'Rising' clusters generated significantly higher livestock incomes when compared to other households in the cluster $(\hat{\alpha}=1.46(0.36), \hat{\beta}=0.92(0.40) \operatorname{pr}(>|\mathrm{F}|)$ $<0.01$ ).

Households in the 'Rising' clusters had significantly higher Food Availability scores and Household Diet Diversity Scores in the good period when compared to 'Subsisting' clusters (Figure 4.5; $\operatorname{pr}(>|\mathrm{F}|)<0.001$, Appendix Table A5).

In the lean period, 'Subsisting crops' households had significantly less diverse diets than 'Rising livestock' households ( $\hat{\alpha}=1.57(0.07), \hat{\beta}=0.21(0.10) \operatorname{pr}\left(>\left|\chi^{2}\right|\right)<0.05$, mixed-effects negative binomial regression). Households in the 'Rising' clusters were significantly more food secure (in terms of access) than 'Subsisting' households $(\hat{\alpha}=9.48(0.61), \hat{\beta}=-2.28(0.80) \operatorname{pr}(>|\mathrm{F}|)<0.01$, 
mixed-effects linear regression).

There was no significant difference in the PPI score; this is understandable as PPI is a slower moving indicator, requiring more time to see significant differences in performance.

Notably, there was no significant difference between clusters in the duration of the lean period (median $=3, \mathrm{IQR}=1$ ), indicating that the pertinent issue is the intensity of hardship, rather than duration. Further, there was no significant difference in performance due to aid or gender of household head (results not shown).
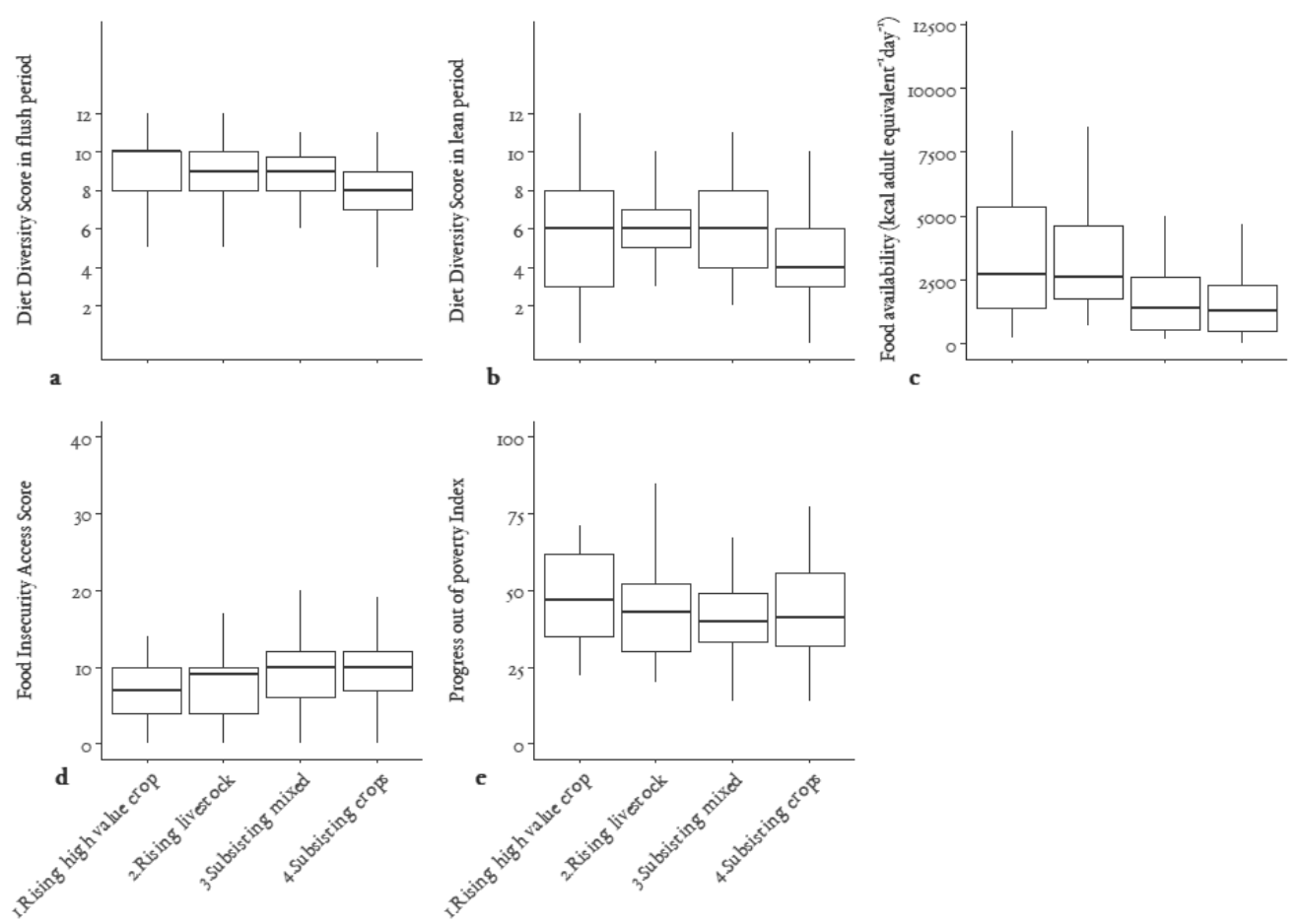

Figure 4.5 Performance indicators by adaptive response cluster in 2015. (a) Household diet diversity scores (HDDS) in the flush period; (b) Household diet diversity dcores in the lean period; (c) Food availability (kcal adult equivalent ${ }^{-1}$ day $^{-1}$ ), including live animal sales; (d) Household food insecurity access scale (HFIAS); (e) Progress out of poverty index score

\subsection{Discussion}

Households in the study site responded to local and national circumstances (e.g. drought months, regional and national economic growth) through a range of adaptive responses which have been classified as 'Rising high value crop', 'Rising livestock', 'Subsisting mixed' and 'Subsisting crops' (summarised in Table 4.3). Overall, within the relatively short time period of three 
years (2012 - 2015), 77\% of households made changes in farm resources or farm characteristics (Figure 4.2a and Table 4.2). Many of these changes can be classified as strategic, requiring considerable investment which will have an influence on the performance of the farming system over a longer period of time (e.g. 17\% of households changing land area by $>1$ ha). Other observed changes (increases in vegetable production, changes in off-farm income) are more difficult to identify as long-term strategic changes as opposed to short-term tactics. A consequence of these rapid changes is that agency interventions need to be adaptable to maintain relevance for such farmers. Our results show that in sites like Lushoto with a good rural to urban connection (such as can be found in several regions of sub-Saharan Africa due to the many rapidly developing urban centres) projects are indeed aiming for a moving target and this will have implications on achieving income and food security outcomes, and requires targeted and rapid monitoring tools. There are valuable lessons that can be learned from this case study for macro development activities in the region (e.g. providing infrastructure and stimulating offfarm industries) as well as micro development activities (e.g. targeting and designing agency interventions).

Some of the most substantial changes we observed in the three year period of study were most likely not related to any of the agency interventions that were being promoted in the region. Increases in land area, for example, coincided with increases in the tomatoes, potatoes, maize and coffee plantings. While there was active promotion of potato cultivation in Boheloi, there were no households in this village that increased land area and potato cultivation, suggesting that this intervention is not, in part, driving this land aggregation. The role that dairy interventions have had in increased livestock-holdings is also not clear. Dairy is actively promoted (through the 'Maziwa zaidi' project branding - bringing multiple partners and projects under the one banner) in four of the villages; households in the 'Rising livestock' cluster that increased milk marketing, however, are spread out across the study site and so it is difficult to definitively attribute these changes to this intervention program.

The change of land expansion seen in the 'Rising' clusters provides a counterpoint to the trend established in the literature of decreasing farm sizes across lower-income countries more broadly, and specifically in Africa (Bosc et al., 2013; Jayne et al., 2003; Lowder et al., 2016; Masters et al., 2013). On a national scale, Jayne et al. (2014) found that average farm sizes in Tanzania, being land abundant, had more than doubled between 1996 and 2003, with increases in land value making parents less willing to subdivide. The conditions for such expansion though, go beyond land value and also relates to the business viability of the farm. The business viability of land expansion depends on the potential to gain economies of scale (Hazell et al., 2010), viable market opportunities and effective risk management (Harris \& Orr, 2014).

Our clusters of change show some similarity to Dorward's classification of farm livelihoods (Dorward, 2009). Our 'Rising' clusters can be compared to the 'Stepping-up' group of households and 'Subsisting' households can be equated to the 'Hanging-in' group (Falconnier et al., 2015; Valbuena et al., 2015), but this study shows these rural households can pursue completely different strategies. In general terms, Dorward's livelihood grouping can be a useful frame- 


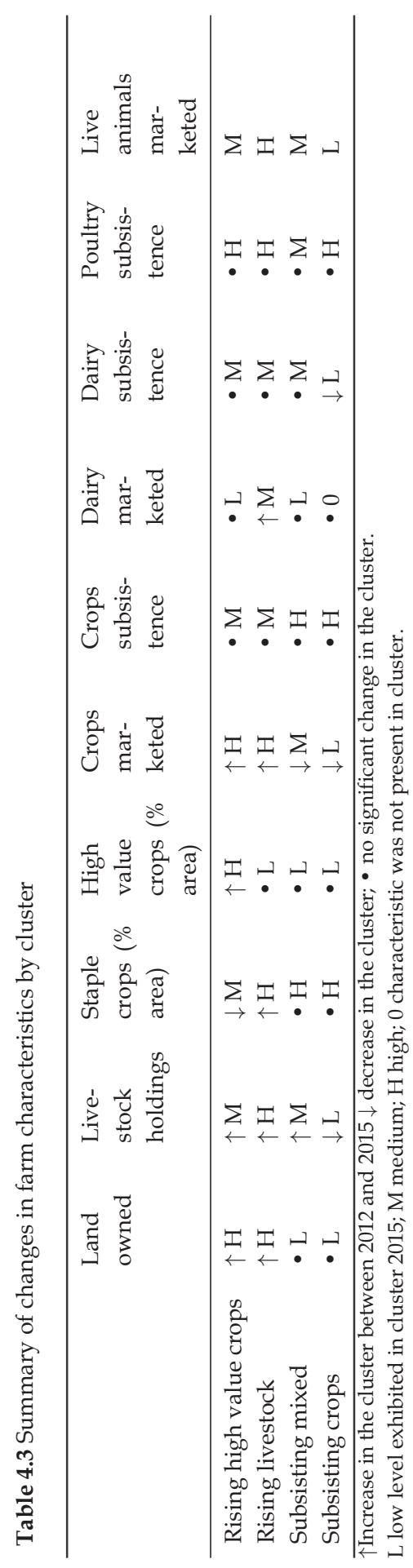


work. In specific applications like in this study, however, it is not the most appropriate way of looking at farm household trajectories.

In an assessment of food availability of more than thirteen thousand households in sub-Saharan Africa, Frelat et al. (2016) make predictions using variables related to livelihoods, namely: household size, number of livestock and land area. Notional food availability though, as seen in this study, does not necessarily translate to improvements in all aspects of food security. Specifically, significant differences in food availability between clusters are not present in HFIAS and HDDS in the lean period (Figure 4.5), suggesting that it is necessary to include multiple metrics of food security, rather than food availability alone.

\subsubsection{Farm income and food security in Lushoto, Tanzania}

Regardless of adaptive response, farmers utilise resources with a high level of production risk and with no guarantee that crops or animal-sourced foods will be purchased above cost, if at all. Households in the 'Rising high value crops' and 'Rising livestock' clusters had a high degree of market orientation, with different approaches to market risk (Table 4.2). The 'Rising high value crop' households' decisions appear to have been financially beneficial, by cultivating more land, with a portfolio of coffee, tomatoes, market vegetables, staples as well as keeping livestock species. It may well be that the increased risk of their expansion strategy was mitigated by an astute set of tactics in response to crop market signals while maintaining or increasing a diversity of crop and livestock species (rather than specialising). The 'Rising livestock' households' focus on livestock and staple crops also returned financial dividends; this is particularly the case for fresh milk producers in the 'Rising' clusters, who are earning significantly more livestock revenue than other households and could indicate greater specialisation for these households (as theorised would happen in such favourable market conditions in McIntire et al., 1992). These clusters of households demonstrate how agile and fast moving households in the study area can be.

The higher performing 'Rising' adaptive response clusters also present a challenge for external organisations seeking to replicate such performance. The complex risk management and market responsiveness that manifests as a diversity of crop and livestock products in these adaptive response clusters is at odds with single focus activities that external organisations tend to promote (as illustrated by free seed not translating into food security or diet diversity performance); further, the land expansion that this strategy depends on for its performance is risky. This potentially represents a future of winners and losers, ultimately with some landholders falling further into poverty rather than leveraging their agricultural enterprises to improve their wellbeing.

Longer term resilience of land-holding households is not guaranteed. Higher performance or subsistence at the expense of the natural resource base can only be sustained for so long. Ongoing cultivation with minimal fallow and low inputs will work to deteriorate soil health in the future, limiting crop and pasture production. Households keeping ruminant livestock species ('Rising' and 'Subsisting mixed') managed integrated crop-livestock systems, which is a posi- 
tive attribute in terms of yields and soil health.

\subsection{Conclusions}

This study observes livelihood dynamics and related poverty and food security performance over a three year period in a high potential, market connected region of Tanzania. Evidence suggests that 1) the drivers for the most significant livelihood changes do not necessarily relate to agency interventions; 2) the adaptive responses that have been implemented in this community incorporate multiple components (e.g. off-farm income, diverse crops and livestock) and are relatively heterogeneous across the study site; and 3) there is a partial disconnect between potential food availability (from income and kcal production) and short and long-term food security. Such evidence has implications for development agendas.

A substantial portion of households in the study site made changes to their livelihoods over the short three-year period analysed in this paper. Changes in land ownership, livestock-holdings and high value crop production are most likely related to market opportunities and personal circumstances, rather than direct interventions. Several households are making substantial strategic changes by expanding land ownership, planting perennial crops and investing in exotic cattle breeds; many households are also tactically utilising their land for diversified, mixed crop-livestock production. The majority of households, however, have either remained stable or are scaling back to subsistence farming. Households that are expanding their land area, present a unique case study in sub-Saharan Africa, where households in land scarce regions (albeit in a land abundant country) are consolidating land, with the potential to gain economies of scale.

Government and non-government organisations face challenges in designing interventions that remain relevant to such rapidly changing rural households, with multifaceted livelihoods and varying 'well-being priorities'. This study highlights, the need for interventions to simultaneously support a diversity of livelihood activities (e.g. dairy, staples and post-farm value chain) targeted at clusters of households. Monitoring of income and food availability is not sufficient to measure well-being, rather multiple well-being indicators are needed.

\subsection{Acknowledgements}

We thank all the people involved in the conversations that formed the basis for this study and especially the farmers for sharing their valuable time. We also thank the three anonymous reviewers for their comments and insights. This work is a joint output of the CGIAR Research Programs on 'Livestock and Fish', 'Climate Change, Agriculture and Food Security' (CCAFS) and 'Maize'. The work was also supported by the USAID-funded Feed the Future Sustainable Intensification Innovation Laboratory. The views expressed in this paper can not be taken to reflect the official opinions of these organisations. 



\section{Chapter 5}

\section{Pathways to food security in rural Burkina Faso: the importance of consumption of home-produced food versus purchased food}

This chapter is based on:

Fraval, S., Yameogo, V., Ayantunde, A., Hammond, J., de Boer, I. J. M., Oosting, S. J., van Wijk, M. T. (submitted). Food Security 


\section{Abstract}

The number of undernourished people and the risk of micro-nutrient deficiency remains high in sub-Saharan Africa (SSA). Decades of policy designed to reverse the trends of food insecurity have illustrated that the causal pathways of intervention to end-point outcomes, such as nutrition, are not necessarily straightforward. Utilising well-established proxies for food security, this study investigates the relative importance of different pathways to food security in two subtly contrasting communities in the Sahelian and Sudanian Savanna zones of Burkina Faso $(n=400)$. In Yatenga province, approximately $31 \%$ of households were classified as 'severely food insecure' in the 'lean' period. In contrast, over $83 \%$ of households sampled in Seno province were classified as being 'severely food insecure' in the lean period. There were statistically significant associations between food security indicators and off-farm income, farm income and production diversity. The source of income had significantly different associations with diet diversity in the two provinces. In Yatenga province, higher gross farm income in the absence of off-farm income was predicted to result in more diverse diets; in Seno province, however, gross farm income was only predicted to result in more diverse diets when households are also earning off-farm income. Our analysis shows that, households are most differentiated by income generating pathways to food security. This finding should not detract from the essential role played by home-produced foods in improving food security. Rather, market-orientated agriculture and production for home consumption, as shown by households in this study, can be combined as part of a more resilient livelihood strategy. 


\subsection{Introduction}

The decade long decline in global chronic undernourishment has been reversed in recent years. The prevalence of chronic undernourishment in sub-Saharan Africa (SSA) has returned to pre-2005 levels, equating to approximately 237 million people unable to meet their energy needs in 2017 (FAO et al., 2018). There is also a high risk of micro-nutrient deficiency in the broader population, termed 'hidden hunger' (another important aspect of malnutrition). Joy et al. (2014) provide startling estimates of deficiency risks for calcium ( $>50 \%$ of the African population), zinc (40\%), selenium (28\%) and iodine (19\%). The individual and societal implications for such nutritional gaps are borne disproportionately by the rural population, indicated by the consistently higher prevalence of stunting in rural SSA (Green et al., 2016).

Given the persistence of undernourishment and hidden hunger, nutrition specific and nutrition sensitive interventions have been implemented across SSA (de Pee et al., 2017). Agricultural interventions have an intuitive link with the most nutritionally vulnerable of communities, particularly those with limited off-farm employment options. The causal pathways from intervention to end-point outcomes, such as nutrition, are less straightforward (Carletto et al., 2017). Increased incomes and energy availability, for example, are necessary for alleviating undernourishment, but not sufficient for addressing 'hidden hunger' (Schipanski et al., 2016; McDermott et al., 2015; Hoddinott, 2012). A greater understanding of these pathways is needed, particularly given the UN's ambitious target of 'zero hunger' by 2030 (as part of the Sustainable Development Goals) with the constraints of stagnating aid flows (OECD, 2015) and low levels of research and development spending in SSA (Pardey et al., 2016).

One challenge in assessing the pathways from agricultural intervention to nutrition outcomes relates to monitoring the food security status of the population. Evaluating food access and micro-nutrient deficiencies has traditionally been time-consuming and invasive. More recently, however, proxies have been introduced to enable wide-scale monitoring and evaluation. Food insecurity scales and diet diversity scores (to a greater extent) have been assessed against diet quality and adequacy ratios, and have emerged as reliable proxies (evident in Rah et al., 2010; Saha et al., 2009; Coates \& Bilinsky, 2007; Savy et al., 2005; Steyn et al., 2006; Arimond \& Ruel, 2004; Torheim et al., 2004). In the one case where 'household diet diversity score' (HDDS) was not associated with diet quality or adequacy ratios, an association was instead identified with 'household food insecurity of access scale/prevalence' (HFIAS/HFIAP; McDonald et al., 2015). As HFIAS/HFIAP and HDDS represent different aspects of food security, both metrics are adopted in the present study.

Utilising these proxies for food insecurity, a growing body of literature has taken shape around the question of what differentiates those that are food insecure from those that are more food secure in high risk communities around the world. Powell et al. (2015) provides a summary of six such studies that identify positive relationships between the diversity of crops cultivated and HDDS. More recently, several studies - largely focused on SSA - have explored these relationships in greater detail. The emerging areas of investigation have centered on the roles of 
subsistence and market-orientated agriculture and off-farm income in HFIAS, HDDS or nutrient adequacy ratios. Income, and thus purchased foods has been found to be highly associated with dietary diversity in the majority of these studies, whereas food from subsistence production, while also significant, had a limited relationship with dietary diversity (Some \& Jones, 2018; Bellon et al., 2016; Koppmair et al., 2016; Luckett et al., 2015; Sibhatu et al., 2015; Snapp \& Fisher, 2015; and Dillon et al., 2014). Jones (2016) and M'Kaibi et al. (2015) in comparison, emphasised the positive relationship farm production has with food security indicators (diet diversity and micro/macro nutrient intake in Jones, 2016; nutrient adequacy ratios and HFIAS in $\mathrm{M}^{\prime}$ Kaibi et al., 2015). In the most geographically diverse study to date, the role of farm production on food security was found to be of varying importance depending on market opportunities, and the relationship was found to be non-linear (Sibhatu et al., 2015). In the existing literature, however, there is a limitation that the relationships between subsistence production, market-orientated agriculture and food security have been modelled indirectly and often at one or two points of time in the year.

This present study seeks to improve our understanding of the causal pathways to improved food security in vulnerable rural communities. We do so by characterising farm systems, household demographics and food security status in subtly contrasting communities in drought prone regions of Burkina Faso. Food security indicators were enumerated for two periods to account for the temporal variability throughout the year. Diet diversity was disaggregated by channel of access to better understand food sourcing behaviour. With this approach we address the questions of: a) what are the differentiating attributes of more food secure households, and more specifically b) what are the roles of subsistence and market-orientated agriculture in improving food availability, food access and the stability of food security.

\subsection{Methods}

\subsubsection{Household characteristics}

The two study areas are located in the Sahel and Sudanian Savanna zones of northern Burkina Faso. Elevation in these regions ranges from 250 to 350 masl., receiving between 300 and 600 $\mathrm{mm}$ of rainfall per year, in a unimodal pattern (based on publicly available GIS data). Soils in northern Burkina Faso are characterised as granite and migmatite derivatives, with poor soil fertility (FAO, 2002). We selected Seno and Yatenga provinces as our study areas as both provinces are vulnerable to food insecurity and have subtly contrasting production potential and ethno-cultural backgrounds.

The prevalence of chronic malnutrition in Burkina Faso remains of concern. According to a nutritional survey conducted in the country in 2016, the national prevalence of chronic malnutrition was estimated to be $7.6 \%$ for all men, women and children (MH \& NISD, 2016). This prevalence varied across the country, with $7.9 \%$ of individuals in the region surrounding Seno identified as malnourished, and $8.2 \%$ in the region surrounding Yatenga. Chronic and hidden hunger are experienced most severely in the lean period. The most food insecure period is 


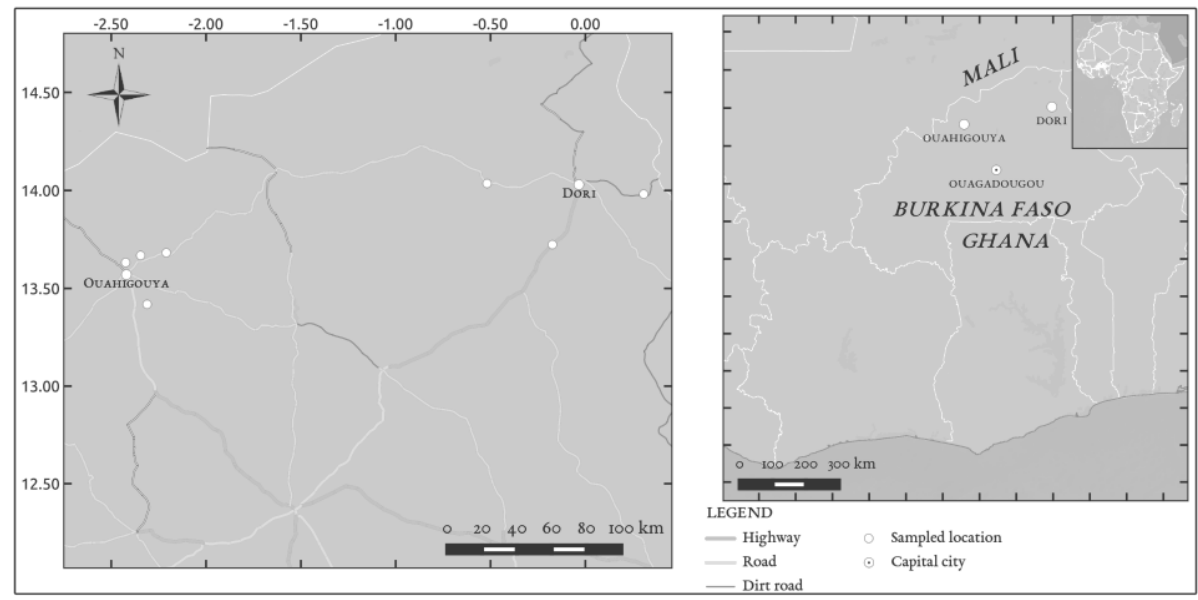

Figure 5.1 Study areas and sampled villages

(Author's composition based on GADM database and Open Steet Maps)

during planting (typically June to August), where the lean period typically extends from May to mid-August - with some variation across agro-ecological zones (Some \& Jones, 2018). In general, diet diversity is lower in the Sahel and Sudanian Savanna zones compared the wider Burkina Faso (ibid.).

Households were sampled from eight villages in Seno and Yantenga provinces for this crosssectional study (Figure 5.1). Both regions have good access to road infrastructure - where major roads are paved and intra-village dirt roads are passable throughout the year. Each region has access to open air markets, where the average travel time for sampled households is approximately 10 kilometres. The largest livestock and produce market in Seno province is located in Bani; the largest livestock market in Yatenga province is located in Aorema, Ouahigouya. Households in Seno province are largely from the Fulani tribe, who have rich pastoralist and livestock keeping traditions. The Fulani pastoralists in the study area have largely been sedentarised for the past three generations. Some households in the region settled more recently due to loss of their animals during the droughts of the 1970s and 1980s (Bovin, 1990). These recently sedentarised households tended to establish communities on the periphery of villages. Households in Yatenga province are largely of the Mossi tribe, which is the largest ethnic group in the country.

Households in both provinces rely largely on rain-fed agriculture. According to the Global Yield Gap Atlas (2016), both provinces fall below their potential in terms of crop production. The rain-water limited yield potential in Dori was 2.7 tonnes per hectare for sorghum (bicolor) and 1.3 tonnes per hectare for millet (predominantly Pennisetum glaucum L. possibly also Eleusine coracana $L$ ), with actual yields estimated to be below one tonne per hectare; water limited yield potential in Yatenga was estimated to be 5.5 tonnes per hectare for sorghum and 2.7 tonnes per 
hectare for millet, with actual yields also estimated to be below one tonne per hectare.

\subsubsection{Data}

Fifty households were randomly sampled from four villages in each region, totalling 400 households. Villages were selected based on the following criteria: i) representativeness (e.g. ethnicity, wealth, scale of production), ii) population (at least 500 households), iii) suitability for onfarm trials, and iv) security risk (northern departments/communes in Yatenga were excluded on this basis). Focus group discussions were conducted in the eight villages, each including 20 to 25 participants. Households were then randomly sampled based on full lists of households - provided by the village leaders. Due to limitations on pre-existing data, sample size was set at 50 households per village - based on an approximate target of $5-10 \%$ of the population (Lapan et al., 2011; village household population is presented in Table 5.1). All selected households agreed to participate. The interview questions were developed based on objectives for the project and the research questions of this study. The questionnaire was pre-tested in each village to ensure the questions were appropriately framed.

Data collection took place in May 2016, administered in French and in local languages when preferred (Fulfulde in Seno province and Moore in Yatenga province). Interviews were conducted by trained enumerators at the respondent's homestead. The household head responded to the majority of questions and other household members were engaged on questions related to food security (e.g. the person who prepares the meals). Respondents were asked detailed questions on household demographics, plot utilisation, livestock holdings, crop yields, farm product utilisation, income, diet, food security, poverty level and labour allocation. Households were asked to recall circumstances from both the most food secure period and the least food secure period of the year (the periods of challenged food security are defined by respondent perceptions of scarcity and presented in the results).

The core indicators assessed in this study were based on from standardised methodologies. 'household food insecurity access prevalence' (HFIAP) and 'household food insecurity access scale' (HFIAS) were calculated based on the nine food access questions from the 'Food And

Table 5.1 Number of households by department and village

\begin{tabular}{lllcc}
\hline Province & Department / commune & Village & $\begin{array}{c}\text { Households in } \\
\text { department } \dagger\end{array}$ & Households in village $\dagger$ \\
\hline Seno & Bani & Bani & 12,102 & 1,030 \\
& Dori & M'Bamga & 21,366 & 655 \\
& Gorgadji & Gorgadji & 5,554 & 823 \\
& Seytenga & Seytenga & 6,102 & 851 \\
Yatenga & Ouahigouya & Aorema & 22,091 & 578 \\
& & Bogoya & & 879 \\
& Namissiguima & Tougou & 6,754 & 687 \\
& Oula & Ziga & 5,536 & 610 \\
\hline
\end{tabular}


Nutrition Technical Assistance' project (FANTA) guidelines (Coates \& Bilinsky, 2007), based on generalised recall of conditions in the 'flush' and 'lean' periods (full results tabulated in Appendix Table B1). 'Household diet diversity scores' (HDDS) were calculated using a 12 food category scale as detailed in the FANTA guidelines (Swindale \& Bilinsky, 2006), based on recall of both periods. The recall period used in this study are an adaptation of existing guidelines, which suggest using 24-hour recall. This adaptation is designed to provide a more consistent metric - independent of the timing or duration of survey implementation. The 'flush' and 'lean' periods of the study were relative to the individual household, where a household could be 'food secure' but still report on the most lean period in the year. The indicator was also adjusted to enumerate the channel of HDDS categories (own-farm or purchased).

We calculated several variables on the household for the purpose of our analysis. These variables included the number of inhabitants and nutritional adequacy ratios. Adult equivalents were calculated based on energy requirements relative to adult female and males (averaged) between 25 and 50 (2500 kcal based on energy requirements from FAO, 2001; Claro et al., 2010). Energy adequacy ratios were calculated for home consumed crop and livestock products and protein adequacy ratios were calculated for livestock products only - based on food composition tables specific to west Africa (FAO, 2012) - and a coarse measure of daily energy (2500 kcal adult equivalent ${ }^{-1}$ day $^{-1}$ ) and protein requirements (56 g adult equivalent ${ }^{-1}$ day $^{-1}$ ).

Variables calculated to characterise the farm and livelihoods of rural households included: farm production diversity, farm practice adoption, livestock holdings, crop yields, market participation, income, cost of production, gendered control of income and wealth. Farm production diversity has been represented several different ways in the literature (e.g. species count in Bellon et al., 2016 and M'Kaibi et al., 2015, diet diversity aligned categories in Koppmair et al. (2016) and Jones (2016) and the debate between the approaches found in the dialogue between Berti, 2015 and Sibhatu et al., 2015). In the present study, we included a measure of crop and livestock diversity (count of species) and production diversity scores (count of products in the HDDS categories). A limitation of the production diversity scores is that they do not capture transformed crop and livestock products (e.g. into fats/oils).

Crop and livestock practice adoption was enumerated for each household, including adoption of irrigation, fertilisation, 'improved' seeds, exotic breeds and value addition (adoption rates presented in Appendix Tables B2 and B3). Livestock holdings were represented as Tropical Livestock Units (TLUs; conversion factors from Njuki et al., 2011). Yields for sorghum, millet and maize were calculated based on farmer reported harvest volumes and area planted. Crop market participation was represented as the proportion sold of the total calorific value of crops produced; livestock market participation was represented as the proportion sold of total protein produced from livestock products. The profitability of agricultural enterprises was calculated using respondent estimated cost of production (COP) values where possible (live animals and livestock products), otherwise gross income was reported (crops). Gendered control of income was represented as the percentage of total income that females have autonomous control over. The 'progress out of poverty index' (PPI) was calculated from 10 country specific questions on 
ownership of assets, education and household composition (Schreiner, 2011).

The cost of production for crops was impacted by item non-response. Due to the high instance of missing data (63\% of crops produced missing) it was not possible to impute these data. The result of this is that crop income is reported in this study as gross income, while livestock income is reported as net income. The proportion of crops sold was only enumerated for species that were marketed, as such missing values were instances where the proportion sold was zero.

\subsubsection{Statistical analysis}

Our analysis was undertaken in a step-wise manner to describe the potential pathways from intervention to improved food security. We assumed that food insecurity of access and diet diversity are determined by on-farm production and by off-farm sourcing through purchase (i.e. excluding hunting and foraging as there is little scope to intervene in these domains). We therefore first assessed the determinants of food security of access status (HFIAP), followed by the determinants of the on-farm and purchased channels of diet diversity. We also assessed to what extent intensification options are practiced by farmers.

Relationships between core indicators and independent variables were modelled using Bayesian regressions, with random effects from village groupings on the intercept. Regressions were weighted based on village populations to correct for over or under representation in some villages - i.e. the sum of weightings equated to the sample size for each province. Multinomial regressions were used to model HFIAP, with the least desirable food security outcome as the reference category. Household diet diversity scores were modelled using negative binomial regressions to model the overdispersion in the HDDS variable (i.e. variation not equal to the mean; McElreath, 2016). Differences between groups were also modelled using a specification equivalent to a t-test, but without assumptions of normality (Kruschke, 2013).

Models were built in an additive fashion, assessing all potential variables that could influence food security or diet diversity. Priors for the beta coefficients were informed by field knowledge of the interaction of farm and household variables with food security. These prior distributions were informative to the extent that the explanatory variables were expected to be positively associated with food security; these priors were weakly informative in the sense that the ranges of plausible beta coefficients were not restricted. Student's t-distributions were used to this effect, with the mass of the prior distribution being centred to reflect a positive association (centred at 0.5$)$, and the tails thicker than a normal distribution $(\mathrm{df}=1)$ to allow for a greater range of plausible values. If for example, we were to use an exponential prior distribution on beta coefficients for HDDS we would constrain the posteriors to a floor of zero and an unconstrained upper ceiling. This could be reasonable if we are confident that the explanatory variables have a positive relationship with the dependent variable - however, we have not constrained the models in such a way.

Models were chosen by minimising the Watanabe-Akaike Information Criterion (WAIC). Specifically, this means that if a variable is theorised to influence food security but is not significant in our models, then we only retain it if the WAIC is minimised. Further, convergence was as- 
sessed using trace plots, and the model's output Rhat, with chains and iterations adjusted as necessary.

Regressions were implemented in R using the 'BRMS' package (v 1.0.1; Buerkner, 2016). The 'BRMS' package compiles Stan code (http:/ / mc-stan.org/), which uses a hybrid Monte-Carlo Markov Chain (MCMC) method to approximate the posterior distribution of the desired conditional probabilities. Thus the logistic regression models estimate the log odds of an observation being in the higher performing category as opposed to the poorest performing category (severely food insecure) given a unit change in an independent variable, with random effects at the village level; the negative binomial models estimate the log of the expected counts holding all else constant.

\subsection{Results}

\subsubsection{Household characteristics and welfare in the two provinces}

There were significant differences in the livelihoods of households between the two provinces. Table 5.2 compares provinces based on variables related to livelihoods that have the potential to influence human nutrition. These variables are presented in the table as follows: resources (adult equivalents, land and livestock ownership), income (including gendered control), wealth (PPI), crop production (diversity, yields, market participation and energy adequacy), and livestock production (diversity, market participation and protein adequacy). There were notable differences between provinces in household demographics, land and land use, market participation, energy/ protein adequacy, and income (significant differences indicated in column 4 of Table 5.2). This section describes the variability and differences in livelihoods.

Household demographics differed across the two provinces. Households in Yatenga province tended to have more inhabitants and therefore, greater potential labour availability and marginally higher nutritional requirements. The household head in Yatenga province was generally older $(\mu=57, \mathrm{sd}=12)$ than in Seno province $(\mu=50, \mathrm{sd}=13$; results not shown), and for the vast majority (>93\%) of households in both provinces, the household head was male (results not shown).

Households in Yatenga province had larger parcels of land (median of 5 ha) than in Seno province (3.5 ha; Table 5.2), and the majority of households in both provinces utilised their land for mixed crop-livestock systems. Livestock holdings were similar across provinces, with medians of approximately five Tropical Livestock Units (TLUs); five households in Seno province, however, kept between 25 and 85 TLUs (results not shown). Land was cultivated in the 'flush' period with sorghum and millet by almost all farmers; cowpeas (Vigna unguiculata L.) were cultivated by the majority of farmers (99\% in Yatenga and 68\% in Seno); sesame (Sesamum indicum L.) and maize (Zea mays L.) was cultivated by approximately a quarter of farmers; groundnut (Arachis hypogaea L.) was cultivated by the majority (96\%) of households in Yatenga province and some households in Seno province (9\%); rice (Oryza spp.) production was exclusively in 
Yatenga province, largely in the Oula department. Vegetable cultivation was also more prevalent in Yatenga, with $20 \%$ of households cultivating up to 1.5 hectares (results not shown). As such, there was greater crop diversity in Yatenga province when compared to Seno province (Table 5.2).

Yields per hectare of staple crops were lower than the rain-water limited yield potential. Maize was the highest yielding staple crop, followed by the more commonly cultivated staples of sorghum and then millet. Crop yields for these three staple crops were marginally higher in Seno when compared to Yatenga (difference in millet yield was not statistically significant; Table 5.2). Households differed in their levels of practice adoption. Improved seeds, fertiliser and irrigation were more readily adopted in Yatenga province; and, value addition was common in both provinces. As a proxy for the diversity of cash crop yield differences, Figure 5.2 presents crop income by adopted practices and province. Crop income was significantly higher for households in Yatenga province that adopted irrigation, fertilisers and/or improved seeds (Wilcoxon rank sum test; $\mathrm{r}=0.51,0.20 \& 0.28$ respectively; $\mathrm{p}<0.01$ ). In terms of livestock, there was a low level of adoption of improved livestock breeds in both Seno and Yatenga provinces.
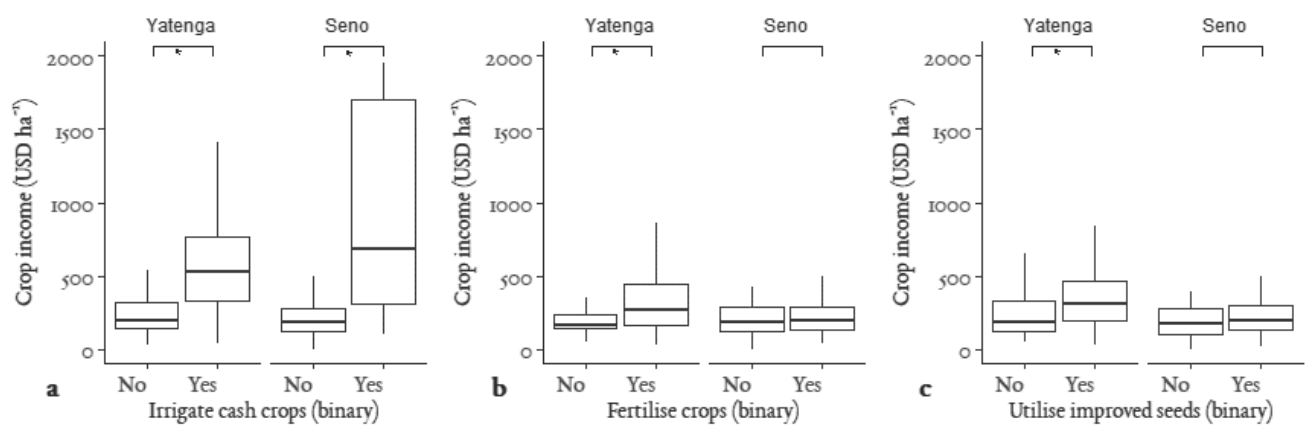

Figure 5.2 Gross crop income by practice adoption (irrigation, fertiliser and improved seeds) and province

*Groups have differing central tendencies

Larger land sizes and higher rates of market participation in Yatenga province resulted in a higher median energy adequacy ratio and higher median crop income, in comparison to Seno (Table 5.2). In Yatenga province, households at the median were potentially self-sufficient in energy needs; in Seno province, the median energy adequacy ratio was below sufficiency, with $80 \%$ of energy needs met by home consumption of crops and animal-source foods. Livestock market participation was more common in Seno province, as was consumption of homeproduced livestock products - as shown in the higher adequacy ratio of protein from animal sources and higher median income from livestock products (Table 5.2). 
Off-farm income was common across provinces (67\% of households in Yatenga, $57 \%$ of households in Seno), with the majority earning under US\$500 per household per annum. For those that did earn off-farm income, the central tendency of earnings was similar across provinces (median of US\$296 in Yatenga and US\$375 in Seno). Households in Yatenga generally had higher gross incomes, yet significantly less income from live animals (Table 5.2). Control of income did not differ significantly by province, where the majority $(85 \%)$ of households had less than $10 \%$ of income controlled by females. Households in Yatenga province tended to have a higher Progress out of Poverty Indicator score (PPI).

Table 5.2 Summary of resources and farming activity of households (median and IQR)

\begin{tabular}{|c|c|c|c|}
\hline Characteristic & $\begin{array}{l}\text { Yatenga } \\
(\mathrm{n}=200)\end{array}$ & $\begin{array}{c}\text { Seno } \\
(\mathrm{n}=200)\end{array}$ & \\
\hline Household inhabitants (adult eq.) & $10.4(5.4)$ & $6.8(5.3)$ & * \\
\hline Land area (ha) & $5.0(4.1)$ & $3.5(3.0)$ & * \\
\hline Livestock holdings (TLUs) ${ }^{a}$ & $5.20(4.8)$ & $5.1(9.0)$ & NS \\
\hline Off-farm income (USD year $\left.{ }^{-1}\right)^{b}$ & $83.25(451.62)$ & $74.92(416.24)$ & NS \\
\hline Crop gross income (USD year $\left.{ }^{-1}\right)^{b}$ & $354.56(637.55)$ & $0.00(8.11)$ & * \\
\hline Live animal net income (USD year $\left.{ }^{-1}\right)^{\mathrm{b}}$ & $12.49(97.90)$ & $60.84(248.72)$ & * \\
\hline Animal product net income (USD year $\left.{ }^{-1}\right)^{b}$ & $0(0)$ & $0(0)$ & NS \\
\hline Relative female control (\% income year ${ }^{-1}$ ) & $0(2)$ & $0(0)$ & * \\
\hline Progress out of Poverty Index score & $38(14)$ & $31(16)$ & * \\
\hline Number of crop species & $5(2)$ & $3(2)$ & * \\
\hline Crop production diversity & $2(1)$ & $2(0)$ & * \\
\hline Sorghum yield $\left(\mathrm{kg} \mathrm{ha}^{-1}\right)$ & $225.0(338.0)$ & $250.0(250.0)$ & * \\
\hline Millet yield $\left(\mathrm{kg} \mathrm{ha}^{-1}\right)$ & $184.0(350.0)$ & $217.0(350.0)$ & NS \\
\hline Maize yield $\left(\mathrm{kg} \mathrm{ha}^{-1}\right)$ & $650(985.0)$ & $720.0(725.0)$ & * \\
\hline $\begin{array}{l}\text { Crop market participation ( } \% \text { of total calo- } \\
\text { ries produced year }{ }^{-1} \text { ) }\end{array}$ & $41(26)$ & $0(1)$ & * \\
\hline $\begin{array}{l}\text { Crops consumed (kcal adequacy ratio adult } \\
\text { equivalent }{ }^{-1} \text { ) }\end{array}$ & $1.00(1.1)$ & $0.8(0.7)$ & * \\
\hline Number of livestock species & $4(2)$ & $4(2)$ & NS \\
\hline Livestock production diversity score & $1(0)$ & $2(1)$ & NS \\
\hline $\begin{array}{l}\text { Livestock market participation ( } \% \text { of protein } \\
\text { produced year }{ }^{-1} \text { ) }\end{array}$ & $0(0)$ & $0(3)$ & NS \\
\hline $\begin{array}{l}\text { Livestock products consumed (protein } \\
\text { adult equivalent }{ }^{-1} \text { adequacy ratio) }\end{array}$ & $0.02(0.02)$ & $0.15(0.27)$ & * \\
\hline \multicolumn{4}{|c|}{ CI does not cross zero. Provinces have differing central tendencies } \\
\hline
\end{tabular}




\subsubsection{Determinants of food (in)security of access}

Households had differing perceptions of the severity and duration of food insecurity. In Yatenga province, the most common period of perceived shortage was between February and October (27\% of households). In Seno province $43 \%$ of households perceived a shortage of food between June and October. Many households perceived that they had just enough food throughout the year (27\% in Yatenga and $20 \%$ in Seno), and a few households considered themselves to be food secure throughout the year (8\% in Yatenga and 6.5\% in Seno). There was only one household per province that perceived a shortage in the period between November and February, where the majority of households considered themselves to be secure during this time. For the following analysis, the 'flush' period can be considered as this period between November and February and the 'lean' period as being more variable in duration and severity - between February and October. Aid in the form of food or money was distributed in the study area. In Yatenga province, $40 \%$ of households received aid, whereas in Seno province, only two households received aid. The most common period of aid provision was between June and October (results not shown).

The majority of households in the 'lean' period were classified as either 'severely food insecure' or 'moderately food insecure' using the Household Food Insecurity Access Prevalence (HFIAP) indicator. In Yatenga province, approximately $31 \%$ of households were classified as 'severely food insecure' in the 'lean' period, $41 \%$ as 'moderately food insecure', $17 \%$ as 'mildly food insecure' and $10 \%$ as 'food secure'. The food security status of households in Seno province was worse, with over $84 \%$ of households classified as being 'severely food insecure' in the 'lean' period, $13 \%$ classified as 'moderately food insecure', $2 \%$ classified as 'mildly food insecure' and less than $2 \%$ classified as 'food secure'.

The HFIAS variable was modelled as a function of gross income (off-farm, crop and livestock), gendered control of income, energy adequacy, species diversity, whether aid was received and province of residence. There was a positive association between gross income and a higher food security of access status (i.e. not severely food insecure) in both provinces in the 'lean' period; this association was stronger in Yatenga - indicated by the significant interaction term (Table 5.3). The number of livestock species kept was positively associated with a higher food security of access status in the 'lean' period. Consumption adequacy, the number of crop species and receiving aid were not associated with food security of access in the 'lean' period (Table 5.3). Furthermore, there were no statistically significant associations identified for relative female control, higher food security status or the number of crop species cultivated in the 'flush' period. 
Table 5.3 Household Food Insecurity Access (logistic regressions $\dagger$ )

\begin{tabular}{lcc}
\hline Fixed effects & Lean period $^{\mathrm{a}}$ & Flush period $^{\mathrm{a}}$ \\
\hline Intercept & $-2.44(-5.20,0.04)$ & $1.08(-1.76,4.59)$ \\
Gross income ('000 USD year $\left.{ }^{-1}\right)$ & $0.34(0.08,0.64)^{*}$ & $0.16(0.02,0.36)^{*}$ \\
Food consumed from own farm (kcal adequacy & $-0.18(-0.45,0.01)$ & $0.02(-0.09,0.15)$ \\
ratio adult equivalent $\left.{ }^{-1}\right)$ & & \\
Number of crop species & $0.11(-0.16,0.37)$ & $0.09(-0.18,0.34)$ \\
Number of livestock species & $0.32(0.10,0.55)^{*}$ & $0.08(-0.12,0.28)$ \\
Aid received $^{\text {b }}$ & $0.08(-0.82,0.97)$ & $0.13(-0.93,1.17)$ \\
Province $^{c}$ & $-0.62(-2.22,1.11)$ & $-0.63(-2.30,1.20)$ \\
\hline Gross income:province $^{\text {con }}$ & $-0.53(-0.95,-0.17){ }^{*}$ & \\
\hline
\end{tabular}

${ }^{\dagger}$ Estimates are presented as posterior $\beta$ estimate and 95\% credible interval (CI)

* CI does not cross zero

${ }^{a}$ Reference category is 'severely food insecure of access'

${ }^{b}$ Reference category for dichotomous variable is 'no'

${ }^{c}$ Reference category is Yatenga province

\subsubsection{Determinants of household diet diversity}

The household diet diversity score differed across periods and provinces. In general, diets were more diverse in the 'flush' period and households in Yatenga province tended to have more diverse diets in the 'lean' period than households in Seno province (intercepts and province coefficient in Table 5.4 and medians in Table 5.5). Table 5.4 presents regression outputs for HDDS in both the 'lean' and 'flush' periods. In the 'lean' period there are interactions between gross farm income, off-farm income and province, which makes the associations difficult to interpret from the combination of coefficients; these interactions are best visualised as marginal effects. Figure 5.3 presents the associations between gross farm income and diet diversity in the 'lean' period. Gross farm income was positively associated with diet diversity in Yatenga province in the 'lean' period, particularly for households that did not earn off-farm income. In Seno province these associations differ, where diet diversity in the 'lean' period is predicted to increase as gross farm income increases - only when off-farm income is also earned. Households that did not earn off-farm income in Seno province were predicted to decreased in diet diversity in the 'lean' period as gross farm income increased.

Crop species diversity was also positively associated with diet diversity in the 'lean' period regardless of province. This statistically significant association, however, did not persist when assessing crop production diversity (count of crop products in HDDS categories) - which, by definition, has a closer association with HDDS.

We also assessed whether: a) the influence of farm income on diet diversity is mediated by female control, and b) food self-sufficiency is positively associated with diet diversity. However, female control of income and food self-sufficiency were not found to be associated with diet diversity in this study. 
Table 5.4 Household diet diversity (Mixed-effects negative binomial regressions $\dagger$ )

\begin{tabular}{|c|c|c|}
\hline Fixed effects & Lean period & Flush period \\
\hline Intercept & $1.26(1.03,1.50)$ * & $2.00(1.78,2.21)$ * \\
\hline Gross farm income (‘000 USD year ${ }^{-1}$ ) & $0.01(-0.06,0.07)$ & $0.02(-0.01,0.04)$ \\
\hline Off-farm income earned ${ }^{a}$ & $0.13(0.01,0.26)$ * & $0.05(-0.03,0.14)$ \\
\hline Relative female control (> $40 \%$ income year ${ }^{-1}$ ) & $0.08(-0.07,0.22)$ & $-0.04(-0.16,0.09)$ \\
\hline Number of crop species & $0.05(0.01,0.09)$ * & $0.01(-0.02,0.04)$ \\
\hline Number of livestock species & $0.00(-0.03,0.04)$ & $0.01(-0.01,0.04)$ \\
\hline Province $^{\mathrm{b}}$ & $-0.31(-0.52,-0.09)$ * & $-0.02(-0.26,0.22)$ \\
\hline Gross farm income:off-farm income earned & $0.03(-0.05,0.12)$ & \\
\hline Gross farm income:province & $-0.10(-0.19,0.00)$ * & \\
\hline Off-farm income earned:province & $0.08(-0.10,0.25)$ & \\
\hline Gross farm income:off-farm income earned:province & $0.16(0.04,0.28)$ * & \\
\hline
\end{tabular}

${ }^{\dagger}$ Estimates are presented as posterior $\beta$ estimate and 95\% credible interval (CI)

${ }^{*} \mathrm{CI}$ does not cross zero

${ }^{a}$ Reference category for dichotomous variable is 'no'

${ }^{b}$ Reference category is Yatenga province

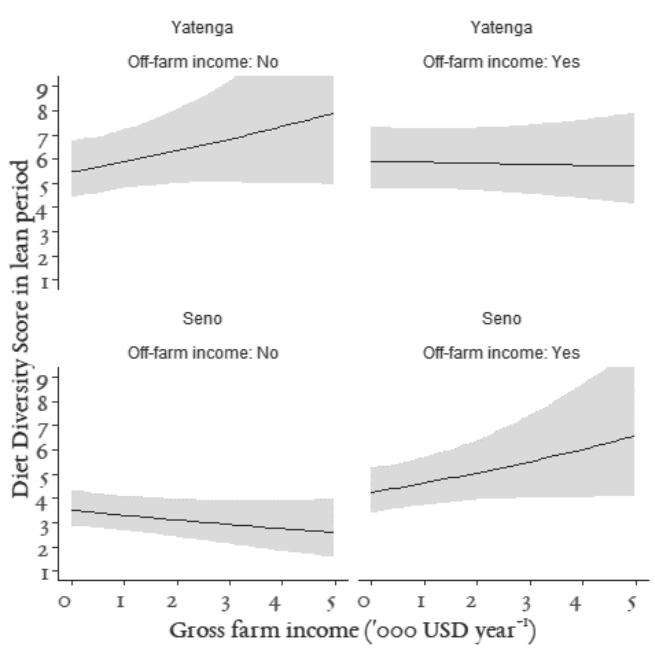

Figure 5.3 Household diet diversity dcore in the 'lean' period. Marginal effects of gross income ('000 USD) by off-farm income and province; dashed lines indicate uncertainty of marginal effect estimates at a $95 \%$ credible interval. All associations represented are statistically significant

The channel of access of food categories provides a disaggregated view of HDDS. In both provinces and periods, purchased diversity was a greater point of differentiation than farmsourced diversity (Table 5.5). The median number of purchased food categories was three times as much as own farm-sourced categories in the 'lean' period and more than double own farm- 
Table 5.5 Summary of Household diet diversity score for households (HDDS; median and IQR)

\begin{tabular}{lccc}
\hline & Seno $(\mathrm{n}=200)$ & Yatenga $(\mathrm{n}=200)$ & \\
\hline HDDS - lean period & $3.5(3.0)$ & $6.0(2.0)$ & $*$ \\
HDDS - flush period & $8.0(4.0)$ & $9.0(1.0)$ & \\
HDDS from farm production - lean period & $1.0(1.0)$ & $2.0(2.0)$ & $*$ \\
HDDS purchased - lean period & $3.0(3.0)$ & $6.0(2.0)$ & $*$ \\
HDDS from farm production - flush period & $3.0(2.0)$ & $3.0(2.0)$ & \\
HDDS purchased - flush period & $7.0(5.0)$ & $7.0(2.0)$ & \\
\hline
\end{tabular}

*Provinces have differing central tendencies

${ }^{a}$ Observations with no purchased food in the 'lean' period removed ( $n=8$ from Yatenga province)

Table 5.6 Household diet diversity accessed through own-farm channel (mixed-effects negative binomial regression $\dagger$ )

\begin{tabular}{lcc}
\hline Fixed effects & Lean period & Flush period \\
\hline Intercept & $-0.08(-0.69,0.52)$ & $0.75(0.38,1.13)^{*}$ \\
Number of crop species & $0.11(0.05,0.18)^{*}$ & $0.05(0.00,0.10)^{*}$ \\
Number of livestock species $_{\text {Province }^{\text {a }}}$ & $0.03(-0.03,0.08)$ & $0.05(0.01,0.09)^{*}$ \\
\hline
\end{tabular}

${ }^{\dagger}$ Estimates are presented as posterior $\beta$ estimate and 95\% credible interval (CI)

${ }^{*}$ CI does not cross zero

${ }^{a}$ Reference category is Yatenga province.

sourced categories in the 'flush' period. Farm-sourced categories were largely limited to the cereals and 'pulses, legumes and nuts' categories, with some households having the addition of vegetables, eggs, meat and/or milk (results not shown).

At the aggregate level, the own-farm channel of food access had a limited association with diet diversity. This is understandable, where in the 'lean' period, households in tended to source only one or two food categories from their farm (Table 5.5). At the disaggregated level, the number of crop species cultivated is associated with diet diversity accessed through the ownfarm channel in the 'lean' period (Table 5.6). In the 'flush' period, both the number of crop and livestock species are associated with diet diversity accessed through the own-farm channel. These associations persisted when assessing crop and livestock production diversity instead of species diversity (results not shown).

At the disaggregated level, there is greater uncertainty around the interactions between purchased diet diversity, farm income, off-farm income and province (Table 5.7). At this disaggregated level we also see an association between the number of crop species cultivated and purchased diet diversity in the 'lean' period. This association cannot be considered causal as the own-farm channel of food access is not represented in Table 5.7. Rather, this result informs us that the purchased channel to diet diversity is not impeded by crop species diversity. 
Table 5.7 Household diet diversity accessed through purchased channel (mixed-effects negative binomial regression†)

\begin{tabular}{|c|c|c|}
\hline Fixed effects & Lean period ${ }^{\mathrm{a}}$ & Flush period \\
\hline Intercept & $1.23(1.01,1.46)$ * & $1.81(1.51,2.12)$ * \\
\hline Gross farm income ('000 USD year ${ }^{-1}$ ) & $0.04(-0.02,0.09)$ & $0.00(0.00,0.00)$ \\
\hline Off-farm income earned ${ }^{\mathrm{b}}$ & $0.14(0.01,0.27)^{*}$ & $0.05(-0.05,0.15)$ \\
\hline Relative female control (> $40 \%$ calories year ${ }^{-1}$ ) & $0.07(-0.09,0.23)$ & $-0.07(-0.21,0.06)$ \\
\hline Number of crop species & $0.04(0.00,0.09)$ * & $0.02(-0.02,0.05)$ \\
\hline Number of livestock species & $-0.01(-0.05,0.02)$ & $0.01(-0.02,0.04)$ \\
\hline Province $^{c}$ & $-0.35(-0.52,-0.16)$ * & $0.00(-0.37,0.39)$ \\
\hline Gross farm income:off-farm income earned & $-0.00(-0.08,0.07)$ & \\
\hline Gross farm income:province & $-0.05(-0.12,0.03)$ & \\
\hline Off-farm income earned:province & $0.14(-0.05,0.33)$ & \\
\hline Gross farm income:off-farm income earned:province & $0.09(-0.02,0.20)$ & \\
\hline \multicolumn{3}{|c|}{${ }^{\dagger}$ Estimates are presented as posterior $\beta$ estimate and $95 \%$ credible interval $(\mathrm{CI})$} \\
\hline \multicolumn{3}{|c|}{${ }^{*} \mathrm{CI}$ does not cross zero } \\
\hline \multicolumn{3}{|c|}{${ }^{a}$ Observations with no purchased food in the 'lean' period removed ( $\mathrm{n}=8$ from Yatenga province) } \\
\hline \multicolumn{3}{|c|}{${ }^{b}$ Reference category for dichotomous variable is 'no' } \\
\hline
\end{tabular}

\subsection{Discussion}

Our analysis shows that in both provinces, the ability to purchase food is what differentiates the more food secure households from their less food secure counterparts. This finding does not detract from the utility of subsistence production - where consumption of own-farm food tended to cater for $91 \%$ of the annual energy requirements in Yatenga province and $72 \%$ in Seno province. Rather, purchasing power was the differentiating factor between households with food availability and those that are more food secure. This differentiation of households is most apparent in the dietary diversity indicator, where in both 'flush' and 'lean' periods, purchased food groups are more numerous than consumption of own-farm produced food groups (Table 5.5). This is logical in this setting where at maximum, households could source nine of the twelve categories from their farm (including processing oil); realistically, households were observed to source two to three categories from their farm in the 'flush' period (similar findings in Some \& Jones, 2018). These farm-sourced categories were largely limited to the cereals and 'pulses, legumes and nuts' categories. This finding is consistent with the majority of recent studies on the relative importance of purchased/farm-sourced foods (Bellon et al., 2016; Koppmair et al., 2016; Luckett et al., 2015; Sibhatu et al., 2015; Snapp \& Fisher, 2015; and Dillon et al., 2014). Similarly, Jones (2016), while emphasising the importance of diverse farm production across wealth strata, noted that the relationship between production diversity and diet diversity may be mediated through income generation (and thus purchased food), as well as farm-sourced food groups. With a growing consensus, can it then be concluded (as implicit 
in the aims of FAO, 2016) that food insecurity will be eradicated by doubling the 'agricultural productivity and incomes of small-scale producers' through on-farm means and off-farm employment/business? Food security is not simply limited to an individual's capacity to access calories. Other important dimensions of food security include: protein and micro-nutrient intake, resilient agricultural practices, maintaining genetic diversity of plants and animals, and maintaining access to culturally relevant foods (FAO, 2008). Further, the allocation of scarce household resources is not solely dedicated to achieving food security. Households use their income to pursue multiple goals (e.g. education), and the allocation of resources depends on needs (including food security and other higher order needs) and complex intra-household dynamics (Kazianga \& Wahhaj, 2017; Galiè et al., 2015).

\subsubsection{Towards a pathway model of food security}

The potential pathways from food and income availability to food security analysed in this study are represented diagrammatically in Figure 5.4. The diagram includes farm resources and activities from Table 5.1 and Figure 5.2 on the left-hand-side, representing the basis for food production. Both market and subsistence (own-farm) channels to food security are represented in a flow (indicated by arrows) from the left-hand-side towards the right-hand-side. Market participation, off-farm income and aid all contribute to net income. Mediated through expenditure and consumption decisions, these two channels of food access (purchased and own-farm) then have a bearing on the availability of food, energy access, diversity of food access, access to culturally relevant foods, and stability of food security over time (right-hand-side of Figure 5.4). The pathways from food and income availability to food security may also influence the pattern of food utilisation within a household. This dimension of food security, however, is beyond the scope of this study.

Pathways from livelihood to food security

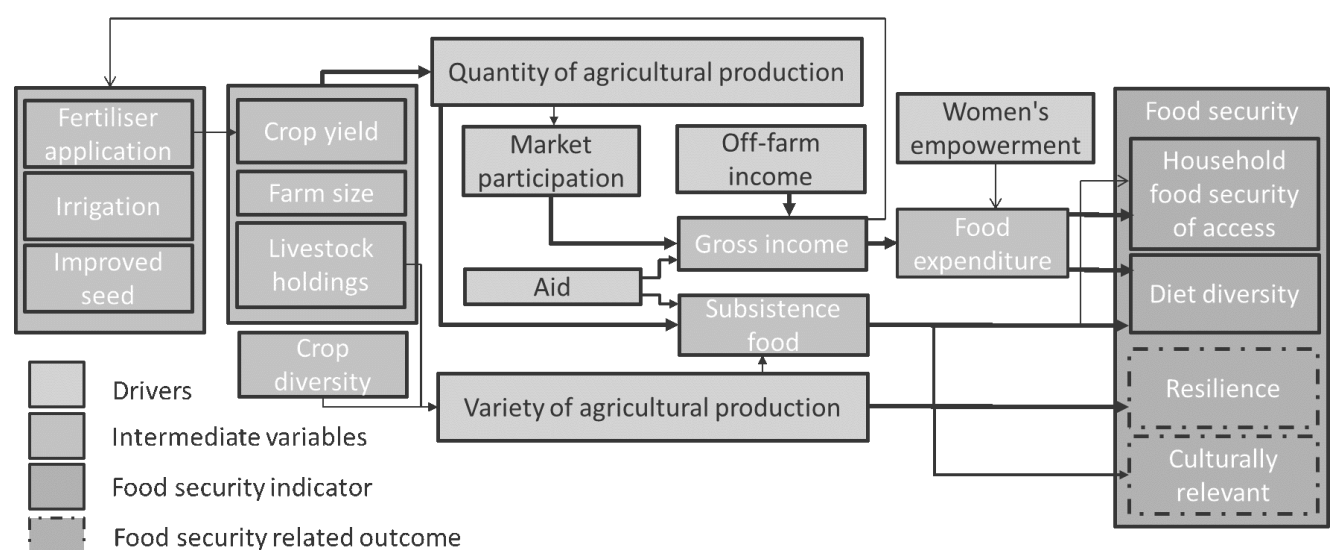

Figure 5.4 Pathways to food security outcomes (adapted from Jones, 2016) 
The relationship between crop diversity and the diversity of food access is a central area of inquiry in the literature. Previous studies have used this relationship to draw conclusions on whether to reduce hidden hunger by supporting market-oriented interventions (upper drivers in Figure 5.4) or by promoting agrobiodiversity (lower driver in Figure 5.4). Our results suggest that these goals do not have to be mutually exclusive. Both gross income and livestock species diversity, for example, are associated with improved food security of access. Similarly, both gross farm income and crop species diversity were associated with more diverse diets. Considering the implications of this more generally, livestock keeping - as part of a diversified portfolio - provides soil health benefits through the recycling of nutrients, as well as reducing livelihood risk by acting as a means to store capital (Moll, 2005; Slingerland, 2000). Similarly, diversified crop production can contribute to pest and disease management; reduce the market risk of volatile prices, and; can also be a part of a soil health strategy (e.g. nitrogen fixation or cover cropping to reduce erosion; Lin, 2011). Each of these benefits can improve the resilience of a farm and a livelihood (contributing to stability in Figure 5.4), specifically in relation to climatic or economic shocks.

The majority of households cultivated sorghum and millet. Access to such culturally relevant and nutritious foods is not guaranteed in the future (Schipanski et al., 2016; Pingali, 2015; Remans et al., 2014). The global trend of increasing food homogeneity (e.g. Khoury et al., 2014) has already resulted in traditional, lower yielding grains such as tef (Eragrostis tef), millet (Pennisetum glaucum L. and Eleusine coracana L) and sorghum (Bicolour) being substituted with maize (Zea mays L.), traditional vegetables replaced with market vegetables, and narrowed livestock genetic resources. The potential trade-offs between energy availability, resilience and the availability of culturally relevant and nutritious foods need to be considered to be able to optimise all aspects of food security. These trade-offs could be addressed - in part - by increased investment in locally relevant breeding (Sibhatu et al., 2015) and the coupling of soil health education with fertiliser-based intensification programs (Fonte et al., 2012). Plant breeding can work to optimise yields and micro-nutrient bioavailability (increasing translocation and reducing inhibition) of locally relevant crops; and soil health can maintain/increase yields and improve soil micro-nutrient availability for the plants and ultimately the household (de Valença et al., 2017; Slingerland et al., 2006).

The 'income pathway' to improved food security has not been fully captured in all its complexity in this study. We observed significant differences in median crop income based on practice adoption. This relationship may be bi-directional, with higher incomes allowing practice adoption (represented as an arrow from gross income to practices on the left-hand-side of Figure 5.2), and practice adoption increasing crop incomes. We also observed associations between gross income and food security (food security of access and diet diversity; Tables 5.3 and 5.4). These associations differed substantially by province and whether off-farm income was earned (in the case of diet diversity). In this study, however, we did not identify any associations or interactions between female control of income and food security - which by no means negates the reality that intra-household dynamics influence food access or food utilisation (e.g. Mason et al., 2015). 
Off-farm income was more common in Yatenga (67\% of households in Yatenga compared to $57 \%$ in Seno), but proved to be a greater differentiating factor in Seno. Having a wage or business income is an apparent advantage over a reliance on agriculture (Reardon et al., 1992). In Seno this advantage provides a pathway to a greater variety of food categories in the 'lean' period - when households are at their most vulnerable. From a policy and intervention perspective, there are macro-economic factors, regional comparative advantages and a range of other elements that drive the opportunities to engage in employment or business. With a growing rural population there is a need to improve rural non-farm opportunities (e.g. Jayne et al., 2014; Haggblade et al., 2010; Tiffen, 2003). This finding suggests that interventions to stimulate such opportunities can be targeted at specific regions or communities to improve household food security. A challenge that may arise in the process of stimulating off-farm opportunities, however, is that the individuals that capture them may not be the most in need; evidence suggests that wealthier households have a greater capacity to gain employment or invest in a non-farm business (Davis et al., 2010; Haggblade et al., 2010; Reardon et al., 1992). The complexities of the labour market are such that not only do the opportunities have to exist, but there also needs to be the availability of quality education options (Jayne et al., 2014) and functioning land tenure, credit and insurance markets (Barrett et al., 2001).

Aid (a potential driver of improved food security in Figure 5.4) was received by a small portion of households in Yatenga province. There was no significant difference in food security status between recipients of aid and other respondents. This is not enough, however, to conclude whether this aid was effective in improving the food security of these households.

The experimental design of this study allowed us to improve our understanding of the causal pathways to improved food security in two subtly contrasting communities in drought prone regions of Burkina Faso. There are, however, some methodological limitations to our approach. Firstly, the sampling of this study was limited to eight villages within seven departments with some departments of Yatenga province excluded from sampling due to safety concerns. Conflict has been identified as an important driver of food insecurity (FAO et al., 2018) and so the results of this study cannot be taken to be representative of northern Yatenga. The limitation in sampling, however, necessitated the use of 1) weightings to correct the representativeness of our study and 2) a power analysis to assess the risk of Type II errors. A post-hoc analysis indicated that at a power of 0.8 (20\% risk of Type II error), these data allowed the detection of small differences in central tendency (Cohen's $d<0.2$; results not tabulated elsewhere). Secondly, we enumerated food security indicators and farm production/marketing based on respondent recall. The complexity and length of recall may have negatively impacted measurement precision and item non-response (Beegle et al., 2012). To counteract this, we designed the survey to minimise respondent fatigue and we trained enumerators to cross-check responses to more complex questions. These design features, unfortunately, did not enable us to enumerate the cost of crop production - which suffered from item non-response. Thirdly, as identified by Some \& Jones (2018), we interviewed the household head on-farm activities - potentially underestimating production diversity. 
The food security status of households is most substantially and positively influenced by a household's ability to purchase food. This finding should not detract from the essential role played by subsistence production. Rather, market-orientated agriculture and production for home consumption, as shown by households in this study, can be combined as part of a broader livelihood strategy. Such livelihood strategies can improve food access and the stability of food security in both the 'flush' and 'lean' periods.

\subsection{Acknowledgments}

We thank the field team for their dedication and the participating rural households for their candor. This study was made possible by the support of the American People provided to the Feed the Future Innovation Lab for Sustainable Intensification through the United States Agency for International Development (USAID). The contents are the sole responsibility of the authors and do not necessarily reflect the views of USAID or the United States Government. Program activities are funded by the United States Agency for International Development (USAID) under Cooperative Agreement No. AID-OAA-L-14-00006. Also support by the CGIAR Research Program on Livestock is gratefully acknowledged. 


\section{Chapter 6}

\section{Dietary gaps in sub-Saharan Africa: prevalence and implications for agricultural interventions}

This chapter is based on:

Fraval, S., Hammond, J., Bogard, J. R., Ng'endo, M., van Etten, J., Herrero, M., Oosting, S. J., de Boer, I. J. M., Lannerstad, M., Teufel, N., Lamanna, C., Rosenstock, T. S., Pagella, T., Vanlauwe, B., Dontsop-Nguezet, P. M., Baines, D., Carpena, P., Njingulula, P., Okafor, C., Wichern, J., Ayantunde, A., Bosire, C., Chesterman, S., Kihoro, E., Rao, J., Skirrow, T., Steinke, J., Stirling, C. M., Yameogo, V., van Wijk, M. T. (submitted). Global Food Security 


\section{Abstract}

Efforts to estimate the prevalence of food insecurity and to understand its associations with rural livelihoods has been hampered by limitations in temporal and spatial representativeness. Food balance sheets provide scalable estimates of chronic and hidden hunger, but fail to represent food access, stability and their causal linkages. In contrast, rural household surveys represent detailed conditions for one or two points of time, but are influenced by survey timing and are often limited in geographical coverage. This study draws on a large sample of rural land-holding households in SSA ( $\mathrm{n}=6,353$; $54 \%$ of which were from semi-arid zones) to estimate the prevalence of dietary gaps and to understand their associations with rural livelihoods and food sourcing behaviour throughout the year. Dietary gaps were identified using diet diversity and food access indicators. Dietary diversity and channel of access (farm or purchased) were enumerated for the 'flush' and 'lean' periods and food security of access was enumerated for the lean period only - making the results of this study independent of survey timing. The identified dietary gaps were then compared with quantified dietary adequacy ratios of subsistence households, and only included in further analysis if there was a statistically significant association. As many as $40 \%$ of households were classified as severely food insecure (in terms of food access) in the lean period. Prevalence of micronutrient dietary gaps were high, with $68 \%$ lacking daily calcium sources, $38 \%$ lacking daily sources of iron, 37\% lacking daily sources of thiamine, 51\% lacking daily sources of riboflavin, $44 \%$ lacking daily sources of niacin, 35\% lacked a source of vitamin B6 and 65\% lacking daily sources of vitamin B12. Vulnerability to dietary gaps differed by household composition and agricultural livelihood characteristics. Market participation, livestock product diversity, crop production diversity, gross income and off-farm income were all positively associated with food security of access and micronutrient access. These associations differed between agro-ecological zones and were predicted to have a limited impact on dietary gaps. Households with a livestock component to their farm consumed more milk, meat and eggs (sources of calcium, riboflavin and vitamin B12). Dairy, fruit and vitamin A-rich produce were predominantly accessed through the farm channel. Households with a livestock component to their farm had a lower prevalence of severe food insecurity and gaps in micronutrient sources.

These findings have implications for the development of nutrition-sensitive and nutrition-specific interventions. Interventions need to be tailored to agroecological zone, household composition, scale of operation and production mix. Increasing income will not necessarily result in improved diet diversity or healthy dietary choices. Interventions focused on income generation should monitor and promote crop and livestock production diversity and provide nutrition education. Our analysis suggests that it is unrealistic or may even be counterproductive to try and shift overall diet diversity substantially, rather it is more useful to target individual food groups that will benefit human nutrition. 


\subsection{Introduction}

Almost one in four people in sub-Saharan Africa (SSA) were estimated to be undernourished in 2017, representing about one-third of the 821 million people suffering from chronic hunger globally (FAO et al., 2018). In addition to a high prevalence of chronic hunger in SSA, many more people suffer from micronutrient deficiencies (Harika et al., 2017; Kumssa et al., 2015; Joy et al., 2014). These deficiencies increasingly co-exist with instances of obesity within the same communities - forming a triple burden on human health and society (May, 2018). Malnutrition is now the greatest risk factor driving a rising global noncommunicable disease burden (GBD 2016 Risk Factors Collaborators, 2017), having direct implications for child growth failure, neonatal disorders, immune function, cognitive function, diabetes, heart disease and cancer (James, 2018; Prentice, 2018; de Pee et al., 2017; Pisa et al., 2017; Akombi et al., 2017; Micha et al., 2015). These burdens will only intensify as rural and urban populations grow, diets change and wealth is further concentrated (FAO et al., 2018; Popkin, 2014).

The majority of the food in SSA is produced by smallholder farmers (Herrero et al., 2017) while they are the most vulnerable to food insecurity and poverty (Fanzo, 2018; Sibhatu \& Qaim, 2017). Hence, smallholder farmers are a crucial entry point for agricultural orientated interventions to improve food and nutrition security. A substantial number of observational studies have assessed the linkages between agriculture and nutrition in the past three years (e.g. Ruel et al., 2018; Gillespie et al., 2017). Despite progress in the analysis of existing observational data and ex-post evaluation of nutrition-sensitive interventions, much remains to be understood with respect to the pathways of intervention to improved food and nutrition security of rural households (Mary et al., 2018).

The causal pathways from intervention to food and nutrition security outcomes are not straightforward (Carletto et al., 2017). An important question, not yet answered by the existing literature (e.g. Ruel et al., 2018; Gillespie et al., 2017) relates to how market participation mediates food and nutrition security in rural communities - especially access to and consumption of diverse diets. Farmers have two ways to obtain their food: 1) growing food crops and/or rearing livestock to consume the products, or 2) selling these products and use the income to buy food for their own consumption. Whether production-based or income-based channels are more important for food and nutrition security is a question without a straightforward answer. For example, increased incomes and energy availability are necessary for alleviating undernourishment but are not sufficient for addressing chronic or hidden hunger (Gödecke et al., 2018; Schipanski et al., 2016; McDermott et al., 2015; Hoddinott, 2012). These causal pathways need to be considered in targeting, designing and implementing nutrition-sensitive interventions of agricultural production systems and value-chains.

Evaluating food access and micro-nutrient deficiencies has traditionally been time-consuming and invasive. More recently, however, proxies have been introduced to enable wide-scale monitoring and evaluation. Food security of access scales and diet diversity scores (to a greater extent) have been favourably assessed as proxies for nutrient adequacy (Lachat et al., 2017; Steyn 
et al., 2006; Torheim et al., 2004) diet quality (Savy et al., 2005) and child growth/stunting (Rah et al., 2010; Saha et al., 2009; Arimond \& Ruel, 2004). The development of these time-efficient metrics has allowed for food and nutrition security indicators to be incorporate into large-scale, multi-purpose farm household surveys. Despite this progress, complications arise when relating farm information and nutrition information: there is a systematic mismatch of time scales. Food and nutrition security is typically assessed over short time scales (e.g. $24 \mathrm{~h}$ or weekly recalls) whereas farm production and consumption of agricultural produce are typically estimated at annual or seasonal time scales (Herrero et al., 2007). Using the annual timescales commonly found in agricultural surveys can create problems because diets of rural households are often highly variable throughout the year (Sibhatu \& Qaim, 2017). For instance, diets in the period after crop harvest are substantially different from the most difficult period of the year. This variability in diet means that survey timing can significantly influence the dietary results obtained in the survey. This means that from a nutrition perspective, surveys need to be executed throughout the year to characterise that temporal variation, while agricultural surveys are usually only executed only once or twice in a year.

This present study seeks to combine diet diversity and food (in)security indicators with householdfarm characteristics to estimate prevalence of dietary gaps and to understand their associations with rural livelihoods and food sourcing behaviour throughout the year. Agricultural systems in SSA are diverse and dynamic, and agro-ecological conditions drive their occurrence (e.g. Garrity et al., 2012). The amount and timing of rainfall determine which crops can be grown and when they can be harvested, thereby affecting the availability of food items throughout the year. The agro-ecological conditions also drive the occurrence of livestock systems, with (agro)pastoral systems in dry areas, and mixed crop-livestock systems in higher rainfall zones. We quantify how farming system characteristics (with a focus on livestock holdings e.g. Headey et al., 2018a and crop production diversity e.g. Jones, 2016) shape the different pathways to food security of access, more diverse diets and access to micronutrients. We do so, by modifying existing diet diversity and food (in)security indicators to 1) provide an overview of food security across the year - independent of survey timing, and 2) identify the channel of food access (e.g. own-farm or purchased). For this purpose, we use the food security indicators included in the 'rural household multiple indicator survey' (RHOMIS) initiative (Hammond et al., 2017), with data collected from almost 8000 households in eight different countries in sub-Saharan Africa.

\subsection{Methods}

\subsubsection{Household data}

This study draws on responses from 7,708 rural land-holding households in SSA. Interviews were conducted through twelve projects operating across eight countries between 2016 and 2018 (Appendix Table C2 provides a summary of sample size by project and country). For the purpose of this meta-analysis, we filtered the database based on data quality criteria, which 
resulted in 1,355 observations being removed (Appendix Table C2 summarises thresholds for excluding observations).

The 'rural household multi-indicator survey' (RHOMIS) was utilised for data collection in all projects, eliciting information about the household composition, farm characteristics, diet diversity and food (in)security of access. The survey is designed to minimise the time burden on the interviewee, to maximise the reliability of responses, and to improve consistency between different studies (described further in Hammond et al., 2017). Households were sampled using a multi-stage clustered design with random selection of villages and households. The sampling of each study was designed to be representative of the rural land-holding population in a given location, except for one study in Tanzania where livestock holders were exclusively targeted ( $14 \%$ of observations in this study).

We adapted existing diet diversity and food (in)security indicators for the purpose of this study. First, our Modified Household Diet Diversity (MHDD) indicator was based on the 'minimum diet diversity for women' (MDD-W) indicator, which is based on a count of 10 food categories (FAO \& FHI360, 2016). The modification to the MDD-W indicator allowed households to recall the frequency of access for each food category in the best and worst month (referred to as 'flush' and 'lean' period herein) rather than 24-hour recall across multiple visits in a year. As an extension of diet diversity indicators, we also asked households to recall the channel of access for each food category - farm, purchased or free/traded. Second, the 'household food security of access prevalence' (HFIAP) indicator is based on a series of nine questions of increasing severity, from worry about food availability to missing an entire day of food due to availability (questions provided in Appendix Table C8; Coates \& Bilinsky, 2007). Severe food insecurity (of access) is defined as regularly eating smaller meals than desired, regularly eating fewer meals than desired or worse. Our 'modified household food insecurity of access prevalence' (MHFIAP) indicator recorded conditions in the worst month experienced ('lean' period) by the household during the previous 12 months (a modification of the 24-hour recall period recommended in the 'Food And Nutrition Technical Assistance' (FANTA) guidelines; Coates $\&$ Bilinsky, 2007). The modifications to the recall period were made so that indicator results would be independent of survey timing and provide greater temporal coverage, rather than providing a snapshot of one or two days.

Our analysis also incorporated demographic, agro-ecological, farm, and economic metrics. Adult equivalents were calculated as the ratio of energy requirements for an age and gender class relative to the average energy requirement of adult males and females between 25 and 50 ( $2500 \mathrm{kcal}$; following Claro et al., 2010 and using energy requirements from FAO, 2001). Agro-ecological zone (AEZ) was extracted from the Harvest Choice (2015) AEZ-16 spatial layer based on globalpositioning system (GPS) points. Market participation was calculated as the proportion of crop and livestock calories sold. Tropical Livestock Units (TLUs) were calculated using conversion factors provided by Njuki et al. (2011). The 'progress out of poverty index' (PPI) was calculated using 10 questions on household characteristics (e.g. housing structure, asset ownership, school attendance) that are correlated with country specific poverty levels (Hammond et al., 
2017). Income was calculated based on responses to questions about farm sales and off-farm income. To compare income across countries, we express these values in purchasing power parity (PPP). Purchasing power parity was calculated using the World Bank database (World Bank, 2018) and exchange rates were taken from the time of survey execution. We also included a metric on recall length - defined as the number of months elapsed at the time of interview since the recall period in question (flush/lean period).

\subsubsection{Triangulation to identify energy, protein and micronutrient gaps}

We used the MHDD and MHFIAP indicators as proxies for dietary gaps in energy, protein and micronutrients. To assess the reliability of these proxies, we compared dietary gaps identified through these indicators with dietary adequacy ratios (overview provided in Figure 6.1). Adequacy ratios were computed as the difference between a household's nutrient requirements and nutrient availability. This triangulation was carried out for 'subsistence farming' households only (households that do not purchase any MHDD food categories; $\mathrm{n}=264$ ), due to data limitations on purchased food volumes. In this triangulation, we only included energy, protein and the 11 micronutrients with established associations with the food categories in the MDDW indicator, as identified by Martin-Prével et al. (2015). Thus, the micronutrients assessed in this triangulation were: calcium, iron, zinc, vitamin A, thiamine, riboflavin, niacin, vitamin B6, folate, vitamin B12 and vitamin C. This triangulation allowed us to identify which quantified dietary adequacy ratios are associated with dietary gaps identified in the MHDD and MHFIAP indicators.

The computation of household nutritional requirements was based on three established estimates: energy requirements (FAO, 2001), safe level of protein intake (WHO \& FAO, 2002) and recommended nutrient intakes (RNI) of micronutrients (FAO \& WHO, 2004). Energy requirements were based on gender, an assumed increase in weight/basal metabolic rate (BMR) with age, an assumed moderate physical activity level (PAL value between 1.7 and 1.99) and assumed good health. With these assumptions, the estimated kilocalorie requirement for an adult male between 25 and 50 was $2750 \mathrm{kcal}$ and $2250 \mathrm{kcal}$ for females. Protein intake requirements were based on age and gender categories for children and adolescents and weight for adults. Micronutrient RNIs were based on age and gender categories. The total household requirements for each of these nutrients were then calculated as the sum of requirements by gender and age requirements. Variations in nutritional requirements due to health status, level of activity and interactions between nutrients (e.g. vitamin D promoting calcium absorption) were not accounted for. These limitations may have resulted in underestimates of nutrient requirements for households with poor health status and those that are more active. The resulting quantified dietary adequacy ratios of subsistence households are presented as boxplots in Appendix Figures $\mathrm{C} 1$ and $\mathrm{C} 2$.

Household nutrient availability was computed using food consumption volumes, which were estimated using farmer reported details of crop and animal-sourced food production, and their estimated proportion consumed. Meat yield from farm slaughtered animals was estimated based on approximate live weights and carcass composition; all households were assumed to 


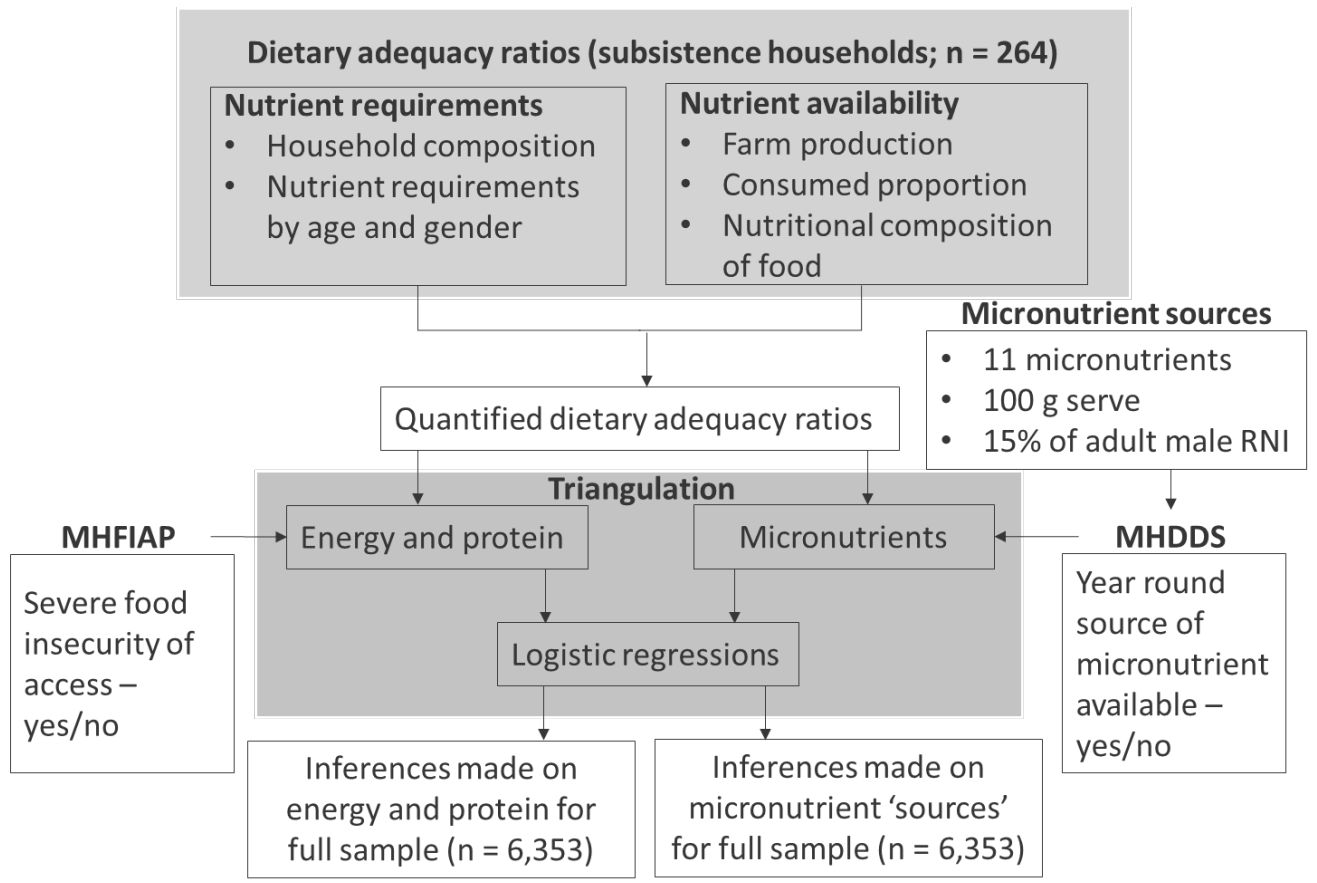

Figure 6.1 Triangulation of dietary gaps. Dietary adequacy ratios are quantified as the difference between household nutrient requirements and nutrient availability. Sources of micronutrients are identified as food categories (MHDD) that contain at least 15\% of a daily adult male's Recommended Nutrient Intake (RNI). Micronutrient sources and severe food insecurity (MHFIAP) are retained in subsequent analyses if they are associated with their respective quantified gaps

consume liver from the animals that they had slaughtered - based on dietary preferences for liver and the need to maximise carcass utilisation. Milk yield (minus suckling) was estimated based on farmer estimates of average daily litres on a seasonal basis (flush and lean), with an assumed lactation length of 270 days. The nutrient availability of farm-sourced foods was derived from food composition tables specific to Tanzania $\left(\mathrm{n}_{\text {fooditems }}=62\right.$; Lukmanji et al., 2008) and supplemented with region-specific values (e.g. fonio millet in West Africa; FAO, 2012) and USDA food composition tables where necessary $\left(\mathrm{n}_{\text {fooditems }}=34\right.$; USDA, 2017). Zinc and iron content was adjusted based on an estimated high dietary phytate to zinc supply ratio (molar ratio > 20 in SSA; Joy et al., 2014; defined as high by Brown et al., 2001) and the common practice of fermenting cereals (i.e. reducing phytate content, resulting in improved bioavailability; Nout, 2009). Thus, the bioavailability of zinc was assumed to be 'moderate', and a 10\% bioavailability was assumed for iron - which was held constant across households. The inedible proportions of food items were removed from the nutrient estimate calculations based on United States Department of Agriculture (USDA) proportion values. Modelling was focused on the total availability of nutrients and so did not factor in discarded edible portions (food 
waste), nor food transformations (e.g. flour and oil).

The association was then assessed between household dietary adequacy ratios and dietary gaps identified through the MHDD and MHFIAP indicators. Severe food insecurity- as identified in the MHFIAP indicator - was considered as a proxy for energy and protein adequacy ratios. Gaps in micronutrient 'sources' - as identified through the MHDD indicator - was compared with micronutrient adequacy ratios. To assess whether households had year-round daily sources of individual micronutrients, we first identified the micronutrients associated with each MHDD food category. A 'source' food category of a given micronutrient was defined by having an average availability of at least $15 \%$ of the daily RNI for an adult male per $100 \mathrm{~g}$ serve (FAO, 1997). The average availability per MHDD category was based on the weighted average nutrient composition of farm production (based on sampled households), on a country and (if data limitations required) a regional basis (i.e. East, central and West Africa). As an exception, dairy was assumed to be a source of calcium, with a $100 \mathrm{~g}$ serve estimated to meet $12 \%$ of an adult male's daily requirements. In East Africa, for example, three food categories in the MHDD indicator are sources of five or more micronutrients: nuts and seeds; meat, fish poultry; and vitamin A rich vegetables (refer to Appendix Table C4 and Appendix Table C5). In contrast, dairy and eggs only provided a limited number of micronutrients but were important sources of those that were less common, namely: calcium (dairy), vitamin A (eggs) and vitamin B12. We assessed whether households had at least one source in both the flush period and lean period and if so, the household was categorised as having a year-round source of that particular micronutrient; if not, they had a dietary gap for that micronutrient.

The statistical associations between quantified adequacy ratios and dietary gaps identified through indicators (gaps in MHDD 'sources'; MHFIAP - severely food insecure) were assessed using logistic regressions for subsistence households only. In this specification, a binary dependent variable (availability of nutrient source through MHDD/HFIAP indicators - yes/no) was modelled with the corresponding adequacy ratio as the independent variable. Logistic regression was used in favour of alternative statistical approaches so that our decision rule on whether to include/exclude a nutrient in further analysis could incorporate the direction of association (expected to be positive) as well as the statistical significance of the association (expected to have a p-value of less than 0.05).

\subsubsection{Associations between dietary gaps and livelihood characteristics}

The prevalence of dietary gaps were weighted based on population estimates of the administrative unit that the households were sampled to represent. Population estimates of the year 2015 were extracted from the 'gridded population of the world' dataset (version 4; CIESIN, 2017) - masking out densely populated areas (>1000 people per $\mathrm{km}^{2}$ ). Observations were then weighted based on the average population density in the administrative unit (persons per $\mathrm{km}^{2}$ ), relative to other administrative units - such that each household within an administrative boundary was weighted equally and relative to other administrative boundaries. The weights of studies that only sampled livestock keeping households were adjusted, assuming that they represent $50 \%$ of the rural population. The sum of weights equated to the sample size. 
We model associations between nutrient gaps and household composition, farm production mix, market participation and income. Agroecological zone (AEZ) was also included as fixed effects in the regression models to control for the effects of differences between semi-arid locations (Length of growing period; LGP 75 - 180 days) and humid/sub-humid locations (LGP > 181 days). We incorporated random effects on the intercept from villages nested within projects in our models. We used negative binomial regressions with mixed-effects to model overdispersed count variables (MHDD) and logistic regressions with mixed-effects to model whether households were severely food insecure (of access) or not and whether households have a gap in sources of micronutrients.

To further explore modelled associations, we developed a farm typology based on the composition of farm production - which influences both cash availability and diversity of ownfarm food availability (Headey et al., 2018a; Jones, 2016). Farms were classified as 'specialised cropping' if they reported two or fewer crop species as being important for their livelihood or sourced two or fewer plant-based food categories (e.g. 'legumes' or 'leafy vegetables') from their farm; farms with three or more crop species/plant-based categories were classified as having 'diverse cultivation'. Livestock holdings (animals under the care of the household) were represented as Tropical Livestock Units (TLU), and households with over 1.5 TLUs (the equivalent of one head of cattle - 1 TLU, one sow - 0.3 TLU and five chickens - 0.04 TLU) were categorised as having a livestock product (meat, milk or eggs) component to their farm, in combination with their cropping activities. This threshold was set marginally higher than one TLU to reduce instances of false positive classifications of households keeping an ox or donkey (0.8 TLU) for draught power purposes. We identified four distinct farm types: 'Specialised cropping', 'Diverse cropping', 'Specialised cropping and livestock', and 'Diverse cropping and livestock'. We use this farm typology to characterise channels of food access and to explore the prevalence of food insecurity and dietary gaps (Appendix Table C7 provides a regional breakdown of farm types.

Differences between farm types were modelled using mixed-effects linear and logistic regressions, with random effects on the intercept from villages nested within projects. Dependent variables of these models included farm-household characteristics, consumption behaviour and dietary gaps. The independent variable in these models was either farm type or an aggregation of farm types (e.g. livestock keeping). All regression models were estimated using a hybrid Monte-Carlo Markov Chain (MCMC) method, implemented in R using the 'BRMS' package (v 1.0.1; Buerkner, 2016). Weakly informative priors (Student's t-distribution with $\mathrm{df}=5$ ) were used, allowing extreme values but maintaining an expectation of minimal association (i.e. central tendency near zero). The posterior distributions were analysed and if $95 \%$ of the density was above or below zero then it was considered to be significantly associated. Models were based on a core set of household and farm variables, with interactions tested additively. All regressions were weighted by population density - minimising bias in generalisations to the sampled locations. 


\subsection{Results}

\subsubsection{Triangulation to identify energy, protein and micronutrient gaps}

Only 7 of the 11 micronutrients met our triangulation decision rules of statistical significance, a positive association (Table 6.1). Thus, the nutrients included in the remainder of the results were limited to calcium, iron, thiamine, riboflavin, niacin, vitamin B6 and vitamin B12. Severe food insecurity (of access) in the lean period was associated with year-round energy and protein sufficiency and thus retained as a proxy to these dietary gaps.

Table 6.1 Associations between quantified adequacy ratios and dietary gaps identified through indicators for subsistence households $(n=264)$. Nutritional elements with an inconsistency were excluded from further analyses (Logistic regression outputs - beta coefficent estimate, standard error and statistical significance)

\begin{tabular}{lccc}
\hline Nutrient & Estimate (SE) & Significance & Retained \\
\hline Energy & $1.00(0.42)$ & $*$ & $\mathrm{x}$ \\
Protein & $0.94(0.40)$ & $*$ & $\mathrm{x}$ \\
Calcium (Ca) & $2.78(0.75)$ & $*$ & $\mathrm{x}$ \\
Iron (Fe) & $0.84(0.40)$ & $*$ & $\mathrm{x}$ \\
Zinc (Zn) & $0.32(0.41)$ & & \\
Vitamin A & $0.92(0.46)$ & & $\mathrm{x}$ \\
Thiamine & $0.96(0.42)$ & $*$ & $\mathrm{x}$ \\
Riboflavin & $0.95(0.46)$ & $*$ & $\mathrm{x}$ \\
Niacin & $0.94(0.42)$ & $*$ & $\mathrm{x}$ \\
Vitamin B6 & $0.80(0.43)$ & $*$ & $\mathrm{x}$ \\
Folate & $-0.40(0.40)$ & & \\
Vitamin B12 & $2.30(0.57)$ & $*$ & \\
Vitamin C & $-0.85(0.54)$ & & \\
\hline 95\% CI does not & & &
\end{tabular}

95\% CI does not cross zero

$\mathrm{x}=$ triangulation decision rules have been met

\subsubsection{Prevalence of severe food insecurity of access and dietary gaps}

Severe food insecurity (of access) was widespread across the surveyed households $(n=6,353)$. In the lean period as many as $40 \%$ of households were classified as severely food insecure according to the food access assessment with the HFIAP indicator. For micronutrients, $68 \%$ of households did not have a year-round daily source of calcium, 38\% lacked a daily source of iron, $37 \%$ lacked a daily source of thiamine, $51 \%$ lacked a daily source of riboflavin, $44 \%$ lacked a daily source of niacin, 35\% lacked a source of vitamin B6 and 65\% lacked a daily source of vitamin B12 (Table 6.2). 
Table 6.2 Prevalence of dietary gaps weighted by population $(n=6,353 ; \%$ of weighted sample)

\begin{tabular}{llc}
\hline Proxy for dietary gap & $\begin{array}{l}\text { Dietary } \\
\text { requirement }\end{array}$ & Prevalence \\
\hline Severe food insecurity & Energy and protein & 40 \\
\hline Source category accessed & Calcium (Ca) & 68 \\
daily throughout the year & Iron (Fe) & 38 \\
& Thiamine (B1) & 37 \\
& Riboflavin (B2) & 51 \\
& Niacin (B3) & 44 \\
& Vitamin B6 & 35 \\
& Vitamin B12 & 65 \\
\hline
\end{tabular}

There are several factors associated with MHFIAP, MHDD and micronutrient sourcing (Table 6.3). Regression results show that the number of household inhabitants was positively associated with diet diversity in the flush and lean periods as well as vitamin B12. The number of household inhabitants was also positively associated with the availability of year-round sources of thiamine and riboflavin in humid/subhumid zones. Female headed households were negatively associated with food security of access in the lean period and were less likely to have year-round sources of calcium. Having children under the age of 10 in the household was negatively associated with food security of access and diet diversity in the lean period, and negatively associated with having year-round sources of calcium and vitamin B12. These results suggest that there are household compositions with greater vulnerability to chronic and hidden hunger, which differs by AEZ in the instance of the number of household inhabitants.

Land cultivated was positively associated with having sources of calcium, iron, thiamine, and vitamin B6. However, in humid/subhumid zones land cultivated was negatively associated with access to sources of calcium. Livestock holdings were negatively associated with food security of access and diet diversity in the lean period. However, the association with diet diversity in the lean period was the weakest of all significant coefficients (Appendix Table C6). Livestock holdings were also positively associated with diet diversity in the flush period (Figure 6.2) and positively associated with the availability of sources for all micronutrients in both semiarid and humid/sub-humid zones.

Market participation was positively associated with food security of access, diet diversity in both the flush and lean periods and positively associated with the availability of calcium, thiamine, riboflavin, vitamin B6 and vitamin B12. Off-farm income was positively associated with food security of access, diet diversity in both periods, as well as iron, thiamine, riboflavin, niacin, vitamin B6 and vitamin B12. Gross income was positively associated with food security of access, diet diversity in the flush and lean periods, and positively associated with the availability of sources of riboflavin and vitamin B12.

Crop production diversity was positively associated with food security of access in semi-arid 
zones, diet diversity in the flush and lean periods. In humid/subhumid zones, crop production diversity was negatively associated with food security of access. Crop production diversity was positively associated with the availability of iron, thiamine and niacin and negatively associated with calcium. The diversity of livestock products produced by a household was positively associated with food security of access, diet diversity in the lean period as well as being positively associated with calcium and vitamin B12. Livestock production diversity was negatively associated with iron, thiamine, and vitamin B6.

These results suggest that associations between diets and farm-household characteristics differ between AEZs. These differences between AEZs were most substantial for market participation and crop production diversity (full regression outputs shown in Appendix Table C6 and additional marginal effects presented in Appendix Figure C3). 


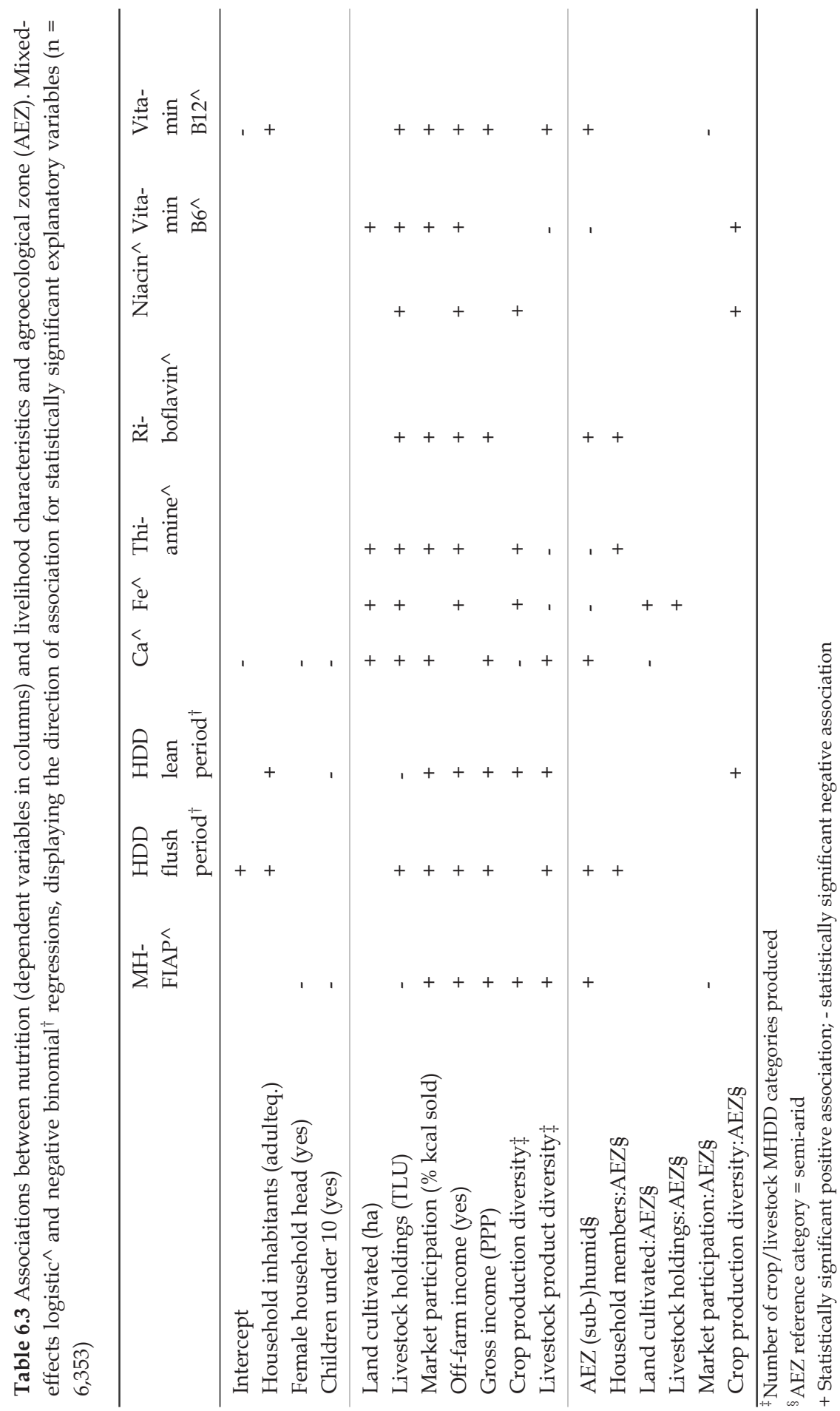


a

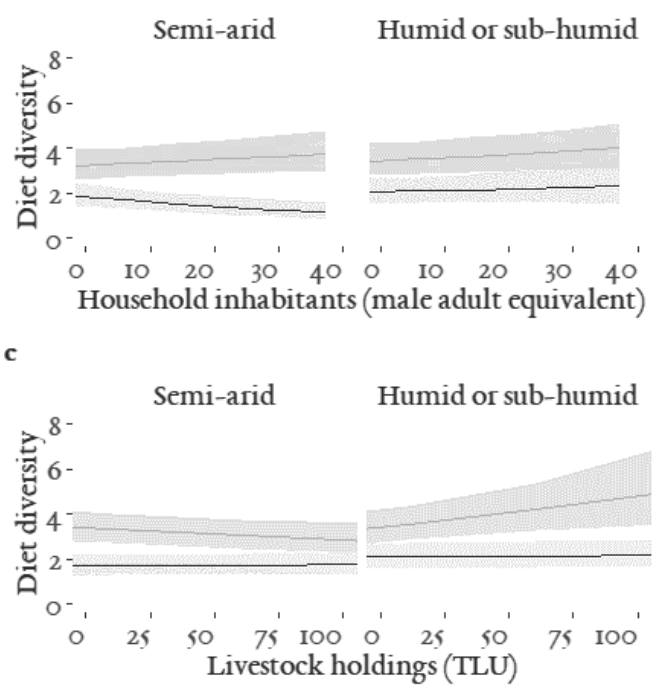

b

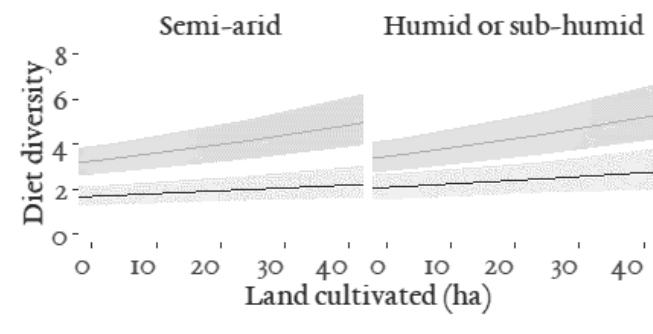

d

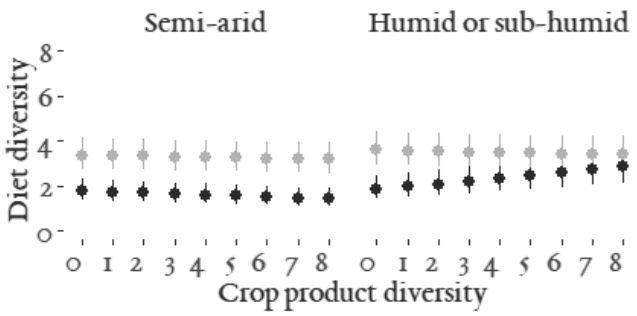

Figure 6.2 Predicted associations between MHDD and a) household inhabitants (adult eq), b) land cultivated, c) livestock holdings (Tropical Livestock Units), d) crop product diversity in the flush (grey line/point) and lean (black line/point) periods by agroecological zone

\subsubsection{Channel of food access and dietary gaps by farm type}

Households with a livestock component tended to have more people in the household, larger land area cultivated, better 'progress out of poverty' and - naturally - more livestock (mixedeffects linear regressions; 95\% CI > 0; Appendix Table C9). 'Diverse cropping' and 'Diverse cropping and livestock' households tended to have greater market participation than their specialised counterparts (mixed-effects linear regression; 95\% CI > 0; Appendix Table C11). Farm types with a livestock component had significantly higher MHDD scores in the flush and lean periods compared to other farm types (Table 6.4; mixed-effects linear regression; $95 \% \mathrm{CI}>0$; Appendix Table C9). As expected, all farm types had higher median MHDD scores in the flush period, compared to the lean period. 
Table 6.4 Summary of resources, income and diet diversity of sampled households by farm type (number, proportion and median-IQR)

\begin{tabular}{lcccc}
\hline & $\begin{array}{c}\text { Specialised } \\
\text { cropping }\end{array}$ & $\begin{array}{c}\text { Diverse } \\
\text { cropping }\end{array}$ & $\begin{array}{c}\text { Specialised } \\
\text { cropping \& } \\
\text { livestock }\end{array}$ & $\begin{array}{c}\text { Diverse } \\
\text { cropping \& } \\
\text { livestock }\end{array}$ \\
\hline $\mathrm{n}$ & 719 & 1596 & 1085 & 2943 \\
Subsistence households (\%) & 4 & 4 & 5 & 4 \\
AEZ (Sub-)humid (\%) & 52 & 61 & 31 & 44 \\
Smallholders (\% $\leq$ ha) & 44 & 39 & 34 & 32 \\
Mixed crop-livestock (\%) & 3 & 4 & 17 & 25 \\
Household members (adult equivalents) & $4.5(3.4)$ & $4.9(3.7)$ & $5.9(4.2)$ & $5.9(3.8)$ \\
\hline Land cultivated (ha) & $1.06(1.39)$ & $1.42(1.62)$ & $2(3.05)$ & $1.82(3.19)$ \\
Livestock holdings (TLUs) & $0.2(0.7)$ & $0.3(0.8)$ & $7.6(24.1)$ & $7.0(10.3)$ \\
Off-farm income (PPP ${ }^{-1}$ year) & $0(0)$ & $0(30)$ & $0(0)$ & $0(150)$ \\
Progress out of Poverty Index score & $33(26)$ & $29(40)$ & $41(23)$ & $45(26)$ \\
Market participation (proportion kcal sold) & $0.03(0.50)$ & $0.25(0.55)$ & $0.05(0.44)$ & $0.25(0.49)$ \\
Crop income (PPP ${ }^{-1}$ year) & $0(210)$ & $86(507)$ & $0(47)$ & $65(629)$ \\
Live animal (PPP ${ }^{-1}$ year) & $0(0)$ & $0(11)$ & $1(128)$ & $3(275)$ \\
Livestock product income (PPP ${ }^{-1}$ year) & $0(9)$ & $0(19)$ & $3(195)$ & $69(480)$ \\
\hline Daily diet diversity - flush period & $2(2)$ & $4(4)$ & $3(2)$ & $4(3)$ \\
Daily diet diversity - lean period & $1(2)$ & $1(3)$ & $2(2)$ & $2(3)$ \\
\hline
\end{tabular}

The channel of accessing MHDD food categories differed by farm type. In Figure 6.3 two channels of access - farm sourced and purchased - and total diet diversity for the four farm types are presented for the lean period (equivalent results for the flush period are presented in Appendix Figure C4).

In Figure 6.3, the probability density function of the count of household diet diversity (MHDD) categories is presented as a black line on the lower half of each facet. The line indicates the probability that a household in a given farm type consumes a given number of categories (1-10). Each facet also presents the proportion of households that consume certain categories for a given count of MHDD. For example, in the top right-hand facet showing 'Specialised cropping' and 'total', the second pillar shows households with only two MHDD food categories, where the most common daily sourced food category was 'grains, roots, tubers and plantains', followed by 'leafy vegetables', 'other vegetables' and then 'legumes'. In contrast, since the far-right pillar shows households which consume all 10 food categories, the proportions of each are equal. Figure 6.4 allows comparison between farm types for a specific channel and within farm types, between channels. Inference from this figure is focused on the central mass of the probability density function - generally between 1 and 5 MHDD categories. 
Farm sourced
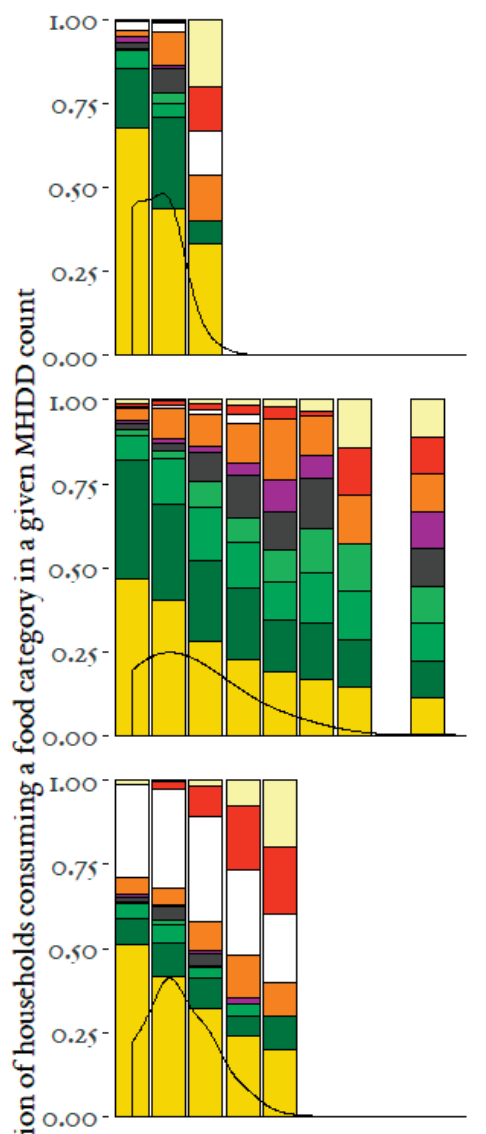

要

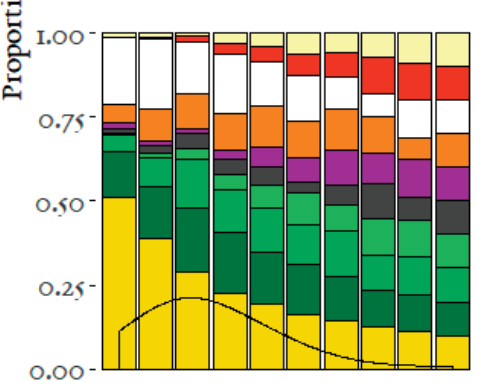

$0.00^{-}$
Purchased
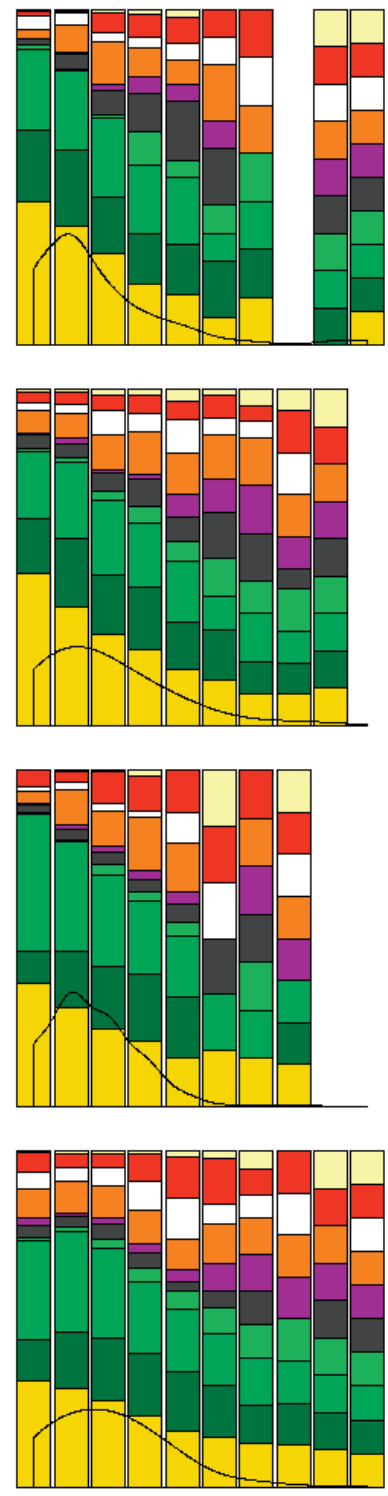

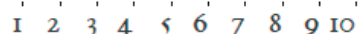

Total
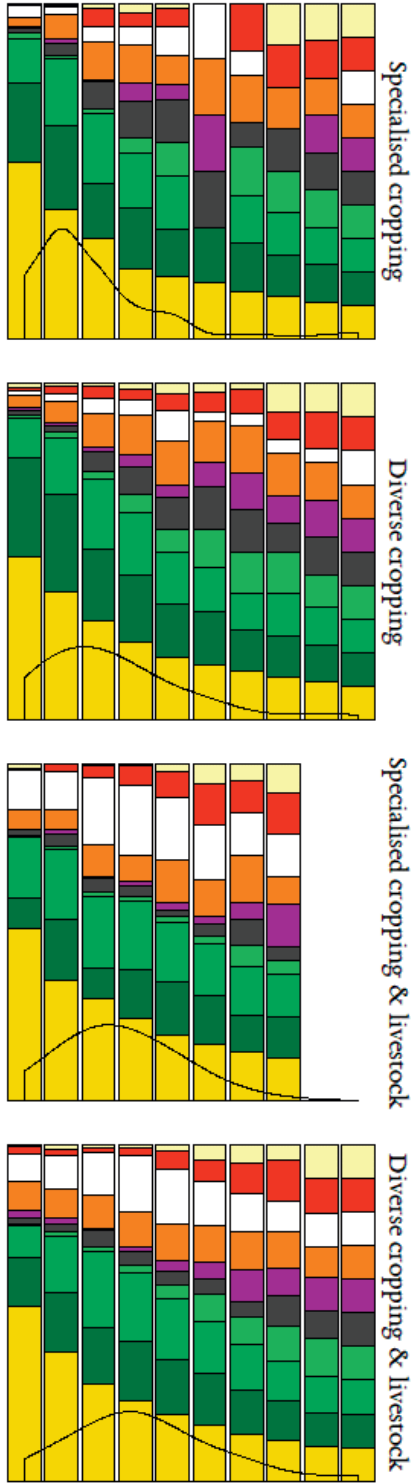

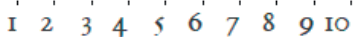
Household diet diversity (MHDD) in the lean period

Category
$\square$ $\begin{aligned} & \text { Eggs } \\ & \text { Meat }\end{aligned} \begin{aligned} & \text { Milk } \\ & \text { Legumes }\end{aligned} \square \begin{aligned} & \text { Fruit } \\ & \text { Nuts \& seeds }\end{aligned} \square \begin{aligned} & \text { Vitamin A rich fruits and vegetables } \\ & \text { Other vegetables }\end{aligned} \begin{aligned} & \text { Leafy vegetables } \\ & \text { Grains, roots, tubers, banana }\end{aligned}$

Figure 6.3 Diet diversity: density and proportion of sampled households $(n=6,353)$ consuming specific food categories by farm type, channel of access and total diet diversity in the lean period. The distribution (probability density function) of diet diversity for each period is represented as a black line on the lower half of each figure facet. Food categories are represented by different colours, showing the proportion of households consuming each category at specific diet diversity levels 
At the aggregate level, farm types with a substantial livestock component consume more livestock products - milk, meat and eggs - in both flush and lean periods (mixed-effects logistic regressions; 95\% CI >0 for all animal source foods; Appendix Table C9). In the lean period, 50\% of households with a livestock component to their farm consumed dairy products compared to less than $17 \%$ of crop-oriented households. In Figure 6.3, it is evident that dairy products are predominantly accessed through the farm channel and are sometimes the only daily sourced food category. Meat consumption - a source of vitamin B12 among several other micronutrients - in the lean period was marginally higher in households with a livestock component (38\% compared to $28 \%$ of crop-based households). Meat was most often purchased, particularly in the flush period - irrespective of farm type. Daily egg consumption - also a source of vitamin B12 and riboflavin - was less common, but consistently higher in households with a livestock component (results not tabulated elsewhere).

A greater proportion of households with a diverse cropping component to their farm tended to source plant-based food categories in the flush period - except 'nuts and seeds' and 'grains, roots, tubers and banana' (mixed-effects logistic regressions; 95\% CI > 0 for all plant-based categories; Appendix Table C11). In the lean period, when compared to other farm types, a smaller proportion of households in the 'Specialised cropping' farm type sourced 'legumes', 'fruit', 'vitamin A rich fruits and vegetables', and 'other vegetables'.

The prevalence of severe food insecurity (of access) was not independent of farm type in both humid/sub-humid and semi-arid agroecological zones (Table 6.5).

Table 6.5 Associations between severe food insecurity, farm type and agroecological zone (AEZ). Mixed-effects logistic regression.

\begin{tabular}{lcc}
\hline & estimate (SE) & Significance \\
\hline Intercept & $-0.51(0.91)$ & \\
Diverse cropping $^{\dagger}$ & $-0.32(0.16)$ & $*$ \\
Specialised cropping \& livestock ${ }^{\dagger}$ & $-0.92(0.16)$ & $*$ \\
Diverse cropping \& livestock ${ }^{\dagger}$ & $-0.41(0.17)$ & $*$ \\
AEZ $^{\ddagger}$ & $0.05(0.12)$ & \\
${ }_{95 \% \text { CI does not cross zero }}$ & & \\
${ }^{\dagger}$ Reference category is 'Specialised cropping' \\
${ }^{\ddagger}$ Reference category is semi-arid
\end{tabular}

Specialised cropping households tended to have a higher prevalence of severe food insecurity when compared with all other farm types (Table 6.5). In humid/sub-humid AEZs, households with 'Diverse cropping \& livestock' had a lower prevalence of severe food insecurity and gaps in all micronutrients, when compared to other farm types (mixed-effects logistic regressions; $95 \%$ CI > 0; Appendix Table C12; Figure 6.4 and Appendix Figure C5). In semi-arid zones, the difference between farm types was more distinct, where households with a livestock component to their farm had a significantly lower prevalence of calcium and vitamin B12 (mixed-effects logistic regressions; 95\% CI >0 for MHFIAP and all micronutrients; Appendix Table C13). 


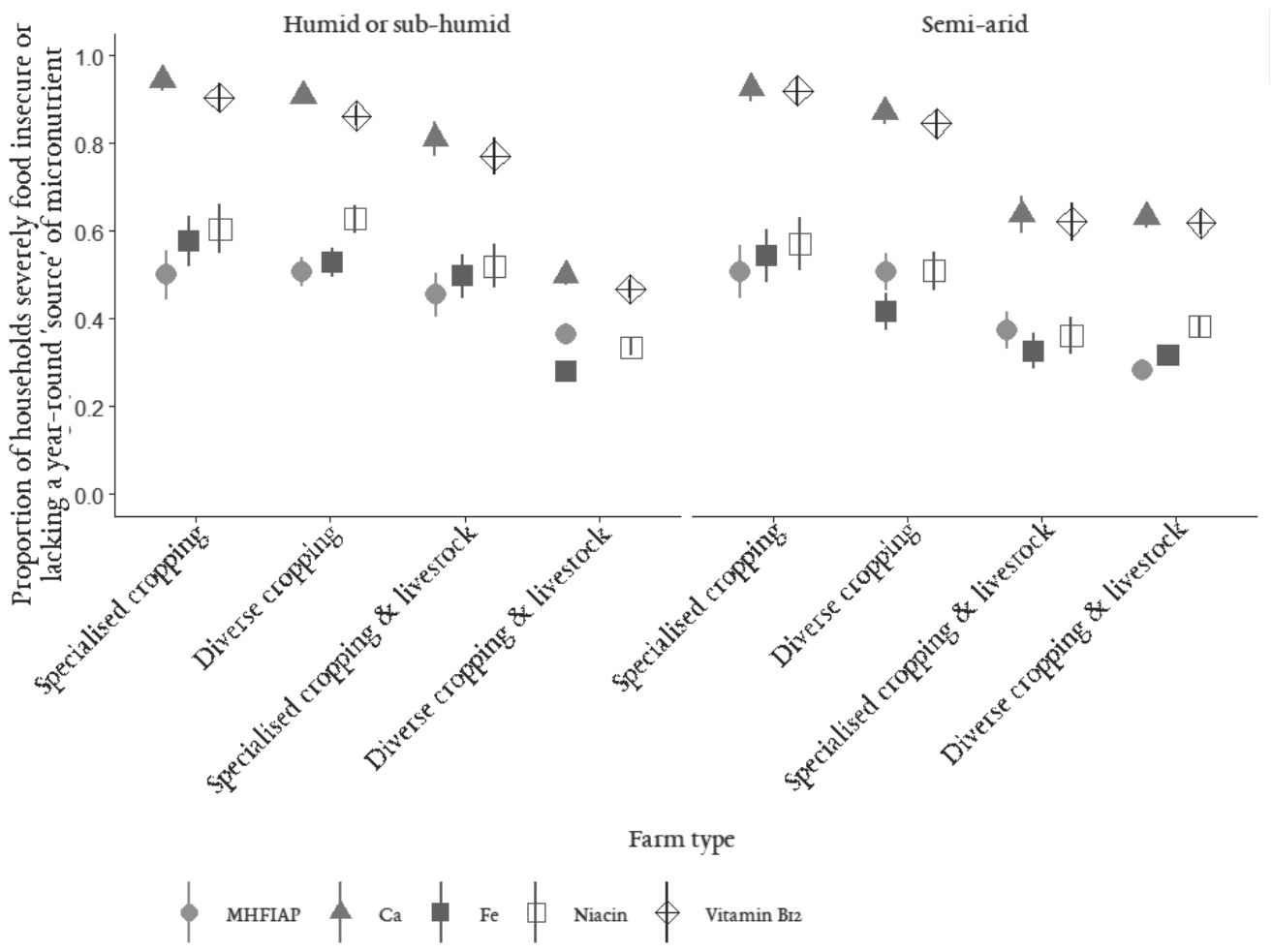

Figure 6.4 Proportion of households ( $n=6,353$ weighted by population) with insecure access to food (MHFIAP) or no 'source' of calcium, iron, niacin, or vitamin B12 by farm type and agroecological zone. A $95 \%$ confidence interval is represented by vertical lines

\subsection{Discussion}

\subsubsection{Food insecurity and dietary gap prevalence}

The aim of this study was to combine diet diversity and food (in)security indicators with householdfarm characteristics to estimate prevalence of dietary gaps and to understand their associations with rural livelihoods and food sourcing behaviour throughout the year. In addition to generating key information on food security of access and dietary diversity over the course of the year for a wide range of contrasting systems in sub-Saharan Africa, our approach also allowed us to quantify dietary gaps for six important micronutrients (Table 6.2): calcium, iron, thiamine, riboflavin, niacin, vitamin B6 and vitamin B12.

The prevalence of dietary gaps in this study are comparable to previous studies, despite the substantial differences in target populations and sampling procedures. An estimated 40\% of sampled households were severely food insecure in their access to food; this is higher than 
reported by the FAO using the Food Insecurity Experience Scale (FIES; Appendix Table C8 provides a comparison of the questions asked) - with an estimated $34 \%$ of the SSA population being severely food insecure in 2017 (FAO et al., 2018). An estimated 68\% of households did not source calcium-rich food categories on a daily basis, which is between deficiency prevalence estimates derived from Martin-Prével et al. (2015, calculated as the inverse weighted average of the probability of adequacy - Appendix Table C9; calcium deficiency prevalence was 91\% of sampled women in Burkina faso, Mali and Uganda) and Joy et al. (2014, 54\% of individuals in Africa). Our estimates of gaps in iron availability (38\% of households) are lower than the deficiency prevalence estimates in Martin-Prével et al. (2015, 78\%), but within the range of estimates in Joy et al. (2014, whose estimates range from 5\% assuming low bioavailability (10\% available), to $43 \%$ for very low bio-availability ( $5 \%$ available)). Our estimates for thiamine $(37 \%)$, riboflavin $(51 \%)$, niacin $(44 \%)$ and vitamin B6 $(35 \%)$ are comparable to estimates in Martin-Prével et al. (2015, thiamine 32\%, riboflavin 56\% and niacin 34\%, vitamin B6 26\%). Additionally, an estimated $66 \%$ of households did not source vitamin B12 rich food categories on a daily basis, which is more conservative than the deficiency prevalence estimates derived from Martin-Prével et al. (2015, 93\% of sampled women).

\subsubsection{Contextual factors for targeting nutrition-sensitive interventions}

There are several factors associated with food security of access, diet diversity and the daily sourcing of micronutrients. From the perspective of designing nutrition-sensitive agricultural interventions, we discuss a) contextual factors that can improve the targeting of interventions and b) factors that can form the basis of an intervention or be incorporated as a complementary intervention.

The contextual factors identified in this study are either not possible to change through agricultural interventions (AEZ and household composition), or relate to complex farmer/household decisions that are beyond the scope of current public and civil society interventions in SSA (farm scale and farm type). These contextual factors can be used as inputs into the intervention targeting decision-making process, where the aim is to maximise the potential for practice adoption and impact on well-being. On the basis of our results, we expect households with 'female heads' and children under 10 years of age to have a higher likelihood of severe food insecurity in the lean period - supporting the need for programmatic strategies on gender inclusion (Mason et al., 2015), as well as focusing on the first 1000 days of life (de Pee et al., 2017). Similarly, households with small land cultivation areas can be targeted to counteract the tendency of limited access to micronutrient sources (land size has been linked to both chronic and hidden hunger; Gödecke et al., 2018).

Understanding the existing production systems (farm types) of rural households within and between locations can inform more advanced intervention targeting decisions. For example, an intervening agent (e.g. government, NGO, etc.) may initially target their interventions based on AEZ, farm scale and sub-sector (e.g. dairy), and then in the advanced stages, design and target interventions based on the prevailing farm types. This approach can improve the suitability of interventions to existing conditions (i.e. by enhancement, diversification, or substi- 
tution; Fiorella et al., 2016) and therefore maximises adoption potential. This contextual factor also provides opportunities to improve the nutrition sensitivity of interventions. Our results show that prevalence rates differ by farm type and AEZ (Figure 6.4). For example, households without a livestock component had high instances $(>80 \%)$ of gaps in calcium and vitamin B12 sources. Intervention packages can be developed to address such dietary gaps, targeting specific farm types in specific AEZs (Hetherington et al., 2017; Mulmi et al., 2017; Hoddinott, 2012). This is also reinforced by Carletto et al. (2015b), who review a series of studies showing that a household's agricultural production can directly influence the dietary patterns of household members, where the extent of impact depends on a variety of factors including location, commodities produced, and whether a household keeps livestock for direct consumption.

\subsubsection{Designing nutrition-sensitive interventions}

There are three factors identified in this study that could be incorporated in nutrition-sensitive agricultural orientated interventions. Increasing farm income (in-part through increasing market participation), improving off-farm employment opportunities (including along the agricultural value-chain; Davis et al., 2017) and diversifying production (crops, home garden and livestock products) each had positive effects on food security of access, dietary diversity, and thereby providing sources of micronutrients. These results are in line with the overview presented by Ruel et al. (2018, p. 147), stating that 'production diversity and livestock ownership are consistently associated with household and dietary diversity and, when measured, with increased intake of essential micronutrients'. There are, however, instances of negative associations with these variables - such as livestock holdings and diet diversity in the lean period. Extreme increases in income or production diversity (i.e. from the lowest end of the scale to the highest), however, is only predicted to increase diet diversity in the lean period by 1 or 2 food categories (Figure 6.2). This limitation needs to be taken into account when designing and monitoring nutrition-sensitive interventions. Success may not be measured in leaps in diet diversity, but rather by adding specific food categories (in sufficient frequency and quantity) that provide micronutrient sources that would otherwise be lacking.

\subsubsection{How do farm types differ in food sourcing behaviour?}

Our results clearly demonstrate that sourcing of food categories was strongly related to farm type (Figure 6.3). We found that the farm-based route to dietary diversity was extremely important: consumption of specific food groups is strongly linked to what farm households produce on-farm. This is a key finding because a substantial part of households that lacked an aspect of production diversity - and thereby miss certain avenues in the farm-based route to dietary diversity - did not choose to supplement their lack of production diversity with an equivalent diversity of purchased food categories. Households with a livestock component to their farm consumed more livestock products - in-part due to their on-farm availability (also identified by Hetherington et al., 2017). Dairy, for example, was predominantly sourced from the farm in the lean period, where $50 \%$ of households with a livestock component to their farm consumed dairy products compared to less than $17 \%$ of crop-oriented households. Similarly, households with a diverse cropping component to their farm sourced a greater diversity of fruit and veg- 
etable food categories (legumes, fruit, vitamin A rich produce, and other vegetables) - mainly from the farm.

The finding that only a subset of households supplement gaps in production diversity with an equivalent diversity of purchased food categories indicates that extra income does not necessarily translate into food and nutrition security - particularly for hidden hunger. Rather, dietary choices are - in part - driven by the retail environment, resulting in increased consumption of processed and sweetened foods (categorised as 'grains, roots, tubers and banana'; 'dairy'), increased instances of obesity and a higher burden of disease (Demmler et al., 2018; GBD 2016 Risk Factors Collaborators, 2017; Popkin, 2014). Therefore, interventions aiming at improving dietary diversity through increasing incomes need to accompany their interventions with nutritional education to stimulate more diverse and nutritious purchases (Dhanarajan, 2017), or by stimulating production to improve local availability (globally, we lack sufficient fruit and vegetables for $22 \%$ of the human population; Siegel et al., 2014). Otherwise, our results suggest that income-based interventions are unlikely to be nutrition-sensitive.

\subsubsection{Methodological considerations}

In this study we identified important associations between agricultural activities and pathways towards food security of access, diverse diets and gaps in micronutrient sources. These results, however, are limited by the means of data collection, the approximations made, the limited scope of analysis and the indicators used.

We used information collected in one-off (i.e. cross-sectional) household surveys, which are prone to non-credible values and reduced measurement precision. In total 1,355 observations $(20 \%)$ were removed from the original dataset - largely due to missing MHDD data, as well as non-credible household or farm characteristics, and enumerator evaluated quality (Appendix Table C3). Surveys were implemented using the same survey design, implimented with multistage clustered sampling strategies. The sampled households were more likely to be in lower socio-economic regions of rural SSA and so can not be taken to represent rural SSA as a whole. Population weightings were based on modelled data based on national statistics with variable quality.

The standard recall procedures of our food security indicators were adapted to enumerate both the lean and flush periods - allowing us to capture the substantial variation of farm household diets throughout the year. This adaptation on the recall procedure, however, means that respondents may need to remember a set of circumstances from up to 11 months prior in order to answer a question - potentially having a negative impact on measurement precision (Beegle et al., 2012).

The triangulation of energy, protein and micronutrients was based on a series of approximations on requirements and availability. These approximations were also based on data with known inaccuracies (Joy et al., 2014) and limited geographical representativeness (utilising food composition data from Tanzania and USDA). These challenges also plague more detailed dietary assessments across Africa (Vila-real et al., 2018) and will only improve if there are con- 
certed efforts to generate high quality national and regional food composition tables across the continent. The triangulation is also limited by only assessing the dietary gaps in subsistence households; the diets of households that purchase foods may differ substantially in composition and quantity (Popkin, 2014). This limitation could be supplemented by information from country specific 24 hour recall datasets. Further work in using diet diversity indicators to assess micronutrient availability could also conduct sensitivity analyses to test the robustness of the triangulation procedure and the effect of farm classification on disaggregated diet gap prevalence.

Limiting our scope to the household level automatically limited the depth of the dietary gap analysis. This has consequences for the interpretation of results. For example, having a source of micronutrient as we have quantified in this study will have different implications for small households (likely to result in sufficiency) as opposed to larger households (they may access a micronutrient daily source but it is not enough for all members). Similarly, we naturally encounter the limitation for any household level indicator: it is not always clear whether we can translate household level findings into consequences for individual members of the family, for example: young children (Caraher, 2016).

In this study, we only assessed a limited set of indicators and associations. Although agriculture is a crucial determinant of food and nutrition security in landholding households, it is important to understand interactions with factors like education, gender, food preparation and sanitation to understand the full nutritional, and health consequences of our findings (in contrast, Gödecke et al., 2018 and Ramankutty et al., 2018 do show associations with education and sanitation and Dzanku, 2019 shows associations with gender). A substantial number of studies have reported the benefits of food security of access and a diverse diet on intermediary nutrition outcomes, such and child and maternal intake of "target" foods and micronutrients. Evidence of impact on nutrition outcomes - particularly child anthropometry and micronutrient status - was much more limited (Gillespie et al., 2017), stressing the limitations of using indicators like dietary diversity when inferring nutritional consequences (e.g. Hetherington et al., 2017 showed weak and inconsistent associations between animal-source food consumption and anthropometric measurements).

Despite these inherent limitations of the analyses, we have quantitatively linked farming system characteristics to food and nutrition security indicators across a wide range of different production systems in sub-Saharan Africa. The most novel feature of this approach is that we can better understand how food security of access, diet diversity and micronutrient sourcing is related to the livelihood characteristics of a rural household over the course of a year (e.g. Hammond et al., 2017). There is substantial variation in household diets, clear associations with livelihood characteristics and differences in food sourcing behaviour between farm types. These insights give confidence that simple approaches - as used in RHOMIS - can inform interventions at various levels to improve food and nutrition security in the diverse rural communities of SSA. 


\subsection{Acknowledgments}

This research was made possible by several donors (listed in Appendix Table C1). We would like to extend our gratitude to the rural households that participated in this research and the enumerators who guided the conversations. 


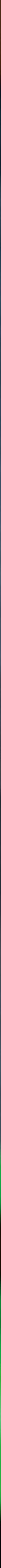


Chapter 7

General discussion 


\subsection{Introduction}

The incidence of adverse health effects due to chronic undernourishment and micronutrient deficiencies are substantially higher in sub-Saharan Africa (SSA) compared to the rest of the world (Gödecke et al., 2018). The individual and societal implications of this food insecurity are borne disproportionately by the rural SSA population (Green et al., 2016). Rural landholders are both vulnerable to the health burdens that stem from food insecurity, and central to improving the availability and affordability of a diversity of wholesome foods. To combat malnutrition, the global community needs to understand the interactions between food and nutrition (in)security and rural livelihoods. This understanding is currently missing.

The present understanding of food (in)security and rural livelihoods has been limited by the geographical and temporal scope of research efforts, and a lack of standardised rural household surveys. There is no one organisation with the resources to frequently monitor the vast diversity of rural communities at risk of food insecurity. Rather, rural household surveys are conducted nationally at in-frequent intervals and sub-nationally by a plethora of organisations. There have been considerable efforts to develop standardised rural household surveys over the past decade (e.g. Carletto, 2009; Herrero et al., 2007). However, these attempts to provide standardised survey designs have not resulted in substantial harmonisation and collaboration. Carletto et al. (2013, p. 39) suggest that further harmonisation can be developed over time, with a "combination of short-term fixes and long-term methodological advancements". Recently, time-efficient proxies to food and nutrition security status have been developed - marking a substantial methodological advancement (Pisa et al., 2017; de Keyzer et al., 2015). These proxies can be readily incorporated into rural household surveys, providing comparable metrics across a diversity of studies to generate insights into the prevalence, spatial distribution and associations of food (in)security.

A growing body of literature utilising these food and nutrition security proxies has generated insights into the role that agricultural production and off-farm income plays in improving food and nutrition security. These findings, however, are dependent on the time of year that the survey is implemented and, have had a limited geographical scope - limiting cross-site comparisons and more generalisable inference.

The primary objective of this thesis was to characterise food and nutrition security in rural landholding households in predominantly mixed crop-livestock agricultural systems of subSaharan Africa (SSA). Characterisation in this respect refers to describing the multiple facets of food and nutrition security, and identifying their associations with livelihoods. The secondary objective was to improve the methodological basis of household level food security studies.

This chapter first presents the research findings related to the harmonisation of rural household surveys to measure and monitor food and nutrition security. Harmonisation of rural household surveys is then discussed in terms of further methodological advances. A synthesis of findings related to food security and livelihoods is then provided. The discussion then continues 
with a focus on food and nutrition security in rural SSA in the context of nutrition-specific and nutrition-sensitive interventions; the stability of food and nutrition security throughout the year and; women's empowerment. The discussion then identifies further methodological advances for measuring food and nutrition security. This chapter is then concluded with a synthesis of findings.

\subsection{Harmonising rural household surveys}

\subsubsection{A balance between customisation and harmonisation}

A standardised rural household survey with an appeal to a wide user base was not available at the start of this $\mathrm{PhD}$ research. In a related PhD project, the rural household multi-indicator survey (RHOMIS) tool was developed to "give a rapid, comprehensive overview of the farming system, which can be used to identify hotspot issues and to develop an evidence base to target deeper research" (Hammond, 2018, P. 84). Chapter 2 summarises this RHOMIS tool which was designed to collect a core set of modules, while being time-efficient, utilitarian, userfriendly, flexible and reliable (left-hand-side of Figure 7.1). By being time-efficient, RHOMIS aims to minimise respondent fatigue and reduces the amount of time needed for survey design, implementation and analysis. The duration of the core set of modules in RHOMIS (listed in Figure 7.1; provided in appendix 1 of Hammond, 2018) is estimated to be between 40 to 60 minutes (Table 2.1). The duration of RHOMIS is half that of comparable surveys - such as the 'integrated modelling platform for mixed animal crop systems' (IMPACTlite; compared in Table 3.1). The food availability indicator took the most time to collect, at a maximum of 35 minutes, followed by diet diversity, taking 10 minutes. The ease of enumeration was evaluated favourably for each module, with over $50 \%$ of interviews being perceived as 'easy' by the interviewer (Chapter 2).

The utilitarian design of RHOMIS means that every question is asked for a purpose. While this may sound logical, it is the norm in non-standardised household surveys to ask additional questions - just in case they are important. In RHOMIS, each question is either incorporated into a composite indicator or used directly. If a variable or module proves to be ineffective, then it is revised or removed. The user-friendly principle of RHOMIS is most prominent in the design of the computer-aided personal interview (CAPI) system, which reduces the need for paper-and-pen entry. These design principles reduce survey time and respondent fatigue and provide efficiencies in data entry and data analysis.

The principle of flexibility refers to the extendibility and localisation of the survey. The core and additional modules are listed in Figure 7.1, providing potential extensions into water, sanitation and hygiene (WASH), household expenditure and many more aspects of rural livelihoods. A survey needs to be adapted to the local language, units (standard measures of volume), foods and species. Over time, these localisations can be reused and improved upon. The RHOMIS tool is now available in 9 languages and has been localised to 48 sub-national locations in SSA, South-East Asia and South and Central America. 
The credibility and consistency of data collected using RHOMIS was evaluated in Chapter 3. RHOMIS stayed within credible bounds more frequently than IMPACTlite and the Living Standards Measurement Study - Integrated Survey on Agriculture (LSMS-ISA). The positive performance of RHOMIS in this respect could be attributed to the localisation of units - minimising respondent estimation error. The inconsistency between IMPACTlite and RHOMIS (forming a test-retest study) was most evident in the diet diversity indicator. The limitations in dietary data collected in IMPACTlite may be explained by an unfortunate combination of poor question design and excessive survey duration. In contrast, the targeted questions in RHOMIS resulted in more realistic diet diversity estimates as there was less item non-response for commonly consumed food groups such as cereals and beans.

The design of RHOMIS has appealed to a diversity of users, including researchers and development organisations. The users of RHOMIS has evolved into a community of practice over the course of this PhD research. The RHOMIS community of practice has made substantial progress in harmonising data collection activities (www.rhomis.org). Throughout the duration of this $\mathrm{PhD}$, the harmonisation of sampling, data pre-processing and testing of proxies was managed on a case-by-case basis (methodological developments listed in the top right of Figure 7.1). These studies served as a proof of concept of effective rural household survey harmonisation. Now that there is an engaged community of practice, there are opportunities to make further methodological advances - including introducing sampling guidelines, providing additional modules to validate indicators and introducing alternative modes of data collection (bottom right of Figure 7.1). This section discusses each of these potential methodological advances.

\subsubsection{Further methodological advances for the RHOMIS approach}

Sampling support was provided to organisations that did not have access to this support elsewhere. Rigorous sampling is the basis of generalisable inference. All datasets utilised in Chapters 4 to 6 impliment multi-stage clustered sampling. Chapter 4 is based on geographically random sampling across villages within a 10-by-10 kilometre research area. Chapter 5 is based on purposively selected villages with random sampling from lists of households. Chapter 6 is based on several independent studies, sampling from lists of households within villages, but differing geographical bounds (e.g. Nationally representative and within a 10-by-10 km area). The consistency of sampling can be improved by providing sampling guidelines that provide details on sample size determination (including reliability assessments - Chapter 3 ) and various sampling methods (e.g. geographically random). The sampling method employed and suitable weightings would then be incorporated in the RHOMIS database as meta-data. This meta-data would then allow the pooling of data-sets with similar sampling methods and geographical bounds.

There are also opportunities to critically assess the proxies used in RHOMIS by validation against more accurate methods. Specifically, in any given study, more detailed data can be gathered from a smaller subset of households to compare with the coarser measurement (referred to as 'two-method measurement designs', Little \& Rhemtulla, 2013). Validating proxies as well as 


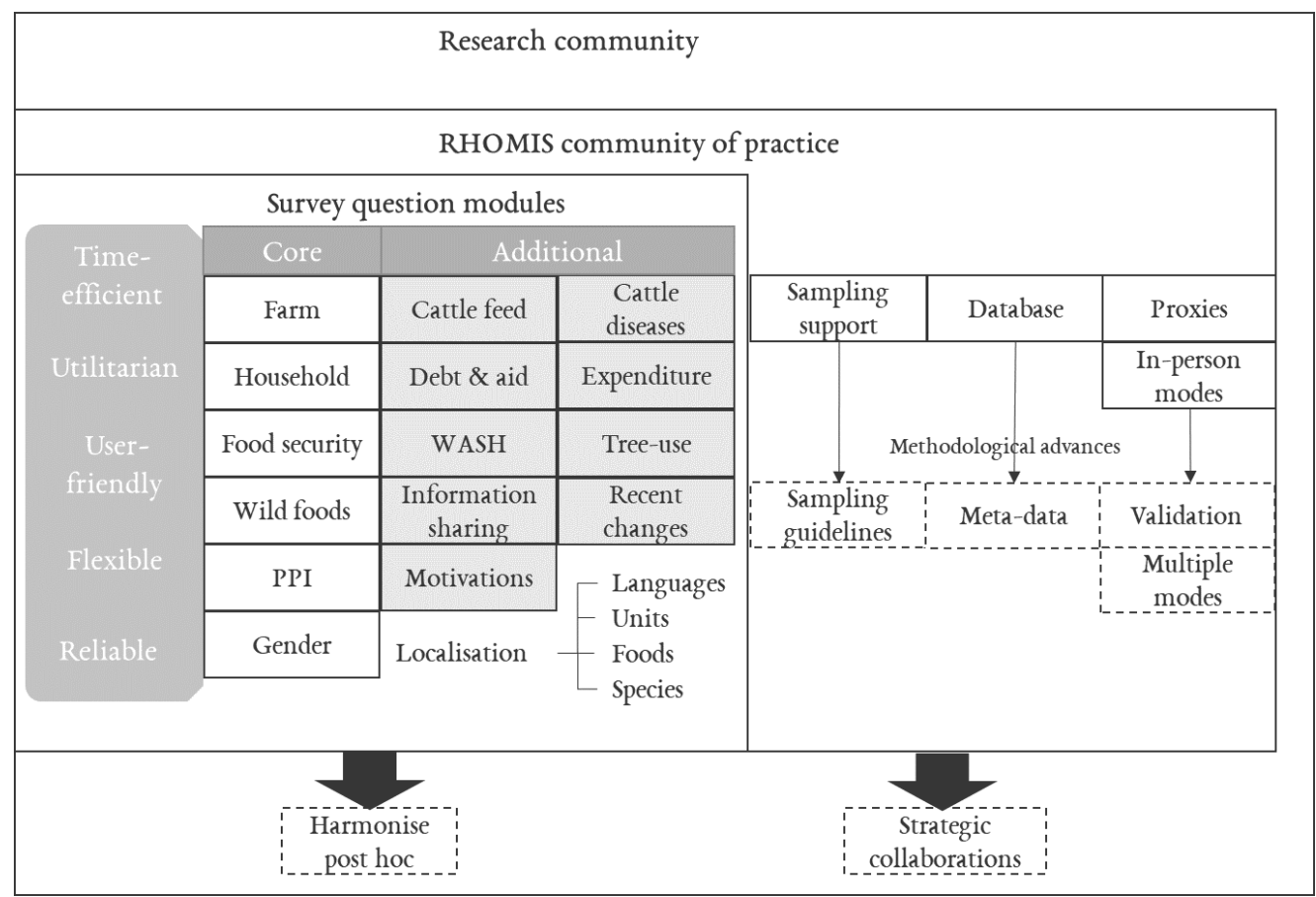

Figure 7.1 Summary of progress and pending developments to harmonise rural household surveys. Including the progress out of poverty index (PPI) and; water, sanitation and health (WASH) modules from the rural household multi-indicator survey

meeting the primary research objectives is challenging to implement. It is particularly challenging to develop and implement two experimental designs - one for the primary purpose of the research and another for the validation study. In the RHOMIS tool - where much of the uncertainty of experimental design has been standardised - an additional validation study is more tractable. Candidate variables for this process include: land size, diets, localisation units, crop yields and milk yield. By implementing two-method measurement designs, there is the potential to correct for errors in the broader dataset and identify methodological improvements.

Research can also be explicitly carried out to validate indicators. In this instance, an experiment is designed to compare alternative indicators against a 'gold standard'. An example of this would be to compare the modified household diet diversity recall periods (Chapters 5 and 6) to quarterly 24 -hour dietary recall $(24 \mathrm{hR})$. Such a research effort could validate one of the alternatives, and potentially identify modifications that need to be made.

The RHOMIS tool has relied on in-person modes of data collection with multiple recall periods. The reliance on multiple recall periods means that respondents may need to remember a set of circumstances from up to 11 months prior in order to answer a question - having a negative 
impact on measurement precision (Beegle et al., 2012). In an initiative such as the RHOMIS community of practice, it is not possible to force users to revisit households multiple times throughout the year. Relying on recall has been a pragmatic reality.

As an alternative to multiple recall periods, multiple modes of data collection can be used to build relationships with respondents in-person and then to follow-up with the same respondents in a cost effective manner. In particular, as $46 \%$ of the SSA population is now connected to mobile networks there is the potential to engage rural households through the use of mobile phones (GSMA Intelligence, 2016). Short messaging services (SMS) and computer-assisted telephone interviewing (CATI) are two alternatives in this respect. In a comparison between face-to-face interviews (CAPI) and CATI, Lamanna et al. (accepted) found that telephone interviews were effective for the majority of questions asked. Sensitive questions on child and maternal health differed significantly by mode. There were also some mode effects at the food category level, with pulses reported more frequently in CATI and milk reported less frequently. These findings suggest that data collection through CATI can introduce biases. The cost of CATI interviews were reported to be US\$5 per successful survey, compared to US\$16 for face-to-face. One concern raised by Lamanna et al. (accepted) was that CATI may disproportionately exclude those less likely to have access to a mobile phone, such as the less wealthy and young women. Aside from the cost savings, this method has the potential to reduce recall period, and to improve the monitoring of communities in conflict zones (as in northern Yatenga - Chapter 5) or communities that are geographically inaccessible.

In addition to methodological improvements, there are also opportunities to harmonise RHOMIS data with other research efforts and to form strategic collaborations (bottom of Figure 7.1). Todate, RHOMIS has been harmonised with other datasets, increasing the total number of observations from 25,000 to 50,000. Even with such a large database, there are still geographical and temporal gaps which can be addressed by forming strategic collaborations, to harmonise with existing RHOMIS data. This can work by coordinating with specific organisations (e.g. UNICEF, CARE or World Vision) that are delivering projects in food insecure locations that currently lack harmonised data.

The harmonisation of rural household surveys is the result of more than a decade of steady progress. Rural households can now be characterised in a standardised way, enumerating multiple indicators of food and nutrition security. These indicators include: food availability, food security of access, diet diversity, food-self-sufficiency (adequacy ratios), sources of micronutrients and duration of food scarcity. This thesis draws on a total of 8,257 household interviews, conducted in 14 projects to characterise food and nutrition security in rural landholding households. 


\subsection{Food and nutrition security in SSA}

\subsubsection{Prevalence and spatial heterogeneity of food insecurity}

In the sample of rural landholders across SSA, as many as $40 \%$ of households were classified as severely food insecure in the 'lean' period - defined as the period of food scarcity. In general, households sourced two food categories on a daily basis in the 'lean' period and three food categories in the 'flush' period (median; results not shown). The implications of diet diversity on micronutrient deficiencies (hidden hunger) differed depending on which food categories were sourced. Disaggregating the count of diet diversity, it was reported in Chapter 6 that $68 \%$ of households did not have a year-round daily source of calcium, 38\% lacked a daily source of iron, 37\% lacked a daily source of thiamine (vitamin B1), 51\% lacked a daily source of riboflavin (vitamin B2), 44\% lacked a daily source of niacin (Vitamin B3), 35\% lacked a daily source of pyridoxine (vitamin B6) and 65\% lacked a daily source of cobalamin (vitamin B12) (Table 6.2). The prevalence of chronic and hidden hunger was highly variable between and within regions. Within-region variability is evident in Chapter 5, where households in two relatively similar provinces of Burkina Faso exhibited markedly different rates of food insecurity. More generally, instances of food insecurity differed by household composition, farm-business characteristics, income diversification and agro-ecological zone (AEZ; Chapter 6).

\subsubsection{Food and nutrition security and livelihoods}

Household composition was significantly associated with food security across sampled regions of rural SSA (Chapter 6). Female-headed households were more likely to be chronically hungry in the lean period and to lack sources of calcium - where the head of the household is defined by asking in the initial stages of the interview. It was also the case that lower performing 'subsisting' households identified in Chapter 4 were predominantly female-headed. Similarly, households with children under the age of 10 were more likely to be chronically hungry in the lean period, and more likely to lack sources of calcium (Table 6.3). Households with children under the age of 10 tended to have more inhabitants, the same level of income, lower progress out of poverty and therefore higher instances of hunger (Appendix Table C14). These findings support the need for programmatic strategies on gender inclusion (bottom right of Figure 7.3; Mason et al., 2015), as well as the need for focusing on maternal and child nutrition (Sharma et al., 2017; de Pee et al., 2017; Arimond \& Ruel, 2004). A livelihood in this thesis is defined as the way resources are utilised to maintain the wellbeing of an individual or social group (Blaikie et al., 1994). In Chapter 4, substantial changes in livelihoods were observed over three years - suggesting that livelihoods are dynamic over a short period of time. Livelihoods were also observed to be highly variable (Chapters 4, 5 and 6). For example, Table 5.2 summarises two sites with relatively low production potential; within and between these sites there was substantial variation in household inhabitants, land area and livestock holdings. Despite this variability, several livelihood characteristics were identified to be associated with food security across sampled regions of SSA - including size of land area, size of livestock holdings, production diversity, level of gross income and extent of income diversification - i.e. earning off-farm 
income.

Households with larger land area cultivated were more likely to have more diverse diets. The effect of land cultivated on diet diversity was most substantial in the flush period. As livestock holdings increased, households were more likely to have access to sources of all micronutrients - regardless of AEZ. The diversity of livestock products produced by a household, furthermore, was positively associated with food security of access, diet diversity in the lean period as well as being positively associated with calcium, iron, thiamine, niacin, vitamin B6 and vitamin B12 (Chapter 6). Crop production diversity was positively associated with food security of access and diet diversity regardless of AEZ. However, the association between crop production diversity and accessing sources of micronutrients differed by AEZ. Households in humid and sub-humid zones were more likely to access micronutrient sources as crop production diversity increased.

In reality, it is the combination of these livelihood characteristics that influences food security status. Chapter 6 identifies four distinct farm types, labelled: 'Specialised cropping', 'Diverse cropping', 'Specialised cropping and livestock', and 'Diverse cropping and livestock'. The prevalence of severe food insecurity and gaps in micronutrient sources depended on farm type. In humid and sub-humid AEZs, households with diverse crops had a lower prevalence of severe food insecurity. Additionally, 'Diverse cropping \& livestock' households in humid and sub-humid zones had a lower prevalence of gaps in all micronutrients. In semi-arid zones, the difference between farm types was more distinct, where households with a livestock component to their farm had a lower prevalence of severe food insecurity and gaps in all micronutrients.

In this discussion, the higher performing farm types that keep livestock are further disaggregated by land area cultivated (Figure 7.2). In humid and sub-humid zones, households labelled as 'Diverse cropping medium-large' ( $n=493)$ were less likely to be chronicly hungry and were more likely to have access to sources of calcium and niacin compared to their smallholder counterparts $(n=797$; mixed-effects logistic regressions; 95\% CI $<0$, Appendix Table C15). In semi-arid zones, 'Specialised cropping medium-large' $(n=402)$ were less likely to be chronicly hungry and were more likely to have access to sources of iron, thiamine, riboflavin, niacin and pyridoxine when compared to their smallholder counterparts ( $n=343$; mixed-effects logistic regressions; 95\% CI < 0; Appendix Table C16). These results suggest that all the relevant interactions between livelihood characteristics are not fully captured in the modelling of Chapters 5 and 6. Rather, food security status is determined by the combination of land area, livestock holdings, production composition and land area - differing by AEZ. 


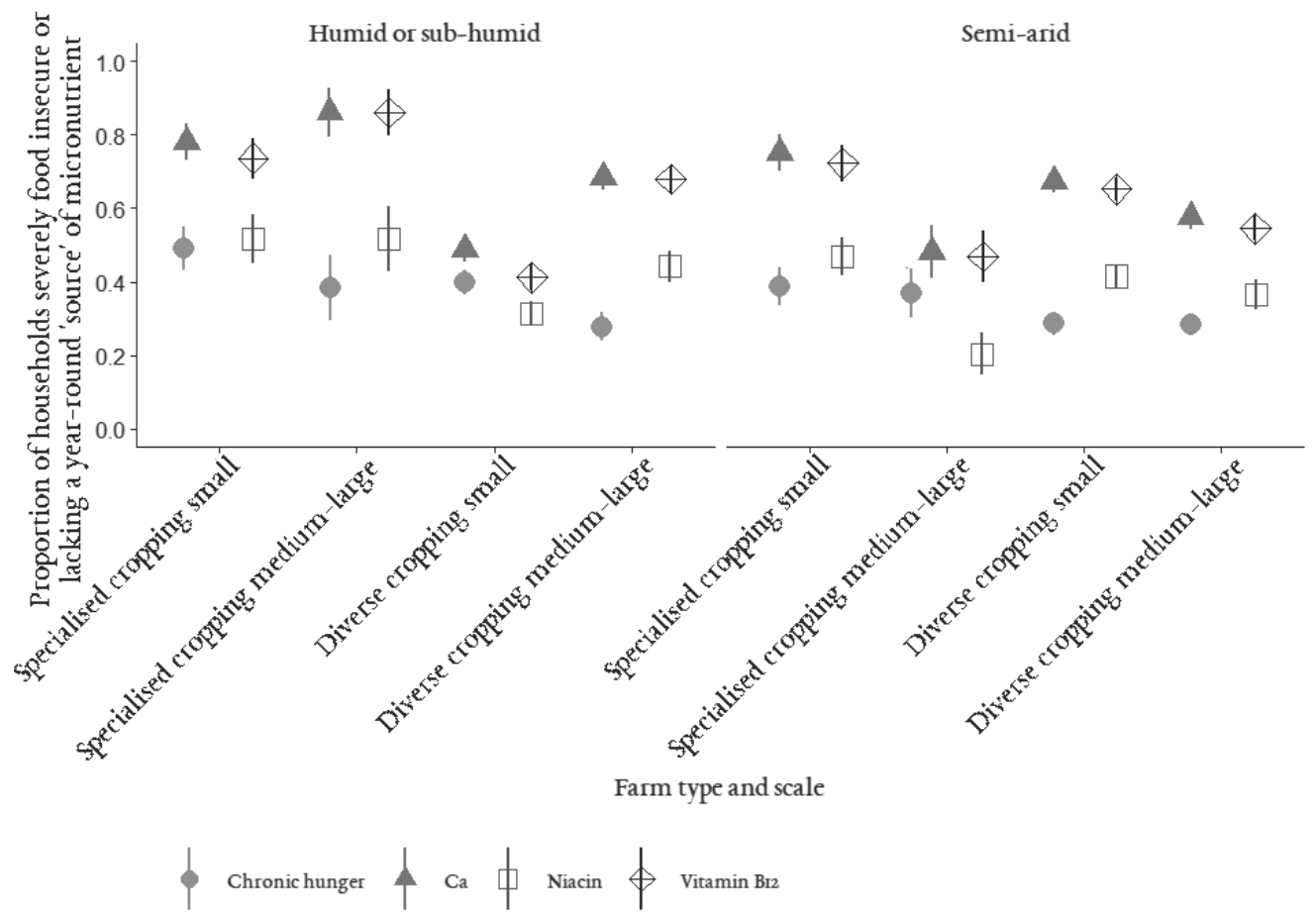

Figure 7.2 Proportion of livestock keeping households ( $n=4,028$ weighted by population) chronically hungry or lacking micronutrient 'source' by farm type, scale and agroecological zone. A 95\% confidence interval is represented by vertical lines

Income diversification was also found to be associated with food security. In Chapter 4, households in Lushoto earning off-farm income in the 'Rising high-value crops' cluster had significantly higher diet diversity in the flush period when compared to others in the cluster. In Chapter 5, households in northern Burkina Faso that earned off-farm income were less likely to be severely food insecure. Off-farm income had a significantly positive effect on diet diversity in Seno province as gross farm income increased. However, in Yatenga province, it was predicted that households not earning off-farm income had a greater potential to have more diverse diets. More generally across a diversity of rural communities of SSA, Chapter 6 showed that off-farm income was positively associated with food security of access, diet diversity, as well as calcium, riboflavin and vitamin B12. The difference between Chapter 5 and 6 in this respect suggests that off-farm income is positively associated with improved food security status in general, but can have differing effects at a site disaggregated level.

The associations between livelihoods and food security are mediated by food sourcing decisions. Households can access food from their own farm, through purchases or by trading, hunting or gathering. This thesis focused on two channels of food access, from own-farm production and purchased foods (presented as 'own production' and 'income' channels in Figure 
7.3). In northern Burkina Faso, own-farm sourcing had the potential to fulfil much of the household's energy needs, and the diversity of diets was most differentiated through purchased foods (Chapter 5). However, in an analysis of multiple sites across SSA, Chapter 6 demonstrates that households fail to purchase food categories that nutritionally complement their own agricultural production. This means that less production diverse households are less likely to access sources of specific micronutrients, such as calcium (dairy), vitamin A (vitamin A rich fruits and vegetables) and vitamin C (other fruits).

Multiple statistically significant associations were identified in this thesis. The causality of these associations could not be fully represented in the models of Chapters 5 and 6. For instance, household composition is associated with food security because headship and stage of life influence livelihood characteristics - not due to a direct causal association. Several livelihood characteristics were associated with food security. It is the combination of these livelihood characteristics and agro-ecological production potential that drive the availability of food and income. Food security is then mediated by food sourcing decisions related to own-farm food availability and income availability. While purchases tend to drive overall diet diversity, a few select food categories are more readily sourced if available through the own-farm channel. These findings suggest that improving food security through rural livelihoods requires a focus on increasing supply, adding nutritional value through the own-farm channel and increasing demand for nutritious foods (relating to the three strategies of Figure 7.3).

\subsection{Interventions, stability of food security and gender}

\subsubsection{Maximising the nutritional impact of interventions}

It has been estimated that much of the chronic and hidden hunger quantified in this thesis can be alleviated by implementing a set of nutrition-specific interventions at a cost of US\$9.6 billion per annum - including programs on fortification, micronutrient supplementation and exclusive breastfeeding promotion (Bhutta et al., 2013). It is emphasised in Bhutta et al. (2013, p. 452) that if such expenditure is "linked to nutrition-sensitive approaches-i.e., women's empowerment, agriculture, food systems, education, employment, social protection, and safety nets-they can greatly accelerate progress in countries with the highest burden of maternal and child undernutrition and mortality.". The implementation of nutrition-specific interventions, in combination with nutrition-sensitive interventions, calls for greater coordination between intervening agencies working across multiple disciplines.

The International Fund for Agricultural Development (IFAD) framework on nutrition-sensitive value-chains defines three strategies that encompass nutrition-sensitive agricultural, food systems and education interventions - namely, increase supply, increase demand and add nutritional value (IFAD, 2018). Strategies to increase supply (Ruel \& Alderman, 2013) aim to increase farm, regional and national food supply by improving productivity and reducing waste (top left box of Figure 7.3). Strategies that increase demand for nutritious food aim at product and nutritional education (bottom-left of Figure 7.3). Strategies that add nutritional value aim to improve the 
nutritional content of food produced, for example, by promoting vitamin A rich sweet potato; maintain the nutritive quality, for example through grain storage or refrigeration; and, improve food safety, for example by reducing aflatoxin contamination. Several nutrition-specific interventions also add nutritional value to the food system and so fall within the scope of the IFAD framework. The remainder of this subsection discusses increasing supply and adding nutritional value.

The framework acknowledges that increasing supply and incomes will not directly improve nutritional status. Rather, individuals need to decide how the additional supply is to be utilised ('own-farm channel') and how income is to be spent ('income channel' in Figure 7.3; Price et al., 2018; Kazianga \& Wahhaj, 2017; Galiè et al., 2015). In fact, a concern of agencies implementing agricultural interventions is that the economics of productivity gains will drive increased specialisation and market orientation, which would reduce production diversity and compromise nutritional status (Tscharntke et al., 2012).
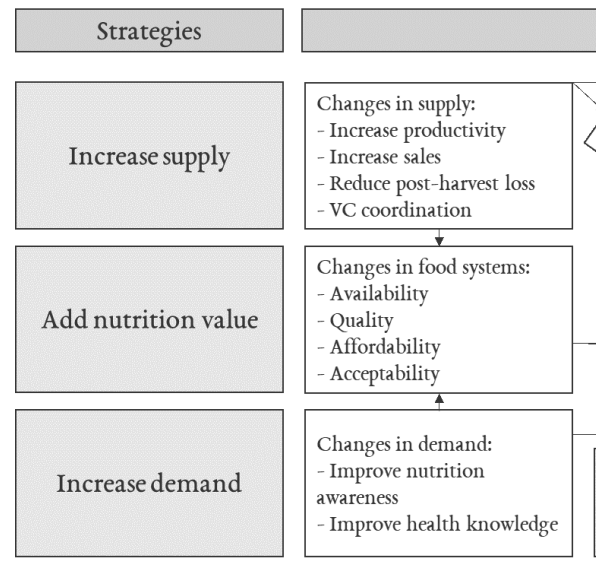

\section{Outcomes}
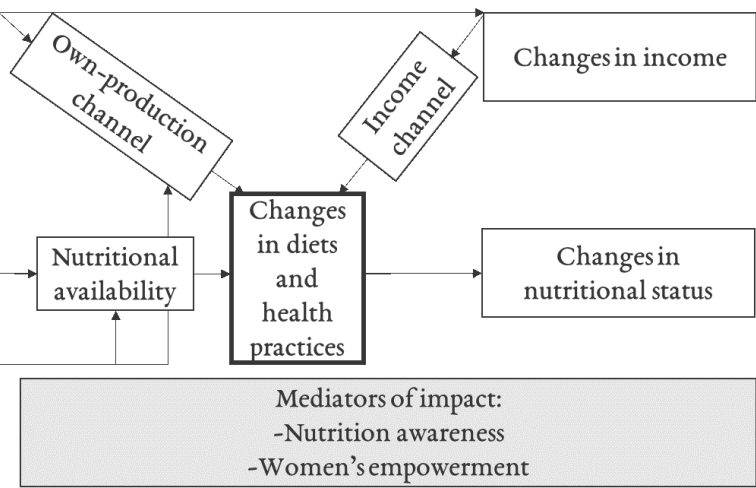

Figure 7.3 Impact pathways of food system-based nutrition-specific and nutrition-sensitive interventions

$\mathrm{VC}=$ value-chain

(Reproduced with permission from IFAD, 2018)

The literature indicates that there are several options for adding nutritional value to food systems. Evidence suggests that interventions supporting livestock production can significantly reduce micronutrient deficiencies and health outcomes. For example, horticulture and poultry training has been found to increase vitamin A levels (Masters et al., 2018). Specifically, increasing animal-source food consumption has been found to significantly reduce stunting in low and middle-income countries (Headey et al., 2018a).

The breeding and genetic modification of crops has also been a promising avenue to add nutritional value to food systems - referred to as biofortification. Biofortification of pro-vitamin 
A crops (orange flesh sweet potato and maize; Bouis \& Saltzman, 2017) and iron (beans and pearl millet) have been found to be effective physiologically and economically (Osendarp et al., 2018). For example, it has been estimated that interventions supporting sweet potato cultivation can save one disability average life year (DALY) for the cost of US\$15 -20 - where a DALY is a standardised measure of human health and life expectancy (Osendarp et al., 2018). The biofortification of folate (B9) has also been tested in several crops and combined B vitamin biofortification is being explored (Strobbe \& Van Der Straeten, 2018).

Directly adding micronutrients to food systems has been identified as being one of the most cost-effective means of addressing hidden hunger (Bhutta et al., 2013; Osendarp et al., 2018). Referred to as fortification, this process adds specific micronutrients at safe levels to commonly consumed foods - such as iodine to salt and bread, zinc and B vitamins to processed cereals, and vitamin D to foods with high oil content. Fortification is most commonly and cost-effectively implemented in collaboration with large-scale food processors. However, such processed foods may not be available to those at most risk to hidden hunger. In these instances, own-produced foods can be fortified by adding micronutrient powders - referred to as complementary food production. Such complementary food production interventions- have been effective at increasing iron and zinc intake in Ethiopia and Nigeria (Masters et al., 2018).

The implementation of agricultural-based interventions to add nutritional value, however, is not as straightforward as fortification programs. As an example, Jenkins et al. (2018) identified a wide range of factors constraining adoption of orange flesh sweet potato in Mozambique including: taste preferences, availability of seed, and volatility of markets. To overcome the challenge of low adoption, programs can be designed as 'packages', which combine agricultural and non-agricultural interventions, such as biofortified crops, complementary feeding, social safety-nets and women's empowerment (Ruel et al., 2018; Jaenicke \& Virchow, 2013). The micronutrient disaggregated analysis in Chapter 6 allows for the identification of potential dietary gaps of sub-populations, facilitating the targeting of such intervention packages. This packaging of interventions, however, requires greater collaboration between intervening agencies working across multiple disciplines, which is currently lacking.

There are several mediators to the effectiveness of nutrition-specific and nutrition-sensitive interventions. The following subsections discuss two mediators raised in this thesis, namely: the temporal variability of food and nutrition security, and the empowerment of women.

\subsubsection{Stability of food and nutrition security throughout the year}

The long-term stability of food and nutritional security is the ultimate goal of any effort to address chronic and hidden hunger. To support long-term stability, providing social protection and safety-nets have been identified as important nutrition-sensitive interventions (Bhutta et al., 2013). An underlying challenge is that livelihoods are influenced by seasonal factors which determine the duration of scarcity, which tend to differ between and within AEZ. Figure 7.4 presents the variability in duration of food scarcity in Burkina Faso and Kenya, by AEZ.

In Burkina Faso, where the majority of households are located in semi-arid zones, over one-third 
of households experienced food scarcity in August (Figure 7.4). In semi-arid zones of Burkina Faso, $63 \%$ of households experienced between one and three months of food scarcity. In contrast, $48 \%$ of households in humid and sub-humid zones did not experience any food scarcity months. The pattern of food scarcity months differed in Kenya, with households in semi-arid zones experiencing longer durations (2-6 months), later in the year (September-October) and households in humid and sub-humid zones experiencing shorter durations (2-4 months) earlier in the year (April). In the context of climate change and globalised markets, rural livelihoods are more exposed to climatic and market shocks, exposing households to the risk of more severe and longer food insecure periods (Fanzo, 2018).

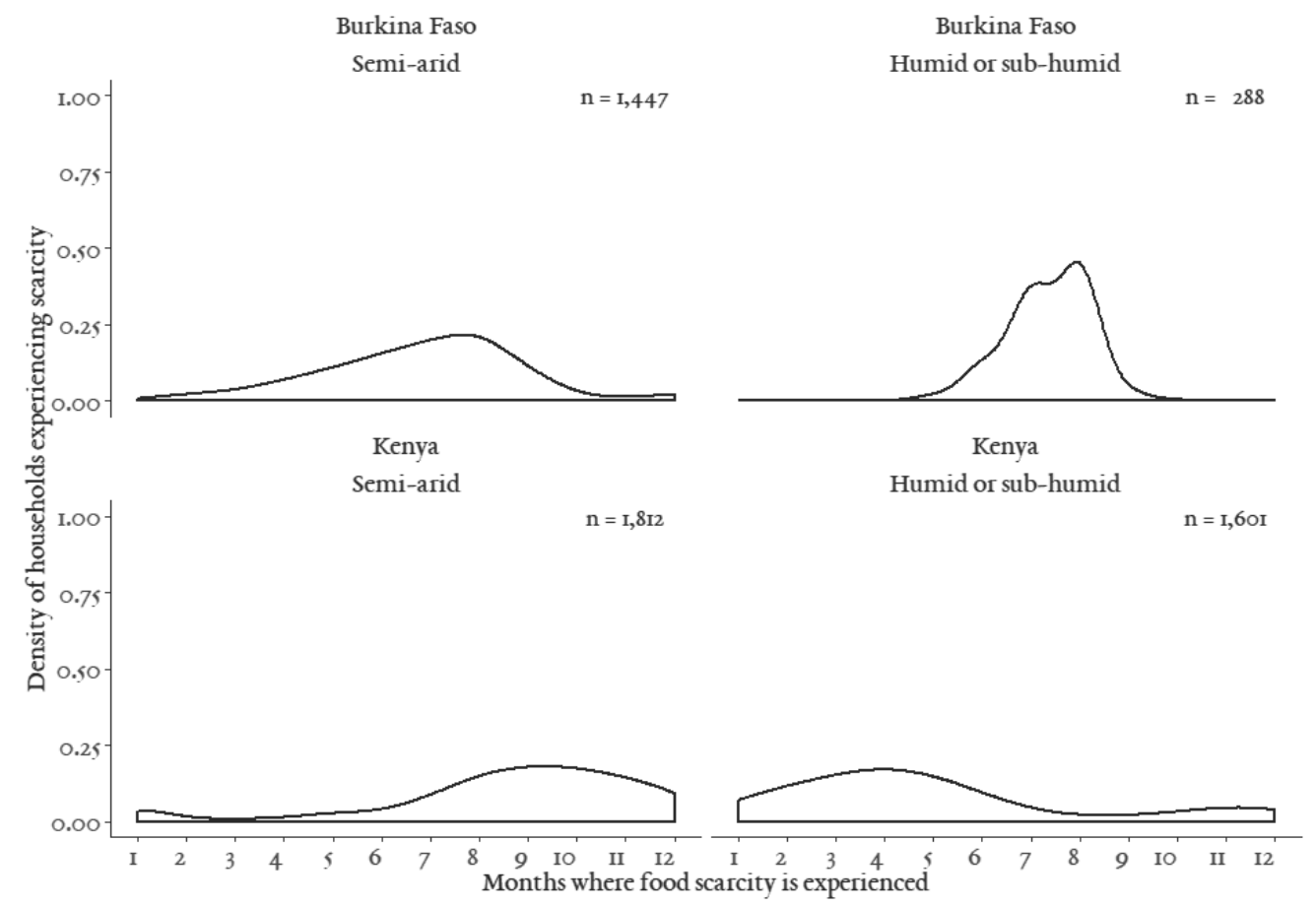

Figure 7.4 Food scarcity months (January to December) of sampled households in Burkina Faso (n = 1070) and Kenya $(n=1030)$ sample by AEZ

(Observations from Chapter 6 only)

Increased exposure to climatic and market shocks have direct implications for the stability of food and nutrition security (Ruel et al., 2018; Tomich et al., 2018; Jaenicke \& Virchow, 2013; Hussein \& Nelson, 1998). Chapter 4 provides a case-study of households rapidly changing their climatic and market risk exposure. In Lushoto, Tanzania, households were found to be dynamic, making substantial changes to their farm over the course of three years. There appeared to be different approaches to market and climatic risks between the two higher performing clusters 
of households. The first cluster of households cultivated more land, with a portfolio of coffee, tomatoes, market vegetables, staples as well as keeping livestock species (agrobiodiverse production); the second cluster of households focused on livestock and staple crops. These differing production compositions have implications for risk exposure. Households in the first cluster may be less resilient to shocks in labour availability (e.g. due to ill health). Households in the second cluster may be more exposed to climatic and market risks due to a reliance on a limited range of crops and the absence of livestock. Notably, social safety-nets in the region have changed considerably over the past 30 years, where "Access to unimproved subsistence land ... was still accepted as every resident's right... right up until the end of 1988" (Feierman, 1990, p. 183), and now safety-nets are based on family and social networks.

The role of agrobiodiversity (count of species) in the long-term stability of food and nutritional security was discussed in Chapter 5. While production diversity has a logical link with micronutrient sufficiency, the direct association with agrobiodiversity was weak (see also Berti, 2015). Rather, agrobiodiversity can co-exist with a market orientated strategy and provide risk management functions (Waha et al., 2018; Jaenicke \& Virchow, 2013; Tscharntke et al., 2012). Livestock keeping - as part of a diversified portfolio - provides soil health benefits through the recycling of nutrients, as well as reducing livelihood risk by being a means to store capital (Moll, 2005; Slingerland, 2000). Similarly, diversified crop production can contribute to pest and disease management; reduce the market risk of volatile prices, and; can also be a part of a soil health strategy (e.g. nitrogen fixation or cover cropping to reduce erosion; Lin, 2011). Each of these benefits can reduce the risk exposure of a livelihood, specifically in relation to environmental or economic shocks. The packaging of interventions, therefore, would be appealing to production and income diversified rural households - where they can adopt the most suitable innovations for their livelihoods.

\subsubsection{Women's empowerment and food security}

Land management, practice adoption and food access decisions are mediated by intra-household dynamics (Stirling, et al., submitted; Tavenner et al., submitted; Dzanku, 2019; Price et al., 2018; Andersson Djurfeldt, 2018a; Haider et al., 2018; Kazianga \& Wahhaj, 2017; Galiè et al., 2015). The empowerment of women - in particular - has been found to be central in changing diets and improving nutritional status (Figure 7.3; Rao et al., 2018; Price et al., 2018; Jaenicke \& Virchow, 2013). As an extension of the analysis in Chapter 6, Table 7.1 presents a summary of households by gender of household head. In line with Andersson Djurfeldt (2018a), these extended results suggest that there was a significant asset bias against female-headed households - cultivating less land and owning fewer heads of cattle (Table 7.1). Female-headed households exhibited a similar level of market participation to their male-headed counterparts. Despite this negative asset bias, female-headed households have comparable energy adequacy ratios from own-farm consumption, duration of scarcity and diet diversity in the lean period - when compared to male-headed households (Table 7.1). Chronic hunger, however, was found to be associated with female headship (Table 6.3). These findings indicate that the prevailing asset biases are the central areas for concern - whether they be cultural or financial. 
Table 7.1 Livelihood characteristics and food security status by head of household (median; $n=6,343$ )

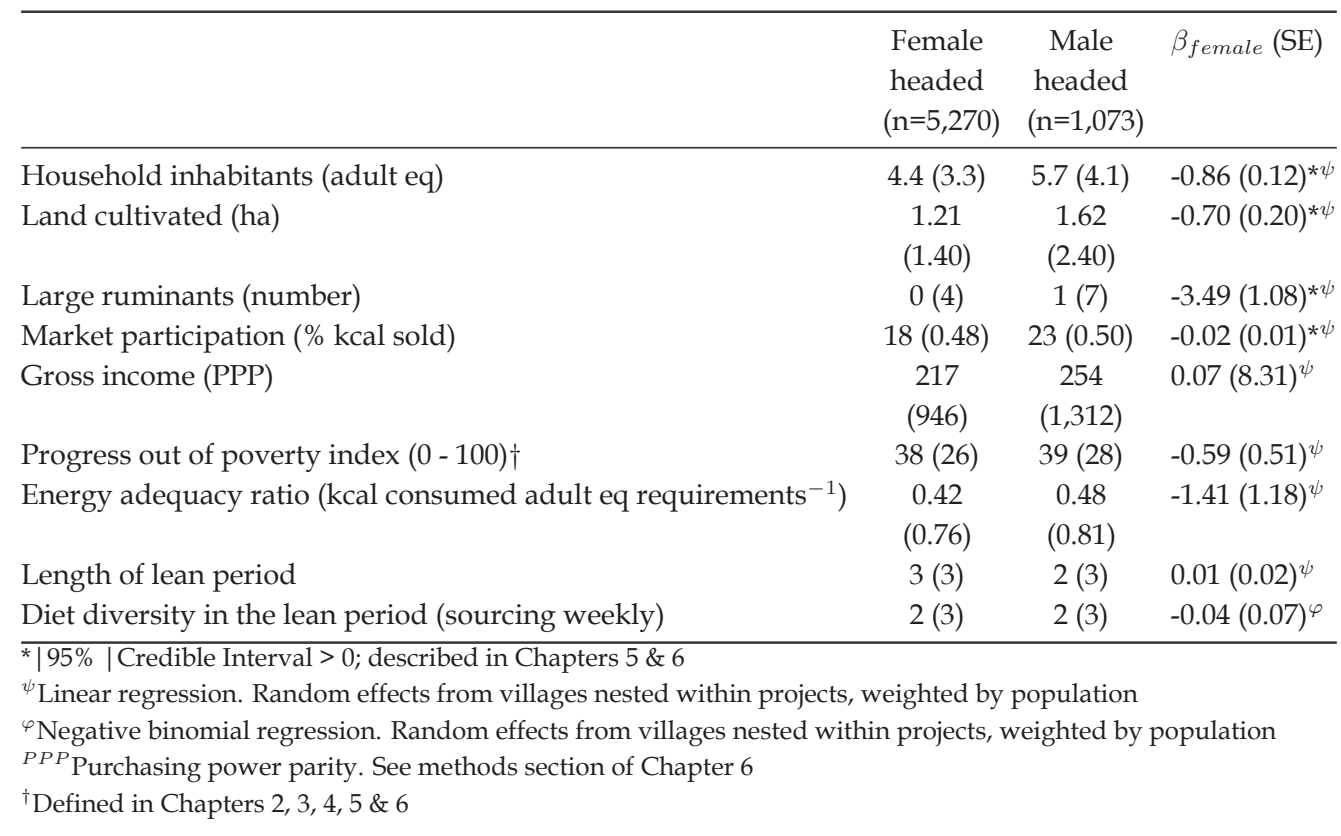

The differences between male-headed and female-headed households demonstrate that gender is an important mediating factor in accessing productive assets and therefore in mediating food security status. It is also expected that the empowerment of women will have an influence on food security within male-headed households (Dzanku, 2019; Price et al., 2018; Andersson Djurfeldt, 2018a). Studies related to this thesis have used the RHOMIS database to identify associations between the empowerment of women and practice adoption (Stirling et al., submitted), as well as the empowerment of women and market orientation (Tavenner et al., submitted). To explore the role of gender in mediating food security empirically, we first calculated a gender equity indicator, quantifying gender disaggregated labour allocation, decision-making, asset ownership and control of income (Chapter 2). This indicator was used in exploratory analysis but was not found to be associated with the various food security indicators. This gender equity indicator was then disaggregated into labour allocation, decision-making, ownership of assets and control of income. Again, these metrics were not found to be associated with food security indicators. However, just because this thesis did not identify associations between food security and gender within male headed households, it does not negate the importance of gender. Rather, it may be a limitation of the quantitative indicator or the analytical approach used in this thesis.

Quantifying complex social dynamics in a cross-sectional interview is challenging. This challenge is compounded by the diversity of surveyed communities. The formulation of questions on labour allocation, decision making, ownership of assets and control of income can be stan- 
dardised in a protocol and through enumerator training. For example, a protocol may specify question phrasing, such as: "How much of the income from milk sales did you control? Where control means that you had full discretion to spend.". However, in such a brief visit to a household, it is difficult to know exactly how the respondent interpreted such an intricate question. For example, one may have full autonomy to spend the income from milk sales, but social norms and power dynamics dictate the expenditure. Alternatively, the gender of the respondent may bias the answers given (Tavenner et al., 2018). The developers of the Women's Empowerment in Agriculture Index (WEAI) addressed these limitations by pre-testing the WEAI in several countries and running 'cognitive testing' by language group and by interviewing men and women separately (Malapit et al., 2015). The resulting questions did inform the design of RHOMIS, but could not be incorporated in its entirety due to the risk of respondent fatigue (adding 30 to 60 minute duration for both the male and female respondent). In 2017, an Abbreviated Women's Empowerment in Agriculture Index (A-WEAI) was piloted, reducing survey time by 30\% (Malapit et al., 2017). Follow-up questions have also been introduced, such as: “To what extent do you feel you can make your own personal decisions?". The three A-WEAI modules currently not represented in RHOMIS are: leadership, group membership and detailed time allocation. These question revisions and modules could be piloted in future RHOMIS implementations. However, from the perspective of better understanding food security, the focus needs to be on labour allocation, decision making and income control. These aspects of gender dynamics will have a direct link with nutritional requirements, and food consumption and purchasing decisions. Indeed, the recent methodological advances in this domain may well provide the crucial empirical understanding needed to better design nutrition-sensitive interventions.

\subsection{Further methodological advances for measuring food and nu- trition security}

In this thesis multiple indicators were used to characterise food security and rural livelihoods. Indicators of food security included food availability, food security of access, diet diversity, food-self-sufficiency (adequacy ratios), sources of micronutrients and duration of food scarcity. The results of this thesis have implications for prioritising intervention beneficiaries, designing interventions and combining interventions into packages to meet the full nutritional needs of rural households throughout the year. Based on the progress in this thesis, there are a number of opportunities to improve methodologically. Specifically, further methodological advances can be made in the following areas: understanding intra-household dynamics; associating dietary proxies with nutrition and health; and, better quantifying dietary choices and obesity. These four developments can reduce the uncertainty around the associations identified in this thesis, and provide a richer understanding of food and nutrition security in rural landholding households.

Limiting our scope to the household level automatically constrained the depth of analysis. As 
such, it is not always clear whether we can translate household level findings into consequences for individual members of the family, for example, young children (Caraher, 2016). Enumerating at the individual level using the RHOMIS tool can be infeasible and result in additional error. Instead, households can be revisited for more in-depth studies. For example, Steinke et al. (submitted) conducted in-depth interviews with 15 high performing households from the database used in Chapter 6. In this study, Steinke et al. (submitted) found that these 'positive deviants' tended to have one or more of the following traits - meticulous labour scheduling, collaborative arrangements with neighbours and opportunistic with small-scale off-farm business. Future in-depth studies could explore the intra-household dynamics of food and nutrition security - including the role of gender and the provision of nutrition in the first 1000 days (Sharma et al., 2017; de Pee et al., 2017).

In this thesis, we assessed a diverse but limited set of indicators and associations. Although agriculture is a crucial determinant of food and nutrition security in landholding households, it is important to understand interactions with factors like education, gender, breastfeeding practices, food preparation, nutritional supplementation, sanitation and instance of disease to understand the full nutritional, and health consequences of the findings. A substantial number of studies have reported the benefits of food security of access and a diverse diet on intermediary nutrition outcomes, such and child and maternal intake of 'target' foods and micronutrients (e.g. Some \& Jones, 2018; Bellon et al., 2016; Koppmair et al., 2016; Luckett et al., 2015; Sibhatu et al., 2015; Snapp \& Fisher, 2015; and Dillon et al., 2014; Siegel et al., 2014). Evidence of impact on nutrition outcomes - particularly child anthropometry and micronutrient status - was much more limited (e.g. Headey et al., 2018a; Gillespie et al., 2017; Rah et al., 2010; Saha et al., 2009), stressing the limitations of using indicators like dietary diversity when inferring nutritional consequences.

By enumerating broad food categories, this thesis has been constrained in assessing the quality of diets - particularly from purchased foods. In part, dietary choices are driven by the retail environment, resulting in increased consumption of processed and sweetened foods (categorised as 'grains, roots, tubers and banana'; 'dairy'), increased instances of obesity and a higher burden of disease (Demmler et al., 2018; GBD 2016 Risk Factors Collaborators, 2017; Popkin, 2014). With the rising burden of obesity, it will be important to better characterise purchased foods and consumption behaviour (Prentice, 2018). Such an evidence base will aid in the ambition to alleviate all forms of malnutrition. 


\subsection{Main conclusions}

This thesis sought to characterise food and nutrition security in rural landholding households of sub-Saharan Africa. The results of this thesis have implications for global efforts to alleviate chronic and hidden hunger.

- Agrobiodiversity can co-exist with a market orientated strategy and provide risk management functions.

- There was a high prevalence of chronic and hidden hunger, which was variable between and within regions.

- The gender of household head and stage of life influence livelihood characteristics (specifically resource availability), household requirements and thus food security. Several livelihood characteristics were identified to be associated with food security - including size of land area, size of livestock holdings, production diversity, level of gross income and extent of income diversification. It is the combination of these livelihood characteristics that influence food security status. The highest performing combination of livelihood characteristics differed by agro-ecological zone.

- Households fail to purchase food categories that nutritionally complement their own agricultural production. Therefore, improving food security through rural livelihoods requires nutrition-sensitive and nutrition specific interventions to increase supply, add nutritional value through the own-farm channel and increase demand for nutritious foods.

- Identifying dietary gaps of sub-populations can facilitate the targeting of interventions. Furthermore, programs can be designed as 'packages' of agricultural and non-agricultural interventions to maximise adoption and impact. 


\section{References}

Akombi, B. J., Agho, K. E., Hall, J. J., Wali, N., Renzaho, A. M. N., \& Merom, D. (2017). Stunting, Wasting and Underweight in Sub-Saharan Africa: A Systematic Review. (pp. 1-18). doi:10.3390/ijerph14080863.

Alkire, S., Malapit, H., Meinzen-Dick, R., Peterman, A., Quisumbing, A., Seymour, G., \& Vaz, A. (2013). Instructional Guide on the Women's Empowerment in Agriculture Index.

Alwin, D. F. (2006). Margins of Error: A Study of Reliability in Survey Measurement. New Jersey: John Wiley \& Sons, Inc. doi:10.1002/9780470146316.

Andersson Djurfeldt, A. (2018a). Assets, Gender, and Rural Livelihoods. In A. Andersson Djurfeldt, F. Mawunyo Dzanku, \& A. Isinika (Eds.), Agriculture, Diversification, and Gender in Rural Africa: Longitudinal Perspectives from Six Countries December chapter 3. (pp. 1-43). Oxford: Oxford University Press. (1st ed.). doi:10.1093/oso/9780198799283.001.0001.

Andersson Djurfeldt, A. (2018b). Gender and Rural Livelihoods: Agricultural Commercialization and Farm / Non-Farm Diversification. In A. Andersson Djurfeldt, F. Mawunyo Dzanku, \& A. Isinika (Eds.), Agriculture, Diversification, and Gender in Rural Africa: Longitudinal Perspectives from Six Countries December chapter 4. (pp. 1-72). Oxford: Oxford University Press. (1st ed.). doi:10.1093/oso/9780198799283.001.0001.

Andersson Djurfeldt, A., Mawunyo Dzanku, F., \& Isinika, A. (2018). Agriculture, Diversification, and Gender in Rural Africa: What Lessons Can We Learn? In A. Andersson Djurfeldt, F. Mawunyo Dzanku, \& A. Isinika (Eds.), Agriculture, Diversification, and Gender in Rural Africa: Longitudinal Perspectives from Six Countries December chapter 11. (pp. 1-11). Oxford: Oxford University Press. (1st ed.). doi:10.1093/oso/9780198799283.001.0001.

Arimond, M., \& Ruel, M. T. (2004). Community and International Nutrition Dietary Diversity Is Associated with Child Nutritional Status: Evidence from 11 Demographic and Health Surveys. The Journal of Nutrition, 134, 2579 - 2585. doi:10.1093/jn/134.10.2579.

Ashley, C., \& Carney, D. (1999). Sustainable livelihoods: Lessons from early experience. Technical Report.

Barrett, C., Reardon, T., \& Webb, P. (2001). Nonfarm income diversification and household livelihood strategies in rural Africa: concepts, dynamics, and policy implications. Food Policy, 26, 315-331. doi:10.1016/S0306-9192(01)00014-8.

Bates, D (2017). Package 'lme4'.

Beegle, K., Carletto, C., \& Himelein, K. (2012). Reliability of recall in agricultural data. Journal of Development Economics, 98, 34-41. doi:10.1016/j.jdeveco.2011.09.005.

Bellon, M. R., Ntandou-Bouzitou, G. D., \& Caracciolo, F. (2016). On-farm diversity and market participation are positively associated with dietary diversity of rural mothers in southern Benin, west Africa. PLoS ONE, 11, 1-20. doi:10.1371/journal.pone.0162535.

Berti, P. (2015). Relationship between production diversity and dietary diversity depends on how number of foods is counted. Proceedings of the National Academy of Sciences of the United States of America, 112, 1. doi:10.1073/pnas.1517006112.

Bhandari, A. (2017). Women's status and global food security: An overview. (pp. 1-17). doi:10.1111/soc4.12479.

Bhutta, Z. A., Das, J. K., Rizvi, A., Gaffey, M. F., Walker, N., Horton, S., Webb, P., Lartey, A., \& Black, 
R. E. (2013). Evidence-based interventions for improvement of maternal and child nutrition: What can be done and at what cost? The Lancet, 382, 452-477. doi:10.1016/S0140-6736(13)60996-4.

Biber-freudenberger, L., Ziemacki, J., \& Tonnang, H. E. Z. (2016). Future Risks of Pest Species under Changing Climatic Conditions. (pp. 1-17). doi:10.1371/journal.pone.0153237.

Blaikie, P., Cannon, T., Davis, I., \& Wisner, B. (1994). At risk: natural hazards, people's vulnerability and disasters. Routledge.

Bosc, P., Berdegué, J., Goïta, M., van der Ploeg, J., Sekine, K., Zhang, L., \& HLPE (2013). Investing in Smallholder Agriculture for Food Security. Technical Report June, WUR Wageningen. URL: http:// www. fao .org/. doi:10.1111/j.1467-9353.2008.00425.x. arXiv :arXiv:1011.1669v3.

Bouis, H. E., \& Saltzman, A. (2017). Improving nutrition through biofortification: A review of evidence from HarvestPlus , 2003 through 2016 volume 12. Elsevier B.V. doi:10.1016/j.gfs.2017.01.009.

Bovin, M. (1990). Nomads of the drought: Fulbe and Wodaabe nomads between power and marginalization in the Sahel of Burkina Faso and Niger Republic. In M. Bovin, \& L. Manger (Eds.), Adaptive strategies in African arid lands (pp. 29-57). Uppsala: Scandinavian Institute of African Studies.

de Brauw, A., Mueller, V., \& Lee, H. L. (2014). The role of rural-urban migration in the structural transformation of Sub-Saharan Africa. World Development, 63, 33-42. doi:10.1016/j.worlddev.2013.10.013.

Breslow N. E., \& Clayton, N. E. (1993). Approximate Inference in Generalized Linear Mixed Models. Journal of the American Statistical Association, 88, 9 - 25.

Brown, K. H., Wuehler, S. E., \& Peerson, J. M. (2001). The importance of zinc in human nutrition and estimation of the global prevalence of zinc deficiency. 22, 113-125. doi:10.1177/156482650102200201.

Buerkner, P, C. (2016). Package 'brms'.

Burchi, F., \& Muro, P. D. (2016). From food availability to nutritional capabilities: Advancing food security analysis. Food Policy, 60, 10-19. doi:10.1016/j.foodpol.2015.03.008.

Campbell, B., Mann, W., Meléndez-Ortiz, R., Streck, C., \& Tennigkeit, T. (2011). Agriculture and Climate Change: A Scoping Report. Agriculture and Climate Change: A Scoping Report.

Caraher, M. (2016). Food Poverty and Insecurity: International Food Inequalities. doi:10.1007/978-3-31923859-3.

Carletto, C., Corral, P., \& Guelfi, A. (2017). Agricultural commercialization and nutrition revisited: Empirical evidence from three African countries. Food Policy, 67, 106-118. doi:10.1016/j.foodpol.2016.09.020.

Carletto, C., Gourley, S., Murry, S., \& Zezza, A. (2016). Cheaper, Faster, and More Than Good Enough Is GPS the New Gold Standard in Land Area Measurement?.

Carletto, C., Jolliffe, D., \& Banerjee, R. (2015a). From Tragedy to Renaissance: Improving Agricultural Data for Better Policies. Journal of Development Studies, 51, 133-148. doi:10.1080/00220388.2014.968140.

Carletto, C., Savastano, S., \& Zezza, A. (2011). Fact or artefact: the impact of measurement errors on the farm size - productivity relationship.

Carletto, C., Zezza, A., \& Banerjee, R. (2013). Towards better measurement of household food security: Harmonizing indicators and the role of household surveys. Global Food Security, 2, 30-40. doi:10.1016/j.gfs.2012.11.006.

Carletto, G. (2009). Improving the Availability, Quality and Policy-Relevance of Agricultural Data: The Living Standards Measurement Study - Integrated Surveys on Agriculture. Technical Report. 
Carletto, G., Ruel, M., Winters, P., \& Zezza, A. (2015b). Farm-Level Pathways to Improved Nutritional Status: Introduction to the Special Issue. The Journal of Development Studies, 51, 945-957. doi:10.1080/00220388.2015.1018908.

Champely, S. (2018). pwr: Basic Functions for Power Analysis.

Christiaensen, L. (2017). Agriculture in Africa - Telling myths from facts: A synthesis. Food Policy, 67, 1-11. doi:10.1016/j.foodpol.2017.02.002.

Central Intelligence Agency of the USA (CIA) (2016a). Death rate: Country Comparison to the World.

Central Intelligence Agency of the USA (CIA) (2016b). Urbanisation: Country Comparison to the World.

Claro, Rafael, M., Levy, R. B., Bandoni, D. H., \& Mondini, L. (2010). Per capita versus adult-equivalent estimates of calorie availability in household budget surveys. Cad Saude Publica, 26, 2188-2195.

Coates, J. (2013). Build it back better: Deconstructing food security for improved measurement and action. Global Food Security, 2, 188-194. doi:10.1016/j.gfs.2013.05.002.

Coates, J., \& Bilinsky, P. (2007). Household Food Insecurity Access Scale (HFIAS) for Measurement of Food Access: Indicator Guide. Technical Report, FHI 360/FANTA Washington, DC.

Coates, J., Frongillo, E. A., Rogers, B. L., Webb, P., Wilde, P. E., \& Houser, R. (2006). Commonalities in the experience of household food insecurity across cultures: What are measures missing? The Journal of Nutrition, 136, 1438S-1448S.

Davis, B., Di Giuseppe, S., \& Zezza, A. (2017). Are African households (not) leaving agriculture? Patterns of households' income sources in rural Sub-Saharan Africa. Food Policy, 67, 153-174. doi:10.1016/j.foodpol.2016.09.018.

Davis, B., Winters, P., Carletto, G., Covarrubias, K., Quiñones, E. J., Zezza, A., Stamoulis, K., Azzarri, C., \& DiGiuseppe, S. (2010). A Cross-Country Comparison of Rural Income Generating Activities. World Development, 38, 48-63. doi:10.1016/j.worlddev.2009.01.003.

De Weerdt, J., Beegle, K., \& Gibson, J. (2015). The Challenge of Measuring Hunger through Survey. LICOS Discussion Paper Series, Discussion Paper 365/2015, (p. 36).

Deininger, K., Carletto, C., Savastano, S., \& Muwonge, J. (2011). Can Diaries Help Improve Agricultural Production Statistics? Evidence from Uganda.

Demmler, K. M., Ecker, O., \& Qaim, M. (2018). Supermarket Shopping and Nutritional Outcomes: A Panel Data Analysis for Urban Kenya. World Development, 102, 292-303. doi:10.1016/j.worlddev.2017.07.018.

Desiere, S., Hung, Y., Verbeke, W., \& Haese, M. D. (2018). Assessing current and future meat and fish consumption in Sub-Sahara Africa: Learnings from FAO Food Balance Sheets and LSMS household survey data. Global Food Security, 16, 116-126. doi:10.1016/j.gfs.2017.12.004.

Desiere, S., Vellema, W., \& D'Haese, M. (2015). A validity assessment of the Progress out of Poverty Index (PPI). Evaluation and Program Planning, 49, 10-18. doi:10.1016/j.evalprogplan.2014.11.002.

Dhanarajan, A. (2017). Sustainable agriculture towards food security.. doi:10.1007/978-981-10-6647-4.

Dillon, A., Mcgee, K., \& Oseni, G. (2014). Agricultural Production, Dietary Diversity, and Climate Variability.

Dorward, A. (2009). Integrating Contested Aspirations, Processes and Policy: Development as Hanging In, Stepping Up and Stepping Out. Development Policy Review, 27, 131-146. doi:10.1111/j.1467-7679.2009.00439.x. 
Doss, C. (2013). Intrahousehold Bargaining and Resource ocation in Developing Countries. The World Bank. doi:doi:10.1596/1813-9450-6337.

Dowler, E. A., \& Seo, Y. O. (1985). Assessment of energy intake. Estimates of food supply v measurement of food consumption. Food Policy, 10, 278-288. doi:10.1016/0306-9192(85)90066-1.

Dzanku, F. M. (2019). Food security in rural sub-Saharan Africa: Exploring the nexus between gender, geography and off-farm employment. World Development, 113, 26-43. doi:10.1016/j.worlddev.2018.08.017.

European Food Safety Authority (EFSA) (2017). Dietary Reference Values for nutrients Summary report. doi:10.2903/sp.efsa.2017.e15121.

Enahoro, D., Lannerstad, M., Pfeifer, C., \& Dominguez-Salas, P. (2018). Contributions of livestockderived foods to nutrient supply under changing demand in low- and middle-income countries. Global Food Security, 19, 1-10. doi:10.1016/j.gfs.2018.08.002.

Evans, B. (1995). On the difference between reliability of measurement and precision of survey instruments. The Canadian Journal of Program Evaluation, 10, 17-32.

Falconnier, G. N., Descheemaeker, K., Van Mourik, T. A., Sanogo, O. M., \& Giller, K. E. (2015). Understanding farm trajectories and development pathways: Two decades of change in southern Mali. Agricultural Systems, 139, 210-222. doi:10.1016/j.agsy.2015.07.005.

Fanzo, J. (2018). The role of farming and rural development as central to our diets. Physiology and Behavior, 193, 291-297. doi:10.1016/j.physbeh.2018.05.014.

Farrington, J., Carney, D., Ashley, C., \& Turton, C. (1999). Sustainable livelihoods in practice: early applications of concepts in rural areas part A. Technical Report 42.

Fecso, R. (2011). A Review of Errors of Direct Observation in Crop Yield Surveys. In P. P. Biemer, R. M. Groves, L. E. Lyberg, N. A. Mathiowetz, \& S. Sudman (Eds.), Measurement errors in surveys chapter 17. (pp. 327-346). Hoboken: John Wiley \& Sons, Inc. doi:10.1002/9781118150382.ch17.

Feierman, S. (1990). Peasant Intellectuals. The University of Wisconsin Press.

Fellows, I (2012). Package 'deducer'.

Finn, A., \& Ranchhod, V. (2017). Genuine Fakes: The Prevalence and Implications of Data Fabrication in a Large South African Survey. The World Bank Economic Review, 31, 129-157. doi:10.1093/wber/lhv054.

Fiorella, K. J., Chen, R. L., Milner, E. M., \& Fernald, L. C. H. (2016). Agricultural interventions for improved nutrition: A review of livelihood and environmental dimensions. Global Food Security, 8, 39-47. doi:10.1016/j.gfs.2016.03.003.

Fisher, M., Reimer, J. J., \& Carr, E. R. (2010). Who should be interviewed in surveys of household income? World Development, 38, 966-973. doi:10.1016/j.worlddev.2009.11.024.

Fonte, S. J., Vanek, S. J., Oyarzun, P., Parsa, S., Quintero, D. C., Rao, I. M., \& Lavelle, P. (2012). Pathways to Agroecological Intensification of Soil Fertility Management by Smallholder Farmers in the Andean Highlands. In Advances in Agronomy chapter 4. (pp. 125-184). Burlington: Elsevier Inc. volume 116. (1st ed.). doi:10.1016/B978-0-12-394277-7.00004-X.

Food and Agriculture Organisation of the UN (FAO) (1997). Guidelines for use of nutrition and health claims. Technical Report, FAO Rome. URL: http://www.fao.org/ag/humannutrition/ 32444-09f5545b8abe9a0c3baf01a4502ac36e4.pdf.

Food and Agricuture Organisation of the UN (FAO) (2001). Human energy requirements: Report of 
a Joint FAO/WHO/UNU Expert Consultation. FAO Food and Nutrition Technical Report Series, 0, 96. doi:92 51052123.

Food and Agriculture Organisation of the UN (FAO) (2002). Country Pasture/Forage Resource Profiles: Burkina.

Food and Agriculture Organisation of the UN (FAO) (2008). An introduction to the basic concepts of food security. Technical Report 1, Food and Agriculture Organisation of the United Nations Rome. URL: http://www.ncbi.nlm.nih.gov/pubmed/21812205\{\%\}5Cnhttp://jn. nutrition. org/content/140/1/153S . abstract $\{\%$ \} Snhttp://link. springer.com/10.1007/ s11205-009-9455-4\{\%\}5Cnhttp://www.fao.org/docrep/013/al936e/al936e00.pdf \{\%\}5Cnwww. andes.info.ec/es/noticias/fao-ecuador-boli. doi:10.1007/s11524-010-9491-z.

Food and Agriculture Organisation of the UN (FAO) (2012). West African Food Composition Table. Rome: FAO.

Food and Agriculture Organisation of the UN (FAO) (2013). Climate smart agriculture. (p. 570). doi:10.1007/978-3-319-61194-5.

Food and Agriculture Organisation of the UN (FAO) (2016). Can smallholders double their productivity and incomes by 2030 ?

Food and Agricuture Organisation of the UN (FAO) (2017a). Food Price Monitoring and Analysis. Technical Report. URL: http://www.fao.org/giews/food-prices/tool/public/index.html\{\#\}/home.

Food and Agricuture Organisation of the UN (FAO) (2017b). Statistical Programme. Technical Report.

Food and Agriculture Organisation of the UN (FAO), \& FHI360 (2016). Minimum Dietary Diversity for Women- A Guide to Measurement.

Food and Agriculture Organisation of the UN (FAO), International Fund for Agricultural Development (IFAD), UNICEF, WFP, \& WHO (2018). The State of Food Security and Nutrition in the World 2018. Building climate resilience for food security and nutrition. Technical Report, Rome.

Food and Agriculture Organisation of the UN (FAO), \& Organisation for Economic Co-operation and Development (OECD) (2015). OECD - FAO Agricultural Outlook 2011-2020. August 2010. doi:10.1017/CBO9781107415324.004. arXiv:arXiv:1011.1669v3.

Food and Agriculture Organisation of the UN (FAO) \& World Health Organisation (WHO) (2004). Vitamin and mineral requirements in human nutrition Second edition.

Förch, W., Kristjanson, P., Cramer, L., Barahona, C., \& Thornton, P. K. (2014). Back to baselines: Measuring change and sharing data. Agriculture and Food Security, 3. doi:10.1186/2048-7010-3-13.

Fraval, S., Hammond, J., Lannerstad, M., Oosting, S. J., Sayula, G., Teufel, N., Silvestri, S., Poole, E. J., Herrero, M., \& van Wijk, M. T. (2018). Livelihoods and food security in an urban linked, high potential region of Tanzania: Changes over a three year period. Agricultural Systems, 160, 87-95. doi:10.1016/j.agsy.2017.10.013.

Frelat, R., Lopez-Ridaura, S., Giller, K. E., Herrero, M., Douxchamps, S., Djurfeldt, A. A., Erenstein, O., Henderson, B., Kassie, M., Paul, B. K., Rigolot, C., Ritzema, R. S., Rodriguez, D., Van Asten, P. J. A., \& Van Wijk, M. T. (2016). Drivers of household food availability in sub-Saharan Africa based on big data from small farms. Proceedings of the National Academy of Sciences of the United States of America, 113, 458-463. doi:10.1073/pnas.1518384112.

Galiè, A., Mulema, A., Mora Benard, M. A., Onzere, S. N., \& Colverson, K. E. (2015). Exploring gender perceptions of resource ownership and their implications for food security among rural livestock own- 
ers in Tanzania, Ethiopia, and Nicaragua. Agriculture E Food Security, 4, 2. doi:10.1186/s40066-0150021-9.

Garrity, D., Dixon, J., \& Boffa, J. (2012). Science and Policy Implications. Technical Report, ACIAR Canberra. URL: http://aciar.gov.au/aifsc/sites/default/files/images/ understanding $\left\{_{-}\right\} \operatorname{african}\left\{\_\right\}$farming $\left\{{ }_{-}\right\}$systems $\left\{_{-}\right\} 11\left\{_{-}\right\} \operatorname{dec}\left\{\_\right\}$update.pdf.

GBD 2016 Risk Factors Collaborators (2017). Global, regional, and national comparative risk assessment of 84 behavioural, environmental and occupational, and metabolic risks or clusters of risks, 1990-2016: A systematic analysis for the Global Burden of Disease Study 2016. The Lancet, 390, 13451422. doi:10.1016/S0140-6736(17)32366-8.

Gebrechorkos, S. H., Hülsmann, S., \& Bernhofer, C. (2018). Changes in temperature and precipitation extremes in Ethiopia, Kenya, and Tanzania. International Journal of Climatology, (pp. 1-13). doi:10.1002/joc.5777.

Gibson, J., Beegle, K., De Weerdt, J., \& Friedman, J. (2015). What does variation in survey design reveal about the nature of measurement errors in household consumption? Oxford Bulletin of Economics and Statistics, 77, 466-474. doi:10.1111/obes.12066.

Giller, K. E., Tittonell, P., Rufino, M. C., van Wijk, M. T., Zingore, S., Mapfumo, P., Adjei-Nsiah, S., Herrero, M., Chikowo, R., Corbeels, M., Rowe, E. C., Baijukya, F., Mwijage, A., Smith, J., Yeboah, E., van der Burg, W. J., Sanogo, O. M., Misiko, M., de Ridder, N., Karanja, S., Kaizzi, C., K'ungu, J., Mwale, M., Nwaga, D., Pacini, C., \& Vanlauwe, B. (2011). Communicating complexity: Integrated assessment of trade-offs concerning soil fertility management within African farming systems to support innovation and development. Agricultural Systems, 104, 191-203. doi:10.1016/j.agsy.2010.07.002.

Gillespie, S., Bold, M. V. D., \& Team, S. (2017). Stories of Change in nutrition: An overview. 13, 1-11. doi:10.1016/j.gfs.2017.02.004.

Global Yield Gap Atlas (2016). Global Yield Gap Atlas.

Gobbo, L. C. D., Khatibzadeh, S., Imamura, F., Micha, R., Shi, P., Smith, M., \& Myers, S. S. (2015). Assessing global dietary habits: a comparison of national estimates from the FAO and the Global Dietary Database 1 - 4. American Journal of Clinical Nutrition, (pp. 1038-1046). doi:10.3945/ajcn.114.087403.INTRODUCTION.

Gödecke, T., Stein, A. J., \& Qaim, M. (2018). The global burden of chronic and hidden hunger: Trends and determinants. Global Food Security, 17, 21-29. doi:10.1016/j.gfs.2018.03.004.

Gollin, D. (2006). Impacts of International Research on Intertemporal Yield Stability in Wheat and Maize: an economic assessment. Mexico: CIMMYT.

Grameen foundation (2015). Progress out of Poverty Index..

Green, R., Sutherland, J., Dangour, A. D., Shankar, B., \& Webb, P. (2016). Global dietary quality, undernutrition and non-communicable disease: a longitudinal modelling study. BMJ Open, (pp. 1-10). doi:10.1136/bmjopen-2015-009331.

GSMA Intelligence (2016). The Mobile Economy. Technical Report, GSM Association London.

Haggblade, S., Hazell, P., \& Reardon, T. (2010). The Rural Non-farm Economy: Prospects for Growth and Poverty Reduction. World Development, 38, 1429-1441. doi:10.1016/j.worlddev.2009.06.008.

Haider, H., Smale, M., \& Theriault, V. (2018). Intensification and intrahousehold decisions: Fertilizer adoption in Burkina Faso. World Development, 105, 310-320. doi:10.1016/j.worlddev.2017.11.012.

Hammond, J. (2018). A scalable approach for efficient and comparable characterisation of smallholder farming 
systems: The Rural Household Multi-Indicator Survey. Ph.D. thesis Bangor University.

Hammond, J., Fraval, S., van Etten, J., Suchini, J. G., Mercado, L., Pagella, T., Frelat, R., Lannerstad, M., Douxchamps, S., Teufel, N., Valbuena, D., \& van Wijk, M. T. (2017). The Rural Household MultiIndicator Survey (RHoMIS) for rapid characterisation of households to inform climate smart agriculture interventions: Description and applications in East Africa and Central America. Agricultural Systems, 151, 225-233. doi:10.1016/j.agsy.2016.05.003.

Harahagazwe, D., Quiros, R., \& Sayula, G. (2014). Improving potato yields for farmers in the Usambara Highlands.

Harahagazwe, D., Quiroz, R., Kuoko, S., Recha, J., Radeny, M., Sayula, G., Schulte-geldermann, E., Brush, G., Msoka, E., Rimoy, M., Asfaw, A., Bonierbale, M., \& Atakos, V. (2016). Participatory Evaluation of Resilient Potato Varieties in Climate-Smart Villages of Lushoto in Tanzania.

Harika, R., Faber, M., Samuel, F., Mulugeta, A., Kimiywe, J., \& Eilander, A. (2017). Are Low Intakes and Deficiencies in Iron, Vitamin A, Zinc, and Iodine of Public Health Concern in Ethiopian, Kenyan, Nigerian, and South African Children and Adolescents? Food and Nutrition Bulletin, 38, 405-427. doi:10.1177/0379572117715818.

Harris, D., \& Orr, A. (2014). Is rainfed agriculture really a pathway from poverty? Agricultural Systems, 123, 84-96. doi:10.1016/j.agsy.2013.09.005.

Hartung, C., Anokwa, Y., Brunette, W., Lerer, A., Tseng, C., \& Borriello, G. (2010). Open data kit: Tools to build information services for developing regions. In ACM International Conference Proceeding Series. doi:10.1145/2369220.2369236.

Harvest Choice (2015). AEZ (16-class, 2009). Technical Report, International Food Policy Research Institute, Washington, DC., and University of Minnesota St. Paul. URL: http://harvestchoice.org/ data/aez16\{_\}clas.

Hazell, P., Poulton, C., Wiggins, S., \& Dorward, A. (2010). The Future of Small Farms: Trajectories and Policy Priorities. World Development, 38, 1349-1361. doi:10.1016/j.worlddev.2009.06.012.

Headey, D., Hirvonen, K., \& Hoddinott, J. (2018a). Animal Sourced Foods and Child Stunting. American Journal of Agricultural Economics, 100, 1302-1319. doi:10.1093/ajae/aay053.

Headey, D., Stifel, D., You, L., \& Guo, Z. (2018b). Remoteness , urbanization , and child nutrition in sub-Saharan Africa. 49, 765-775. doi:10.1111/agec.12458.

Henderson, B., Godde, C., Medina-Hidalgo, D., van Wijk, M., Silvestri, S., Douxchamps, S., Stephenson, E., Power, B., Rigolot, C., Cacho, O., \& Herrero, M. (2016). Closing system-wide yield gaps to increase food production and mitigate GHGs among mixed crop-livestock smallholders in Sub-Saharan Africa. Agricultural Systems, 143, 106-113. doi:10.1016/j.agsy.2015.12.006.

Hengl, T., Mendes De Jesus, J., Heuvelink, G. B. M., Gonzalez, M. R., Kilibarda, M., Blagotí, A., Shangguan, W., Wright, M. N., Geng, X., Bauer-Marschallinger, B., Guevara, M. A., Vargas, R., Macmillan, R. A., Batjes, N. H., Leenaars, J. G. B., Ribeiro, E., Wheeler, I., Mantel, S., \& Kempen, B. (2016). SoilGrids250m: Global Gridded Soil Information Based on Machine Learning.

Herrero, M., González-Estrada, E., Thornton, P. K., Quirós, C., Waithaka, M. M., Ruiz, R., \& Hoogenboom, G. (2007). IMPACT: Generic household-level databases and diagnostics tools for integrated crop-livestock systems analysis. Agricultural Systems, 92, 240-265. doi:10.1016/j.agsy.2006.03.008. arXiv: ILP.

Herrero, M., Thornton, P. K., Power, B., Bogard, J. R., Remans, R., Fritz, S., Gerber, J. S., Nelson, G., 
See, L., Waha, K., Watson, R. A., West, P. C., Samberg, L. H., van de Steeg, J., Stephenson, E., van Wijk, M., \& Havlík, P. (2017). Farming and the geography of nutrient production for human use: a transdisciplinary analysis. The Lancet Planetary Health, 1, e33-e42. doi:10.1016/S2542-5196(17)30007-4.

Hetherington, J. B., Wiethoelter, A. K., Negin, J., \& Mor, S. M. (2017). Livestock ownership, animal source foods and child nutritional outcomes in seven rural village clusters in SubSaharan Africa. Agriculture \& Food Security, (pp. 1-11). doi:10.1186/s40066-016-0079-z.

Hoddinott, J. (2012). Agriculture, health, and nutrition: Toward conceptualizing the linkages. In Reshaping Agriculture for Nutrition and Health February chapter 2. (pp. 13-20). Washington, DC: International Food Policy Research Institute. doi:10.2499/9780896296732.

Hussein, K., \& Nelson, J. (1998). Sustainable livelihood diversification.

International Fund for Agricultural Development (IFAD) (2016). Rural Development Report 2016.

International Fund for Agricultural Development (IFAD) (2018). Nutrition-sensitive value chains from a smallholder perspective.

Intergovernmental Panel on Climate Change (IPCC) (2006). IPCC guidelines for national greenhouse gas inventories: Volume 4: Agriculture, forestry and other land use. Technical Report, Intergovernmental Panel on Climate Change Paris. URL: http://www .ipcc-nggip.iges .or.jp/public/2006gl/vol4.html.

Islam, A., Edwards, D. G., \& Asher, C. J. (1980). pH optima for crop growth - Results of a flowing solution culture experiment with six species. Plant and Soil, 54, 339-357. doi:10.1007/BF02181830.

Jaenicke, H., \& Virchow, D. (2013). Entry points into a nutrition-sensitive agriculture. Food Security, 5, 679-692. doi:10.1007/s12571-013-0293-5. arXiv : arXiv: 1011 .1669v3.

James, W. P. T. (2018). From Treating Childhood Malnutrition to Public Health Nutrition. Annals of Nutrition and Metabolism, (pp. 202-209). doi:10.1159/000487273.

Janowiak, J. E. (1999). CAMS-OPI: A global satellite-rain gauge merged product for real-time precipitation monitoring applications. Journal of Climate, 12, 3335-3342. doi:10.1175/1520-0442(1999)012<3335:COAGSR>2.0.CO;2.

Jayne, T. S., Chamberlin, J., \& Headey, D. D. (2014). Land pressures, the evolution of farming systems, and development strategies in Africa: A synthesis. Food Policy, 48, 1-17. doi:10.1016/j.foodpol.2014.05.014.

Jayne, T. S., Chamberlin, J., Traub, L., Sitko, N., Muyanga, M., Yeboah, F. K., Anseeuw, W., Chapoto, A., Wineman, A., Nkonde, C., \& Kachule, R. (2016). Africa's changing farm size distribution patterns: the rise of medium-scale farms. Agricultural Economics, 47, 197-214. doi:10.1111/agec.12308.

Jayne, T. S., Yamano, T., Weber, M. T., Tschirley, D., Benfica, R., Chapoto, A., \& Zulu, B. (2003). Smallholder income and land distribution in Africa: Implications for poverty reduction strategies. Food Policy, 28, 253-275. doi:10.1016/S0306-9192(03)00046-0.

Jenkins, M., Shanks, C. B., Brouwer, R., \& Houghtaling, B. (2018). Factors affecting farmers' willingness and ability to adopt and retain vitamin A-rich varieties of orange-fleshed sweet potato in Mozambique. Food Security, doi:10.1007/s12571-018-0845-9.

Jerven, M., \& Johnston, D. (2015). Statistical Tragedy in Africa? Evaluating the Data Base for African Economic Development. The Journal of Development Studies, 51, 111-115. doi:10.1080/00220388.2014.968141.

Jin, M., \& Iannotti, L. L. (2014). Livestock production, animal source food intake, and young child growth: The role of gender for ensuring nutrition impacts. Social Science \& Medicine, 105, 16-21. 
doi:10.1016/j.socscimed.2014.01.001.

Johnson, K. B., \& Diego-Rosell, P. (2015). Assessing the cognitive validity of the women's empowerment in agriculture index instrument in the Haiti multi-sectoral baseline survey. Survey Practice, 8.

Jones, A. D. (2016). On-Farm Crop Species Richness Is Associated with Household Diet Diversity and Quality in Subsistence- and Market-Oriented Farming Households in Malawi. The Journal of Nutrition, 147, 86-96. doi:10.3945/jn.116.235879.The.

Joy, E. J. M., Ander, E. L., Young, S. D., Black, C. R., Watts, M. J., Chilimba, A. D. C., Chilima, B., Siyame, E. W. P., Kalimbira, A. A., Hurst, R., Fairweather-Tait, S. J., Stein, A. J., Gibson, R. S., White, P. J., \& Broadley, M. R. (2014). Dietary mineral supplies in Africa. Physiologia Plantarum, 151, 208-229. doi:10.1111/ppl.12144.

Juster, F. T., Cao, H., Couper, M., Hill, D., Hurd, M. D., Lupton, J., Perry, M., \& Smith, J. P. (2007). Enhancing the Quality of Data on the Measurement of Income and Wealth.

Kassambara, A., \& Mundt, F. (2016). factoextra: Extract and Visualize the Results of Multivariate Data Analyses.

Kazianga, H., \& Wahhaj, Z. (2017). Intra-household resource allocation and familial ties. Journal of Development Economics, 127, 109-132. doi:10.1016/j.jdeveco.2017.03.002.

Kennedy, G., Ballard, T., \& Dop, M. C. (2013). Guidelines for Measuring Household and Individual Dietary Diversity. (p. 53).

Kenward, M. G., \& Roger, J. H. (1997). Small Sample Inference for Fixed Effects from Restricted Maximum Likelihood. Biometrics, 53, 983 - 987.

de Keyzer, W., Bracke, T., Mcnaughton, S. A., Parnell, W., Moshfegh, A. J., Pereira, R. A., Lee, H.-s., Henauw, S. D., Huybrechts, I., Sciences, F., Vesalius, G.-c., Pintelaan, D., Sciences, N., Zealand, N., Human, B., Service, N. M., \& Team, P. (2015). Cross-Continental Comparison of National Food Consumption Survey Methods - A Narrative Review. Nutrients, (pp. 3587-3620). doi:10.3390/nu7053587.

Khoury, C. K., Bjorkman, A. D., Dempewolf, H., Ramirez-Villegas, J., Guarino, L., Jarvis, A., Rieseberg, L. H., \& Struik, P. C. (2014). Increasing homogeneity in global food supplies and the implications for food security. Proceedings of the National Academy of Sciences of the United States of America, 111, 4001-4006. doi:10.1073/pnas.1313490111.

Kilelu, C., Klerkx, L., Omore, A., Baltenweck, I., Leeuwis, C., \& Githinji, J. (2017). Value Chain Upgrading and the Inclusion of Smallholders in Markets: Reflections on Contributions of Multi-Stakeholder Processes in Dairy Development in Tanzania. European Journal of Development Research, 29, 1102-1121. doi:10.1057/s41287-016-0074-z.

Kilic, T., Carletto, C., Zezza, A., \& Savastano, S. (2013). Missing (Ness) in Action: Selectivity Bias in Gps-Based Land Area Measurements. doi:10.1016/j.worlddev.2016.11.018.

Kilic, T., \& Sohnesen, T. P. (2015). Same Question But Different Answer: Experimental Evidence on Questionnaire Design's Impact on Poverty Measured by Proxies. doi:10.1111/roiw.12343.

Kimeli, P., Lyamchai, C., \& Sayula, G. (2014). Better bean varieties for Usambara's rural poor CCAFS: CGIAR research program on Climate Change. Agriculture and Food Security [WWW Document].

Klapwijk, C. J., van Wijk, M. T., Rosenstock, T. S., van Asten, P. J. A., Thornton, P. K., \& Giller, K. E. (2014). Analysis of trade-offs in agricultural systems: Current status and way forward. Current Opinion in Environmental Sustainability, 6, 110-115. doi:10.1016/j.cosust.2013.11.012.

Koppmair, S., Kassie, M., \& Qaim, M. (2016). Farm production, market access and dietary diversity in 
Malawi. Public Health Nutrition, 20, 325-335. doi:10.1017/S1368980016002135.

Kristjanson, P., Neufeldt, H., Gassner, A., Mango, J., Kyazze, F. B., Desta, S., Sayula, G., Thiede, B., Förch, W., Thornton, P. K., \& Coe, R. (2012). Are food insecure smallholder households making changes in their farming practices? Evidence from East Africa. Food Security, 4, 381-397. doi:10.1007/s12571-0120194-z.

Kruschke, J. K. (2013). Bayesian Estimation Supersedes the t Test. Journal of Experimental Psychology: General, 142, 573-603. doi:10.1037/a0029146.

Kumssa, D. B., Joy, E. J. M., Ander, E. L., Watts, M. J., Young, S. D., Walker, S., \& Broadley, M. R. (2015). Dietary calcium and zinc deficiency risks are decreasing but remain prevalent. Nature Publishing Group, (pp. 1-11). doi:10.1038/srep10974.

Lachat, C., Raneri, J. E., Smith, K. W., Kolsteren, P., Van Damme, P., Verzelen, K., Penafiel, D., Vanhove, W., Kennedy, G., Hunter, D., Odhiambo, F. O., Ntandou-Bouzitou, G., De Baets, B., Ratnasekera, D., Ky, H. T., Remans, R., \& Termote, C. (2017). Dietary species richness as a measure of food biodiversity and nutritional quality of diets. Proceedings of the National Academy of Sciences, 115, 201709194. doi:10.1073/pnas.1709194115.

Lamanna, C., Hachhethu, K., Chesterman, S., Singhal, G., Mwongela, B., Ng'endo, M., Passeri, S., Farhikhtah, A., Kadiyala, S., Bauer, J.-M., \& Rosenstock, T. S. (accepted). Strengths and limitations of computer assisted telephone interviews (CATI) for nutrition data collection in rural Kenya. PLoS ONE.

Lapan, S. D., Quartaroli, M. T., \& Riemer, F. J. (Eds.) (2011). Qualitative research: An introduction to methods and designs. (1st ed.). San Francisco: Jossey-Bass.

Leeuw, E. D. D. (2005). To Mix or Not to Mix Data Collection Modes in Surveys. Journal of Official Statistics, 21, 233-255.

Lesnoff, M., Lancelot, R. (2012). Package 'aod'.

Lin, B. B. (2011). Resilience in Agriculture through Crop Diversification: Adaptive Management for Environmental Change. BioScience, 61, 183-193. doi:10.1525/bio.2011.61.3.4.

Lipper, L., Thornton, P., Campbell, B. M., Baedeker, T., Braimoh, A., Bwalya, M., Caron, P., Cattaneo, A., Garrity, D., Henry, K., Hottle, R., Jackson, L., Jarvis, A., Kossam, F., Mann, W., McCarthy, N., Meybeck, A., Neufeldt, H., Remington, T., Sen, P. T., Sessa, R., Shula, R., Tibu, A., \& Torquebiau, E. F. (2014). Climate-smart agriculture for food security. Nature Climate Change, 4, 1068-1072. doi:10.1038/nclimate2437.

Little, P. D., Mahmoud, H., \& Coppock, D. L. (2001). When deserts flood: risk management and climatic processes among East African pastoralists . Climate Research, 19, 149-159.

Little, T. D., \& Rhemtulla, M. (2013). Planned Missing Data Designs for Developmental Researchers. Child Development Perspectives, 7, 199-204. doi:10.1111/cdep.12043.

Livingston, G., Schonberger, S., \& Delaney, S. (2011). Sub-Saharan Africa: the state of smallholders in agriculture. IFAD Conference on New Directions for Smallholder Agriculture.

Lowder, S. K., Skoet, J., \& Raney, T. (2016). The Number, Size, and Distribution of Farms, Smallholder Farms, and Family Farms Worldwide. World Development, 87, 16-29. doi:10.1016/j.worlddev.2015.10.041.

Luan, Y., Zhu, W., Cui, X., \& Fischer, G. (2018). Cropland yield divergence over Africa and its implication for mitigating food insecurity. Mitigation and Adaptation Strategies for Global Change. 
Luckett, B. G., DeClerck, F. A. J., Fanzo, J., Mundorf, A. R., \& Rose, D. (2015). Application of the Nutrition Functional Diversity indicator to assess food system contributions to dietary diversity and sustainable diets of Malawian households. Public Health Nutrition, 18, 2479-2487. doi:10.1017/S136898001500169X.

Lukmanji, Z., Hertzmark, E., Mlingi, N., Assey, V., Ndossi, G., \& Wafaie, F. (2008). Tanzania Food Composition Tables. Technical Report November.

Lyamchai, C., Yanda, P., Sayula, G., \& Kristjanson, P. (2011). Summary of Baseline Household Survey Results. Summary of baseline household survey results: Lushoto.

Ma, Y., Olendzki, B. C., Pagoto, S. L., Hurley, T. G., Magner, R. P., Ockene, I. S., Schneider, K. L., Merriam, P. A., \& Hébert, J. R. (2009). Number of 24-Hour Diet Recalls Needed to Estimate Energy Intake. Annals of Epidemiology, doi:10.1016/j.annepidem.2009.04.010.

Malapit, H., Kovarik, C., Sproule, K., Meinzen-dick, R., \& Quisumbing, A. (2015). Instructional Guide on the Abbreviated Women's Empowerment in Agriculture Index ( A-WEAI ) 1. (pp. 1-74).

Malapit, H., Quisumbing, A., \& Meinzen-dick, R. (2017). The Abbreviated Women's Empowerment in Agriculture Index ( A-WEAI ).

Martin-Prével, Y., Allemand, P., Wiesmann, D., Arimond, M., Ballard, T., Deitchler, M., Dop, M., Kennedy, G., Lee, W., \& Moursi, M. (2015). On choosing a standard operational indicator of women's dietary diversity. Rome: FAO.

Mary, S., Saravia-Matus, S., \& Gomez y Paloma, S. (2018). Does nutrition-sensitive aid reduce the prevalence of undernourishment? Food Policy, 74, 100-116. doi:10.1016/j.foodpol.2017.11.008.

Mason, R., Ndlovu, P., Parkins, J. R., \& Luckert, M. K. (2015). Determinants of food security in Tanzania: gendered dimensions of household headship and control of resources. Agriculture and Human Values, 32, 539-549. doi:10.1007/s10460-014-9568-5.

Masters, W. A., Djurfeldt, A. A., De Haan, C., Hazell, P., Jayne, T., Jirström, M., \& Reardon, T. (2013). Urbanization and farm size in Asia and Africa: Implications for food security and agricultural research. Global Food Security, 2, 156-165. doi:10.1016/j.gfs.2013.07.002.

Masters, W. A., Rosettie, K. L., Kranz, S., Danaei, G., Webb, P., Mozaffarian, D., Bhattacharjee, L., Chandrasekhar, S., Christensen, C., Desai, S., Kazi-Hutchins, N., Levin, C., Paarlberg, R., Vosti, S., Adekugbe, O., Atomsa, G. E., Badham, J., Baye, K., Beyero, M., Covic, N., Dalton, B., Dufour, C., Fracassi, P., Getahun, Z., Haidar, J., Hailu, T., Kebede, A., Kinabo, J., Kussaga, J. B., Mavrotas, G., Mwanja, W. W., Oguntona, B., Oladipo, A., Oniang'o, R., Sibanda, S., Sodjinou, R., Tom, C., Wamani, H., Wendelin, A., Adhikari, R. K., Amatya, A., Bhattarai, M., Brahmbhatt, V., Chandyo, R. K., Gulati, S., Kapil, U., Mehta, R., Mohan, S., Prabhakaran, D., Prakash, V., Puri, S., Roy, S. K., Sharma, R., Shivakoti, S., Thorne-Lyman, A., Rana, P. P., \& Trilok-Kumar, G. (2018). Designing programs to improve diets for maternal and child health: Estimating costs and potential dietary impacts of nutrition-sensitive programs in Ethiopia, Nigeria, and India. Health Policy and Planning, 33, 564-573. doi:10.1093/heapol/czy013.

Mathiowetz, N. a., Brown, C., \& Bound, J. (2001). Measurement Error in Surveys of the Low-Income Population volume 1 .

Maxwell, S., \& Smith, M. (1992). Household Food Security: a conceptual review.

May, J. (2018). Keystones affecting sub-Saharan Africa's prospects for achieving food security through balanced diets. Food Research International, 104, 4-13. doi:10.1016/j.foodres.2017.06.062.

McDermott, J., Johnson, N., Kadiyala, S., Kennedy, G., \& Wyatt, A. J. (2015). Agricultural research for 
nutrition outcomes - rethinking the agenda. Food Security, 7, 593-607. doi:10.1007/s12571-015-0462-9.

McDonald, C. M., McLean, J., Kroeun, H., Talukder, A., Lynd, L. D., \& Green, T. J. (2015). Household food insecurity and dietary diversity as correlates of maternal and child undernutrition in rural Cambodia. European journal of clinical nutrition, 69, 1-5. doi:10.1038/ejcn.2014.161. arXiv: arXiv: 1011.1669v3.

McElreath, R. (2016). Multi-level models. In Statistical Rethinking: A Bayesian Course with Examples in $R$ and Stan chapter 12. (pp. 355-469). Boca Raton: Chapman and Hall/CRC. (1st ed.). doi:10.3102/1076998616659752.

McIntire, J., Bourzat, D., \& Pingali, P. (1992). Crop-livestock interaction in sub-Saharan Africa.

Micha, R., Coates, J., Leclercq, C., Charrondiere, U. R., \& Mozaffarian, D. (2018). Global Dietary Surveillance: Data Gaps and Challenges. Food and Nutrition Bulletin, 39, 175-205. doi:10.1177/0379572117752986.

Micha, R., Khatibzadeh, S., Shi, P., Andrews, K. G., Engell, R. E., \& Mozaffarian, D. (2015). Global, regional and national consumption of major food groups in 1990 and 2010: A systematic analysis including 266 country-specific nutrition surveys worldwide. BMJ Open, 5. doi:10.1136/bmjopen2015-008705. arXiv: S0140-6736 (09) 61794-3.

Mina, K., Fritschi, L., \& Knuiman, M. (2008). Do aggregates of multiple questions better capture overall fish consumption than summary questions? Public Health Nutr, 11, 196-202. doi:10.1017/s1368980007000468.

Ministry of Health Burkina Faso (MH), \& National Institute of Statistics and Demography Burkina Faso (NISD) (2016). Burkina Faso National Nutrition Survey 2016. Technical Report.

M'Kaibi, F. K., Steyn, N. P., Ochola, S., \& Du Plessis, L. (2015). Effects of agricultural biodiversity and seasonal rain on dietary adequacy and household food security in rural areas of Kenya. BMC Public Health, 15, 422. doi:10.1186/s12889-015-1755-9.

Moll, H. A. J. (2005). Costs and benefits of livestock systems and the role of market and nonmarket relationships. Agricultural Economics, 32, 181-193. doi:10.1111/j.0169-5150.2005.00210.x.

Moore, J. C., Stinson, L. L., \& Welniak, E. J. J. (2000). Income Measurement Error in Surveys: A Review. Journal of Official Statistics, 16, 31-361.

Morchain, D., Prati, G., Kelsey, F., \& Ravon, L. (2015). What if gender became an essential, standard element of Vulnerability Assessments? Gender and Development, 23, 481-496. doi:10.1080/13552074.2015.1096620.

Mulmi, P., Masters, W. A., Ghosh, S., Namirembe, G., Rajbhandary, R., Manohar, S., Shrestha, B., West, K. P., \& Webb, P. (2017). Household food production is positively associated with dietary diversity and intake of nutrient-dense foods for older preschool children in poorer families: Results from a nationally-representative survey in Nepal. PLOS ONE, 12, 1-23. doi:10.1371/journal.pone.0186765.

Nakawuka, P., Langan, S., Schmitter, P., \& Barron, J. (2017). A review of trends, constraints and opportunities of smallholder irrigation in East Africa. Global Food Security, (pp. 1-17). doi:10.1016/j.gfs.2017.10.003.

National Bureau of Statistics Tanzania (NBST) (2014). Tanzania National Panel Survey Wave 3, 2012-2013. Technical Report, Dar es Salaam.

National Bureau of Statistics Tanzania (NBST) (2015). Integrated labour force survey analytical report. Technical Report.

National Bureau of Statistics Tanzania (NBST) (2016). National Accounts Statistics. Technical Report, Dar 
es Salaam.

Ndakidemi, P., \& Semoka, J. (2006). Soil Fertility Survey in Western Usambara Mountains, Northern Tanzania. Pedosphere, 16, 237-244. doi:10.1016/S1002-0160(06)60049-0.

Neri, A., \& Ranalli, M. G. (2012). To misreport or not to report? The measurement of household financial wealth. doi:10.1162/JEEA.2008.6.6.1109.

Neufeldt, H., Jahn, M., Campbell, B. M., Beddington, J. R., DeClerck, F., De Pinto, A., Gulledge, J., Hellin, J., Herrero, M., Jarvis, A., LeZaks, D., Meinke, H., Rosenstock, T., Scholes, M., Scholes, R., Vermeulen, S., Wollenberg, E., \& Zougmoré, R. (2013). Beyond climate-smart agriculture: Toward safe operating spaces for global food systems. Agriculture and Food Security, 2. doi:10.1186/2048-7010-2-12.

de Nicola, F., \& Giné, X. (2014). How accurate are recall data? Evidence from coastal India. Journal of Development Economics, 106, 52-65. doi:10.1016/j.jdeveco.2013.08.008.

Njuki, J., Poole, J., Johnson, N., Baltenweck, I., Pali, P., Lokman, Z., \& Mburu, S. (2011). Gender, Livestock and Livelihood Indicators. Technical Report October, International Livestock Research Institute Nairobi.

Nout, M. J. R. (2009). Rich nutrition from the poorest - Cereal fermentations in Africa and Asia. Food Microbiology, 26, 685-692. doi:10.1016/j.fm.2009.07.002.

Oddo, V. M., \& Ickes, S. B. (2018). Maternal employment in low- and middle-income countries is associated with improved infant and young child feeding. The American Journal of Clinical Nutrition, 107, 335-344. doi:10.1093/ajcn/nqy001.

Ollenburger, M. H., Descheemaeker, K., Crane, T. A., Sanogo, O. M., \& Giller, K. E. (2016). Waking the Sleeping Giant: Agricultural intensification, extensification or stagnation in Mali's Guinea Savannah. Agricultural Systems, 148, 58-70. doi:10.1016/j.agsy.2016.07.003.

van Oort, P., Saito, K., Dieng, I., Grassini, P., Cassman, K., \& van Ittersum, M. (2016). Can yield gap analysis be used to inform R\&D prioritisation? Global Food Security, 12, 109-118. doi:10.1016/j.gfs.2016.09.005.

Organisation for Economic Co-operation and Development (OECD) (2009). Methods to Monitor and Evaluate the Impacts of Agricultural Policies on Rural Development. Technical Report, OECD Paris.

Organisation for Economic Co-operation and Development (OECD) (2015). 2015 Global aid prospects and projections. Technical Report, The Organisation for Economic Co-operation and Development Paris.

Organisation for Economic Co-operation and Development (OECD), \& Food and Agricuture Organisation of the UN (FAO) (2017). OECDFAO Agricultural Outlook 20172026.

Orr, A., \& Mwale, B. (2001). Adapting to adjustment: Smallholder livelihood strategies in southern Malawi. World Development, 29, 1325-1343. doi:10.1016/S0305-750X(01)00042-0.

Osendarp, S. J., Martinez, H., Garrett, G. S., Neufeld, L. M., De-Regil, L. M., Vossenaar, M., \& DarntonHill, I. (2018). Large-Scale Food Fortification and Biofortification in Low- and Middle-Income Countries: A Review of Programs, Trends, Challenges, and Evidence Gaps. Food and Nutrition Bulletin, 39, 315-331. doi:10.1177/0379572118774229.

Pardey, P. G., Chan-Kang, C., Dehmer, S. P., \& Beddow, J. M. (2016). Agricultural R\&D is on the move. doi:10.1038/537301a.

de Pee, S., Taren, D., \& Bloem, M. W. (Eds.) (2017). Nutrition and Health in Developing World. (3rd ed.). New York.

Pender, J., Jagger, P., Nkonya, E., \& Sserunkuuma, D. (2001). Development pathways and land degrada- 
tion in Uganda: Causes and implications. Policies for Improved Land Management in Uganda: Summary of Papers and Proceedings of a Workshop Held at Hotel Africana.

Perry, B. D., Randolph, T. F., McDermott, J. J, Thornton, P. K. \& Sones, K. R (2002). Investing in animal health research to alleviate poverty. doi:10.1177/1098612X11432823. arXiv: arXiv:1011.1669v3.

Phillips, G. W., \& Jiang, T. (2016). Measurement Error and Equating Error in Power Analysis. 21.

Pica-ciamarra, U., Morgan, N., \& Baker, D. (2012). Core livestock data and indicators: results of a stakeholder survey. Technical Report May, World Bank, FAO, ILRI Rome.

Pingali, P. (2015). Agricultural policy and nutrition outcomes - getting beyond the preoccupation with staple grains. Food Security, 7, 583-591. doi:10.1007/s12571-015-0461-x.

Pisa, P. T., Landais, E., Margetts, B., Vorster, H. H., Friedenreich, M., Huybrechts, I., Martin-prevel, Y., Branca, F., Lee, W. T. K., Leclercq, C., Jerling, J., Zotor, F., Jawaldeh, A. A., Aderibigbe, O. R., Hounkpatin, W., Anderson, C. A. M., Aounallah-skhiri, H., Atek, M., Benhura, C., Chifamba, J., Covic, N., Dary, O., Ati, J. E., Hamdouchi, A. E., Rhazi, K. E., Faber, M., Kalimbira, A., Korkalo, L., Kruger, A., Ledo, J., Mahachi, C., Mathe, N., Mokori, A., Mouquet, C., Mutie, C., Nashandi, H. L., Norris, S. A., Onabanjo, O., Rambeloson, Z., Saha, F. B. U., Ubaoji, I., Zaghloul, S., \& Slimani, N. (2017). Inventory on the dietary assessment tools available and needed in Africa: a prerequisite for setting up a common methodological research infrastructure for nutritional surveillance, research, and prevention of diet-related non- communicable diseases. Critical Reviews in Food Science and Nutrition, 58, 37-61. doi:10.1080/10408398.2014.981630.

Popkin, B. M. (2014). Nutrition, agriculture and the global food system in low and middle income countries. Food Policy, 47, 91-96. doi:10.1016/j.foodpol.2014.05.001.

Popkin, B. M., Horton, S. H., \& Kim, S. (2001). The nutrition transition and prevention of diet-related diseases in Asia and the Pacific. Food and Nutrition Bulletin, 22, 54-58.

Powell, B., Thilsted, S. H., Ickowitz, A., Termote, C., Sunderland, T., \& Herforth, A. (2015). Improving diets with wild and cultivated biodiversity from across the landscape. Food Security, (pp. 535-554). doi:10.1007/s12571-015-0466-5.

Prentice, A. M. (2018). The Double Burden of Malnutrition in Countries Passing through the Economic Transition. Hot Topics in Nutrition, 72, 47-54. doi:10.1159/000487383.

Price, M., Galiè, A., Marshall, J., Agu, N., Price, M., Galie, A., Marshall, J., \& Agu, N. (2018). Development in Practice Elucidating linkages between women's empowerment in livestock and nutrition: a qualitative study. 4524. doi:10.1080/09614524.2018.1451491.

Proctor, F. J. (2014). Rural economic diversification in sub-Saharan Africa.

Rah, J. H., Akhter, N., Semba, R. D., de Pee, S., Bloem, M. W., Campbell, A. A., Moench-Pfanner, R., Sun, K., Badham, J., \& Kraemer, K. (2010). Low dietary diversity is a predictor of child stunting in rural Bangladesh. European journal of clinical nutrition, 64, 1393-1398. doi:10.1038/ejcn.2010.171.

Ramankutty, N., Mehrabi, Z., Waha, K., Jarvis, L., Kremen, C., Herrero, M., \& Rieseberg, L. H. (2018). Trends in Global Agricultural Land Use: Implications for Environmental Health and Food Security. Annual Review of Plant Biology, 69. doi:10.1146/annurev-arplant-042817-040256.

Randall, S., \& Coast, E. (2015). Poverty in African Households: the Limits of Survey and Census Representations. Journal of Development Studies, 51, 162-177. doi:10.1080/00220388.2014.968135.

Randall, S., Coast, E., Antoine, P., Compaore, N., Dial, F.-b., Fanghanel, A., Gning, S. B., Thiombiano, B. G., Golaz, V., \& Wandera, S. O. (2015). UN Census “ Households" and Local Interpretations in 
Africa Since Independence. doi:10.1177/2158244015589353.

Rao, N., Gazdar, H., Chanchani, D., Ibrahim, M., \& Asia, S. (2018). Women's agricultural work and nutrition in South Asia: From pathways to a cross-disciplinary, grounded analytical framework. Food Policy, (pp. 1-13). doi:10.1016/j.foodpol.2018.10.014.

Reardon, T., Delgado, C., \& Matlon, P. (1992). Determinants and effects of income diversification amongst farm households in Burkina Faso. Journal of Development Studies, 28, 264-296. doi:10.1080/00220389208422232. arXiv : 978-92-5-105980-7.

Remans, R., Wood, S. A., Saha, N., Anderman, T. L., \& DeFries, R. S. (2014). Measuring nutritional diversity of national food supplies. Global Food Security, 3, 174-182. doi:10.1016/j.gfs.2014.07.001.

Revelle, W. (2017). psych: Procedures for Personality and Psychological Research.

Ricciardi, V., Ramankutty, N., Mehrabi, Z., Jarvis, L., \& Chookolingo, B. (2018). How much of the world's food do smallholders produce? Global Food Security, 17, 64-72. doi:10.1016/j.gfs.2018.05.002.

Ritzema, R. S., Frelat, R., Douxchamps, S., Silvestri, S., Rufino, M. C., Herrero, M., Giller, K. E., LópezRidaura, S., Teufel, N., Paul, B. K., \& van Wijk, M. T. (2017). Is production intensification likely to make farm households food-adequate? A simple food availability analysis across smallholder farming systems from East and West Africa. Food Security, 9, 115-131. doi:10.1007/s12571-016-0638-y.

Rosenstock, T. S., Lamanna, C., Chesterman, S., Hammond, J., Kadiyala, S., Luedeling, E., Shepherd, K., Derenzi, B., \& Wijk, M. T. V. (2017). When less is more: innovations for tracking progress toward global targets. Current Opinion in Environmental Sustainability, 26-27, 54-61. doi:10.1016/j.cosust.2017.02.010.

Ruel, M. T., \& Alderman, H. (2013). Nutrition-sensitive interventions and programmes: How can they help to accelerate progress in improving maternal and child nutrition? The Lancet, 382, 536-551. doi:10.1016/S0140-6736(13)60843-0. arXiv : arXiv: 1504.04883v1.

Ruel, M. T., Quisumbing, A. R., \& Balagamwala, M. (2018). Nutrition-sensitive agriculture: What have we learned so far? Global Food Security, 17, 128-153. doi:10.1016/j.gfs.2018.01.002.

Rufino, M. C., Quiros, C., Boureima, M., Desta, S., Douxchamps, S., Herrero, M., Kiplimo, J., Lamissa, D., Mango, J., Moussa, A. S., Naab, J., Ndour, Y., Sayula, G., Silvestri, S., Singh, D., Teufel, N., \& Wanyama, I. (2013). Developing generic tools for characterizing agricultural systems for climate and global change studies ( IMPACTlite - phase 2 ). Technical Report January, ILRI Nairobi.

Saha, K. K., Frongillo, E. a., Alam, D. S., Arifeen, S. E., Persson, L. a., \& Rasmussen, K. M. (2009). Household food security is associated with growth of infants and young children in rural Bangladesh. Public Health Nutrition, 12, 1556-1562. doi:10.1017/S1368980009004765.

Samberg, L. H., Gerber, J. S., Ramankutty, N., Herrero, M., \& West, P. C. (2016). Subnational distribution of average farm size and smallholder contributions to global food production. Environmental Research Letters, 11, 1-11. doi:10.1088/1748-9326/11/12/124010.

Sandefur, J., \& Glassman, A. (2015). The Political Economy of Bad Data: Evidence from African Survey and Administrative Statistics. Journal of Development Studies, 51, 116-132. doi:10.1080/00220388.2014.968138.

Savy, M., Martin-Prével, Y., Sawadogo, P., Kameli, Y., \& Delpeuch, F. (2005). Use of variety/diversity scores for diet quality measurement: relation with nutritional status of women in a rural area in Burkina Faso. European journal of clinical nutrition, 59, 703-716. doi:10.1038/sj.ejcn.1602135.

Schipanski, M. E., MacDonald, G. K., Rosenzweig, S., Chappell, M. J., Bennett, E. M., Kerr, R. B., Blesh, J., Crews, T., Drinkwater, L., Lundgren, J. G., \& Schnarr, C. (2016). Realizing resilient food systems. 
BioScience, 66, 600-610. doi:10.1093/biosci/biw052.

Schreiner, M. (2011). PPI for Burkina Faso. Technical Report.

Scoones, I. (1998). Sustainable rural livelihoods: A framework for analysis.

Seré, C., Steinfeld, H., \& Groenewold, J. (1996). World livestock production systems. Technical Report.

Sharma, R., Gaffey, M. F., Alderman, H., Bassani, D. G., Bogard, K., Darmstadt, G. L., Das, J. K., de Graft-Johnson, J. E., Hamadani, J. D., Horton, S., Huicho, L., Hussein, J., Lye, S., Pérez-Escamilla, R., Proulx, K., Marfo, K., Mathews-Hanna, V., Mclean, M. S., Rahman, A., Silver, K. L., Singla, D. R., Webb, P., \& Bhutta, Z. A. (2017). Prioritizing research for integrated implementation of early childhood development and maternal, newborn, child and adolescent health and nutrition platforms. Journal of Global Health, 7. doi:10.7189/jogh.07.011002.

Shrout, P. E., \& Fleiss, J. L. (1979). Intraclass correlations: uses in assessing rater reliability.1. Shrout PE, Fleiss JL: Intraclass correlations: uses in assessing rater reliability. Psychol Bull 1979, 86:420-8. Psychological bulletin, 86, 420-8.

Sibhatu, K. T., Krishna, V. V., \& Qaim, M. (2015). Production diversity and dietary diversity in smallholder farm households. Proceedings of the National Academy of Sciences of the United States of America, 112, 10657-10662. doi:10.1073/pnas.1510982112.

Sibhatu, K. T., \& Qaim, M. (2017). Rural food security, subsistence agriculture, and seasonality. PLoS ONE, 12, 1-15. doi:10.1371/journal.pone.0186406.

Siegel, K. R., Ali, M. K., Srinivasiah, A., Nugent, R. A., \& Narayan, K. M. (2014). Do we produce enough fruits and vegetables to meet global health need? PLOS ONE, 9. doi:10.1371/journal.pone.0104059.

Silvestri, S., Douxchamps, S., Kristjanson, P., Wiebke, F., Maren, R., Mutie, I., Quiros, C., Herrero, M., Ndungu, A., Ndiwa, N., Mango, J., Claessens, L., \& Rufino, M. C. (2015). Households and food security: lessons from food secure households in East Africa. Agriculture E Food Security, 4. doi:10.1186/s40066-015-0042-4.

Slingerland, M. (2000). Mixed farming: scope and constraints in West African Savanna. Ph.D. thesis Wageningen University.

Slingerland, M., Traore, K., Kayodé, A., \& Mitchikpe, C. (2006). Fighting Fe deficiency malnutrition in West Africa: an interdisciplinary programme on a food chain approach. NJAS - Wageningen Journal of Life Sciences, 53, 253-279. doi:10.1016/S1573-5214(06)80009-6.

Smyth, I., \& Sweetman, C. (2015). Introduction: Gender and Resilience. Gender and Development, 23, 405-414. doi:10.1080/13552074.2015.1113769.

Snapp, S. S., \& Fisher, M. (2015). "Filling the maize basket" supports crop diversity and quality of household diet in Malawi. Food Security, 7, 83-96. doi:10.1007/s12571-014-0410-0.

Sofa, \& Doss, C. (2011). The role of women in agriculture.

Some, J. W., \& Jones, A. D. (2018). The influence of crop production and socioeconomic factors on seasonal household dietary diversity in Burkina Faso. PLOS ONE, 13, 1-16. doi:10.1371/journal.pone.0195685.

Steinke, J., Mgimiloko, G., Graef, F., Hammond, J., van Wijk, M. T., \& van Etten, J. (2019). Prioritising household-specific options for agricultural development through the Positive Deviance approach. PLoS ONE, 14(2). doi:10.1371/journal.pone.0212926.

Steyn, N. P., Nel, J. H., Nantel, G., Kennedy, G., \& Labadarios, D. (2006). Food variety and dietary 
diversity scores in children: are they good indicators of dietary adequacy? Public Health Nutrition, 9, 644-650. doi:10.1079/PHN2005912.

Stirling, C. M., Farnworth, C. R., Hammond, J., Chinyophiro, A., Fraval, S., \& van Wijk, M. T. (submitted). Household Methodologies to Reduce Gender Inequality and Increase Household Resilience to Climate and Other Shocks: A Case Study from Malawi. Climatic change.

Strobbe, S., \& Van Der Straeten, D. (2018). Toward Eradication of B-Vitamin Deficiencies: Considerations for Crop Biofortification. Frontiers in Plant Science, 9, 1-19. doi:10.3389/fpls.2018.00443.

Swanepoel, F., Stroebel, A., Moyo, S., University of the Free State., International Livestock Research Institute., Technical Centre for Agricultural and Rural Cooperation (Ede, N., \& World Conference on Animal Production (10th : 2008: Cape Town, S. A. (2010). The role of livestock in developing communities : enhancing multifunctionality. UFS and CTA.

Swindale, A., \& Bilinsky, P. (2006). Household Dietary Diversity Score (HDDS) for Measurement of Household Food Access: Indicator Guide (v.2). Technical Report, USAID Washington, DC.

Tavenner, K., Fraval, S., Omondi, I., \& Crane, T. A. (2018). Gendered reporting of household dynamics in the Kenyan dairy sector: trends and implications for low emissions dairy development. Gender, Technology and Development, 22, 1-19. doi:10.1080/09718524.2018.1449488.

Tavenner, K., van Wijk, M. T., Fraval, S., Hammond, J., de Haan, N., \& Baltenweck, I. (submitted). Intensifying Inequality? Gendered Trends in Commercializing and Diversifying Smallholder Farm Systems in East Africa. Frontiers in Sustainable food systems.

Thornton, P. K., \& Herrero, M. (2015). Livestock farming systems in sub-Saharan Africa. Nature Publishing Group, 5, 830-836. doi:10.1038/nclimate2754.

Tibesigwa, B., Visser, M., Lokina, R., \& Jacob, R. Z. (2018). Contribution of smallholder agriculture to daily calories, macronutrients, minerals and vitamins in male-and female-headed farm households in sub-Saharan Africa. In Agricultural Adaptation to Climate Change in Africa (pp. 297-339). ROUTLEDGE in association with GSE Research volume 297.

Tiffen, M. (2003). Transition in Sub-Saharan Africa: Agriculture, urbanization and income growth. World Development, 31, 1343-1366. doi:10.1016/S0305-750X(03)00088-3.

Tittonell, P., \& Giller, K. E. (2013). When yield gaps are poverty traps: The paradigm of ecological intensification in African smallholder agriculture. Field Crops Research, 143, 76-90. doi:10.1016/j.fcr.2012.10.007.

Tomich, T. P., Lidder, P., Coley, M., Gollin, D., Meinzen-Dick, R., Webb, P., \& Carberry, P. (2018). Food and agricultural innovation pathways for prosperity. Agricultural Systems, (pp. 1-15). doi:10.1016/j.agsy.2018.01.002.

Torheim, L. E., Ouattara, F., Diarra, M. M., Thiam, F. D., Barikmo, I., Hatløy, A., \& Oshaug, A. (2004). Nutrient adequacy and dietary diversity in rural Mali: association and determinants. European journal of clinical nutrition, 58, 594-604. doi:10.1038/sj.ejcn.1601853.

Tscharntke, T., Clough, Y., Wanger, T. C., Jackson, L., Motzke, I., Perfecto, I., Vandermeer, J., \& Whitbread, A. (2012). Global food security, biodiversity conservation and the future of agricultural intensification. doi:10.1016/j.biocon.2012.01.068. arXiv : arXiv:1011.1669v3.

Uganda Bureau of Statistics (UBOS) (n.d.). The Uganda national panel survey 2009/10: Basic Information Document. Technical Report July.

Uganda Bureau of Statistics (UBOS) (2002). 2002 Uganda Population and Housing Cen- 
sus Analytical Report. Technical Report, UBOS Kampala. URL: http://www.ubos.org/ onlinefiles/uploads/ubos/pdfdocuments/2002CensusPopnSizeGrowthAnalyticalReport.pdf. arXiv: /www.ubos.org/onlinefiles/uploads/ubos/pdf\%20documents/2002\%20Census\%20Final\%20Reportdoc.pdf

Uganda Bureau of Statistics (UBOS) (2007). Uganda national household survey 2005/2006. Technical Report, Uganda Bureau of Statistics Kampala. URL: http://www.ubos.org/onlinefiles/uploads/ubos/ statistical\{_\}abstracts/StatisticalAbstract2014.pdf. Accessed: August15, 2016.

Ulrich, A., Ifejika Speranza, C., Roden, P., Kiteme, B., Wiesmann, U., \& Nüsser, M. (2012). Small-scale farming in semi-arid areas: Livelihood dynamics between 1997 and 2010 in Laikipia, Kenya. Journal of Rural Studies, 28, 241-251. doi:10.1016/j.jrurstud.2012.02.003.

United Nations Framework Convention on Climate Change (UNFCCC) (2012). Standard for sampling and surveys for CDM project activities and programme of activities. Technical Report, UNFCCC Bonn.

United Nations (UN) (1959). Handbook of population census methods: Volume III-Demographic and social characteristics of the population. Technical Report, Statistical Office of the United Nations New York.

United Nations (UN) (2014). World Urbanization Prospects: The 2014 revision, highlights. Technical Report, Department of Economic and Social Affairs, Population Division Washington, DC.

United Nations (UN) (2015). Probabilistic Population Projections Based on the World Population Prospects: The 2015 Revision.

United Nations Department of Economic and Social Affairs (UN) (2005). Household Sample Surveys in Developing and Transition Countries volume F.

United States Department of Agriculture (USDA) (2017). USDA Branded Food Products Database.

United States Agency for International Development (USAID) (2009). Preliminary Rural Livelihood Zoning: Tanzania. Technical Report September. URL: http://www.fews.net/east-africa/tanzania/ livelihood-zone-map/november-2009.

United States Agency for International Development (USAID) (2012). Livelihoods classification of Kenyan regions. Technical Report.

Valbuena, D., Groot, J. C. J., Mukalama, J., Gérard, B., \& Tittonell, P. (2015). Improving rural livelihoods as a "moving target": trajectories of change in smallholder farming systems of Western Kenya. Regional Environmental Change, 15, 1395-1407. doi:10.1007/s10113-014-0702-0.

de Valença, A. W., Bake, A., Brouwer, I. D., \& Giller, K. E. (2017). Agronomic biofortification of crops to fight hidden hunger in sub-Saharan Africa. Global Food Security, 12, 8-14. doi:10.1016/j.gfs.2016.12.001.

Venables, W. N., Ripley, B. D. (2002). Package 'MASS'.

van Etten, J. (2011). Crowdsourcing crop improvement in sub-Saharan Africa: A proposal for a scalable and inclusive approach to food security. IDS Bulletin, 42, 102-110. doi:10.1111/j.1759-5436.2011.00240.x.

Vila-real, C., Pimenta-martins, A., Gomes, A. M., Pinto, E., Maina, N. H., Pimenta-martins, A., Gomes, A. M., Pinto, E., \& Vila-real, C. (2018). How dietary intake has been assessed in African countries? A systematic review. Critical Reviews in Food Science and Nutrition, 58, 1002-1022. doi:10.1080/10408398.2016.1236778.

Waha, K., van Wijk, M. T., Fritz, S., See, L., Thornton, P. K., Wichern, J., \& Herrero, M. (2018). Agricultural diversification as an important strategy for achieving food security in Africa. Global Change Biology, 24, 3390-3400. doi:10.1111/gcb.14158. 
Weisburg, H. (2005). The Total Survey Error Approach. Chicago: The University of Chicago Press.

World Health Organisation (WHO) \& Food and Agriculture Organisation of the UN (FAO) (2002). Protein and amino acid requirements in nutrition.

van Wijk, M. T. (2014). From global economic modelling to household level analyses of food security and sustainability: How big is the gap and can we bridge it? Food Policy, 49, 378-388. doi:10.1016/j.foodpol.2014.10.003.

van Wijk, M. T., Rufino, M. C., Enahoro, D., Parsons, D., Silvestri, S., Valdivia, R. O., \& Herrero, M. (2014). Farm household models to analyse food security in a changing climate: A review. Global Food Security, 3, 77-84. doi:10.1016/j.gfs.2014.05.001.

Winowiecki, L., Vågen, T.-G., Massawe, B., Jelinski, N. A., Lyamchai, C., Sayula, G., \& Msoka, E. (2016). Landscape-scale variability of soil health indicators: effects of cultivation on soil organic carbon in the Usambara Mountains of Tanzania. Nutrient Cycling in Agroecosystems, 105, 263-274. doi:10.1007/s10705-015-9750-1.

World Bank (n.d.). Living Standards Measurement Study-Integrated Surveys on Agriculture.

World Bank (2017). Living Standards Measurement Study.

World Bank (2018). Programmatic Access to Data and Statistics from the World Bank API.

Zezza, A., Federighi, G., Adamou, K., \& Hiernaux, P. (2014). Milking the Data: Measuring Income from Milk Production in Extensive Livestock Systems Experimental Evidence from Niger. 


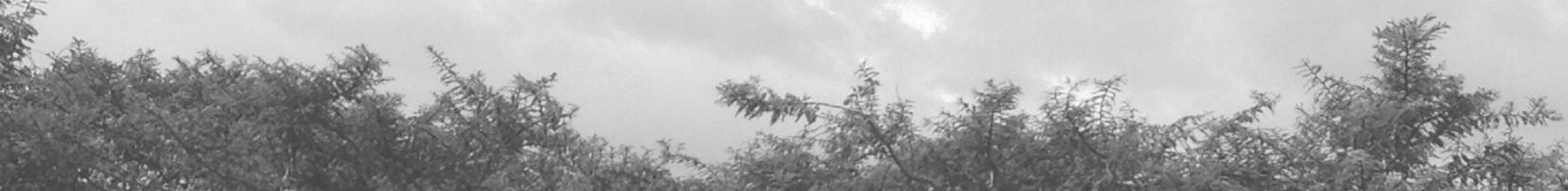

. (4)

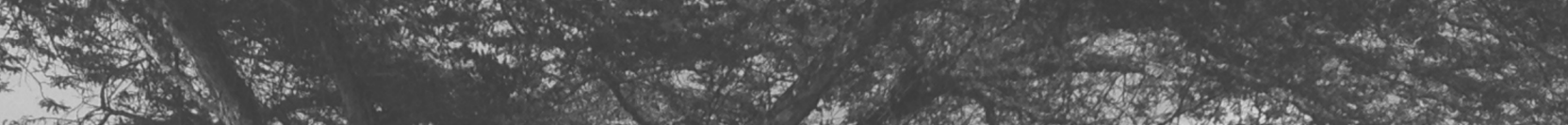

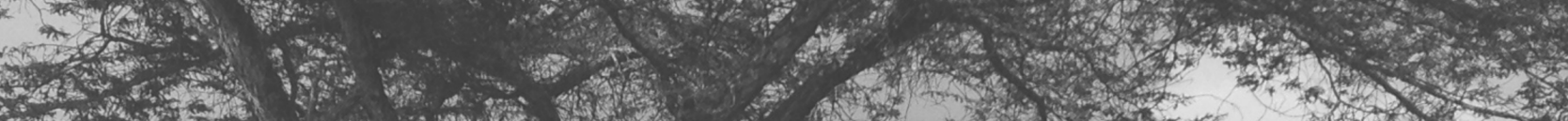

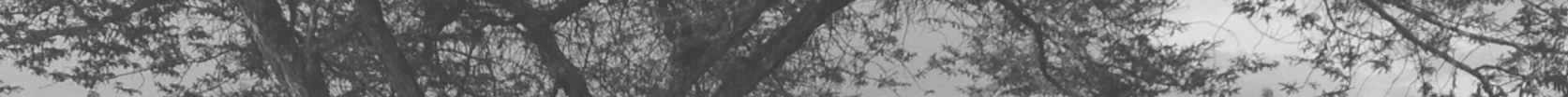
$+20$

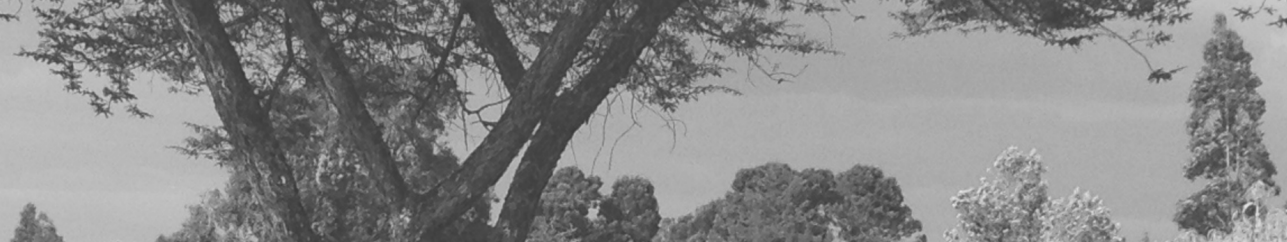

等, (A) 17. (2) 16.t. (1)

(1)

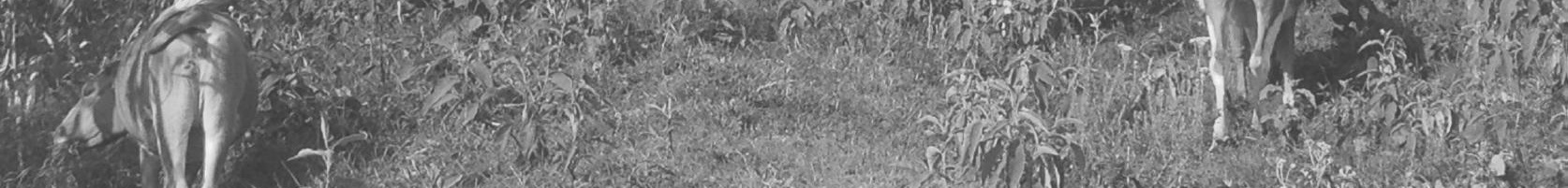

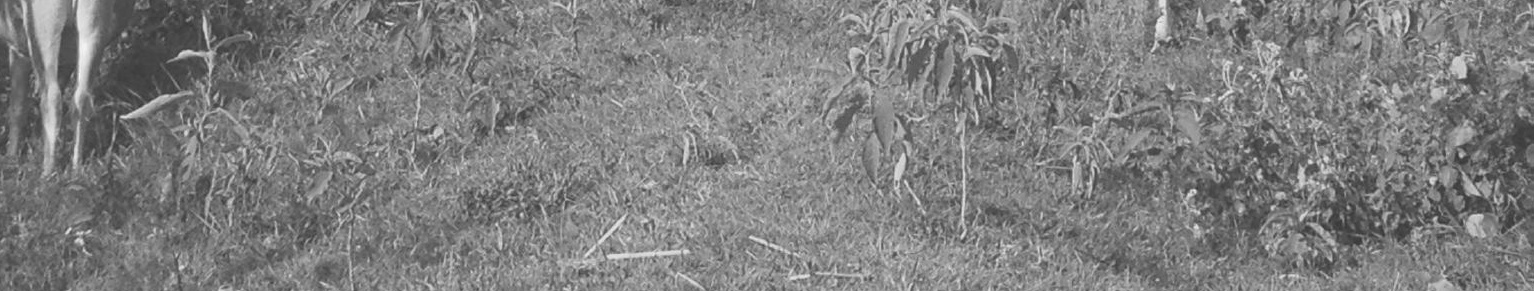

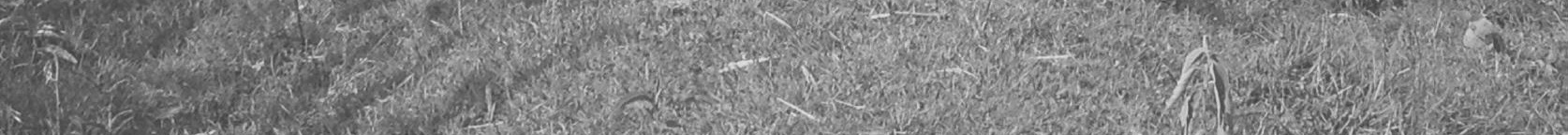

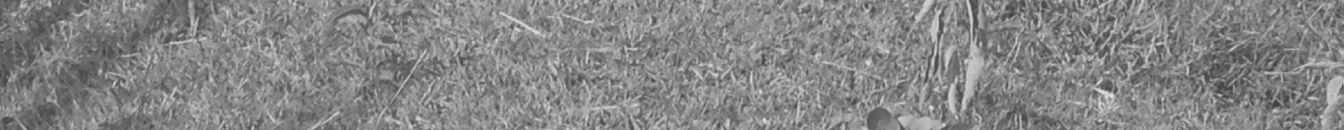

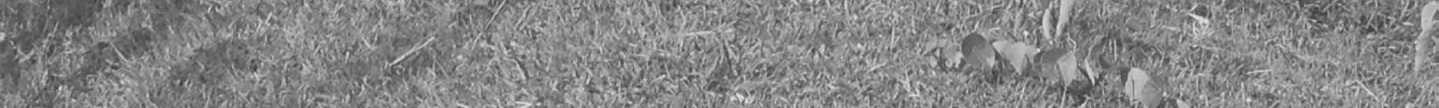
A. 
Appendices 


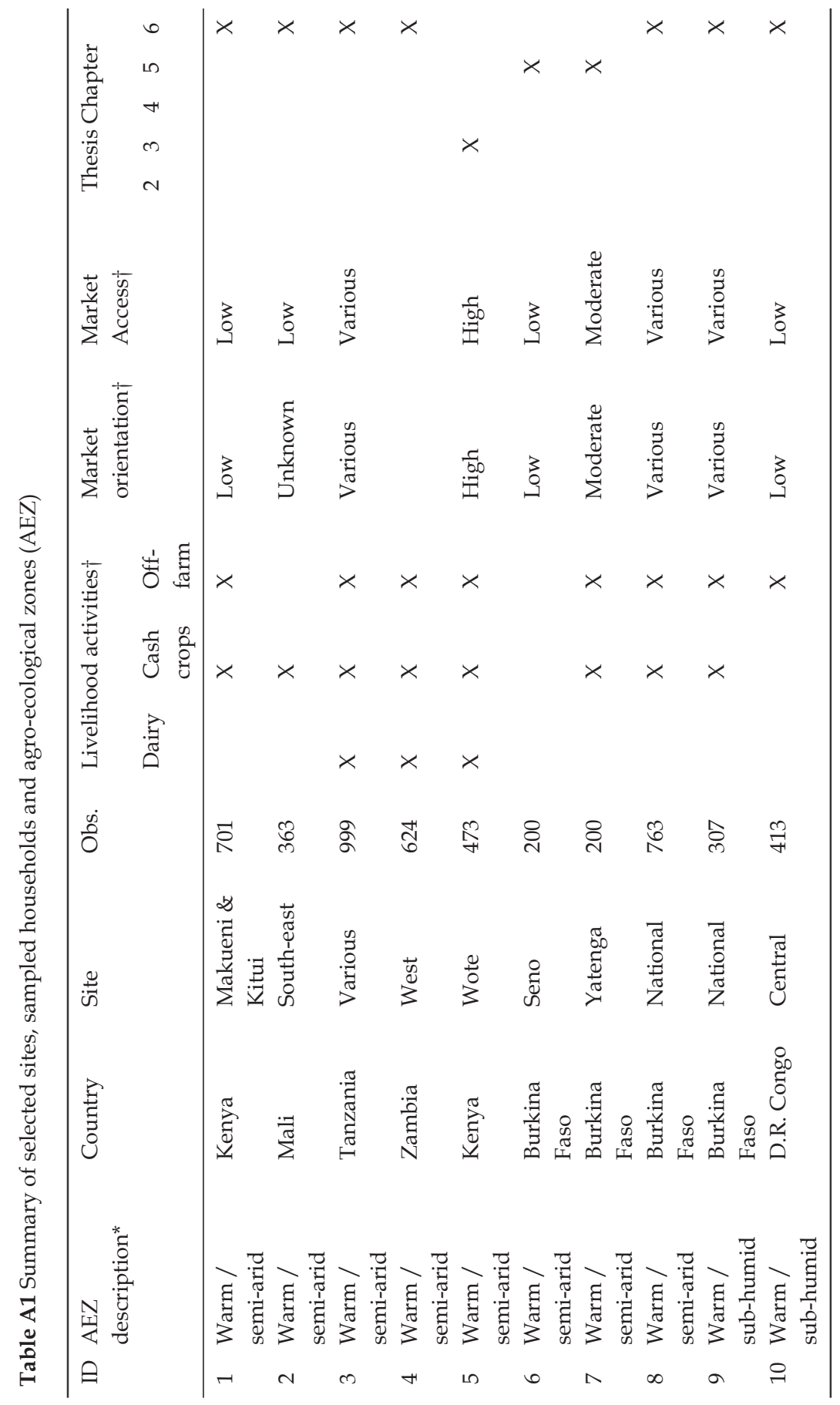




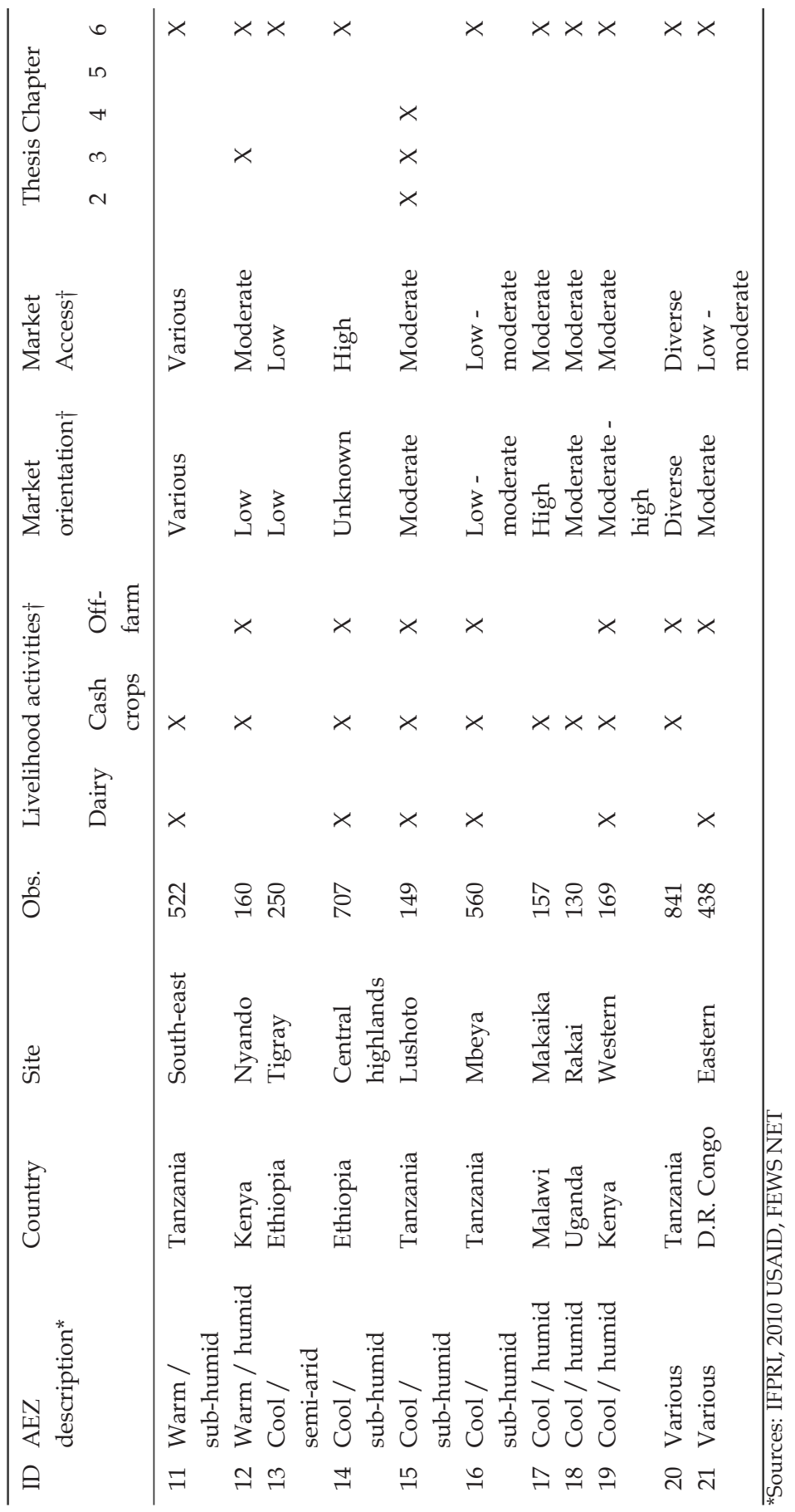


Table A2 Association between farm-household characteristics and survey year. Mixed-effects linear regressions.

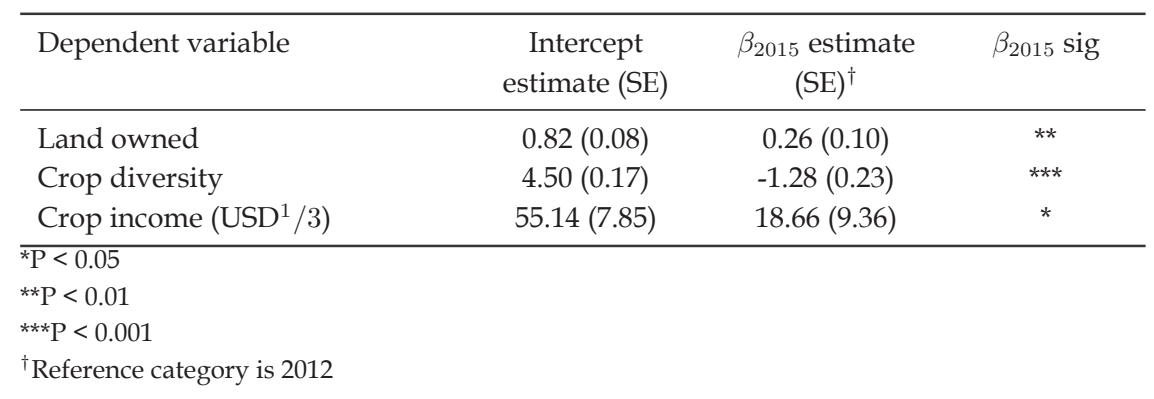

Table A3 Association between farm-household characteristics and gender of household head. Mixedeffects linear regressions.

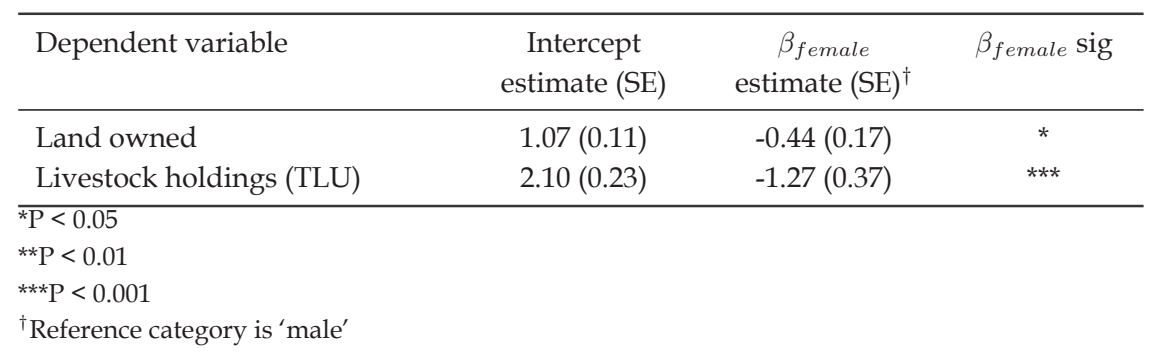

Table A4 Association between farm-household characteristics and gender of household head in 'Subsisting mixed' households. Mixed-effects linear regressions.

\begin{tabular}{lccc}
\hline Dependent variable & $\begin{array}{c}\text { Intercept } \\
\text { estimate (SE) }\end{array}$ & $\begin{array}{c}\beta_{\text {female }} \\
\text { estimate (SE) }\end{array}$ & $\beta_{\text {female }}$ sig \\
\hline Land owned & $0.96(0.12)$ & $-0.37(0.23)$ & NS \\
Livestock holdings (TLU) & $2.03(0.19)$ & $-0.85(0.37)$ & $*$ \\
\hline${ }^{*} \times 0.05$ & & & \\
${ }^{\dagger}$ Reference category is 'male' & & &
\end{tabular}


Table A5 Association of food security indicators and farm type - 'Subsisting' vs. 'Rising'. Mixedeffects regressions.

\begin{tabular}{|c|c|c|c|}
\hline Dependent variable & $\begin{array}{l}\text { Intercept } \\
\text { estimate (SE) }\end{array}$ & $\begin{array}{c}\beta_{\text {Rising }} \text { estimate } \\
(\mathrm{SE})^{\dagger}\end{array}$ & $\beta_{\text {Rising }}$ sig \\
\hline $\begin{array}{l}\text { Food availability (kcal adult } \\
\text { equivalent }{ }^{-1} \text { day }^{-1} \text { ) }\end{array}$ & $435(45)$ & $287(134)$ & $* *$ \\
\hline $\begin{array}{l}\text { Household Diet Diversity Score } \\
\text { in flush period }{ }^{\ddagger}\end{array}$ & $2.10(0.04)$ & $0.11(0.05)$ & * \\
\hline $\begin{array}{l}\text { Household Diet Diversity Score } \\
\text { in lean period }{ }^{\ddagger}\end{array}$ & $1.67(0.05)$ & $0.09(0.08)$ & \\
\hline
\end{tabular}




\section{Appendix B}

Table B1 Food security of access by period and by province (\% of site)

\begin{tabular}{llcccc}
\hline & Food secure & $\begin{array}{c}\text { Mildly food } \\
\text { insecure }\end{array}$ & $\begin{array}{c}\text { Moderately food } \\
\text { insecure }\end{array}$ & $\begin{array}{c}\text { Severely food } \\
\text { insecure }\end{array}$ \\
\hline Lean period & Seno & 1.5 & 2 & 13 & 83.5 \\
& Yatenga & 10.5 & 17 & 41 & 31.5 \\
Flush period & Seno & 22 & 11 & 18 & 49 \\
& Yatenga & 14.5 & 45 & 24 & 16.5 \\
\hline
\end{tabular}

Table B2 Intensification practices adopted in Seno for the 2015 cropping period (\% of households)

\begin{tabular}{lcc}
\hline & Adopted & Not adopted \\
\hline Improved livestock breeds $^{\text {Value addition }}{ }^{\mathrm{a}}$ & 1 & 99 \\
Irrigate cash crops $_{\text {Fertiliser }}$ & 76 & 24 \\
Improved seed & 6 & 94 \\
\hline
\end{tabular}

${ }^{a}$ Value addition of crops such as dehusking, hulling, polishing, milling ect.

Table B3 Intensification practices adopted in Yatenga for the 2015 cropping period (\% of households)

\begin{tabular}{lcc}
\hline & Adopted & Not adopted \\
\hline Improved livestock breeds & 0.5 & 99.5 \\
Value addition & 87.5 & 12.5 \\
Irrigate cash crops & 27.5 & 72.5 \\
Fertiliser & 39.5 & 60.5 \\
Improved seed & 62.0 & 38.0 \\
\hline
\end{tabular}




\section{Appendix C}

Table C1 Summary of funding sources

\begin{tabular}{ll}
\hline Acronym & Full name \\
\hline AVCD & Accelerated Value Chain Development \\
BMGF & Bill and Melinda Gates Foundation \\
CCAFS & Climate Change, Agriculture and Food Security \\
CLiP & Crop-Livestock integration Project \\
DI & Darwin Initiative \\
FORETS & FOrmation, Recherche, Environnement dans la TShopo \\
EU & European Union \\
LSHTM-IMMANA & The London School of Hygiene \& Tropical Medicine - \\
& Innovative Metrics and Methods for Agriculture Nutrition Action \\
SAIRLA & Sustainable Agricultural Intesification Research and Learning in Africa \\
SIDA & Swedish International Development Agency \\
USAID & U.S. Agency for International Development \\
\hline
\end{tabular}




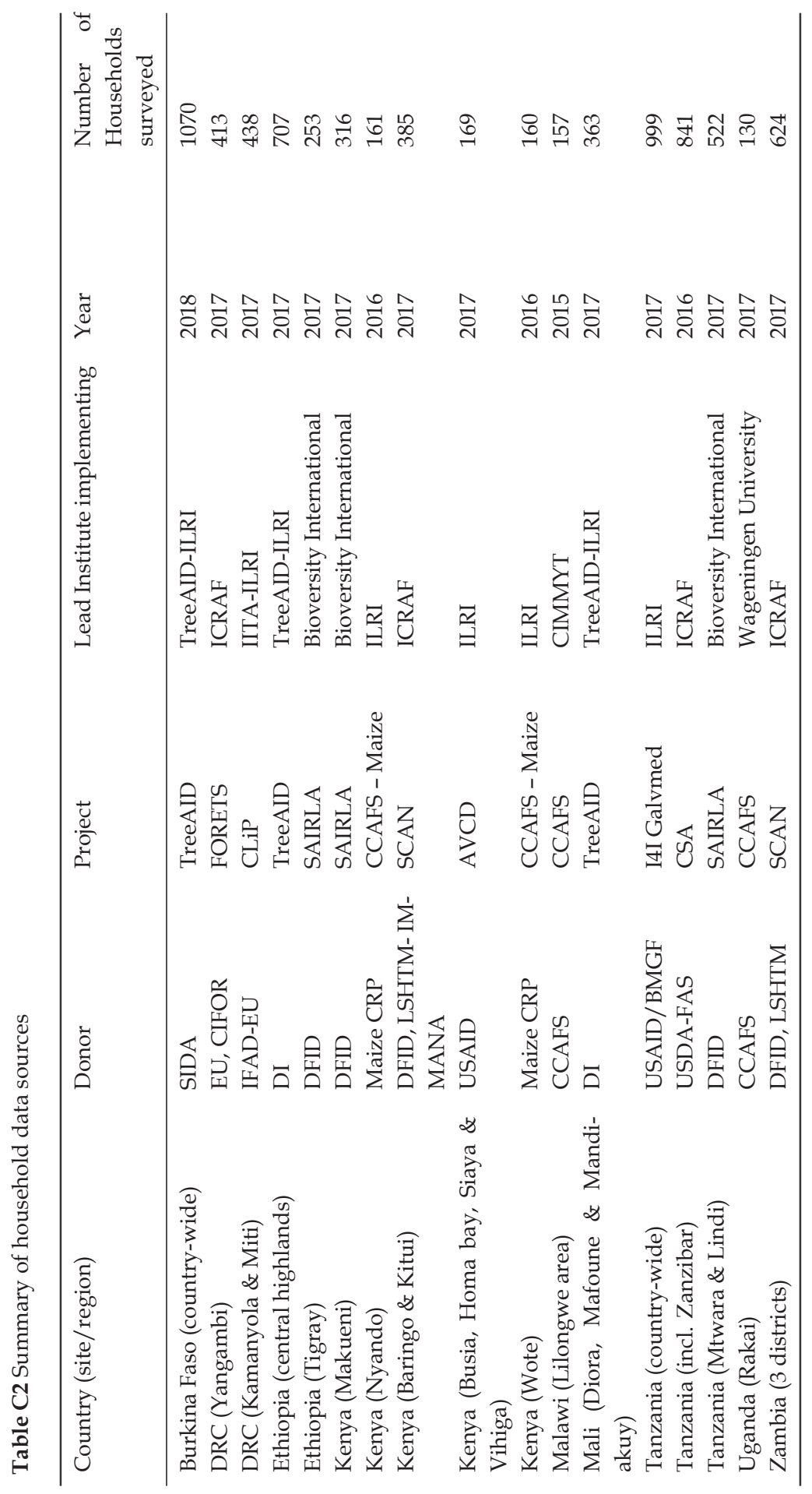


Table C3 Thresholds for removing observations (removed households may exceed multiple thresholds)

\begin{tabular}{lcc}
\hline Variable & Threshold & Number of observations \\
\hline Household members (adult equivalents) & $>30$ & 48 \\
& $=0$ & 68 \\
Land area (ha) & $>100$ & 9 \\
Livestock holdings (TLUs) & $>250$ & 72 \\
Income (PPP) & $>100,000$ & 93 \\
Modified Household Diet Diversity & $=0$ & 776 \\
Enumerator assessed reliability & Regular doubts & 25 \\
& Occasional doubts & 200 \\
Enumerator assessed ease to build rapport & Very difficult & 26 \\
\hline
\end{tabular}

Observations were removed in instances where no MHDD was enumerated or where land cultivated, livestock holdings or household population were non-credible ( $n=1,355)$. Approximately $10 \%$ of observations were removed from Burkina Faso, Kenya and Tanzania. After removing these observations, 6,612 households remained in this study. 
Table C4 Sources of micronutrients in Modified Household Diet Diversity categories in East Africa (source defined as providing $15 \%$ of adult male requirement)

\begin{tabular}{|c|c|c|c|c|c|c|c|c|c|c|c|}
\hline & $\mathrm{Ca} \dagger$ & $\mathrm{Fe}$ & $\mathrm{Zn}$ & VitA & $\begin{array}{l}\text { Thi- } \\
\text { amine }\end{array}$ & $\begin{array}{l}\text { Ri- } \\
\text { boflav }\end{array}$ & $\begin{array}{l}\text { Nia } \\
\text { vin }\end{array}$ & $\begin{array}{c}\mathrm{nVi}- \\
\text { ta- } \\
\text { min } \\
\text { B6 }\end{array}$ & $\begin{array}{l}\text { Fo- } \\
\text { late }\end{array}$ & $\begin{array}{l}\text { Vi- } \\
\text { ta- } \\
\text { min } \\
\text { B12 }\end{array}$ & $\begin{array}{l}\text { Vi- } \\
\text { ta- } \\
\text { min } \\
\text { C }\end{array}$ \\
\hline Grains, roots, tubers and plantain & & $x$ & & & $x$ & & $x$ & $x$ & & & \\
\hline Pulses & & & & & & & & $x$ & $x$ & & \\
\hline Nuts and seeds & $x$ & $x$ & $x$ & & $x$ & $x$ & $x$ & $x$ & $x$ & & \\
\hline Dairy & $x$ & & & & & & & & & $x$ & \\
\hline Meat, poultry and fish & & & $x$ & $x$ & & $x$ & $x$ & $x$ & & $x$ & \\
\hline Eggs & & & & $x$ & & $x$ & & & & $x$ & \\
\hline Leafy vegetables & & & & $x$ & & & & & & & $x$ \\
\hline Vitamin A rich vegetables & & $x$ & $x$ & $x$ & $x$ & & & & & & $x$ \\
\hline \multicolumn{12}{|l|}{ Other vegetables } \\
\hline Other fruits & & & & & & & & & & & $x$ \\
\hline
\end{tabular}

${ }^{\dagger}$ Threshold set at $12 \%$

$\underline{\text { Table C4 continued }}$

$\begin{array}{llllllll}\mathrm{Cu} & \mathrm{K} & \mathrm{Mg} & \mathrm{Mn} & \mathrm{P} & \begin{array}{l}\text { Pan- } \\ \text { tothenic } \\ \text { acid }\end{array} & \begin{array}{l}\text { Vitamin } \\ \mathrm{D}\end{array} & \begin{array}{l}\text { Vita- } \\ \text { min }\end{array} \\ & & & & \mathrm{E}\end{array}$

\begin{tabular}{llllllll}
\hline $\begin{array}{l}\text { Grains, roots, tubers } \\
\text { and plantain }\end{array}$ & & $\mathrm{x}$ & $\mathrm{x}$ & $\mathrm{x}$ & & \\
$\begin{array}{l}\text { Pulses } \\
\text { Nuts and seeds }\end{array}$ & $\mathrm{x}$ & $\mathrm{x}$ & $\mathrm{x}$ & $\mathrm{x}$ & $\mathrm{x}$ & $\mathrm{x}$ & $\mathrm{x}$ \\
$\begin{array}{l}\text { Dairy } \\
\text { Meat, poultry and fish }\end{array}$ & & & & $\mathrm{x}$ & & \\
Eggs & & & $\mathrm{x}$ & & $\mathrm{x}$ & \\
Leafy vegetables & & & & & & & \\
Vitamin A rich fruits & $\mathrm{x}$ & $\mathrm{x}$ & $\mathrm{x}$ & $\mathrm{x}$ & & $\mathrm{x}$ \\
and vegetables & & & & & & \\
$\begin{array}{l}\text { Other vegetables } \\
\text { Other fruits }\end{array}$ & & & & & \\
\hline
\end{tabular}


Table C5 Sources of micronutrients in Modified Household Diet Diversity categories in Central and West Africa (source defined as providing 15\% of adult male requirement)

\begin{tabular}{|c|c|c|c|c|c|c|c|c|c|c|c|}
\hline & $\mathrm{Ca} \dagger$ & $\mathrm{Fe}$ & $\mathrm{Zn}$ & VitA & $\begin{array}{l}\text { Thi- } \\
\text { amine }\end{array}$ & $\begin{array}{l}\text { Ri- } \\
\text { boflavin }\end{array}$ & Niacin & $\begin{array}{l}\text { Vita- } \\
\text { min } \\
\text { B6 }\end{array}$ & $\begin{array}{l}\text { Fo- } \\
\text { late }\end{array}$ & $\begin{array}{l}\text { Vita- } \\
\text { min } \\
\text { B12 }\end{array}$ & $\begin{array}{l}\text { Vi- } \\
\text { ta- } \\
\text { min } \\
\text { C }\end{array}$ \\
\hline $\begin{array}{lr}\text { Grains, roots, } \\
\text { tubers and } \\
\text { plantain }\end{array}$ & & $x$ & & & $x$ & & & $x$ & & & \\
\hline Pulses & & $x$ & $x$ & & $x$ & $x$ & & $x$ & $x$ & & \\
\hline Nuts and seeds & $x$ & $x$ & $x$ & & $x$ & & $x$ & $x$ & $x$ & & \\
\hline Dairy & $x$ & & & & & $x$ & & & & $x$ & \\
\hline $\begin{array}{l}\text { Meat, poultry } \\
\text { and fish }\end{array}$ & & $x$ & $\mathrm{x}$ & $x$ & $x$ & $x$ & $x$ & $x$ & & $x$ & \\
\hline Eggs & & & & $\mathrm{x}$ & & $\mathrm{x}$ & & & & $\mathrm{x}$ & \\
\hline Leafy vegetables & & & & $x$ & & & & & $x$ & & $x$ \\
\hline $\begin{array}{l}\text { Vitamin A rich } \\
\text { vegetables }\end{array}$ & & $x$ & & & $\mathrm{x}$ & & & & & & $\mathrm{x}$ \\
\hline Other vegetables & & & & & & & & & & & $x$ \\
\hline Other fruits & & & & & & & & & & & $x$ \\
\hline
\end{tabular}

${ }^{\dagger}$ Threshold set at $12 \%$

Table C5 continued

\begin{tabular}{|c|c|c|c|c|c|c|c|c|}
\hline & $\mathrm{Cu}$ & K & $\mathrm{Mg}$ & $\mathrm{Mn}$ & $\mathrm{P}$ & $\begin{array}{l}\text { Pan- } \\
\text { tothenic } \\
\text { acid }\end{array}$ & $\begin{array}{l}\text { Vitamin } \\
\text { D }\end{array}$ & $\begin{array}{l}\text { Vita- } \\
\text { min } \\
\text { E }\end{array}$ \\
\hline $\begin{array}{l}\text { Grains, roots, tubers } \\
\text { and plantain }\end{array}$ & & & $\mathrm{x}$ & $x$ & $\mathrm{x}$ & & & \\
\hline Pulses & $x$ & $\mathrm{x}$ & $\mathrm{x}$ & $x$ & $\mathrm{x}$ & $x$ & & \\
\hline Nuts and seeds & $x$ & $x$ & $x$ & $x$ & $x$ & $x$ & & $\mathrm{x}$ \\
\hline Dairy & & & & & $x$ & & & \\
\hline Meat, poultry and fish & & & & & $x$ & $x$ & $x$ & \\
\hline Eggs & & & & & $x$ & $x$ & $x$ & \\
\hline Leafy vegetables & & & & & & & & $x$ \\
\hline $\begin{array}{l}\text { Vitamin A rich fruits } \\
\text { and vegetables }\end{array}$ & & & $\mathrm{x}$ & $\mathrm{x}$ & & & & \\
\hline Other vegetables & & & & & & & & \\
\hline Other fruits & & & & & & & & \\
\hline
\end{tabular}

The quantified adequacy ratios among subsistence households ( $\mathrm{n}=264$ ) varied substantially by nutrient ( $\mathrm{C} 1$ and $\mathrm{C} 2$ ). There were consistently large gaps in the availability of vitamin $\mathrm{A}$ and vitamin $\mathrm{C}$. Conversely, there were no micronutrient requirements that were consistently sufficient for all subsistence households. 


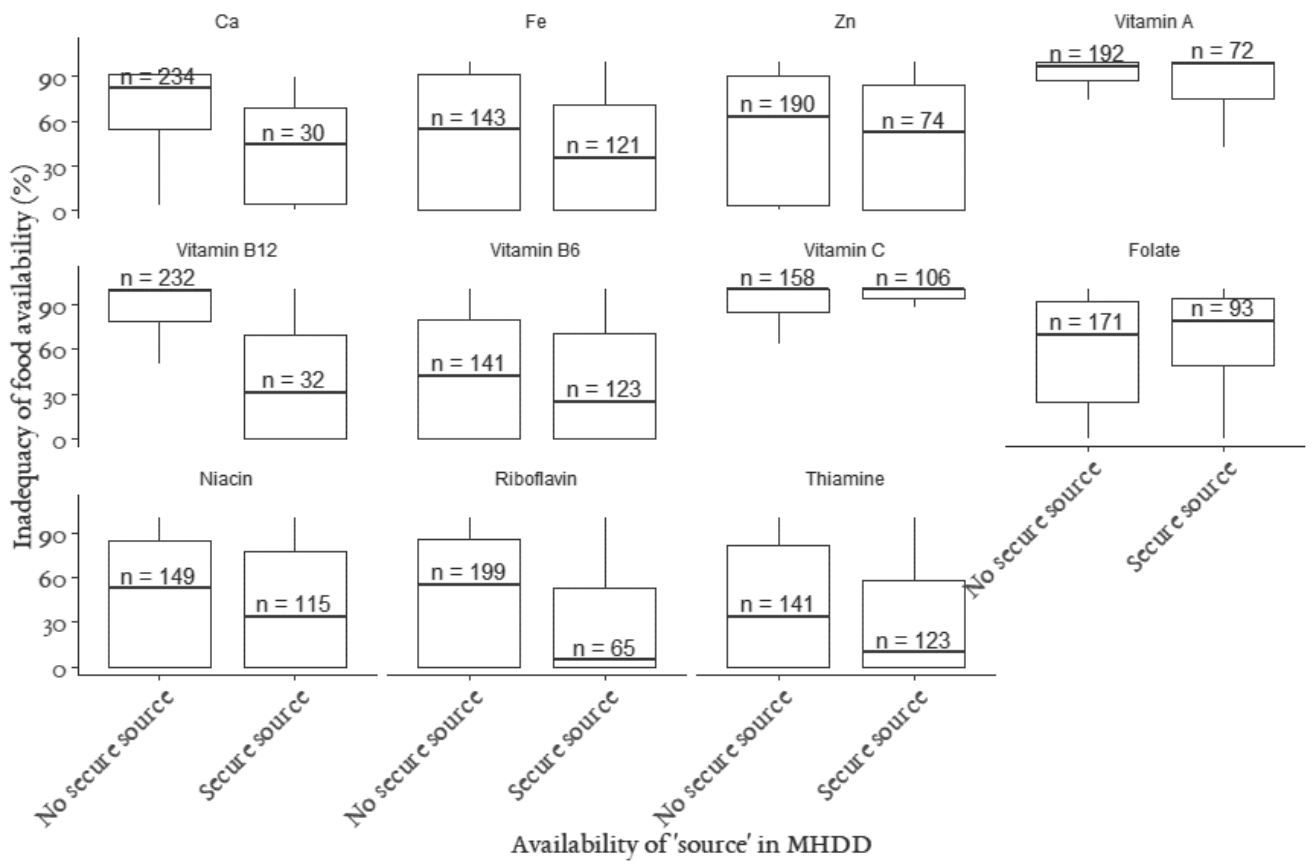

Figure C1 Comparison of all micronutrient gaps from farm production (y axis) and 'sources' in the Modified Household Diet Diversity (MHDD) indicator (x axis). This figure is limited to farm dependent households. The ' $n$ ' above the median line is the number of farm dependent households. A 'secure source' is defined by a household consuming a food category on a daily basis in both the flush and lean period. The number of observations are indicated on the figure 


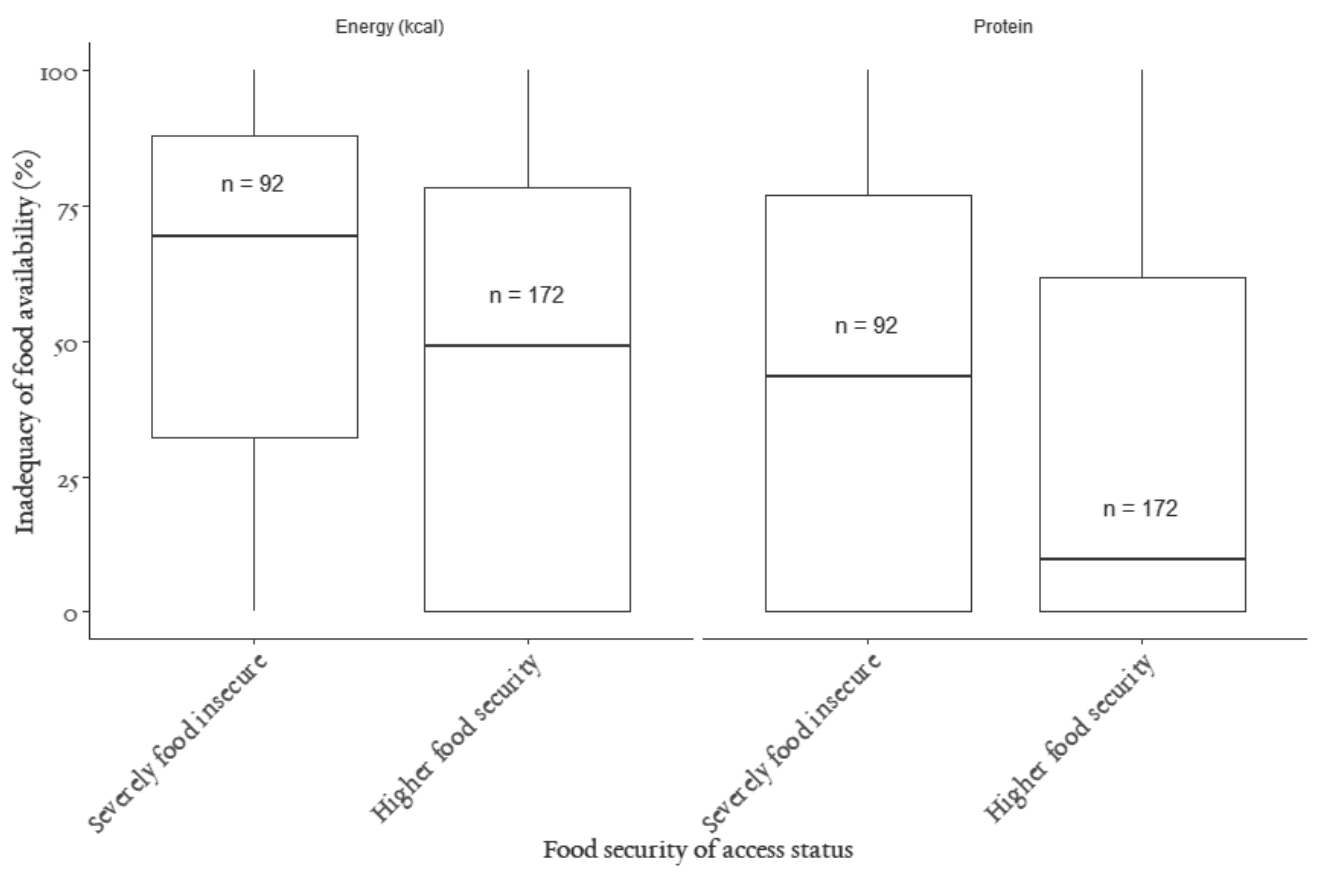

Figure C2 Comparison of dietary gaps from farm production and Household Food Insecurity of Access Prevalence (MHFIAP) indicator. This figure is limited to farm dependent households. Food security status is represented by two categories: 'Severely food insecure' and an amalgamation of the higher 3 MHFIAP food security categories into the category 'Higher food security'. The number of observations are indicated on the figure 


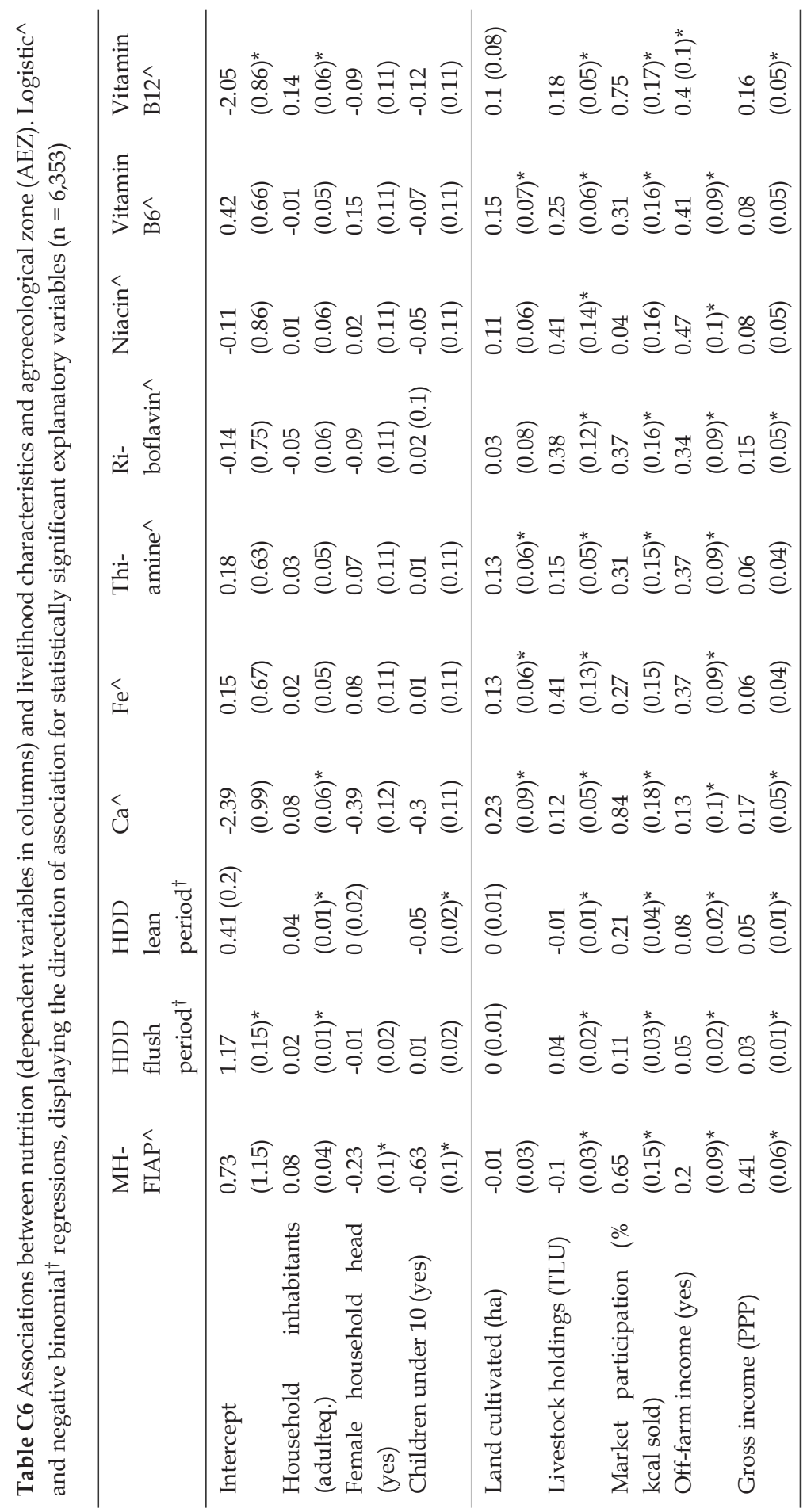




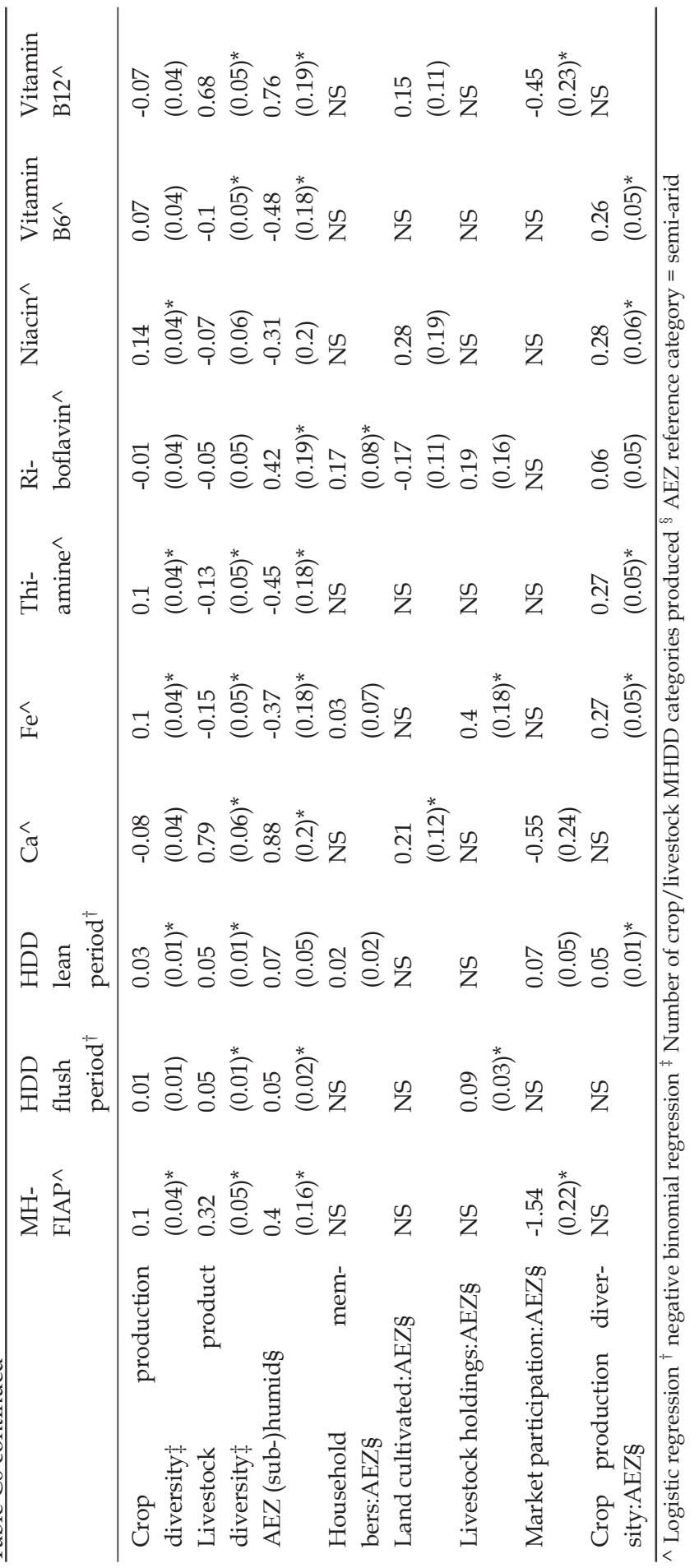


a

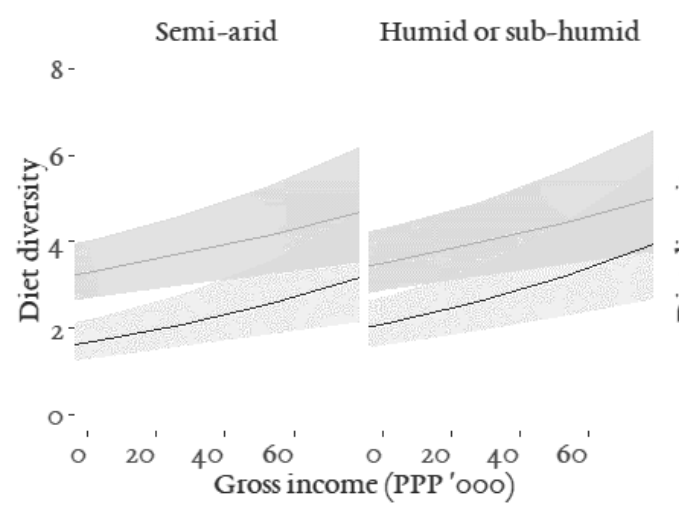

c

b

d

8- Semi-arid Humid or sub-humid

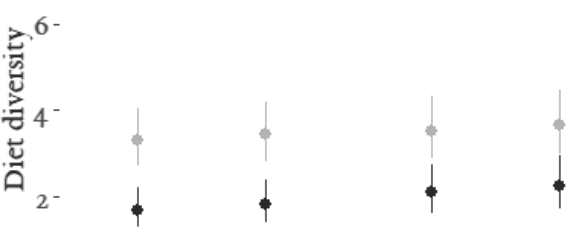

$0-$

No' Yes $\quad$ No' Yes'

Semi-arid Humid or sub-humid $8-$

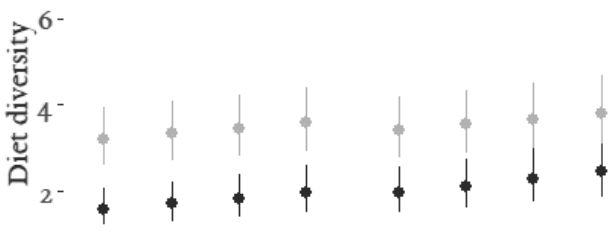

o-

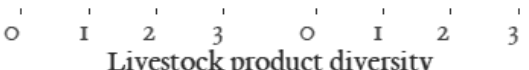

Figure C3 Predicted association between other variables and MHDD in the the flush (grey line/point) and lean (black line/ point) periods by agroecological zone

Table C7 Proportion of households in farm types by region

\begin{tabular}{lccc}
\hline Farm type & East Africa & Central Africa & West Africa \\
\hline Specialised cropping & 0.69 & 0.12 & 0.19 \\
Diverse cropping & 0.65 & 0.26 & 0.1 \\
Specialised cropping \& livestock & 0.80 & 0.03 & 0.18 \\
Diverse cropping \& livestock & 0.70 & 0.08 & 0.22 \\
\hline
\end{tabular}


Farm sourced
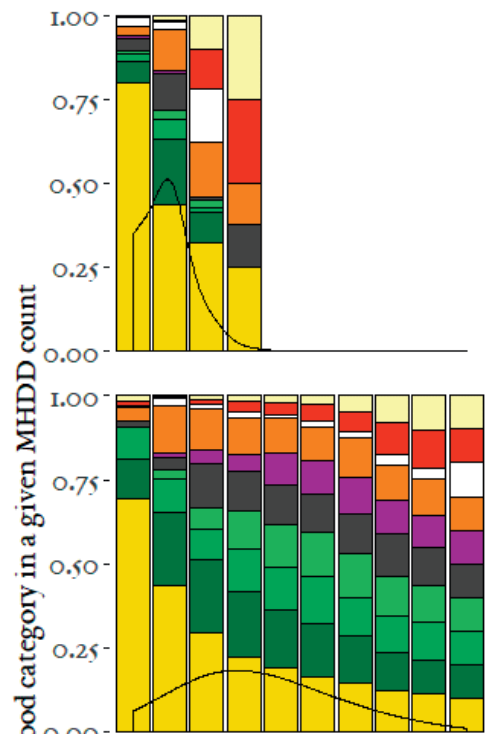

రి
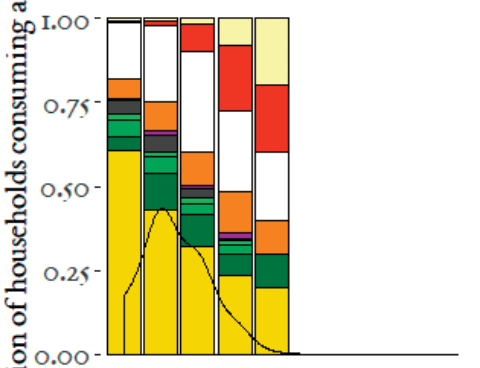

.

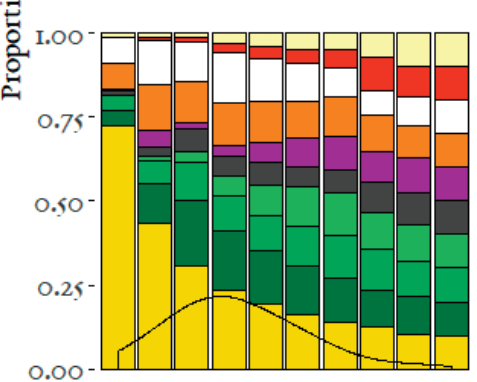

$0.00^{-}$

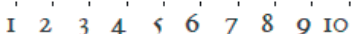

Purchased
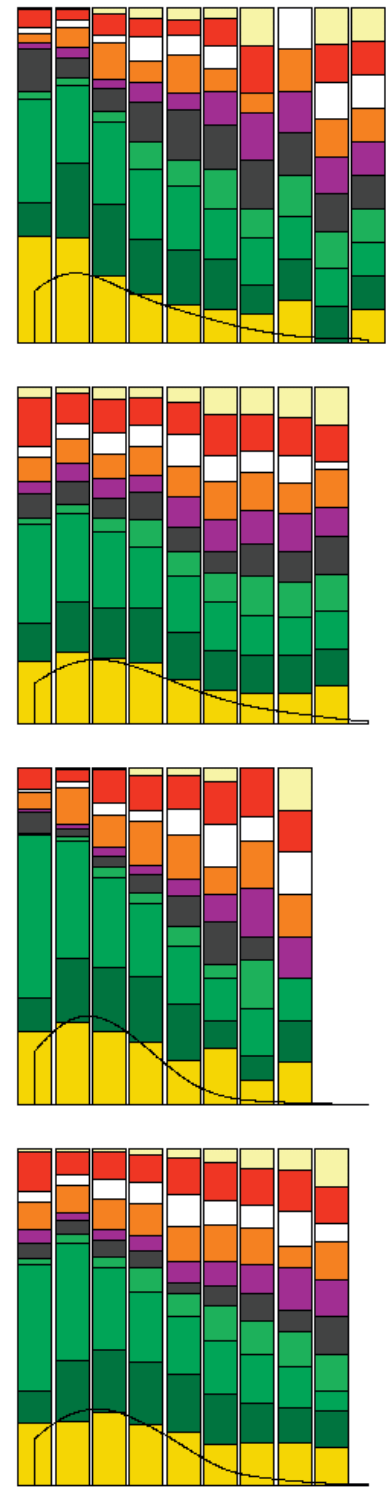

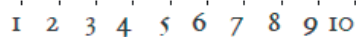

Total
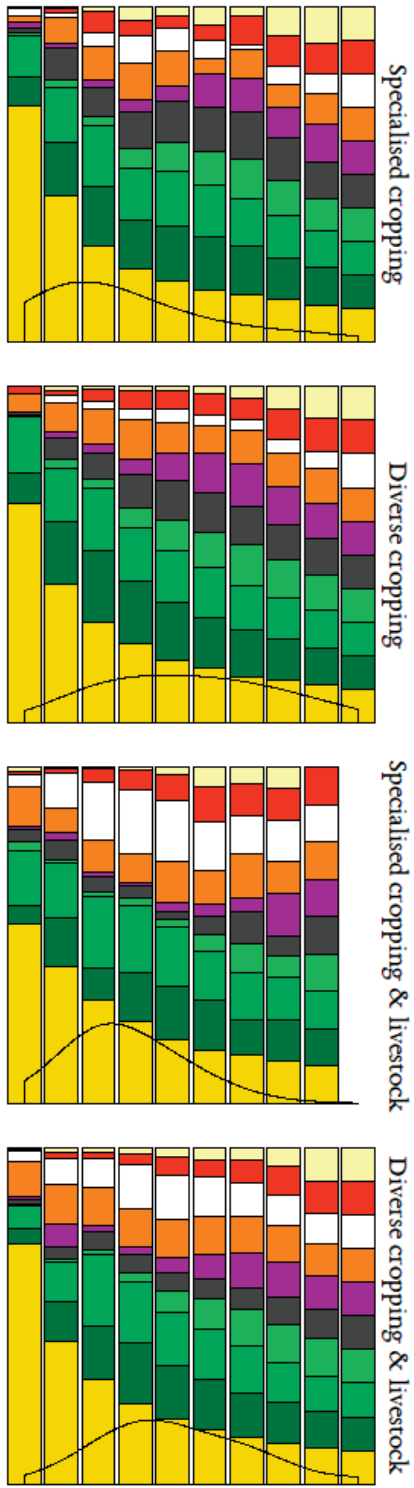

I 23345567899 IO Household diet diversity (MHDD) in the flush period

\begin{tabular}{|c|c|c|c|c|c|}
\hline \multirow{2}{*}{ Category } & Eggs & Milk & Fruit & Vitamin A rich fruits and vegetables & Leafy vegetables \\
\hline & Meat & Legumes & Nuts \& seeds & Other vegetables & Grains, roots, tubers, banana \\
\hline
\end{tabular}

Figure C4 Diet diversity: density and proportion of households $(n=6,353)$ consuming specific food categories by farm type and channel of access in the flush period. The distribution (probability density function) of diet diversity for each period is represented as a black line on the lower half of each figure facet. Food categories are represented by different colours, showing the proportion of households consuming each category at specific diet diversity levels 


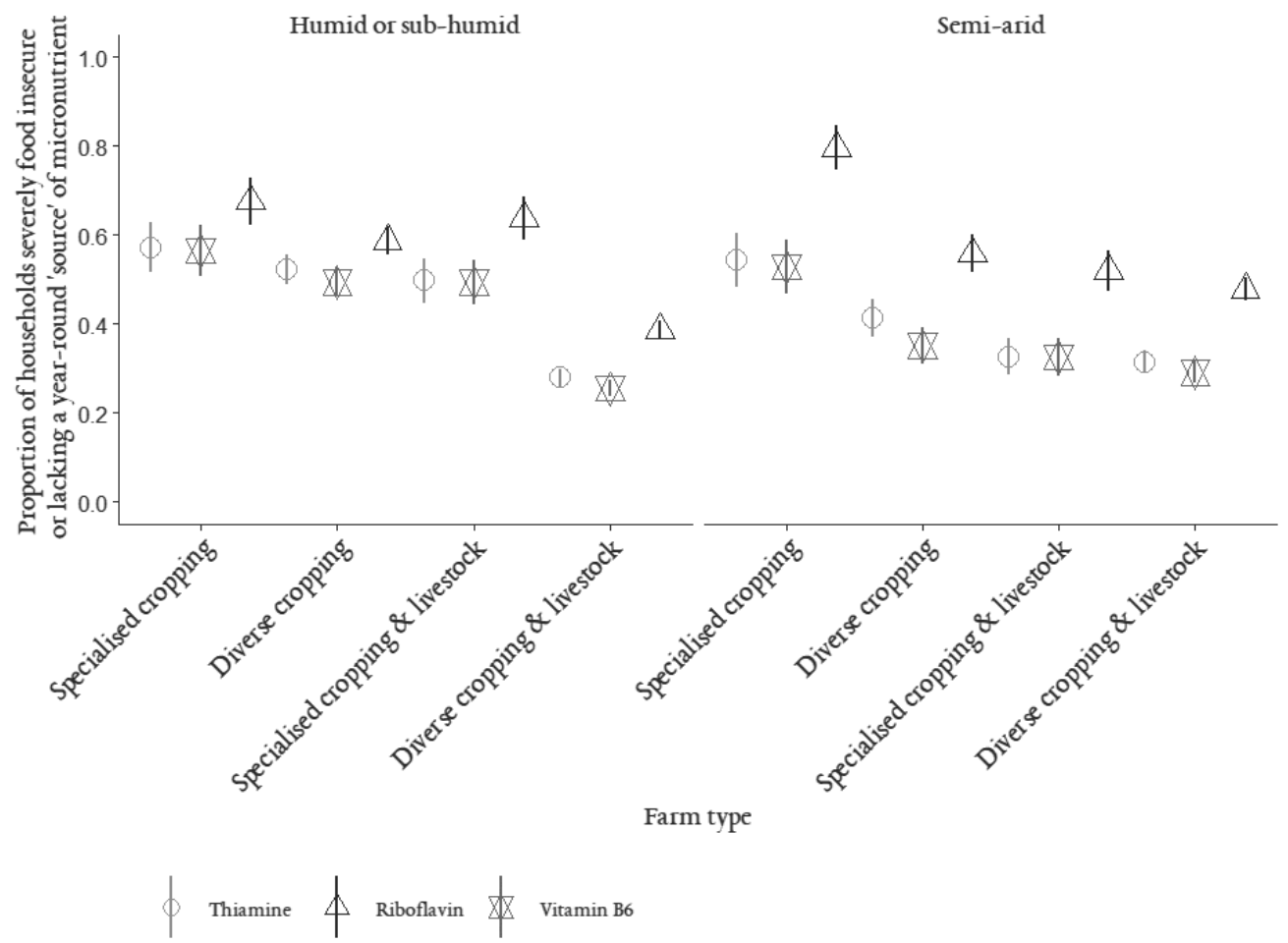

Figure C5 Proportion of households $(n=6,353)$ weighted by population with insecure access to food (MHFIAP) or no 'source' of thiamine, riboflavin or vitamin B6 by farm type and agroecological zone. A $95 \%$ confidence interval is represented by vertical lines

- The difference in severe food insecurity prevalence is minimal.

- Micronutrient estimates are consistently lower for 'cropping' households when the threshold is set to 0.5 TLU. The statistically significant difference between 'cropping' and 'livestock' households, however, remains.

- A threshold based on animal protein produced was also considered, but is not as suited for a farm type categorisation because it is not as easily observed as TLUs. 
Table C8 Questions asked in MHFIAP and FIES

\begin{tabular}{|c|c|}
\hline MHFIAP & FIES \\
\hline $\begin{array}{l}\text { Did you worry that your household } \\
\text { would not have enough food? }\end{array}$ & $\begin{array}{l}\text { Was there a time when you were worried you would not } \\
\text { have enough food to eat because of a lack of money or other } \\
\text { resources }\end{array}$ \\
\hline $\begin{array}{l}\text { Was anyone unable to eat your } \\
\text { preferred foods due to lack of re- } \\
\text { sources? }\end{array}$ & $\begin{array}{l}\text { Was there a time when you were unable to eat healthy } \\
\text { and nutritious food because of a lack of money or other } \\
\text { resources? }\end{array}$ \\
\hline $\begin{array}{l}\text { Did anyone have to eat a limited } \\
\text { variety of foods due to lack of re- } \\
\text { sources? }\end{array}$ & $\begin{array}{l}\text { Was there a time when you ate only a few kinds of foods } \\
\text { because of a lack of money or other resources? }\end{array}$ \\
\hline $\begin{array}{l}\text { Did anyone have to eat undesirable } \\
\text { foods due to lack of resources? }\end{array}$ & $\begin{array}{l}\text { Was there a time when you had to skip a meal because } \\
\text { there was not enough money or other resources to get } \\
\text { food? }\end{array}$ \\
\hline $\begin{array}{l}\text { Did anyone have to eat smaller } \\
\text { meals than was felt needed because } \\
\text { of limitations in food availability? }\end{array}$ & $\begin{array}{l}\text { Was there a time when you ate less than you thought you } \\
\text { should because of a lack of money or other resources? }\end{array}$ \\
\hline \multicolumn{2}{|l|}{$\begin{array}{l}\text { Did anyone have to eat fewer meals } \\
\text { in a day due to a lack of food? }\end{array}$} \\
\hline $\begin{array}{l}\text { Was there ever no food of any kind } \\
\text { in your household because of a lack } \\
\text { of resources? }\end{array}$ & $\begin{array}{l}\text { Was there a time when your household ran out of food be- } \\
\text { cause of a lack of money or other resources? }\end{array}$ \\
\hline $\begin{array}{l}\text { Did anyone go to sleep at night hun- } \\
\text { gry because there was not enough } \\
\text { food? }\end{array}$ & $\begin{array}{l}\text { Was there a time when you were hungry but did not eat } \\
\text { because there was not enough money or other resources } \\
\text { for food? }\end{array}$ \\
\hline $\begin{array}{l}\text { Did anyone go a whole day and } \\
\text { night without eating because there } \\
\text { was not enough food? }\end{array}$ & $\begin{array}{l}\text { Was there a time when you went without eating for a whole } \\
\text { day because of a lack of money or other resources? }\end{array}$ \\
\hline
\end{tabular}


Table C9 Prevalence estimates derived from Martin-Prével et al. (2015)

\begin{tabular}{|c|c|c|c|c|c|c|c|c|}
\hline & \multicolumn{6}{|c|}{ Probability of adequacy (mean) } & \multirow[b]{2}{*}{$\begin{array}{l}\text { Vita- } \\
\text { min } \\
\text { B6 }\end{array}$} & \multirow[b]{2}{*}{$\begin{array}{l}\text { Vita- } \\
\text { min } \\
\text { B12 }\end{array}$} \\
\hline & $\mathrm{n}$ & $\mathrm{Ca}$ & $\mathrm{Fe}$ & $\begin{array}{l}\text { Thi- } \\
\text { amine }\end{array}$ & $\begin{array}{c}\text { Ri- } \\
\text { boflavin }\end{array}$ & Niacin & & \\
\hline Burkina Faso 1 & 182 & 0.03 & 0.23 & 0.39 & 0.08 & 0.17 & 0.53 & 0.07 \\
\hline Burkina Faso 2 & 407 & 0.23 & 0.51 & 0.43 & 0.47 & 0.71 & 0.36 & 0.03 \\
\hline Mali & 102 & 0.04 & 0.53 & 0.6 & 0.28 & 0.31 & 0.67 & 0.17 \\
\hline Uganda 1 & 452 & 0.06 & 0.08 & 0.84 & 0.33 & 0.76 & 0.97 & 0.18 \\
\hline Uganda 2 & 954 & 0.07 & 0.13 & 0.77 & 0.56 & 0.73 & 0.83 & 0.03 \\
\hline Total & 2097 & 197 & 464 & 1422 & 918 & 1392 & 1542 & 152 \\
\hline Weighted probability adequate & & 0.09 & 0.22 & 0.68 & 0.44 & 0.66 & 0.74 & 0.07 \\
\hline Weighted deficiency prevalence & & 0.91 & 0.78 & 0.32 & 0.56 & 0.34 & 0.26 & 0.93 \\
\hline
\end{tabular}

Table C10 Association between farm-household-diet characteristics and farm type - non-livestock oriented vs. livestock orientated. Mixed-effects regressions.

\begin{tabular}{|c|c|c|c|}
\hline Dependent variable & $\begin{array}{c}\text { Intercept } \\
\text { estimate (SE) }\end{array}$ & $\begin{array}{c}\hat{\beta}_{\text {livestock }} \\
\text { estimate }(\mathrm{SE})^{\dagger}\end{array}$ & \\
\hline $\begin{array}{l}\text { Household inhabitants (Adult } \\
\text { eq) }\end{array}$ & $5.46(0.51)$ & $0.92(0.13)$ & * \\
\hline Land cultivated (ha) & $1.95(0.49)$ & $0.72(0.20)$ & * \\
\hline Livestock holdings (TLU) & $3.18(4.08)$ & $8.64(1.16)$ & * \\
\hline Progress out of poverty & $33.68(6.73)$ & $3.45(0.56)$ & * \\
\hline MHDDS flush period ${ }^{\ddagger}$ & $1.86(0.08)$ & $0.04(0.02)$ & * \\
\hline MHDDS lean period $\ddagger$ & $1.44(0.10)$ & $0.12(0.02)$ & * \\
\hline Milk consumed in lean period $\psi$ & $-1.33(0.71)$ & $1.39(0.11)$ & * \\
\hline Meat consumed in lean period $\psi$ & $-0.80(0.46)$ & $0.45(0.11)$ & * \\
\hline Eggs consumed in lean period $\psi$ & $-2.08(0.39)$ & $0.63(0.11)$ & * \\
\hline \multicolumn{4}{|c|}{$95 \%$ CI does not cross zero } \\
\hline \multicolumn{4}{|c|}{ †Reference category is 'non-livestock oriented farm types' } \\
\hline \multicolumn{4}{|c|}{${ }^{\ddagger}$ Negative binomial regression } \\
\hline
\end{tabular}


Table C11 Association between farm-household-diet characteristics and farm type - specialised cropping vs. diverse. Mixed-effects linear regressions.

\begin{tabular}{|c|c|c|c|}
\hline Dependent variable & $\begin{array}{c}\text { Intercept } \\
\text { estimate }(\mathrm{SE})\end{array}$ & $\begin{array}{c}\hat{\beta}_{\text {diverse }} \text { estimate } \\
(\mathrm{SE})^{\dagger}\end{array}$ & \\
\hline $\begin{array}{l}\text { Market participation } \\
\text { (proportion kcal sold) }\end{array}$ & $0.25(0.05)$ & $0.07(0.01)$ & * \\
\hline Crop income (PPP) & $8.74(21.30)$ & $0.49(7.63)$ & \\
\hline $\begin{array}{l}\text { Vitamin A rich consumed in } \\
\text { lean period } \psi\end{array}$ & $0.31(0.41)$ & $0.51(0.08)$ & * \\
\hline $\begin{array}{l}\text { Dark leafy veg consumed in } \\
\text { lean period } \psi\end{array}$ & $2.27(0.58)$ & $1.02(0.11)$ & * \\
\hline $\begin{array}{l}\text { Other veg consumed in lean } \\
\text { period } \psi\end{array}$ & $2.50(0.53)$ & $0.51(0.11)$ & * \\
\hline Fruit consumed in lean period $\psi$ & $-0.32(0.59)$ & $0.52(0.08)$ & * \\
\hline $\begin{array}{l}\text { Nuts/seeds consumed in lean } \\
\text { period } \psi\end{array}$ & $-0.34(0.08)$ & $0.50(0.08)$ & * \\
\hline
\end{tabular}

95\% CI does not cross zero

'Reference category is 'non-livestock oriented farm types'

Table C12 Association between severe food insecurity / micronutrient access and diverse cropping, livestock keeping households in humid \& sub-humid zones. Mixed-effects logistic regressions.

\begin{tabular}{lccc}
\hline Dependent variable & $\begin{array}{c}\text { Intercept } \\
\text { estimate (SE) }\end{array}$ & $\begin{array}{c}\hat{\beta}_{\text {diverse \& livestock }} \\
\text { estimate (SE) }\end{array}$ & \\
\hline Severely food insecure $^{\ddagger}$ & $-0.86(0.73)$ & $-0.15(0.16)$ & $*$ \\
Calcium $^{\ddagger}$ & $-2.27(0.99)$ & $0.98(0.16)$ & $*$ \\
Iron $^{\ddagger}$ & $-0.05(0.37)$ & $0.67(0.13)$ & $*$ \\
Thiamine $^{\ddagger}$ & $0.01(0.32)$ & $0.67(0.13)$ & $*$ \\
Riboflavin $^{\ddagger}$ & $-0.27(0.37)$ & $0.52(0.19)$ & $*$ \\
Niacin $^{\ddagger}$ & $-0.27(0.48)$ & $0.63(0.15)$ & $*$ \\
Pyridoxine $^{\ddagger}$ & $0.16(0.39)$ & $0.61(0.13)$ & $*$ \\
Cobalamin $^{\ddagger}$ & $-1.58(0.57)$ & $0.85(0.15)$ & $*$ \\
\hline
\end{tabular}

95\% CI does not cross zero

${ }^{\dagger}$ Reference category is 'specialised or no livestock component'

${ }^{\ddagger}$ Reference category is 'did not consume' 
Table C13 Association between severe food insecurity / micronutrient access and specialised cropping, livestock keeping farm types in arid semi-arid zones. Mixed-effects logistic regressions.

\begin{tabular}{lccc}
\hline Dependent variable & $\begin{array}{c}\text { Intercept } \\
\text { estimate (SE) }\end{array}$ & $\begin{array}{c}\hat{\beta}_{\text {livestock }} \\
\text { estimate (SE) }\end{array}$ & \\
\hline Chronic hunger $^{\ddagger}$ & $0.34(0.71)$ & $0.64(0.14)$ & $*$ \\
Calcium $^{\ddagger}$ & $-1.96(1.27)$ & $0.99(0.19)$ & $*$ \\
Iron $^{\ddagger}$ & $0.87(0.92)$ & $0.17(0.15)$ & \\
Thiamine $^{\ddagger}$ & $0.83(0.81)$ & $0.18(0.15)$ & \\
Riboflavin $^{\ddagger}$ & $-0.24(1.25)$ & $0.23(0.17)$ & \\
Niacin $^{\ddagger}$ & $0.64(0.92)$ & $0.27(0.59)$ & \\
Pyridoxine $^{\ddagger}$ & $1.17(1.03)$ & $0.08(0.16)$ & \\
Cobalamin $^{\ddagger}$ & $-2.01(1.27)$ & $1.23(0.18)$ & $*$ \\
\hline
\end{tabular}

95\% CI does not cross zero

${ }^{\dagger}$ Reference category is 'no livestock component'

${ }^{\ddagger}$ Reference category is 'did not consume’

Table C14 Association between farm-household-diet characteristics and the presence of children. Mixed-effects regressions.

\begin{tabular}{lccc}
\hline Dependent variable & $\begin{array}{c}\text { Intercept } \\
\text { estimate (SE) }\end{array}$ & $\begin{array}{c}\hat{\beta}_{\text {children }} \\
\text { estimate (SE) }\end{array}$ & \\
\hline Household inhabitants (Adult & $4.38(0.45)$ & $2.21(0.11)$ & $*$ \\
eq) & $66.39(11.33)$ & $-3.45(4.15)$ & \\
Age of household head & $2.09(0.49)$ & $0.42(0.17)$ & $*$ \\
Land cultivated (ha) & $4.48(4.85)$ & $4.85(0.99)$ & $*$ \\
Livestock holdings (TLU) & $1479.95(411.92)$ & $0.60(8.73)$ & $*$ \\
Gross income (PPP) & $43.00(7.46)$ & $-9.61(0.46)$ & $*$ \\
Progress out of poverty & & & \\
\hline
\end{tabular}

95\% CI does not cross zero

'Reference category is 'no children'

${ }^{\ddagger}$ Negative binomial regression 
Table C15 Association between chronic hunger (severe food insecurity) and micronutrient access and scale for diverse cultivating, livestock keeping farm types in humid \& sub-humid zones. Mixed-effects logistic regressions.

\begin{tabular}{lccc}
\hline Dependent variable & $\begin{array}{c}\text { Intercept } \\
\text { estimate (SE) }\end{array}$ & $\begin{array}{c}\hat{\beta}_{\text {medium-large }} \\
\text { estimate (SE) }\end{array}$ & \\
\hline Chronic hunger $^{\ddagger}$ & $-0.37(0.32)$ & $-0.70(0.20)$ & $*$ \\
Calcium $^{\ddagger}$ & $-1.57(1.21)$ & $0.42(0.26)$ & $*$ \\
Iron $^{\ddagger}$ & $0.38(0.74)$ & $0.25(0.24)$ & \\
Thiamine $^{\ddagger}$ & $0.49(0.64)$ & $0.28(0.23)$ & \\
Riboflavin $^{\ddagger}$ & $0.07(0.60)$ & $-0.04(0.20)$ & \\
Niacin $^{\ddagger}$ & $-0.05(0.84)$ & $0.62(0.27)$ & $*$ \\
Pyridoxine $^{\ddagger}$ & $0.53(0.75)$ & $0.41(0.22)$ & \\
Cobalamin $^{\ddagger}$ & $-1.05(0.98)$ & $0.45(0.24)$ & \\
${ }^{95 \% \text { CI does not cross zero }}$ & & & \\
${ }^{\dagger}$ Reference category is 'small scale' & & & \\
${ }^{\ddagger}$ Reference category is 'did not consume' & &
\end{tabular}

Table C16 Association between chronic hunger (severe food insecurity) and micronutrient access and scale for specialised cropping, livestock keeping farm types in arid semi-arid zones. Mixed-effects logistic regressions.

\begin{tabular}{lccc}
\hline Dependent variable & $\begin{array}{c}\text { Intercept } \\
\text { estimate (SE) }\end{array}$ & $\begin{array}{c}\hat{\beta}_{\text {medium-large }} \\
\text { estimate (SE) }\end{array}$ & \\
\hline Chronic hunger $^{\ddagger}$ & $-0.84(5.93)$ & $0.45(0.22)$ & $*$ \\
Calcium $^{\ddagger}$ & $-1.99(1.91)$ & $0.30(0.30)$ & \\
Iron $^{\ddagger}$ & $1.04(1.01)$ & $0.50(0.26)$ & $*$ \\
Thiamine $^{\ddagger}$ & $1.04(1.00)$ & $0.49(0.27)$ & $*$ \\
Riboflavin $^{\ddagger}$ & $-0.56(1.54)$ & $0.44(0.28)$ & \\
Niacin $^{\ddagger}$ & $0.97(1.08)$ & $0.30(0.27)$ & $*$ \\
Pyridoxine $^{\ddagger}$ & $1.08(0.93)$ & $0.55(0.27)$ & $*$ \\
Cobalamin $^{\ddagger}$ & $-1.57(2.02)$ & $-0.11(0.31)$ & \\
\hline
\end{tabular}

95\% CI does not cross zero

${ }^{\dagger}$ Reference category is 'small scale'

${ }^{\ddagger}$ Reference category is 'did not consume’ 


\section{Acknowledgements}

I am grateful to the many people who have inspired, challenged and supported me throughout my PhD trajectory. I extend my gratitude and indebtedness first and foremost to the rural households that shared a small part of their stories with us. I also wish to express my gratitude to the enumerators who guided these detailed and at times sensitive discussions.

To my promotor, Imke de Boer, thank you for asking such challenging questions, for the frank and open discussions and for hosting me. To your credit, you have cultivated a high performing and supportive work culture, for which I am glad to have been a part. To my co-promotor Simon Oosting, thank you for your support, for sharing your insights and for your dedicated input right up to submission. To my co-promotor Mark van Wijk, your leadership and collaborative spirit has provided exciting opportunities to better understand the circumstances of rural households across Africa, Asia and south-central America. I am grateful for your insights, feedback and encouragement. You have shaped and enriched this thesis and have given me the freedom to make this research my own. Thank you.

To my unofficial supervisor, Mats Lannerstad, you were instrumental in the formation of this $\mathrm{PhD}$ project and have been an active contributor throughout my PhD trajectory. Your leadership in the CLEANED project provided me with immense opportunities to develop my research capacities. I would also like to thank you for the brainstorming sessions, critical feedback and well-timed bouts of laughter.

To my other highly esteemed co-authors, it has been a pleasure to work with you all. I would like to take the opportunity to single out a few individuals in this public acknowledgement. The development and refinement of the RHOMIS tool was driven by James Hammond, with many, many hours of dutiful labour. It was great to collaborate and share in a genuine commitment to improve the standard of living in rural communities. I would like to express my gratitude to Mario Herrero, Nils Teufel, Todd Rosenstock, Jacob van Etten, Tim Pagella, Bernard Vanlauwe, Augustine Ayantunde and Ken Giller. As co-authors, you provided thought provoking comments and as scientists you have set the bar high - thank you. Thank you to Jessica Bogard and Mary Ng'endo for the discussions on human nutrition. Thank you to George Sayula and Viviane Yameogo for your dedication to the communities in Lushoto and northern Burkina Faso. Thank you to Pietro Carpena, David Baines and the team at TreeAID for their tireless efforts to support the most vulnerable rural communities.

From my early research career in Australia, I would like to thank Helen Scarborough and Phil Hone; thank you to Tim Ada, and the fine people in the 'Agribusiness team', the Rutherglen research centre and the Ellinbank research center; thank you to John Moran; thank you to Zita Ritchie and the 'grads'; thank you to Robyn Alders and the Kyeema team, and; thank you to Richard Eckard for your support.

Thank you to my colleagues in ILRI for sharing your wealth of knowledge and for your camaraderie. To name but a few, I would like to thank Isabelle Baltenweck, Amos Omore, Ben Lukuyu, Karen Marshall, Jane Poole, An Notenbaert and Carlos Queros; Thomas Randolph and 
Delia Grace Randolph; Todd Crane, Katie Tavennar and Stanley Ng'ang'a; Edmund Githoro, Simon Mugatha, Eunice Kariuki, Emmanuel Kithuna, Julius Githingi, Leone Mawa, Gregory Sikumba and Jusper Ronno; Beth Njoroge, Pauline Aluoch and Assenath Kabugi; Asaah Ndambi and Patric Brandt. Thank you to Polly Ericksen for your support during my PhD.

Thank you to Pierre Gerber for providing such interesting research topics earlier in my career and for taking an interest in my PhD trajectory. Thank you to Theun Vellinga for the very early brainstorming on my $\mathrm{PhD}$.

I would like to thank the WIAS staff. I thank the scientific director Johan van Leeuwen for his leadership and for taking an active role in the delivery of $\mathrm{PhD}$ courses. Thank you to the WIAS secretariat Janneke van Seters, Marianne Bruining and Bernie Coenders. Thank you to my study advisor Guido Bosch. Thank you to Walter Gerrits and Michiel Kleerebezem for the critical feedback on my proposal.

To the team at APS, I would like to express my sincere and heartfelt gratitude for welcoming and supporting me. To Eddie Bokkers, Kees van Reenen and Henk Udo, thank you for your leadership in the group. To Theo Viets and Fokje Steenstra, thank you for your tireless efforts in the group and for modelling what it is to be educators with impact. To Lia Verheijen, thank you for your support and good humour. I have really enjoyed the discussions (without boundaries), walks and outings with APS. I am grateful for your focus on (human) animal welfare - you have been a kind and generous source of support. Thank you to Aart van der Linden, Abigail Muscat, Aimable Uwizeye, Akke Kok, Alejandro Parodi, Brain Akakpo, Cindy Klootwijk, Corina van Middelaar, Evelien de Olde, Hannah van Zanten, Heleen van Kernebeek, Iris Boumans, Laura Webb, Louise Kremer, Margret Wenker, Ollie van Hal, Pim Mostert, Pim Post, Raimon Ripoll Bosch, Salome 'Sally' Migose, Simon Nyokabi, Titis Apdini, Windi al Zahra and Ylva Ran.

Thank you to my colleagues in the Plant Production Systems group. Jannike Wichern, I really enjoyed our in-depth discussions on food security and rural livelihoods - it has been great to be on this journey with you. Joost van Heerwaarden, Wytze Marinus, Eva Thuijsman, Anne de Valença, I enjoyed our discussions. I am grateful to the team at CDI for providing opportunities to carry out my pedogeological training. In particular, thank you to Ted Schrader and Diane Bosch. Thank you to Bas Engel for the enlightening discussions on statistics. Thank you to Emmanual Koyano for translating the summary of this thesis into Kiswahili.

I would also like to express my sincere gratitude to the members of the committee for taking the time to evaluate my thesis and to participate in the public defense.

Thank you to my dear parents for cultivating my curiosity, diligence, and compassion. Thank you to my brothers, sisters, nephews and nieces for the inspiration that you have given me. Thank you to Roland Fraval, Shari Cohen and the good people of Brunswick who made me feel at home in my hometown during the analysis phase of my PhD. Rafiki zangu kutoka Afrika Mashariki - asanteni sana. Ulinikaribishwa na hunifundisha sana sana. Pamoja na neema ya Mungu, natumaini tutaboresha maisha ya watu wanaopunguzwa. 


\section{Summary}

Malnutrition affects the quality of life for a substantial portion of the human population. The incidence of adverse health effects due to chronic undernourishment and micronutrient deficiencies are substantially higher in sub-Saharan Africa (SSA) compared to the rest of the world. The individual and societal implications for such nutritional gaps are borne disproportionately by the rural population, indicated by the consistently higher prevalence of stunting in rural SSA. Members of rural households are both vulnerable to the health burdens that stem from food insecurity and central to improving the availability and affordability of a diversity of wholesome foods for both rural and urban markets.

It has been estimated that much of the chronic and hidden hunger that we see today can be alleviated by implementing a suite of nutrition-specific interventions at a cost of US $\$ 9.6$ billion per annum. The effectiveness of such investments can be accelerated with complementary food system-based interventions. However, such food system-based interventions are hampered by a limited understanding of the prevalence of food insecurity, the spatial distribution of food insecurity, and the associations between food insecurity and rural livelihoods. The primary objective of this thesis was to describe, analyse and understand food security in rural landholding households in predominantly mixed crop-livestock agricultural systems of sub-Saharan Africa (SSA). The secondary objective was to improve the methodological basis of household level food security studies.

The rural household multi-indicator survey (RHOMIS) tool was developed to describe and analyse the circumstances of rural households - including food security status. Chapter 2 describes the design principles and core modules of the RHOMIS tool. The RHOMIS tool aims to adhere to the principles of being time-efficient, utilitarian, user-friendly, flexible and reliable. The core modules include farm characteristics, household composition, food security, progress out of poverty and 'gender'. Chapter 2 provides a preliminary evaluation of the time-efficiency and user-friendliness of the RHOMIS tool. The duration of RHOMIS is half that of comparable surveys. The ease of enumeration was evaluated favourably for each module, with over $50 \%$ of interviews being perceived as 'easy' by the interviewer.

A critical evaluation of the quality of data produced by rural household surveys is then carried out in Chapter 3. This chapter evaluates the credibility, consistency and reliability of data collected using three different farm household surveys deployed in four African countries. Several limitations in data quality were identified. First, variables which might be considered 'easy to estimate' had instances of non-credible observations. For example, in the food security and food self-sufficiency indicators, between $29 \%$ and $57 \%$ of observations in the World Bank's 'living standards measurement survey' were deemed beyond credible bounds. In contrast, the shorter and more targeted survey tool, RHOMIS, performed better - with $25 \%$ of observations beyond credible bounds. Measurements of maize yields and land area owned were found to be less reliable than other variables such as household inhabitants and livestock holdings. This lack of reliability has implications for monitoring food security status, poverty status and the land productivity of households. Despite the limitations in data quality, our analysis shows that if the 
same farm households are followed over time, the sample sizes needed to detect substantial changes are in the order of hundreds of surveys, and not in the thousands. Chapter 3 concludes that targeted and systematised household surveys are essential in detecting differences and changes in rural communities.

The RHOMIS tool was then used to quantify changes in livelihoods and food security status in an urban linked, high potential region of Tanzania. Chapter 4 incorporates paired observations from 20 villages in Lushoto district, Tanzania, over three years. This chapter evaluates the extent to which changes in livelihoods, poverty and food security were taking place in such a short span of time. Households in the study site adaptively responded to local and national circumstances and can be grouped in four clusters, namely: 'Rising high value crop', 'Rising livestock', 'Subsisting mixed' and 'Subsisting staples'. A substantial portion of households in the study site made changes to their livelihoods over the short three-year period of observation. Changes in land ownership, livestock-holdings and high value crop production were most likely related to market opportunities and personal circumstances, rather than to direct interventions. Several households made strategic changes by expanding land ownership, planting perennial crops and investing in exotic cattle breeds; many households tactically utilised their land for diversified, mixed crop-livestock production. The majority of households, however, had either remained stable or were scaling back to subsistence farming. Chapter 4 finds that the complex risk management strategies and market responsiveness demonstrated by the 'Rising' clusters are at odds with single focus activities that external organisations tend to promote.

Subsequently, instances of chronic and hidden hunger were analysed in two subtly contrasting regions of Burkina Faso. Chapter 5 describes and analyses the household composition, farm systems and food security status in these regions. Food security indicators were enumerated for two periods to account for the temporal variability throughout the year. Diet diversity (a proxy for hidden hunger) was disaggregated by channel of access to better understand food sourcing behaviour. The results of this chapter show that in both provinces, the ability to purchase food is what differentiates the more food secure households from their less food secure counterparts. This finding does not detract from the utility of subsistence production - where consumption of own-farm sourced food catered for $91 \%$ of the annual energy requirements in Yatenga province and $72 \%$ in Seno province. Further, households were observed to be pursuing market-oriented strategies in combination with production diversification. Production diversification was not driving differences in diet diversity in this instance but was likely to reduce risk exposure to climatic or economic shocks.

Chapter 6 draws on a large sample of rural landholding households across SSA to estimate the prevalence of dietary gaps and to understand their associations with rural livelihoods and food sourcing behaviour throughout the year. As many as $40 \%$ of households were classified as chronically hungry in the lean period. Prevalence of micronutrient dietary gaps were high, ranging from $35 \%$ of households lacking daily sources of pyridoxine, and $68 \%$ lacking daily sources of calcium. Vulnerability to dietary gaps differed by household composition, livelihood characteristics and agro-ecological zone (AEZ). Market participation, livestock product diver- 
sity, crop diversity, gross income and off-farm income were all associated with chronic and hidden hunger - differing by AEZ. Any given livelihood characteristic had a limited impact on food security indicators. Rather, it is the combination of these livelihood characteristics and the agro-ecological production potential that drive the availability of food and income. Households with a livestock component to their farm consumed more milk, meat and eggs (sources of calcium, riboflavin and vitamin B12). Dairy, fruit and vitamin A-rich produce were predominantly accessed through the farm channel - more so by diverse cropping households. The results of Chapter 6 suggest that households fail to purchase food categories that nutritionally complement their own agricultural products. Furthermore, households with a livestock component to their farm were found to have a lower prevalence of chronic and hidden hunger.

Methodological considerations and empirical findings of this thesis are further evaluated in a general discussion. The general discussion in Chapter 7 summarises the progress that has been made in harmonising rural household surveys through the RHOMIS tool. The RHOMIS tool is now available in 9 languages and has been localised to 48 sub-national locations in SSA, SouthEast Asia and, South and Central America. A community of practice has formed around the use of the tool which provides opportunities for further methodological developments in sampling, validation, alternative modes of data collection, improved enumeration and modelling of women's empowerment and improvements in measuring food and nutrition security.

This thesis has drawn upon a total of 8,257 household interviews, conducted in 14 projects to describe and analyse food and nutrition security in rural landholding households. Chapter 7 reiterates the high prevalence rates of chronic and hidden hunger identified in this thesis, noting the variability between and within regions. The factors identified to be associated with food and nutrition security in Chapters 4, 5 and 6 are then analysed and discussed further. In extended analyses, the gender of household head and stage of life were found to be associated with the number of household inhabitants and thus influence nutritional requirements and food security status. The high prevalence of food insecurity, the complexity of associations and the failure to nutritionally complement own-production with purchases have implications for developing effective interventions. The discussion concludes that programs can be designed as 'packages' of agricultural and non-agricultural interventions to maximise adoption and maximise the positive impact on food and nutrition security throughout the year. 


\section{Muhtasari}

Hali duni ya afya inayosababishwa na lishe duni na upungufu wa vurutubisho muhimu ni kubwa sana katika nchi za kusini mwa jangwa la Sahara ikilinganishwa na sehemu nyingine duniani. Athari za madhara binafsi na madhara kwa jamii yanayosababishwa na utofauti huu mkubwa wa kilishe mara nyingi hubebwa na jamii zinazoishi vijijini zikiashiriwa na uwepo mkubwa zaidi wa utapiamlo kwenye mazingira ya vijiji ikilinganishwa na mazingira ya mijini. Jamii zinazoishi kwenye mazingira ya vijijini ziko katika hali hatarishi zaidi ya mizigo ya magonjwa yanayotokana na upungufu wa chakula na tatizo la kuwezesha upanikanaji na uthamani wa mazao mbalimbali ya chakula kwenye masoko ya mijini na vijijini. Inakadiriwa kuwa kiasi kikubwa cha njaa sugu iliyojificha (utapiamlo) tunayoiona wakati huu inaweza kuondolewa kwa kufuata afua zinazolenga lishe bora kwa gharama ya dola bilioni 9.6 kwa mwaka. Matokeo mazuri ya uwekezaji kama huu yanaweza kuongezewa kasi kwa kutumia mfumo wenye hatua zenye kutumia vyakula mbadala ingawa mifumo yenye kutumia afua zinazotumia vyakula mbadala inaharibiwa na uelewa mdogo wa uwepo wa upungufu mkubwa na chakula, mgawanyo wa kutokuwa na ulinzi wa chakula maeneo mengi na uhusiano kati ya uhaba wa chakula na maisha ya vijijini.

Lengo kuu la tafiti hii lilikuwa ni kuelezea, kutathmini na kuelewa uhaba uwepo wa chakula kwenye kaya zilizopo maeneo ya vijijini hasa hasa ambayo huzalisha mazao mchanganyiko, na mifumo ya wakulima wafugaji chini ya jangwa la Sahara. Lengo la pili lilikuwa ni kuboresha misingi ya njia za masomu yanayohusiana na ulinzi wa chakula. Nyenzo za ukusanyaji wa takwimu tofauti za tathmini ya viashiria mablimbali vya maisha vijijini zilitengenzwa kuelezea na kutathmini hali halisi za kaya zilizoko maeneo hayo pamoja na hali halisi ya ulinzi wa chakula.

Sura ya 2 inaelezea kanuni na muundo wa msingi wa nyenzo za ukusanyaji wa takwimu hizi za tathmini. Nyenzo za ukusanyaji wa takwimu hizi zina lengo la kuzingatia kanuni za kuwa na ufanisi wa muda, zenye urahisi wa kutumia, kubadilishwa na kuaminika. Vipengele vya msingi vya nyenzo za ukusanyaji wa takwimu hizi ni pamoja na sifa za shamba, muundo wa kaya, lishe, maendeleo ya umaskini na 'jinsia'.

Sura ya 3 inatoa tathmini ya awali ya ufanisi wa muda na ni rafiki kwa mtumiaji. Muda wa ambao nyenzo za ukusanyaji wa takwimu hizi hutumia ni takribani nusu ya nyenzo za ukusanyaji wa takwimu za utafiti zinazofanana. Vilevile zaidi ya asilimia hamsini ya mahojiano yameonekana kuwa rahisi kwa mhojiwa. Sura ya 3 inaonyesha maadili yasiyo ya kawaida, thabiti na yenye takwimu za kuaminika zilizokusanywa kwa kwenye tafiti tatu za kilimo kwa ngazi ya kaya katika nchi nne za Afrika. Vikwazo kadhaa vya ubora wa takwimu vilibainishwa. Kwanza, majibu ambayo watafiti wanafikiri ni 'rahisi kupatikana' yalikuwa na matukio ya makosa. Kwa mfano, viashiria vya lishe na upatikanaji wa chakula cha kutosha, kati ya asilimia 29 na 57 ya tathmini zilizofanyika za hali ya ubora wa maisha kwa 'viwango vya maisha' vya bank kuu ya dunia zilionekana kuwa na makosa ikilinganishwa na nyenzo za kukusanya takwimu za mfupi na ambazo huchukua walengwa zaidi, (RHOMIS) zilifanya vizuri kwa asilimia zaidi $25 \%$ ya tathmini. Vilevile, upimaji wa mavuno ya mahindi, na ukubwa wa mashamba 
ulionekana kuwa hauna uhakika zaidi ikilinganishwa na vigezo vingine kama vile idadi ya watu na umiliki wa mifugo. Ukosefu wa kuaminika wa nyenzo za ukusanyaji wa takwimu hauthiri tathmini za ukosefu wa lishe, hali ya umasikini na mavuno ya mazao kwa kaya. Licha ya mapungufu katika ubora wa takwimu, uchambuzi wetu unaonyesha kuwa ikiwa kaya zinafuatiliwa, ukubwa wa sampuli unaohitajika kutoa matokeo sahihi sio wa kaya maelfu bali ni wa kaya mamia. Sura ya 3 inahitimisha kuwa, uchunguzi wa kaya unaofuata utaratibu sahihi ni muhimu sana katika huhakikisha kuwa kupata tawimu sahihi za tofauti na mabadiliko katika jamii zilizoko vijijini.

Nyenzo za ukusanyaji wa takwimu za RHOMIS zilikuwa kilikuwa zinatumiwa kupima mabadiliko ya hali ya maisha na hali ya lishe nchini Tanzania katika nyanja zinazohusiana na masoko na zina uwezo mzuri wa uzalishaji wa takwimu sahihi. Sura ya 4 inafafanua uchunguzi uliofanyika kwenye vijiji 20 vilivyoainishwa katika wilaya ya Lushoto, Tanzania kwa zaidi ya miaka mitatu. Sura hii inachunguza kiwango cha mabadiliko ya maisha, umasikini na lishe kilichotokea kwa kipindi cha muda mfupi majumbani. Tafiti za majumbani zilizofanyika kwenye tovuti hutegemea mazingira ya ndani ya nchi husika ambayo yanaweza kugawanywa katika makundi manne, yaani: 'kuongezeka kwa thamani ya mazao', 'kuongezeka kwa thamani ya mifugo', 'mazao mchanganyiko ya kujikimu' and 'mazao makuu ya kujikimu'. Sehemu kubwa ya kaya katika tovuti ya utafiti zilifanya mabadiliko ya maisha yao kwa muda mfupi wa uchunguzi wa miaka mitatu. Mabadiliko katika umiliki wa ardhi, ufugaji wa mifugo na uzalishaji wa mazao ya thamani ya juu yalikuwa na uwezekano mkubwa wa kuhusiswa na fursa za masoko na hali za kibinafsi, badala ya hali za kijamii. Kaya kadhaa zilifanya mabadiliko ya kimkakati katika kupanua umiliki wa ardhi, kuwekeza katika mifugo na kukuza mazao ya thamani ya juu; kaya nyingi zilitumia ardhi yao kwa ajili ya kilimo cha mazao mbalimbali, na uzalishaji wa mifugo. hata hivyo, kaya nyingi, zilikuwa imara au zilikuwa zikitumia mazao yaliyozalishawa nyumbani. Sura ya 4 inabainisha kuwa mikakati ya usimamizi na ufumbuzi wa masoko imewezeshwa sana na makundi ya vyakula 'yanayochipukia' ikilinganishwa na kazi za ambazo zinahimizwa sana na mashirika ya nje.

Vilevile, matukio ya 'ukosefu wa nishati' na 'ukosefu wa virutubishi' yalichambuliwa katika mikoa miwili tofauti ya Burkina Faso. Sura ya 5 inaelezea na inachambua muundo wa kaya, mifumo ya kilimo na hali ya lishe katika mikoa hii. Viashiria vya lishe vilichapishwa kwa muda wa vipindi viwili kwenye kwa utofauti wa mwaka mzima. Njia za upatikanaji wa chakula mchanganyiko (kipimo cha 'ukosefu ya virutubishi') zilitofautiana. Matokeo ya sura hii yanaonyesha tofauti mablimabali kujipatia chakula ikilinganishwa na uwezo wa kipato wa kaya kwenye mikoa yote. Matokeo haya hayakupunguza thamani ya chakula kinachotumiwa kutoka mashambani ambacho huchangia asilimia 91 ya mahitaji mwaka ya nishati katika jimbo la Yatenga na asilimia 72 katika jimbo la Seno. Zaidi ya hayo, kaya zilionekana kuzingatia mikakati inayotokana na soko, pamoja na aina mablimbali za uzalishaji. Hivyo basi, uzalishaji mbadala huenda ukapunguza hatari ya hali ya hewa au hatari ya kiuchumi.

Sura ya 6 inatathmini sampuli kubwa ya kaya za vijijini nchini Afrika ya Kusini ili kukadiria upungufu ya chakula na kuelewa vyanzo vya kipato na maisha ya vijijini na upatikanaji wa 
chakula kwa mwaka mzima. Takriban asilimia 38 ya kaya zilionekana kuwa na 'njaa kali'. Hali ya kuenea kwa upungufu wa chakula ulikuwa ni ya juu, kutoka takribani asilimia 41 ya kaya kukosa vyanzo vya chakula chenye madini chuma kila siku na madini ya 'thiamine' na asilimia 72 kutokuwa na vyanzo vya kila siku vya vitamini B12. Mapungufu ya chakula hutofautiana na mfumo wa kaya sifa ya sifa nyanda za ki-agroikolojia. Aina za masoko, utofauti wa mifugo, utofauti wa mazao, mapato ya jumla na mapato ya nje ya kilimo yalihusishwa na 'upungufu wa virutubishi' ikilinganishwa na nyanda za ki-agroikolojia. Tabia moja pekee ilikuwa na athari ndogo juu ya viashiria vya usalama wa chakula. Badala yake, mchanganyiko wa tabia hizi pamoja na eneo la ki-agroekolojia huchangia mabadiliko katika mapato na upatikanaji wa chakula. Kaya zilizo kuwa na mifugo zilitumia maziwa zaidi, nyama na mayai (vyanzo vya madini chuma, riboflavin na vitamini B12) Maziwa, matunda na vitamini A, hupatikana kwa wingi kadri mazao ya mashamba yanavyoongezeka. Matokeo ya Sura ya 6 yanaonyesha kwamba kaya hazijinunulii makundi ya chakula ili kukidhi mahitaji yao yote ya lishe. Zaidi ya hayo, kaya zilizo na mifugo zilikuwa na lishe bora kuliko nyingine.

Masuala ya njia ya utafiti na matokeo ya utafiti huu yanatathminiwa zaidi katika mjadala wa jumla. Mjadala wa jumla katika Sura ya 7 unaonesha muhtasari wa maendeleo ambayo yamefanyika katika kuunganisha tafiti za kaya za vijijini kwa njia ya nyenzo za ukusanyaji wa takwimu za RHOMIS. Nyenzo za ukusanyaji wa takwimu za RHOMIS sasa zinapatikana katika lugha 9 na zimefanyika maeneo 48 ya kitaifa katika nchini Afrika ya kusini, Kusini-mashariki mwa Asia na, kusini na katikati mwa Marekani. Kwa kuwa kuna watumiaji wengi wenye mahitaji ya nyenzo hii, kuna fursa za maendeleo zaidi ya ya nyenzo hii ikiwa ni pamoja na sampuli, uthibitisho, njia mbadala za ukusanyaji wa takwimu, kuelewa uwezo wa wanawake na kuboresha upimaji lishe. Tafiti hii imefanya jumla ya mahojiano ya kaya 8,257, katika miradi 14 inayolenga kuelezea na kuchambua masuala ya lishe ya kaya vijijini.

Sura ya 7 inaelezea viwango vya juu vya kuenea kwa 'upungufu wa nishati' na 'upungufu wa virutubishi', akibainisha tofauti kati ya mikoa na maeneo ndani ya nchi husika. Sababu ambazo zinahusiana na lishe katika Sura ya 4, 5 na 6 zimeonesha kufuatiliwa na kujadiliwa zaidi. Uchambuzi zaidi umeonesh kuwa jinsia, ukuu wa kaya na hali ya maisha vimehusishwa zaidi na idadi ya watu kwenye kaya na basi kuathiri mahitaji ya lishe na hali ya 'kukosa lishe'. Hiyo ni mchanganyiko wa sifa hizi za maisha ambazo huamua hali ya usalama wa chakula kwa mwaka mzima. Matokeo haya yote yana maana katika kuendeleza hatua za ufanisi. Mjadala huu unahitimisha kuwa programu zinaweza kuundwa kama 'vikundi' ya hatua za kilimo na zisizo za kilimo ili kuboresha hatua za kupunguza lishe kwa mwaka mzima. 


\section{About the author}

Simon Fraval was born on the 30th of December 1983 in Ascot, England. In 2007, Simon earned a Bachelor of Commerce with honors in economics from Deakin University (Melbourne, Australia). His minor thesis was titled 'Determining financial support for Australian electricity generators in an emission constrained economy”.

Between 2008 and 2012, Simon was employed by the state government of Victoria, Australia. During his tenure, he was stationed at the head office in Melbourne, the Rutherglen lamb and viticulture research centre, and the national centre for dairy research and development. His research interests centred on agricultural trade, including topics of production trends, market access, animal welfare of live exports and the environmental impacts of exported livestock products. In 2010, Simon co-authored an article published in the Journal of Dairy Science, titled 'The water footprint of dairy products: case study involving skim milk powder'. In 2012, Simon presented his work titled 'Sustainable Value Chain Analysis: Victorian lamb exported to the USA' to the IFAMR conference in Frankfurt, Germany.

In 2012, Simon joined the International Livestock Research Institute (ILRI). Soon after moving to Nairobi, Kenya, Simon took part in a Comprehensive Africa Agriculture Development Programme (CAADP) meeting, discussing the alignment between policy and research agendas. He then focused his research on the quantification and mitigation of greenhouse gas (GHG) emissions in smallholder diary production, with research sites in western Kenya. In collaboration with the FAO, the Kenyan ministry of agriculture and Unique Forestry, Simon co-authored a methodology for incentivising GHG mitigation, titled 'Smallholder dairy methodology: Draft Methodology for Quantification of GHG Emission Reductions from Improved Management in Smallholder Dairy Production Systems using a Standardized Baseline'.

Simon continued his research in ILRI under the auspice of the project titled 'Comprehensive Livestock Environmental Assessment for Improved Nutrition, a Secured Environment and Sustainable Development' (CLEANED). In a collaboration between ILRI, CIAT, SEI and CSIRO, the CLEANED project sought to provide a method to estimate the environmental impact of livestock interventions in low and middle income countries prior to implementation. Simon was involved throughout the research process, from conceptual development, piloting, analysis and reporting. Simon led the GHG and biodiversity components of the framework and co-led participatory GIS activities in Kenya and Tanzania.

In 2015, Simon began the field work for his PhD. Hosted by ILRI and the Animal Production Systems group of Wageningen University \& Research, Simon sought to understand and describe the nature of food security in rural sub-Saharan Africa. During the process of his $\mathrm{PhD}$, Simon co-authored five peerreviewed articles and two book chapters. Simon has also been active in the research community - reviewing journal articles and presenting his work. Simon's research interests include topics related to food security, rural livelihoods, environmental impact assessment and remote sensing. 


\section{Peer-reviewed journal publications}

Ridoutt, B. G., Williams, S. R. O., Baud, S., Fraval, S., \& Marks, N. (2010). Short communication: The water footprint of dairy products: case study involving skim milk powder. Journal of Dairy Science, 93(11), 5114-7. doi:10.3168/jds.2010-3546

Hammond, J., Fraval, S., van Etten, J., Suchini, J. G., Mercado, L., Pagella, T., Frelat, R., Lannerstad, M., Douxchamps, D., Teufel, N., Valbuena, D., \& van Wijk, M. T. (2017). The Rural Household MultiIndicator Survey (RHoMIS) for rapid characterisation of households to inform climate smart agriculture interventions: Description and applications in East Africa and Central America. Agricultural Systems, 151, 225-233. doi:10.1016/j.agsy.2016.05.003

Ng'ang'a, S., Ritho, C., Herrero, M., \& Fraval, S. (2018). Household-oriented benefits largely outweigh commercial benefits derived from cattle in Mabalane District, Mozambique. The Rangeland Journal, 40(6), 565-576. doi:10.1071/RJ17115

Tavenner, K., Fraval, S., Omondi, I., \& Crane, T. A. (2018). Gendered reporting of household dynamics in the Kenyan dairy sector: trends and implications for low emissions dairy development. Gender, Technology and Development, 22(1), 1-19. doi:10.1080/09718524.2018.1449488

Fraval, S., Hammond, J., Wichern, J., Oosting, S. J., de Boer, I. J. M., Teufel, N., Lannerstad, M., Waha, K., Pagella, T., Rosenstock, T. S., Giller, K. E., Herrero, M., Harris, D., \& van Wijk, M. T. (2018). Making the most of imperfect data: a critical evaluation of standard information collected in farm household surveys. Experimental Agriculture, 1-21. doi:10.1017/S0014479718000388.

Fraval, S., Hammond, J., Lannerstad, M., Oosting, S. J., Sayula, G., Teufel, N., Silvestri, S., Poole, E. J., Herrero, M., \& van Wijk, M. T. (2018). Livelihoods and food security in an urban linked, high potential region of Tanzania: Changes over a three year period. Agricultural Systems, 160 (January 2018), 87-95. doi:10.1016/j.agsy.2017.10.013

\section{Submitted manuscripts}

Fraval, S., Yameogo, V., Ayantunde, A., Hammond, J., de Boer, I. J. M., Oosting, S. J., \& van Wijk, M. T. (submitted). Pathways to food security in rural Burkina Faso. Food Security

Fraval, S., Hammond, J., Bogard, J. R., Ng'endo, M., van Etten, J., Herrero, M., Oosting, S. J., de Boer, I. J. M., Lannerstad, M., Teufel, N., Lamanna, C., Rosenstock, T. S., Pagella, T., Vanlauwe, B., DontsopNguezet, P. M., Baines, D., Carpena, P., Njingulula, P., Okafor, C., Wichern, J., Ayantunde, A., Bosire, C., Chesterman, S., Kihoro, E., Rao, J., Skirrow, T., Steinke, J., Stirling, C. M., Yameogo, V., \& van Wijk, M. T. (submitted). Dietary gaps in sub-Saharan Africa: prevalence and implications for agricultural interventions. Global Food Security

Ritzema, R., van Wijk, M., Phengsavanh, P., Hammond, J., Fraval, S., Hok, L., Thi Minh Long, C., Bolliger, A., \& Douxchamps, S. (submitted). Household-level drivers of dietary diversity in transitioning agricultural systems: Evidence from the Greater Mekong Subregion Stanley northern Kenya. Agricultural systems

\section{Book chapters}

Fraval, S., van Middelaar, C., Ridoutt, B., \& Opio, C. (2018). Life Cycle Assessment of Food Products. In P. Ferranti, E. M. Berry, \& J. R. Anderson (Eds.), Encyclopedia of Food Security and Sustainability (Vol. 3, pp. 488-496). Elsevier. doi:10.1016/B978-0-08-100596-5.21427-3 
Wijk, M. T. Van, Hammond, J., Frelat, R., \& Fraval, S. (2018). Unequal Access to Land: Consequences for the Food Security of Smallholder Farmers in Sub Saharan Africa. In P. Ferranti, E. M. Berry, \& J. R. Anderson (Eds.), Encyclopedia of Food Security and Sustainability (pp. 1-6). Elsevier. doi:10.1016/B978-012-812687-5.22311-3

\section{Other scientific publications}

Opio, C., Gerber, P., Baltenweck, I., Fraval, S., Mbae, R., Kessei, L., Wilkes, A., Tennigkeit, T., Marroquin, L., Baumann, T., \& Hardy, P. (2016). Smallholder dairy methodology: Draft Methodology for Quantification of GHG Emission Reductions from Improved Management in Smallholder Dairy Production Systems using a Standardized Baseline.

Morris, J., Fraval, S., Githoro, E., Ran, Y., \& Mugatha, S. (2015). Comprehensive Livestock Environmental Assessment for Improved Nutrition, a Secured Environment and Sustainable Development along Livestock and Aquaculture Value Chains Project: PGIS workshop summary report. (2015 No. 05). Stockholm.

\section{Conference proceedings}

Fraval, S., Marks, N., Fearne, A., \& Ridoutt, B. G. (2011). Sustainable Value Chain Analysis: Victorian lamb exported to the USA. The Road to 2050: Sustainability as a Business Opportunity. Frankfurk: IFAMR. Available on https://www.ifama.org/2011-Frankfurt

Fraval, S., Hammond, J., Bogard, J. R., Ng'endo, M., van Etten, J., Herrero, M., Oosting, S. J., de Boer, I. J. M., Lannerstad, M., Teufel, N., Lamanna, C., Rosenstock, T. S., Pagella, T., Vanlauwe, B., DontsopNguezet, P. M., Baines, D., Carpena, P., Njingulula, P., Okafor, C., Wichern, J., Ayantunde, A., Bosire, C., Chesterman, S., Kihoro, E., Rao, J., Skirrow, T., Steinke, J., Stirling, C. M., Yameogo, V., \& van Wijk, M. T. (2018). Food access channels in tropical sub-Saharan Africa. In Accelerating the End of Hunger and Malnutrition. Bangkok: IFPRI-FAO. Available on https://www.ifpri-faobangkokconference.org/files/ 2018/11/Slide43.jpg

Fraval, S., Hammond, J., Bogard, J. R., Ng'endo, M., van Etten, J., Herrero, M., Oosting, S. J., de Boer, I. J. M., Lannerstad, M., Teufel, N., Lamanna, C., Rosenstock, T. S., Pagella, T., Vanlauwe, B., DontsopNguezet, P. M., Baines, D., Carpena, P., Njingulula, P., Okafor, C., Wichern, J., Ayantunde, A., Bosire, C., Chesterman, S., Kihoro, E., Rao, J., Skirrow, T., Steinke, J., Stirling, C. M., Yameogo, V., \& van Wijk, M. T. (2019). Dietary gaps in rural sub-Saharan Africa. 4th International Congress on Hidden Hunger. Stuttgart: SNFS. Available on http://hiddenhunger.net

Teufel, N., Hammond, J., Fraval, S., \& van Wijk, M. T. (2018). Dynamics of food security and livelihood strategies in Eastern Africa. In Strengthening food and nutrition security through a Planetary Health lens in resource-limiting settings conference. Dar es Salaam: University of Sydney. Available on https://sydney . edu.au/vetscience/research/Nkuku4U/images/Nkuku4U-program.pdf 


\section{WIAS education certificate}

\section{Completed training and supervision plan ${ }^{1}$}

The Basic Package (1.8 ECTS)

- WIAS Introduction Day (2017)

- WGS course 'Ethics and philosophy in life sciences' (2017)

\section{Disciplinary Competences (11.6 ECTS)}

- Resilience of living systems (2018)

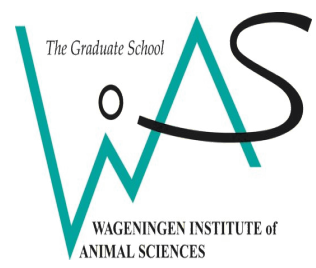

- Writing PhD research proposal

- Soil4life: sustainable soil management (2016)

- Machine learning (2016)

- Data science (2015)

\section{Professional Competences (9.4 ECTS)}

- WGS PhD workshop carousel (2018)

- Didactic skills: Teaching outside academia (2017)

- How to review a scientific paper (2017)

- Scientific writing (2015)

- Swahili (2015)

\section{Presentation Skills (4.0 ECTS)}

- Congress hidden hunger, Stuttgart, Germany (2019)

- WIAS science day, Wageningen, the Netherlands (2019)

- Accelerating the End of Hunger and Malnutrition, Bangkok, Thailand (2018)

- WaCASA, Wageningen, the Netherlands (2018)

- RHOMIS user group workshop, Wageningen, the Netherlands (2018)

- Global agenda for action on climate change, Nairobi, Kenya (2013)

\section{Teaching Competences (4.2 ECTS)}

- Guest lecture and support in Future Livestock Systems course (2018)

- Assistance with supervising MSc student (2015)

- Leading tutorials and online discussions in two undergraduate courses $(2007,2011)$

\section{Total: 31.0}

\footnotetext{
${ }^{1}$ With the activities listed the PhD candidate has complied the educational requirements set by the Graduate School of Wageningen Institute of Animal Sciences (WIAS) of Wageningen University \& Research, which comprises of a minimum of 30 ECTS (European Credit Transfer and accumulation System). One ECTS equals a study load of 28 hours.
} 


\section{Colophon}

This research received funding from the CGIAR Research Programs on 'Livestock and Fish', 'Climate Change, Agriculture and Food Security' (CCAFS) and 'Maize' and its donors and by support of the American People provided to the Feed the Future Innovation Lab for Sustainable Intensification through the United States Agency for International Development (USAID).

Several donors and organisations supported this research indirectly. A full list of contributing donors and organisations can be found in Appendix Table C2.

The views expressed in this thesis cannot be taken to reflect the official opinions of these organisations.

Images used in this thesis:

- Shared plate by Albert Gonzalez Farran from UNAMID

- Food items were downloaded from pngmart.com

- Plough with oxen was sourced from the WUR image library

- Woman harvesting grain was sourced from unsplash.com

- Chapter 5 photo by Ollivier Girard from CIFOR

- Chapter 7 photo from ILRI

All other images were taken by the author or acknowledged in-text

Cover design by Simon Fraval and Fokje Steenstra

Printed by ProefschriftMaken, www.proefschriftmaken.nl 



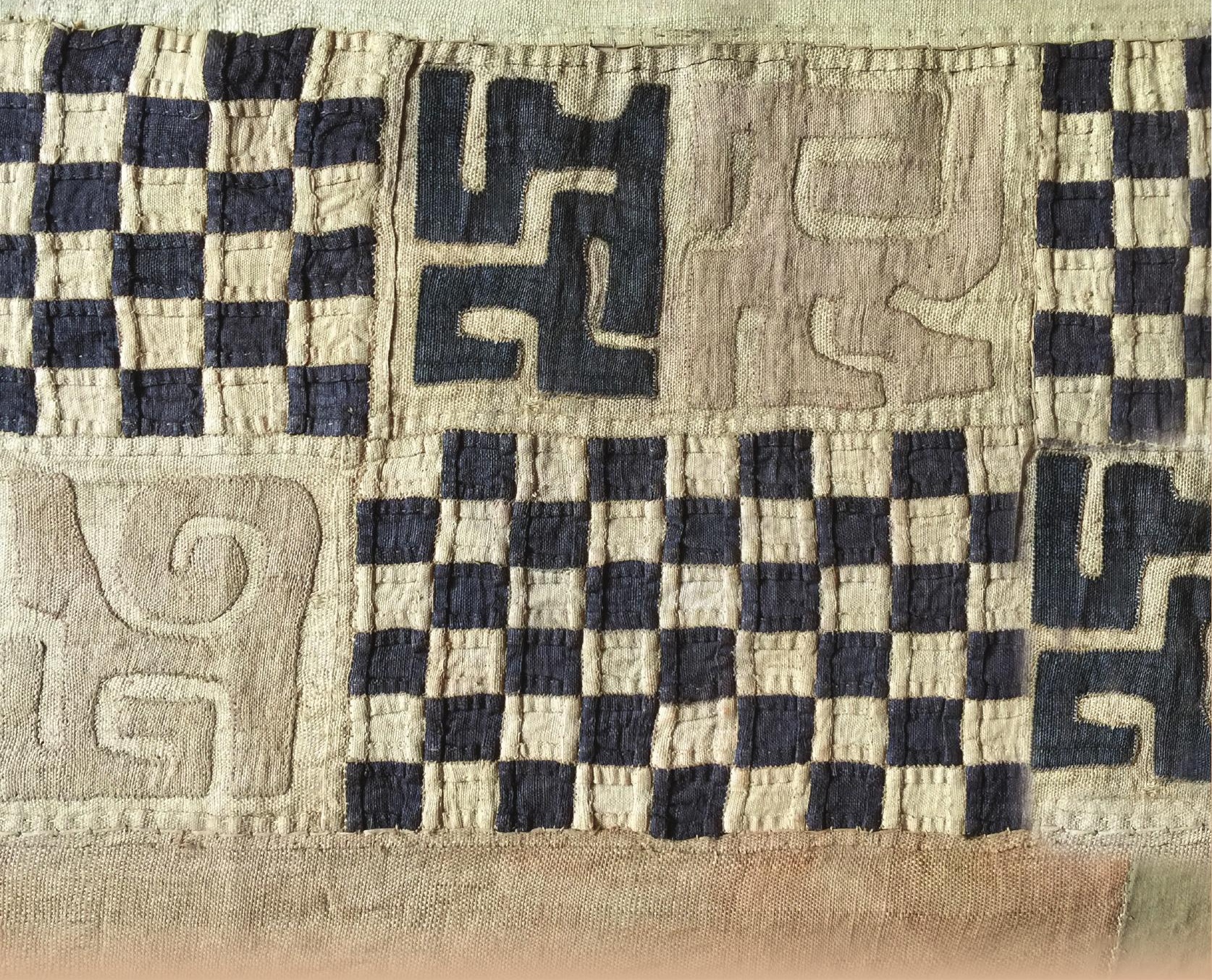

